\title{
Facts and Fantasies About Factor Investing
}

\author{
Zélia Cazalet \\ Quantitative Research \\ Lyxor Asset Management, Paris \\ zelia.cazalet@lyxor.com
}

\author{
Thierry Roncalli \\ Quantitative Research \\ Lyxor Asset Management, Paris \\ thierry.roncalli@lyxor.com
}

October 2014

\begin{abstract}
The capital asset pricing model (CAPM) developed by Sharpe (1964) is the starting point for the arbitrage pricing theory (APT). It uses a single risk factor to model the risk premium of an asset class. However, the CAPM has been the subject of important research, which has highlighted numerous empirical contradictions. Based on the APT theory proposed by Ross (1976), Fama and French (1992) and Carhart (1997) introduce other common factors models to capture new risk premia. For instance, they consequently define equity risk factors, such as market, value, size and momentum. In recent years, a new framework based on this literature has emerged to define strategic asset allocation. Similarly, index providers and asset managers now offer the opportunity to invest in these risk factors through factor indexes and mutual funds. These two approaches led to a new paradigm called 'factor investing' (Ang, 2014). Factor investing seems to solve some of the portfolio management issues that emerged in the past, in particular for long-term investors. However, some questions arise, especially with the number of risk factors growing over the last few years (Cochrane, 2011). What is a risk factor? Are all risk factors well-rewarded? What is their level of stability and robustness? How should we allocate between them? The main purpose of this paper is to understand and analyze the factor investing approach in order to answer these questions.
\end{abstract}

Keywords: Factor investing, risk premium, CAPM, risk factor model, anomaly, size, value, momentum, volatility, idiosyncratic risk, liquidity, carry, quality, mutual funds, hedge funds, alternative beta, strategic asset allocation.

JEL classification: C50, C60, G11.

\section{Introduction}

Risk factor investing has grown in popularity in recent years and has become an important concept within investment portfolios. It is best defined as an attempt to capture systematic risk premia. In the CAPM theory, there is a single market risk premium, which can be obtained by investing in market-capitalization indexes. But since CAPM was introduced, academic researchers have put forward convincing evidence that there are other systematic sources of return. These alternative risk premia include, for example, risk factors related to a stock's size or valuation. The idea of factor investing is then to enlarge the asset universe by adding these risk factors to the existing market risk factors, which are simply asset classes such as equities and bonds. The goal is then to generate more returns in the long run. As explained by Ang (2014), "it is precisely because factors episodically lose money in bad 
Facts and Fantasies About Factor Investing

times that there is a long-run reward for being exposed to factor risk. Factor premiums are rewards for investors enduring losses during bad times."

One of the issues with factor investing is to define which factors really matter. For a long time, the standard model was the four factor model of Carhart (1997). Based on the model developed by Fama and French (1992), which is based on the size and value factors, Carhart (1997) proposed to add the momentum factor found by Jegadeesh and Titman (1993). More recently, other factors have emerged such as the volatility, low beta, quality or liquidity factors, to name just a few. However, the existence of more and more factors does not help. In fact, Cochrane (2011) has recently referred to a "zoo of new factors". For instance, Harvey et al. (2014) counted over 300 in various academic papers, and their number has been increasing exponentially (see Figure 1). In such situations, the investor may be lost in front of the factor proliferation.

Figure 1: Factors and publications (Harvey et al., 2014)

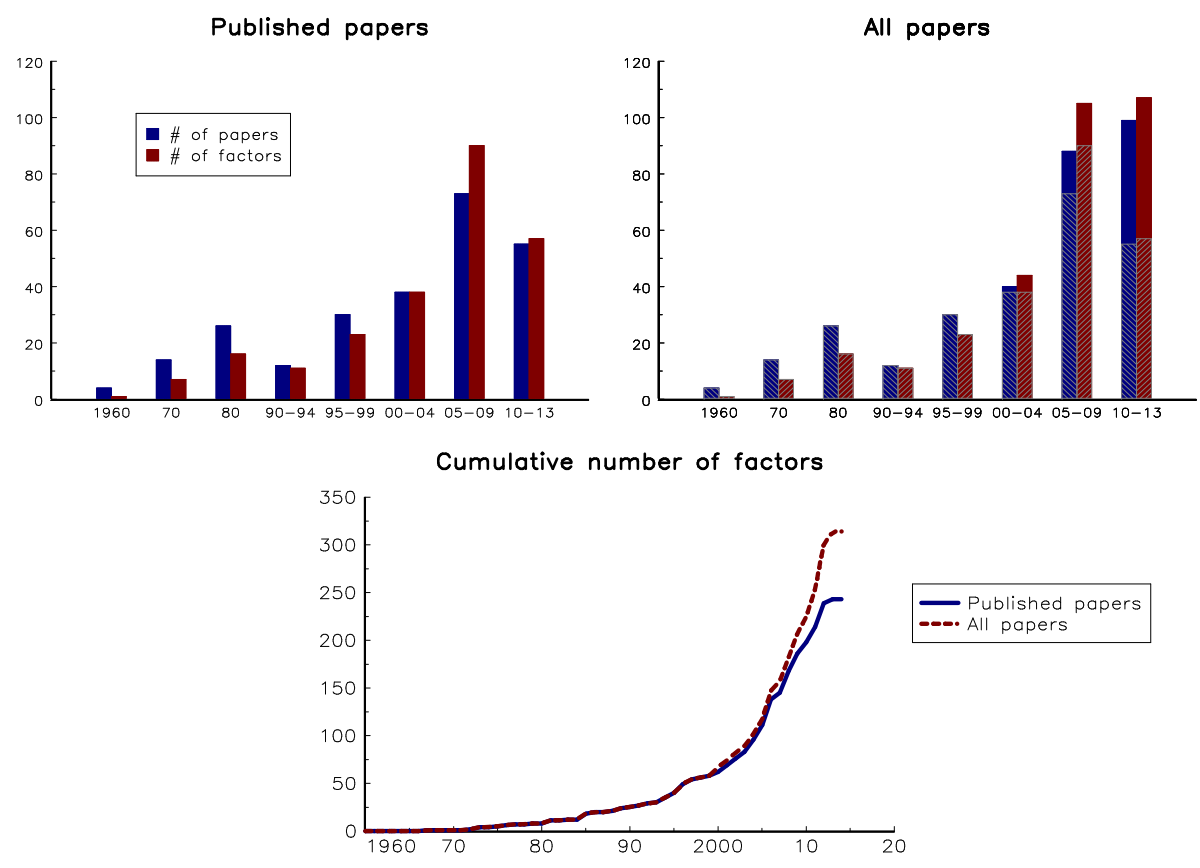

In this context, the pertinence of risk factors is an open issue. In fact, the literature on risk factors generally focuses on 'the cross-section of expected returns'. The underlying idea is to discover independent patterns that can help to explain the dispersion of asset returns. For that, academics use a standard method based on the pioneer research of Chan et al. (1991) and Fama and French (1993). The procedure consists in forming sorted portfolios based on some characteristics and to test whether portfolio returns are sensitive to a given pattern. One of the issues is the alpha puzzle of the cross-section. Indeed, if one factor model is valid, this implies that portfolio returns adjusted by risk factors have no alpha. For instance, if the Carhart model is appropriate, this implies that there is alpha in diversified portfolios if we only use the Fama-French risk factors. If we now consider that the relevant model is a five factor model composed of the previous Carhart risk factors and the low volatility anomaly, this implies that alpha is present in diversified portfolios if we consider the Carhart risk factors. And the story is repeating itself with the discovery of new factors like quality or liquidity. Here is the mystery. How can alpha always come back? 
Facts and Fantasies About Factor Investing

Another issue with factors concerns the nature of these patterns. Are they risk factors or anomalies? The notion of risk factor refers to a natural risk premium, which rewards the risk taken by investors. For instance, we can think that the size factor is a risk factor, because small stocks are more risky than large stocks. But we can also think that the momentum factor is more an anomaly. In this case, the abnormal return posted by this factor is not a risk premium, but can only be explained by investment behaviors. The question of the value factor is more complicated. On the one hand, some portfolio managers consider that the goal of value strategies is to build aggressive portfolio by selecting distressed stocks. For instance, this point of view is supported by Fama and French (1998). On the other hand, other portfolio managers consider that the goal of value strategies is to build defensive portfolio by selecting quality stocks (Piotroski, 2000). The value factor encompasses two different realities: one is clearly a risk premium and the other is clearly an anomaly. And each of these realities may be illustrated by the behaviorial difference of the value strategy during the 2008 financial crisis and the dot-com bubble in 2000 .

Over the last few years, factor investing has rapidly attracted the asset managers and also large institutional investors. It is now a hot topic in the investment industry. However, most of the time it is presented as a very simple investment approach that gives superior results compared to traditional approaches, such as strategic asset allocation based on asset classes. But as noted by Ang (2014), "each factor defines a different set of bad times". This means that factor returns are time-varying and factors may highly underperform for a long time. In this context, a constant mix allocation based on risk factors makes sense only for long-term investors and the question of the horizon time is decisive. Are investors ready to wait ten years if small caps or value stocks underperform large caps or growth stocks? The answer has to be no. This is why factor investing raises the question of multi-factor allocation. It is true that diversifying across factors is a way to diversify across all these bad times. Unfortunately, these bad times are not always uncorrelated.

Implementation is another aspect of factor investing. Until recently, these factors were available by investing in mutual funds. Now, both active management and passive management propose investment vehicles and give access to these factors. The development of factor indexes will certainly help to rationalize the asset management industry. However, one question remains. How to transform these academic risk factors into investible portfolios? This implies studying the capacity, turnover and transaction costs of these factor portfolios and also the impact of the constraints on such investments such as long-only restrictions.

Behind the marketing operation where factors are everywhere and everything is a factor, it is tempting to reject this approach by saying that it is just the latest fashion. However, factor investing is a necessary tool to understand where the performance comes from and a powerful concept to challenge and enhance long-term investment strategies. Thus, factor benchmarks proposed by Ang (2014) are a new step to help long-term investors to assess the performance of their investments. However, there is a gap between ex-post analysis (or performance measurement) and ex-ante capital budgeting (or portfolio allocation). The goal of this paper is then to provide an overview of the two sides of factor investing (risk factors and long-run allocation) and to show that it is not as simple as it is often presented. In the real world, factor investing is complex, but remains powerful when it is properly understood and used.

This article is organized as follows. In section two, we introduce the risk factor framework. In section three, we review the universe of risk factors and anomalies that can explain the cross-section of expected returns. The conversion of academic risk factors into factor benchmarks and indexes is explained in the fourth section. Section 5 treats the allocation process with risk factors. Section five offers some concluding remarks. 


\section{The risk factor framework}

\subsection{Back to the CAPM}

The capital asset pricing model (CAPM) was introduced by Sharpe in 1964, and may be viewed as an equilibrium model based on the framework defined by Markowitz (1952). In his paper, Markowitz developed the efficient frontier concept, i.e. the set of optimal meanvariance portfolios. Later, Tobin (1958) showed that the efficient frontier becomes a straight line in the presence of a risk-free asset. Contrary to Markowitz' results, it can then be shown that there is only one optimal portfolio of risky assets, which is called the tangency portfolio. One of the issues is that the tangency portfolio depends on the parameter values ${ }^{1}$ of each investor. This was partially solved by Sharpe (1964). Under some assumptions ${ }^{2}$, he showed that the tangency portfolio corresponds to the market-capitalization portfolio (or market portfolio). He then deduced the now familiar relationship between the risk premium of asset $i$ and the risk premium of the market portfolio:

$$
\mathbb{E}\left[R_{i}\right]-R_{f}=\beta_{i}^{m}\left(\mathbb{E}\left[R_{m}\right]-R_{f}\right)
$$

where $R_{i}$ and $R_{m}$ are the asset and market returns, $R_{f}$ is the risk-free rate and the coefficient $\beta_{i}^{m}$ is the beta of the asset $i$ with respect to the market portfolio:

$$
\beta_{i}^{m}=\frac{\operatorname{cov}\left(R_{i}, R_{m}\right)}{\sigma^{2}\left(R_{m}\right)}
$$

The capital asset pricing model highlights the role of beta, which represents the asset's systematic risk. Contrary to idiosyncratic risks, systematic risk cannot be diversified, and investors are compensated for taking this risk. However, Black et al. (1972) verified empirically that the expected excess return on an asset is not proportional to its beta. A large number of studies were to follow, and confirmed the non-empirical evidence of the CAPM ${ }^{3}$.

\subsection{Arbitrage pricing theory and factor models}

Ross (1976) proposed an alternative model to the CAPM, which he called the arbitrage pricing theory (APT). In this model, the return of asset $i$ is driven by a standard linear factor model:

$$
R_{i}=\alpha_{i}+\sum_{j=1}^{m} \beta_{i}^{j} \mathcal{F}_{j}+\varepsilon_{i}
$$

where $\alpha_{i}$ is the intercept, $\beta_{i}^{j}$ is the sensitivity of asset $i$ to factor $j$ and $\mathcal{F}_{j}$ is the (random) value of factor $j . \varepsilon_{i}$ is the idiosyncratic risk of asset $i$, implying that:

1. $\mathbb{E}\left[\varepsilon_{i}\right]=0$;

2. $\operatorname{cov}\left(\varepsilon_{i}, \varepsilon_{k}\right)=0$ for $i \neq j$;

3. $\operatorname{cov}\left(\varepsilon_{i}, \mathcal{F}_{j}\right)=0$.

\footnotetext{
${ }^{1}$ These are the expected returns and the covariance matrix of the assets.

${ }^{2}$ For instance, investors have homogeneous beliefs and the market is efficient.

${ }^{3}$ We should point out that testing the CAPM is nevertheless difficult, because it requires the exact composition of the market portfolio to be known (Roll, 1977).
} 
Using arbitrage theory, we can show that the risk premium of asset $i$ is a linear function of the risk premia of the factors:

$$
\pi_{i}=\mathbb{E}\left[R_{i}\right]-R_{f}=\sum_{j=1}^{m} \beta_{i}^{j} \pi\left(\mathcal{F}_{j}\right)
$$

where $\pi\left(\mathcal{F}_{j}\right)=\mu\left(\mathcal{F}_{j}\right)-R_{f}$ and $\mu\left(\mathcal{F}_{j}\right)=\mathbb{E}\left[\mathcal{F}_{j}\right]$. The proof is given in Appendix A.1.

The underlying idea of APT is that systematic risks are not captured by one market risk. Contrary to CAPM, which requires that the Markowitz model is valid ${ }^{4}$, APT does not assume a specific utility function. However, it assumes that there are a large number of assets to build a portfolio which is sufficiently diversified with no specific risk in respect of individual assets.

A number of implementations have been proposed. We generally distinguish three approaches to define the risk factors:

- The first approach uses factor analysis (e.g. principal component analysis) to build statistical factors. SunGard's APT risk solution is the best-known example of this approach.

- The second approach requires specification of macroeconomic factors.

- The third approach uses market factors, such as the Fama-French factors.

\subsection{Algebra of multi-factor models}

\subsubsection{Computing some basic statistics}

We consider a set of $n$ assets $\left\{\mathcal{A}_{1}, \ldots, \mathcal{A}_{n}\right\}$ and a set of $m$ risk factors $\left\{\mathcal{F}_{1}, \ldots, \mathcal{F}_{m}\right\}$. We denote by $R$ the $(n \times 1)$ vector of asset returns at time $t$, while $\mu$ is its mean vector and $\Sigma$ is its associated covariance matrix. We also denote by $\mathcal{F}$ the $(m \times 1)$ vector of factor returns at time $t$ and $\Omega$ its associated covariance matrix. We assume the following linear factor model:

$$
R=\alpha+B \mathcal{F}+\varepsilon
$$

where $\alpha$ is a $(n \times 1)$ vector, $B$ is a $(n \times m)$ matrix and $\varepsilon$ is a $(n \times 1)$ centered random vector of covariance $D$. This relationship is the matrix form of Equation (2), meaning that $(B)_{i, j}=\beta_{i}^{j}$ is the sensitivity of asset return $i$ with respect to factor $j$. We have:

$$
\begin{aligned}
\mu & =\mathbb{E}[R] \\
& =\alpha+B \mathbb{E}[\mathcal{F}] \\
& =\alpha+B \mu(\mathcal{F})
\end{aligned}
$$

and:

$$
\begin{aligned}
\Sigma & =\mathbb{E}\left[(R-\mu)(R-\mu)^{\top}\right] \\
& =\mathbb{E}\left[(B(\mathcal{F}-\mu(\mathcal{F})+\varepsilon))(B(\mathcal{F}-\mu(\mathcal{F})+\varepsilon))^{\top}\right] \\
& =B \mathbb{E}\left[(\mathcal{F}-\mu(\mathcal{F}))(\mathcal{F}-\mu(\mathcal{F}))^{\top}\right] B^{\top}+\mathbb{E}\left[\varepsilon \varepsilon^{\top}\right] \\
& =B \Omega B^{\top}+D
\end{aligned}
$$

\footnotetext{
${ }^{4}$ This implies that investors adopt a mean-variance analysis.
} 
Let us now consider a portfolio $x$. Its return is equal to:

$$
\begin{aligned}
R(x) & =x^{\top} R \\
& =x^{\top} \alpha+\beta(x)^{\top} \mathcal{F}+x^{\top} \varepsilon_{t}
\end{aligned}
$$

where $\beta(x)=B^{\top} x$ is the sensitivity vector of portfolio $x$ to the risk factors. One important property is that we can easily aggregate the betas. Indeed, we have $\beta(x)=$ $\left(\beta^{1}(x), \ldots, \beta^{m}(x)\right)$ with:

$$
\beta^{j}(x)=\sum_{i=1}^{n} x_{i} \beta_{i}^{j}
$$

In a similar way, we can deduce that the expected return of the portfolio is:

$$
\mu(x)=x^{\top} \alpha+\beta(x)^{\top} \mu(\mathcal{F})
$$

whereas its volatility has the following expression:

$$
\begin{aligned}
\sigma(x) & =\sqrt{\beta(x)^{\top} \Omega \beta(x)+x^{\top} D x} \\
& =\sqrt{\sigma_{\mathcal{F}}^{2}(x)+\sigma_{\varepsilon}^{2}(x)}
\end{aligned}
$$

where $\sigma_{\mathcal{F}}(x)=\sqrt{\beta(x)^{\top} \Omega \beta(x)}$ is the systematic (or factor) portfolio volatility and $\sigma_{\varepsilon}(x)=$ $\sqrt{x^{\top} D x}$ is the specific (or idiosyncratic) volatility.

Remark 1 To compute the beta $\beta(x \mid b)$ of portfolio $x$ with respect to benchmark $b$, we use the following formula:

$$
\begin{aligned}
\beta(x \mid b) & =\frac{\operatorname{cov}(R(x), R(b))}{\sigma^{2}(R(b))} \\
& =\frac{\beta(x)^{\top} \Omega \beta(b)+x^{\top} D b}{\beta(b)^{\top} \Omega \beta(b)+b^{\top} D b}
\end{aligned}
$$

\subsubsection{Risk allocation}

Let $\mathcal{R}(x)$ be a risk measure applied to portfolio $x$. We assume that the risk measure is convex. In this case, the risk measure satisfies the Euler decomposition:

$$
\mathcal{R}(x)=\sum_{i=1}^{n} \mathcal{R C}_{i}=\sum_{i=1}^{n} x_{i} \frac{\partial \mathcal{R}(x)}{\partial x_{i}}
$$

With this relationship, we can allocate risk to the assets in a straightforward way. Risk allocation with respect to factors is more difficult. However, Meucci (2007) proposes decomposing the portfolio's asset exposures $x$ by the portfolio's risk factors exposures $y$ as follows:

$$
x=A^{+} y+\tilde{A}^{+} \tilde{y}
$$

where $A^{+}$is the Moore-Penrose inverse of $B^{\top}$ and $\tilde{A}^{+}$is any $n \times(n-m)$ matrix that spans the left nullspace of $A^{+}$. $\tilde{y}$ is the exposure corresponding to $n-m$ residual (or additional) factors that have no economic interpretation ${ }^{5}$. It follows that:

$$
\left\{\begin{array}{l}
y=B^{\top} x \\
\tilde{y}=\tilde{A} x
\end{array}\right.
$$

\footnotetext{
${ }^{5}$ The residual factors are not determined in a unique way. They are only defined in order to calculate the risk contributions of the factors $y$. Therefore, interpreting the risk contributions of these residual factors is not meaningful.
} 
where $\tilde{A}=\operatorname{ker}\left(B^{\top}\right)^{\top}$. In this case, the marginal risk of assets is related to the marginal risk of factors in the following way:

$$
\frac{\partial \mathcal{R}(x)}{\partial x}=\frac{\partial \mathcal{R}(x)}{\partial y} A+\frac{\partial \mathcal{R}(x)}{\partial \tilde{y}} \tilde{A}
$$

We deduce that the marginal risk of the $j^{\text {th }}$ factor exposure is given by:

$$
\frac{\partial \mathcal{R}(x)}{\partial y_{j}}=\left(B^{+} \frac{\partial \mathcal{R}(x)}{\partial x^{\top}}\right)_{j}
$$

For the residual factors, we have:

$$
\frac{\partial \mathcal{R}(x)}{\partial \tilde{y}_{j}}=\left(\tilde{A} \frac{\partial \mathcal{R}(x)}{\partial x^{\top}}\right)_{j}
$$

Let us note $\mathcal{R C}\left(\mathcal{F}_{j}\right)=y_{j} \cdot \partial_{y_{j}} \mathcal{R}(x)$ the risk contribution of factor $j$ with respect to risk measure $\mathcal{R}$. We obtain:

$$
\mathcal{R C}\left(\mathcal{F}_{j}\right)=\left(B^{\top} x\right)_{j} \cdot\left(B^{+} \frac{\partial \mathcal{R}(x)}{\partial x^{\top}}\right)_{j}
$$

and:

$$
\mathcal{R C}\left(\tilde{\mathcal{F}}_{j}\right)=(\tilde{A} x)_{j} \cdot\left(\tilde{A} \frac{\partial \mathcal{R}(x)}{\partial x^{\top}}\right)_{j}
$$

Following Meucci (2007), Roncalli and Weisang (2012) show that these risk contributions satisfy the allocation principle:

$$
\mathcal{R}(x)=\sum_{j=1}^{m} \mathcal{R C}\left(\mathcal{F}_{j}\right)+\sum_{j=1}^{n-m} \mathcal{R C}\left(\tilde{\mathcal{F}}_{j}\right)
$$

We also obtain a risk decomposition by factors similar to the Euler decomposition by assets.

Remark 2 When the risk measure $\mathcal{R}(x)$ is the volatility of the portfolio $\sigma(x)=\sqrt{x^{\top} \Sigma x}$, the risk contribution of the $j^{\text {th }}$ factor is:

$$
\mathcal{R C}\left(\mathcal{F}_{j}\right)=\frac{\left(B^{\top} x\right)_{j} \cdot\left(B^{+} \Sigma x\right)_{j}}{\sigma(x)}
$$

For the residual risk factors $\tilde{\mathcal{F}}_{t}$, the results become:

$$
\mathcal{R C}\left(\tilde{\mathcal{F}}_{j}\right)=\frac{(\tilde{A} x)_{j} \cdot(\tilde{A} \Sigma x)_{j}}{\sigma(x)}
$$

\subsubsection{Beta exposures versus risk contributions}

We notice that the factor exposures $y$ are in fact the beta exposures $\beta(x)$ of the portfolio. These exposures are difficult to interpret because they do not depend on the specification of the covariance matrix $\Omega$. From a financial point of view, the risk contributions contain more useful information, but one drawback is that they depend on the parametrization of the model. In order to illustrate these problems, we consider some examples. 
Facts and Fantasies About Factor Investing

Table 1: Volatility decomposition with respect to the factors (in \%)

\begin{tabular}{|c|c|c|c|c|}
\hline & $\beta_{j}$ & $\operatorname{MR}\left(\mathcal{F}_{j}\right)$ & $\mathrm{RC}\left(\mathcal{F}_{j}\right)$ & $\mathrm{RC}^{\star}\left(\mathcal{F}_{j}\right)$ \\
\hline $\mathcal{F}_{1}$ & 96.00 & 20.10 & 19.30 & 97.28 \\
\hline $\mathcal{F}_{2}$ & 19.00 & 2.29 & 0.44 & 2.22 \\
\hline $\mathcal{F}_{3}$ & 62.50 & 0.03 & 0.02 & 0.10 \\
\hline$\tilde{\mathcal{F}}$ & & & 0.08 & $\overline{0} . \overline{4} 2$ \\
\hline$\sigma(x$ & & & 19.84 & \\
\hline
\end{tabular}

Table 2: Comparison of risk decompositions

\begin{tabular}{|c|c|c|c|c|c|c|}
\hline \multirow[t]{2}{*}{ Case } & \multicolumn{2}{|r|}{$\# 0$} & \multicolumn{2}{|r|}{$\# 1$} & \multicolumn{2}{|r|}{$\# 2$} \\
\hline & $\beta_{j}$ & $\mathrm{RC}^{\star}\left(\mathcal{F}_{j}\right)$ & $\beta_{j}$ & $\mathrm{RC}^{\star}\left(\mathcal{F}_{j}\right)$ & $\beta_{j}$ & $\mathrm{RC}^{\star}\left(\mathcal{F}_{j}\right)$ \\
\hline $\mathcal{F}_{1}$ & 96.00 & 97.28 & 96.00 & 45.65 & 96.00 & 87.82 \\
\hline $\mathcal{F}_{2}$ & 19.00 & 2.20 & I 19.00 & 40.37 & 19.00 & 11.76 \\
\hline $\mathcal{F}_{3}$ & 62.50 & 0.10 & 62.50 & 11.94 & 62.50 & 0.08 \\
\hline$\widetilde{\mathcal{F}}$ & & $\overline{0} . \overline{4} 2$ & 1 & 2.04 & & $0 . \overline{4}$ \\
\hline
\end{tabular}

Example 1 We consider $n=6$ assets and $m=3$ factors. The loadings matrix is:

$$
B=\left(\begin{array}{rrr}
0.9 & 0.3 & 2.5 \\
1.1 & 0.5 & -1.5 \\
1.2 & 0.6 & 3.4 \\
0.8 & -0.8 & -1.2 \\
0.8 & -0.2 & 2.1 \\
0.7 & -0.4 & -5.2
\end{array}\right)
$$

The three factors are uncorrelated and their volatilities are equal to $20 \%, 15 \%$ and $1 \%$. We consider a diagonal matrix $D$ with specific volatilities $10 \%, 13 \%, 5 \%, 8 \%, 18 \%$ and $8 \%$.

If we consider the portfolio $x=(30 \%, 10 \%, 30 \%, 5 \%, 5 \%, 20 \%)$, the betas are equal to $96 \%, 19 \%$ and $62.5 \%$. With these figures, we have the impression that the portfolio is exposed firstly to the factor $\mathcal{F}_{1}$, then to the factor $\mathcal{F}_{3}$ and finally to the factor $\mathcal{F}_{2}$. The problem is that the volatilities of these factors are not comparable. If we perform a risk allocation using the volatility risk measure, it appears that the second factor is in fact more important than the third factor (see Table 1). Of course, this risk decomposition depends greatly on the specification of the covariance matrix $\Omega$. Let us consider for instance the following two other cases:

- The volatilities of the factors become $5 \%, 30 \%$ and $5 \%$.

- The correlation between $\mathcal{F}_{1}$ and $\mathcal{F}_{2}$ is equal to $90 \%$.

In Table 2 , we report the beta and risk contribution of each factor. We verify that the relationship between the exposures $\beta_{j}$ and the risk contribution $\mathrm{RC}^{\star}\left(\mathcal{F}_{j}\right)$ is not straightforward.

Remark 3 If we want the risk contributions to be proportional to the betas, the following conditions must be satisfied:

1. the volatility of the factors is equal to one and the factors are perfectly correlated $\left(\Omega=11^{\top}\right)$; 
Facts and Fantasies About Factor Investing

Table 3: Volatility decomposition with respect to the factors (in \%)

\begin{tabular}{|c|c|c|c|c|}
\hline & $\beta_{j}$ & $\operatorname{MR}\left(\mathcal{F}_{j}\right)$ & $\mathrm{RC}\left(\mathcal{F}_{j}\right)$ & $\mathrm{RC}^{\star}\left(\mathcal{F}_{j}\right)$ \\
\hline $\mathcal{F}_{1}$ & 96.00 & 16.88 & 16.20 & 81.67 \\
\hline $\mathcal{F}_{2}$ & 19.00 & 1.69 & 0.32 & 1.61 \\
\hline $\mathcal{F}_{3}$ & 62.50 & 0.19 & 0.12 & 0.59 \\
\hline$\tilde{\mathcal{F}}_{4}^{-} / \tilde{\mathcal{F}}_{9}^{-}$ & & & 3.20 & $\overline{16} \overline{1} \overline{2}$ \\
\hline$\sigma(x)$ & & & 19.84 & \\
\hline
\end{tabular}

Table 4: Volatility decomposition with respect to the factors (in \%)

\begin{tabular}{|c|cccc|}
\hline & $\beta_{j}$ & $\mathrm{MR}\left(\mathcal{F}_{j}\right)$ & $\mathrm{RC}\left(\mathcal{F}_{j}\right)$ & $\mathrm{RC}^{\star}\left(\mathcal{F}_{j}\right)$ \\
\hline $\mathcal{F}_{2}$ & 19.00 & 7.72 & 1.47 & 7.39 \\
$\mathcal{F}_{3}$ & 62.50 & 0.22 & 0.14 & 0.70 \\
\hline$\tilde{\mathcal{F}}^{\prime}$ & - & \multicolumn{5}{|c|}{$18.2 \overline{3}$} & $-\overline{91.91}$ \\
\hline$\sigma(x)$ & \multicolumn{5}{|c|}{19.84} \\
\hline
\end{tabular}

2. the idiosyncratic contribution is negligible.

As explained above, the shortcoming is that the risk decomposition depends on the parametrization model. For instance, we can write Equation (2) as follows:

$$
\begin{aligned}
R_{t} & =\alpha+\left(\begin{array}{cc}
B & I
\end{array}\right)\left(\begin{array}{c}
\mathcal{F}_{t} \\
\epsilon_{t}
\end{array}\right) \\
& =\alpha+B^{\prime} \mathcal{F}_{t}^{\prime}
\end{aligned}
$$

By considering specific risks as common risks, we will change the risk allocation. With Example 1, we obtain the risk allocation given in Table 3. We observe that the risk contributions of the specific risks ${ }^{6}$ now explain $16.12 \%$ of the volatility, whereas this was only $0.34 \%$ previously.

We can also treat some common risks as specific risks. If we split the common risks as follows: $B \mathcal{F}_{t}=B^{1} \mathcal{F}_{t}^{1}+B^{2} \mathcal{F}_{t}^{2}$, we obtain:

$$
R_{t}=\alpha+B^{1} \mathcal{F}_{t}^{1}+\epsilon_{t}^{\prime}
$$

with $^{7} \epsilon_{t}^{\prime}=\epsilon_{t}+B^{2} \mathcal{F}_{t}^{2}$. If we incorporate the first factors in the specific risk, we obtain the results in Table 4 . We observe that the risk contribution of the second factor has increased considerably.

\section{Empirical evidence of risk factors}

There is extensive literature on this topic. Some risk factors are long established, such as the size factor (Banz, 1981; Basu, 1983) and the value factor (Basu, 1977; Rosenberg et al., 1985; Chan et al., 1991), whereas others are more recent, such as the quality factor.

\footnotetext{
${ }^{6}$ They are now treated as common risks $\left(\tilde{\mathcal{F}}_{4}, \ldots, \tilde{\mathcal{F}}_{9}\right)$.

${ }^{7}$ In this case, $\epsilon_{t}^{\prime}$ is independent from the factors $\mathcal{F}_{t}^{1}$ if $\operatorname{cov}\left(\mathcal{F}_{j}^{1}, \mathcal{F}_{j}^{2}\right)=0$.
} 


\subsection{Fama-French risk factors}

In 1992, Fama and French studied several factors to explain average returns (size, E/P, leverage and book-to-market equity). Fama and French (1993) subsequently extended their empirical work and proposed a three factor-model:

$$
\mathbb{E}\left[R_{i}\right]-R_{f}=\beta_{i}^{m}\left(\mathbb{E}\left[R_{m}\right]-R_{f}\right)+\beta_{i}^{s m b} \mathbb{E}\left[R_{s m b}\right]+\beta_{i}^{h m l} \mathbb{E}\left[R_{h m l}\right]
$$

where $R_{s m b}$ is the return of small stocks minus the return of large stocks, and $R_{h m l}$ is the return of stocks with high book-to-market values minus the return of stocks with low book-to-market values. Since its publication, this model has become standard in the asset management industry.

\subsubsection{Fama-French methodology}

Fama and French (1993) looked at the US market using stocks listed on the NYSE, AMEX and NASDAQ. The breakpoint for the size factor is the median NYSE market value (or market equity, ME) at the end of June, and is used to rebalance the portfolio in July. For the book-to-market $(\mathrm{B} / \mathrm{M})$ ratio, the breakpoints correspond to the $30^{\text {th }}$ and $70^{\text {th }}$ percentiles measured in December. In this case, the portfolio is rebalanced in January. This gives us 6 portfolios ${ }^{8}$ :

\begin{tabular}{l|ccc} 
& Value & Neutral & Growth \\
\hline Small & SV & SN & SG \\
Big & BV & BN & BG
\end{tabular}

For instance, the SV portfolio corresponds to stocks, such that ${ }^{9} \mathrm{ME}_{i}<\mathcal{M}(\mathrm{ME})$ and $\mathrm{B} / \mathrm{M}_{i}<$ $\mathcal{Q}_{30 \%}(\mathrm{~B} / \mathrm{M})$. For the $\mathrm{SN}$ portfolio, we have $\mathrm{ME}_{i}<\mathcal{M}(\mathrm{ME})$ and $\mathcal{Q}_{30 \%}(\mathrm{~B} / \mathrm{M}) \leq \mathrm{B} / \mathrm{M}_{i}<$ $\mathcal{Q}_{70 \%}(\mathrm{~B} / \mathrm{M})$. The Fama-French factors are the difference between portfolio returns:

$$
\mathrm{SMB}_{t}=\frac{1}{3}\left(R_{t}(\mathrm{SV})+R_{t}(\mathrm{SN})+R_{t}(\mathrm{SG})\right)-\frac{1}{3}\left(R_{t}(\mathrm{BV})+R_{t}(\mathrm{BN})+R_{t}(\mathrm{BG})\right)
$$

and:

$$
\mathrm{HML}_{t}=\frac{1}{2}\left(R_{t}(\mathrm{SV})+R_{t}(\mathrm{BV})\right)-\frac{1}{2}\left(R_{t}(\mathrm{SG})+R_{t}(\mathrm{BG})\right)
$$

To test their model, Fama and French consider two linear regressions. The first corresponds to the CAPM:

$$
R_{i}-R_{f}=\alpha_{i}^{\mathrm{CAPM}}+\beta_{i}^{m}\left(R_{m}-R_{f}\right)+\varepsilon_{i}^{\mathrm{CAPM}}
$$

whereas the second regression uses the three-factor model:

$$
R_{i}-R_{f}=\alpha_{i}^{\mathrm{FF}}+\beta_{i}^{m}\left(R_{m}-R_{f}\right)+\beta_{i}^{s m b} R_{s m b}+\beta_{i}^{h m l} R_{h m l}+\varepsilon_{i}^{\mathrm{FF}}
$$

If the Fama-French model is valid, we must reject the assumption $\mathcal{H}_{0}: \alpha_{i}^{\mathrm{CAPM}}=0$ and accept the assumption $\mathcal{H}_{1}: \alpha_{i}^{\mathrm{FF}}=0$. Moreover, the estimates $\hat{\beta}_{i}^{\text {smb }}$ and $\hat{\beta}_{i}^{h m l}$ must be significant, and we should notice an improvement in the power explanation, meaning that $R_{\mathrm{FF}}^{2} \gg R_{\mathrm{CAPM}}^{2}$.

\footnotetext{
${ }^{8}$ Fama and French (1993) justify the sorting procedure into three groups based on the B/M ratio and only two groups based on size, because they consider that "book-to-market equity has a stronger role in average stock returns than size".

${ }^{9} \mathcal{M}(X)$ and $\mathcal{Q}_{\alpha}(X)$ correspond to the median and the percentile $\alpha$ of the statistic $X$.
} 
Facts and Fantasies About Factor Investing

It is important to note that Fama and French performed regressions on portfolios and not on individual stocks to explain the cross-section of expected stock returns. To do this, they adopted the sorting procedure of Chan et al. (1991) and consider a two-way grouping based on size and B/M (see Figure 2). To estimate the risk premium of each factors, they used the two-stage approach of Fama and MacBeth (1973).

Figure 2: The testing procedure

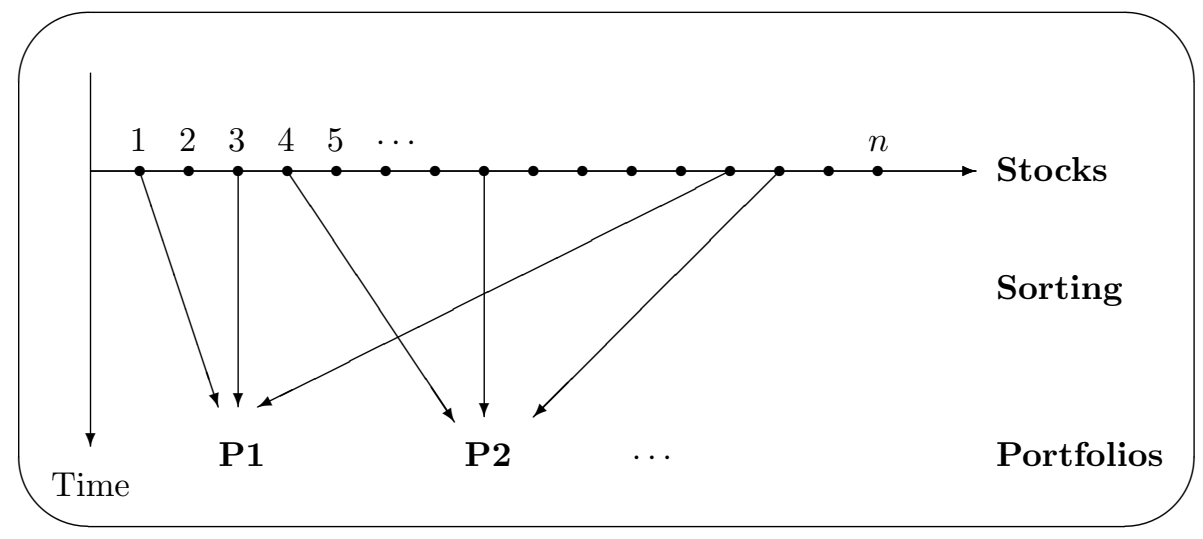

\subsubsection{Results for the US market}

The Fama-French risk factors are available on the website ${ }^{10}$ of Kenneth French. Since 1993, the data have been updated and now include the value of factors and portfolios for different regions ${ }^{11}$. In Figure 3, we report the cumulative performance of the risk factors for the US market. In their original paper, Fama and French found that the market factor captures a large part of the common variation in stock returns, but that adding the two other factors SMB and HML significantly improves the coefficient of determination $R^{2}$. In Table 5, we report some statistics they obtained for different portfolios. On average, the R-squared increases by 15\%. Using the data published by Kenneth French on his website,

Table 5: Statistics of $R^{2}$ (in \%)

\begin{tabular}{l|ccc} 
& Minimum & Average & Maximum \\
\hline CAPM & 61.0 & 77.9 & 92.0 \\
Fama-French & 83.0 & 93.1 & 97.0
\end{tabular}

we can update this study. To do this, we consider the 25 value-weighted portfolios, which are built from independent sorts into five size groups and five B/M groups ${ }^{12}$. For each

${ }^{10}$ http://mba.tuck. dartmouth.edu/pages/faculty/ken.french/data_library.html.

${ }^{11}$ The Fama-French methodology differs slightly in this case

${ }^{12}$ Kenneth French explains the construction of the 5x5 Size-B/M portfolios as follows:

"The portfolios, which are constructed at the end of each June, are the intersections of 5 portfolios formed on size (market equity, ME) and 5 portfolios formed on the ratio of book equity to market equity $(B / M)$. The size breakpoints for year $t$ are the NYSE market equity quintiles at the end of June of $t . B / M$ for June of year $t$ is the book equity for the last fiscal year end in $t-1$ divided by $M E$ for December of $t-1$. The $B / M$ breakpoints are NYSE quintiles." 
Figure 3: Fama-French US risk factors (1930 - 2013)

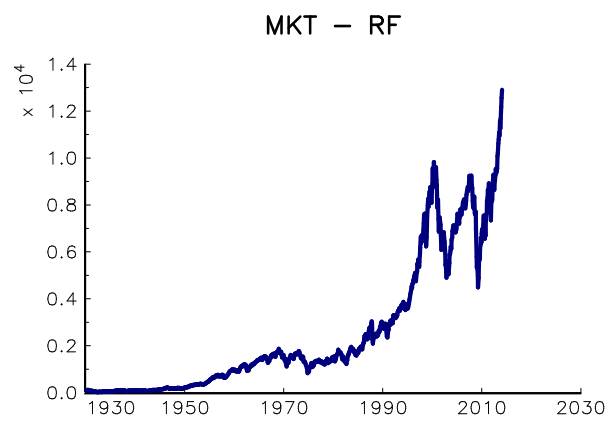

SMB

HML
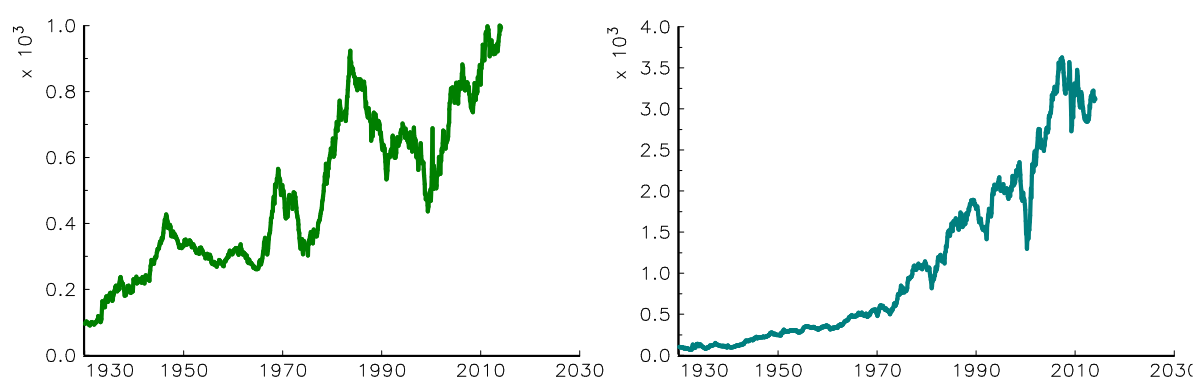

portfolio, we estimate the factor model using a rolling window of five years. We report some statistics relating to the $R^{2}$ coefficient for the one-factor (CAPM) and three-factor (Fama-French) models in Figure 4. At each date $t$, these statistics are the minimum and maximum, the first and third quartiles, and the median of the $R^{2}$ coefficient estimated for the 100 portfolios. The use of the three-factor model greatly increases the explanatory part and significantly reduces the dispersion of the $R^{2}$ coefficient. For instance, we report the difference $\Delta R^{2}=R_{\mathrm{FF}}^{2}-R_{\mathrm{CAPM}}^{2}$ in the third panel. In some cases, this difference can be larger than $50 \%$. However, the improvement of the $R^{2}$ coefficient is not uniform and we distinguish four periods:

- From 1995 to 1999 , the size and B/M factors significantly improve the $R^{2}$ coefficient, implying that $\Delta R^{2}$ ranges from $18 \%$ to $23 \%$.

- This improvement increases considerably during the period 2000-2004. On average, the difference $\Delta R^{2}$ is larger than $30 \%$, and the peak is reached in $2001^{13}$.

- The difference $R_{\mathrm{FF}}^{2}-R_{\mathrm{CAPM}}^{2}$ then decreases during the period 2005-2008, and is about $11 \%$ during the financial crisis.

- Finally, $\Delta R^{2}$ stabilizes at around 7\% on average between 2009 and 2013.

\subsubsection{Extension to other developed markets}

The original paper by Fama and French concerns the US market. Fama and French (1998) tested whether there is a value premium in markets outside the United States and found strong evidence, confirming the results of Chan et al. (1991) in the case of Japanese stocks.

\footnotetext{
${ }^{13}$ The mean of $R_{\mathrm{FF}}^{2}-R_{\mathrm{CAPM}}^{2}$ is $36.1 \%$ in 2001 (see Table 6 ).
} 
Figure 4: Dynamics of the $R^{2}$ coefficient (in \%)

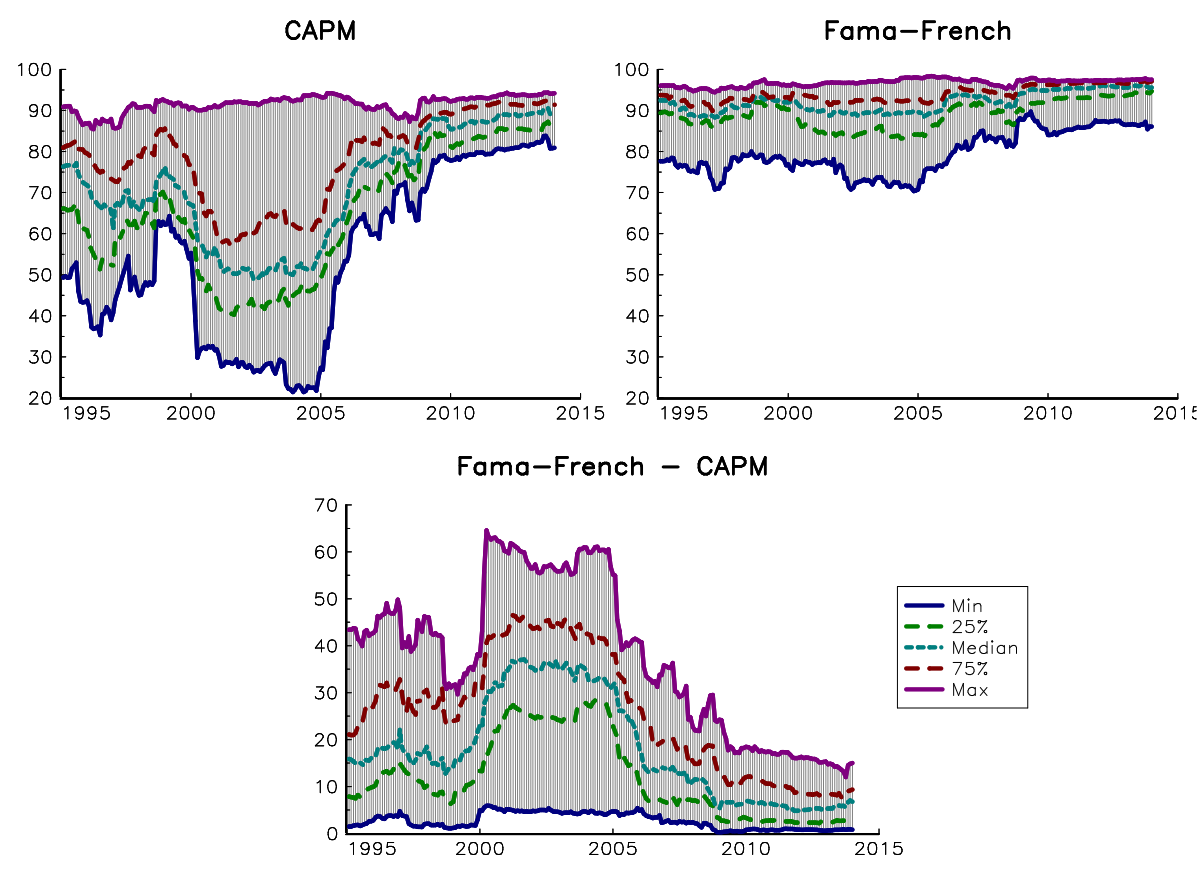

One issue was raised at the beginning of the 2000s: are the Fama and French factors global or country specific? This question is the title of an article by Griffin (2002), who concluded that "practical applications of the three-factor model [...] are best performed on a countryspecific basis". This approach has now been adopted by many practitioners and academics. For instance, Fama and French (2012) estimate the risk factors for four regions (Asia Pacific, Europe, Japan and North America). Results are reported in Appendix B.2 on Page 102. The SMB and HML factors are given in Figures 35 and 34, whereas the dynamics of the $R^{2}$ coefficient correspond to Figures 36-39. In Table 6, we summarize these results by computing the average of $\Delta R^{2}$ per year ${ }^{14}$. We obtain similar conclusions as previously. In particular, we observe that the three-factor model significantly improves the CAPM model. However, we also notice some differences. For instance, the behavior of $\Delta R^{2}$ is similar for European and American stocks, but this is not the case for Asian and Japanese stocks. In Asia Pacific, the value of $\Delta R^{2}$ is not very high, even during the internet bubble. In Japan, the average of $\Delta R^{2}$ has been larger than $10 \%$ in recent years.

The previous analysis looked at both the size and value factors. However, the contribution of these two factors is not the same. In Appendix B.1 on Page 90, we report the difference $\Delta R^{2}$ by considering two other linear regressions. In Table 37, we consider a variant of the model (4) using the market and SMB factors:

$$
R_{i}(t)-R_{f}(t)=\alpha_{i}+\beta_{i}^{m}\left(R_{m}(t)-R_{f}(t)\right)+\beta_{i}^{s m b} R_{s m b}(t)+\epsilon_{i}(t)
$$

In Table 38, we replace the SMB factor with the HML factor:

$$
R_{i}(t)-R_{f}(t)=\alpha_{i}+\beta_{i}^{m}\left(R_{m}(t)-R_{f}(t)\right)+\beta_{i}^{h m l} R_{h m l}(t)+\epsilon_{i}(t)
$$

\footnotetext{
${ }^{14} \Delta R^{2}$ does not measure the difference in $R^{2}$ for a given year $t$, but for a given period of five years ending at year $t$.
} 
Facts and Fantasies About Factor Investing

Table 6: Average of $\Delta R^{2}$ (in \%)

\begin{tabular}{|c|ccccc|}
\hline Year & Asia Pacific & Europe & Japan & North America & US \\
\hline 1995 & 12.1 & 13.7 & 10.0 & 17.9 & 18.0 \\
1996 & 11.7 & 14.4 & 9.8 & 22.5 & 23.0 \\
1997 & 12.7 & 17.6 & 11.1 & 22.4 & 20.2 \\
1998 & 13.0 & 19.1 & 14.0 & 21.1 & 18.4 \\
1999 & 12.8 & 19.9 & 15.2 & 19.2 & 19.2 \\
2000 & 13.1 & 27.2 & 20.4 & 29.5 & 31.6 \\
2001 & 13.0 & 26.4 & 21.1 & 30.3 & 36.1 \\
2002 & 12.3 & 23.4 & 20.9 & 28.6 & 35.0 \\
2003 & 13.3 & 20.3 & 19.4 & 27.3 & 34.4 \\
2004 & 13.5 & 17.5 & 19.3 & 27.1 & 33.2 \\
2005 & 11.5 & 11.6 & 13.9 & 17.7 & 23.7 \\
2006 & 11.3 & 8.8 & 14.2 & 13.0 & 15.7 \\
2007 & 12.5 & 7.5 & 15.4 & 11.3 & 13.6 \\
2008 & 9.6 & 6.3 & 15.8 & 10.0 & 11.4 \\
2009 & 6.1 & 5.0 & 15.5 & 7.1 & 7.8 \\
2010 & 5.9 & 5.7 & 15.0 & 6.8 & 7.9 \\
2011 & 5.4 & 5.1 & 14.1 & 5.9 & 6.9 \\
2012 & 4.8 & 4.9 & 13.7 & 5.3 & 6.3 \\
2013 & 5.3 & 5.1 & 12.1 & 5.3 & 6.3 \\
\hline
\end{tabular}

We notice that the improvement of the $R^{2}$ coefficient is principally due to the size factor, particularly in these last few years. These results are confirmed by considering the linear regression in specific periods (see Table 7). For instance, $\Delta R^{2}$ is equal on average to $1.7 \%$, $1.4 \%$ and $1.5 \%$ for the Asia Pacific, Europe and North America regions if we consider the HML factor. For Japanese stocks, it is higher, but significantly smaller than the $R^{2}$ improvement due to the SMB factor.

Table 7: Average of $\Delta R^{2}$ (in \%) for different periods

\begin{tabular}{|l|crrrr|}
\hline Model & Asia Pacific & Europe & Japan & North America & US \\
\hline \multicolumn{7}{|c}{$1995 / 2013$} \\
\hline SMB & 7.1 & 7.8 & 13.3 & 11.8 & 11.0 \\
HML & 2.7 & 3.4 & 4.0 & 6.4 & 8.0 \\
FF & 9.9 & 11.2 & 16.9 & 17.5 & 19.8 \\
\hline \multicolumn{7}{|c}{$2004 / 2013$} \\
\hline SMB & 4.9 & 4.5 & 12.2 & 5.0 & 5.3 \\
HML & 1.5 & 1.1 & 2.9 & 1.8 & 2.4 \\
FF & 6.4 & 5.6 & 14.7 & 6.7 & 7.6 \\
\hline \multicolumn{7}{|c}{$2009 / 2013$} \\
SMB & 5.1 & 4.3 & 9.4 & 4.5 & 4.7 \\
HML & 1.7 & 1.4 & 3.0 & 1.5 & 2.1 \\
FF & 6.7 & 5.7 & 12.3 & 5.8 & 6.8 \\
\hline
\end{tabular}




\subsubsection{Robustness of the Fama-French risk model}

There is extensive literature on the evidence for the Fama-French risk factors. It covers the US market (Jensen et al., 1997; Davis et al., 2000), as well as other developed markets (Chan et al. (1991) for Japanese stocks; Gaunt (2004) for Australian stocks; Bauer et al. (2010) for European stocks) and emerging markets (Drew et al. (2003) for Chinese stocks; Lischewski and Voronkova (2012) for Polish stocks). The Fama-French model has since become a benchmark framework for the asset management industry, used in particular to analyze the performance of active managers. For instance, the equity style box reported in Figure 5, which was created by Morningstar and is intensively used by investors, is a visual representation used to classify mutual funds in terms of Fama-French risk factors.

Figure 5: The Morningstar style box

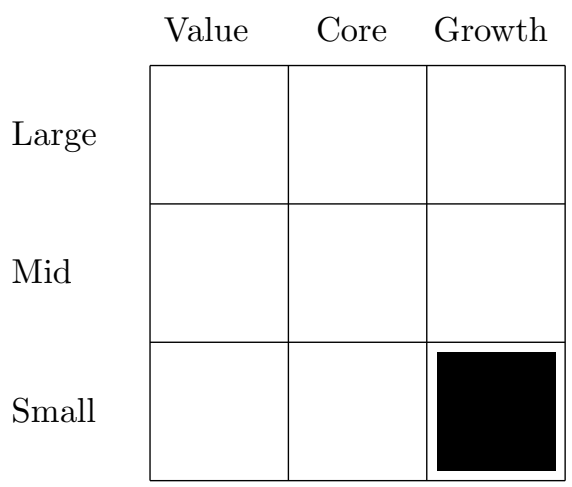

However, while accepted in the professional community, the empirical findings of the Fama-French model have been a source of debate among academics, and there is still no consensus. These criticisms concern both the model itself and the interpretation of the results.

Spurious regression and data snooping One of the main criticisms is the data mining approach used to obtain these empirical results. Black (1993) was one of the first and the most virulent opponent of the Fama-French results ${ }^{15}$. In his view, the empirical results obtained by Fama and French may be explained by data mining ${ }^{16}$. This conclusion had previously been reached by Lo and MacKinlay (1990), who showed that statistical tests

\footnotetext{
${ }^{15}$ Although it concerns the article published by Fama and French in 1992, his criticisms may also be applied to the article published in 1993.

${ }^{16}$ Here are some quotes extracted from Black [1993]:

- "I think, Fama and French, in the text of that article, misinterpret their own data (and the findings of others)."

- "[...] they find no size effect at all, whether or not they control for beta. Yet they claim in their paper that size is one of the variables that captures the cross-sectional variation in average stock returns. Fama and French also give no reasons for a relation between size and expected return. [...] Lack of theory is a tipoff: watch out for data mining!"

- "I think it is quite possible that even the book-to-market effect results from data mining and will vanish in the future."

- "I especially attribute their results to data mining when they attribute them to unexplained priced factors or give no reasons at all for the effects they find."
} 
Facts and Fantasies About Factor Investing

based on size-sorted portfolios are examples of data snooping ${ }^{17}$ (White, 2000). It is therefore difficult to know if the estimated model will work in the future (MacKinlay, 1995; Ferson et al., 2003). For instance, Kothari et al. (1995) conjectured that the relationship between average return and the $\mathrm{B} / \mathrm{M}$ factor are affected by survivor bias in COMPUSTAT data ${ }^{18}$. Jagannathan and McGrattan (1995) also noticed that the results for the market factor obtained by Fama and French (1992) were completely different from those obtained by Fama and MacBeth (1973), even though they used the same statistical procedure. They suggested that the Fama-French results have a high level of sensitivity with respect to the sample period. Another criticism concerns the way Fama and French build their portfolios. By considering portfolios instead of individual stocks, the results are more convincing. For instance, we report in Figure 6 the frequency of the $R^{2}$ coefficient in the case of S\&P 500 stocks for the period 1995-2013. On average, the improvement in $R^{2}$ is about $7 \%$. Nevertheless, the large amount of empirical evidence published in the last twenty years does not prove that the Fama-French model is a data-driven model although, we will see that some of the empirical results found in the original papers are less significant today.

Figure 6: Frequency of the $R^{2}$ coefficient with S\&P 500 stocks

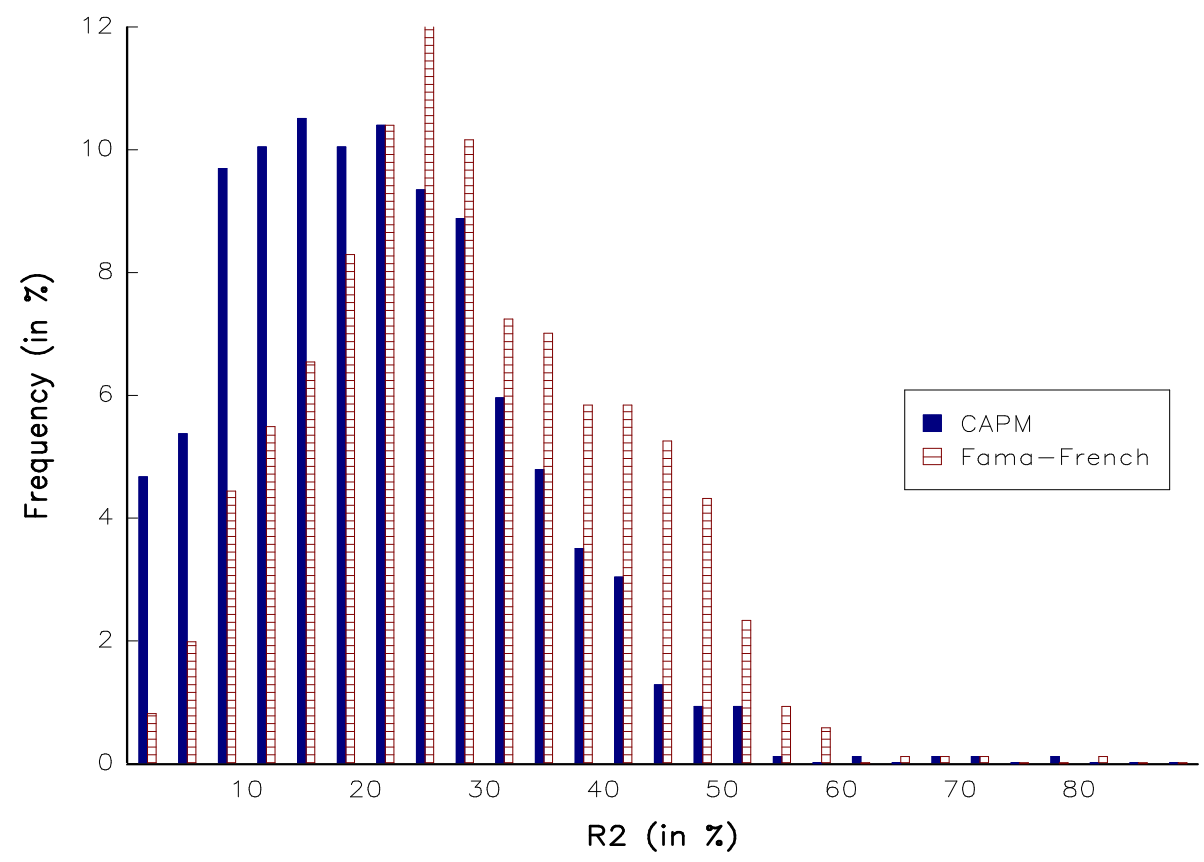

Another problem with empirical evidence of asset pricing models is that the results may be based on spurious regressions. Suppose that the true model is:

$$
R_{i}(t)=\alpha_{i}+\beta_{i} \mathcal{F}(t)+\epsilon_{i}(t)
$$

where $\mathcal{F}(t)$ is an autocorrelated process. This implies that the ex-ante expected return is

\footnotetext{
${ }^{17}$ Data snooping generally refers to statistical inference performed by the researcher after looking at the data.

${ }^{18}$ Breen and Korajczyk (1993) showed that this problem is not important for NYSE/AMEX stocks, but may be more relevant for NASDAQ stocks.
} 
Facts and Fantasies About Factor Investing

also autocorrelated. We then consider the following regression:

$$
R_{i}(t)=\alpha_{i}^{\star}+\beta_{i}^{\star} \mathcal{F}^{\star}(t)+\epsilon_{i}^{\star}(t)
$$

where $\mathcal{F}^{\star}(t)$ is another autocorrelated process. In this case, we will find that the estimated coefficient $\hat{\beta}_{i}^{\star}$ is significant because $R_{i}(t)$ and $\mathcal{F}^{\star}(t)$ are autocorrelated. In Table 8 , we report the estimated values of the first-order correlation $\rho$ for the different Fama-French risk factors. Even if the null hypothesis $\mathcal{H}_{0}: \rho=0$ is not always accepted at the $95 \%$ confidence level, the estimated values are relatively low, except for the HML factor for Asia Pacific. We cannot therefore conclude that Fama-French regressions are spurious.

Table 8: First-order autocorrelation (in \%) of the risk factors

\begin{tabular}{|l|ccccc|}
\hline Factor & Asia Pacific & Europe & Japan & North America & \multicolumn{1}{c|}{ US } \\
\hline MKT - RF & 13.77 & 14.81 & 16.82 & 12.25 & 11.62 \\
SMB & 16.26 & -1.65 & 1.36 & -8.72 & -7.50 \\
HML & 6.36 & 37.51 & 16.18 & 10.41 & 11.31 \\
\hline
\end{tabular}

The first-order autocorrelation is computed for the period 1995-2013.

The associated $t$-statistic is equal to $6.17 \%$.

Interpretation of the Fama-French results One of the issues with the SMB and HML factors concerns their interpretation as risk factors. If we assume that the market is efficient, this implies that the equity risk cannot be reduced to the market risk and idiosyncratic risks. In this case, common risk is multidimensional and includes other risks, which are related to size and B/M effects. The difficulty is then to determine which economic risks are rewarded. Fama and French (1995) argued that they correspond to relative distress. For instance, they showed that weak firms with poor earnings tend to have high $\mathrm{B} / \mathrm{M}$ values, whereas strong firms with high earnings tend to have low $\mathrm{B} / \mathrm{M}$ values. They then concluded that there is a compensation in terms of average returns to hold stocks with a positive slope on the HML factor. Similarly, they showed that small stocks tend to have lower earnings than large stocks, and they concluded that there is a compensation in terms of average returns to hold stocks with a positive slope on the SMB factor. They then suggest that the relationship (4) is an equilibrium pricing model and a special case of an ICAPM or APT model (Merton, 1973; Ross, 1976).

This interpretation as risk factors caused a lot of controversy. Contrary to Fama and French (1995), Haugen (1994) thinks that the market is not efficient. In this perspective, the value premium is not a compensation for distress risk, but an asset pricing anomaly. For instance, Lakonishok et al. (1994) and La Porta et al. (1997) suggest that the B/M effect is due to investor overreaction. Haugen and Baker (1996) show that stocks with higher expected and realized returns have lower volatility risk. The debate has continued since the publication of these pioneer studies, and it is difficult to conclude that the $\mathrm{B} / \mathrm{M}$ effect is a compensation for distress risk or a pricing anomaly ${ }^{19}$.

\footnotetext{
${ }^{19}$ On the one hand, Petkova and Zhang (2005), Zhang (2005) and Kapadia (2011) presented some research in favor of the distress risk explanation. On the other hand, Berk (1995), Daniel and Titman (1997), Griffin and Lemmon (2002), Ali et al. (2003), Gomes et al. (2003), Campbell et al. (2008) and Phalippou (2008) concluded that the $\mathrm{B} / \mathrm{M}$ effect is not a compensation for distress risk.
} 
Facts and Fantasies About Factor Investing

\subsubsection{Performance of the SMB and HML risk factors}

One of the challenges is to estimate the risk premium associated with different risk factors. Using the French data, we computed the performance of the different factors by considering three periods:

\#1 January 1995 - March 2000

\#2 April 2000 - March 2009

\#3 April 2009 - December 2013

The results are reported in Tables 9, 10 and 11. For each period and each region, we indicate the annual return $\mu(x)$ and the volatility $\sigma(x)$ expressed in \%. We also compute the corresponding Sharpe ratio SR $(x \mid r)$. We notice that the risk premia vary considerably from one country to another, as well as from one period to another. For instance, the size factor posts a negative return before the year 2000 and a positive return thereafter, except for Asia Pacific. Moreover, we notice that the performance is stronger in the United States and Japan than in Europe. As regards the HML factor, its performance is high during the period April 2000 - March 2009, particularly in Europe and Japan. From April 2009, the value factor has a smaller return. If we consider statistics year by year, we observe very mixed results (see Tables 39, 40 and 41 on Page 91). For instance, the performance is low in Europe and high in the United States for 2012, whereas the reverse is true for 2013.

Table 9: Performance of the MKT - RF factor

\begin{tabular}{|c|c|c|c|c|c|c|}
\hline Statistic & Period & Asia Pacific & Europe & Japan & North America & US \\
\hline \multirow[b]{2}{*}{$\mu(x)$} & $\# 1$ & 1.9 & 14.4 & -2.5 & 20.6 & 21.0 \\
\hline & $\# 2$ & 1.4 & -4.1 & -9.1 & -6.7 & -7.5 \\
\hline & $\# 3$ & 21.2 & 18.8 & 12.7 & 22.3 & 22.7 \\
\hline & $\overline{\#} 1^{-}$ & $\overline{22.6}$ & $\overline{1} 2.2^{-}$ & $\overline{2} 2.0$ & $\overline{1} \overline{4} . \overline{3}$ & $1 \overline{4} . \overline{5}$ \\
\hline \multirow[t]{3}{*}{$\sigma(x)$} & $\# 2$ & 20.7 & 18.8 & 18.4 & 16.4 & 16.4 \\
\hline & $\# 3$ & 22.1 & 21.4 & 14.2 & 15.0 & 14.6 \\
\hline & $\# 1$ & $0 . \overline{0} 8^{-}$ & $\overline{1} . \overline{1} 8^{-}$ & $=\overline{0} . \overline{1} 1^{-}$ & $\overline{1} . \overline{4} \overline{4}$ & $\overline{1} . \overline{4} \overline{5}$ \\
\hline \multirow[t]{2}{*}{$\operatorname{SR}(x \mid r)$} & $\# 2$ & 0.07 & -0.22 & -0.50 & -0.41 & -0.45 \\
\hline & $\# 3$ & 0.96 & 0.88 & 0.90 & 1.49 & 1.55 \\
\hline
\end{tabular}

Table 10: Performance of the SMB factor

\begin{tabular}{|c|c|c|c|c|c|c|}
\hline Statistic & Period & Asia Pacific & Europe & Japan & North America & US \\
\hline \multirow{3}{*}{$\mu(x)$} & $\# 1$ & -2.0 & -4.2 & -8.8 & -4.3 & -2.9 \\
\hline & $\# 2$ & -6.2 & 0.8 & 2.3 & 2.6 & 3.7 \\
\hline & $\# 3$ & 1.0 & 1.9 & 2.0 & 4.1 & 4.6 \\
\hline & $\overline{\#} 1$ & $\overline{1} \overline{2} . \overline{5}$ & $\overline{9.6}-$ & $\overline{14.5}$ & $\overline{1} \overline{6} . \overline{3}$ & $\overline{1} \overline{6} . \overline{8}$ \\
\hline \multirow{2}{*}{$\sigma(x)$} & \#2 & 10.3 & 7.9 & 9.9 & 9.7 & 10.9 \\
\hline & $\# 3$ & 8.9 & 6.4 & 7.5 & 7.1 & 7.8 \\
\hline & $\# 1$ & $-\overline{0} . \overline{1} \overline{6}$ & $-\overline{0} . \overline{4} \overline{4}^{-}$ & $-\overline{0} . \overline{6} 0^{-}$ & $-\overline{0} . \overline{2} \overline{6}$ & $-\overline{0.1 \overline{7}}$ \\
\hline \multirow{2}{*}{$\operatorname{SR}(x \mid r)$} & $\# 2$ & -0.60 & 0.11 & 0.23 & 0.27 & 0.34 \\
\hline & $\# 3$ & 0.11 & 0.31 & 0.26 & 0.58 & 0.60 \\
\hline
\end{tabular}


Facts and Fantasies About Factor Investing

Table 11: Performance of the HML factor

\begin{tabular}{|c|c|c|c|c|c|c|}
\hline Statistic & Period & Asia Pacific & Europe & Japan & North America & US \\
\hline \multirow{3}{*}{$\mu(x)$} & $\# 1$ & 5.2 & -4.3 & -7.9 & -6.6 & -6.7 \\
\hline & \#2 & 9.9 & 14.5 & 15.8 & 9.2 & 8.0 \\
\hline & \#3 & 4.0 & -0.6 & 0.1 & 2.3 & 2.3 \\
\hline & $\overline{\#} 1-$ & 15.7 & 8.4 & 11.3 & $\overline{1} \overline{1} . \overline{8}$ & $1 \overline{2} . \overline{2}$ \\
\hline \multirow[t]{3}{*}{$\sigma(x)$} & \#2 & 10.5 & 8.2 & 10.1 & 14.0 & 12.6 \\
\hline & \#3 & 7.1 & 9.9 & 7.8 & 6.7 & 7.8 \\
\hline & $\overline{\#} 1-$ & $0 . \overline{33}$ & $-\overline{0} . \overline{5} 1^{-}$ & ${ }^{-} \overline{0} . \overline{7} 0$ & $-\overline{0} . \overline{5} \overline{6}$ & $-0.5 \overline{5}$ \\
\hline \multirow[t]{2}{*}{$\operatorname{SR}(x \mid r)$} & \#2 & 0.93 & 1.75 & 1.57 & 0.66 & 0.64 \\
\hline & \#3 & 0.55 & -0.06 & 0.02 & 0.35 & 0.30 \\
\hline
\end{tabular}

One of the issues with the risk factors computed by Fama and French is the value premium. In their 2012 article, they recognized that the value premium is larger for small stocks, except in the case of Japan. Some authors go further and consider that a value premium exists only for small stocks and not for large stocks. By studying the performance evaluation, Cremers et al. (2012) found a "disproportional weight that the Fama-French factors place on small value stocks". Similarly, Lambert and Hübner (2014) showed that the original Fama-French sorting procedure "creates a theoretical bias in the premium definition that underestimates the size effect while overestimating the value-growth one". They also proposed building the factors in a more robust way and concluded that there is a strong size effect, but a small value effect.

To understand the issue, we can rewrite the HML factor as the sum of two components:

$$
\begin{aligned}
\mathrm{HML}_{t} & =\frac{1}{2}\left(R_{t}(\mathrm{SV})+R_{t}(\mathrm{BV})\right)-\frac{1}{2}\left(R_{t}(\mathrm{SG})+R_{t}(\mathrm{BG})\right) \\
& =\frac{1}{2}\left(R_{t}(\mathrm{SV})-R_{t}(\mathrm{SG})\right)+\frac{1}{2}\left(R_{t}(\mathrm{BV})-R_{t}(\mathrm{BG})\right) \\
& =\frac{1}{2} \mathrm{SHML}_{t}+\frac{1}{2} \mathrm{BHML}_{t}
\end{aligned}
$$

The first component SHML is the HML factor for small stocks, whereas the second component BHML is the HML factor for big stocks. In this case, the HML factor may be biased toward a size factor because of two effects:

- the SHML factor contributes more than the BHML factor;

- the BHML factor is itself biased by a size effect.

In Figure 7, we report the performance of the SHML and BHML factors. It is obvious that the SHML factor produces a better performance than the BHML factor. In the case of the US market, the performance of the BHML factor is negative (see Table 12). The only exception is the Japanese market, where the contribution of the factors is almost the same. In Asia Pacific and Europe, the BHML factor explains less than 25\% of the performance of the HML factor. We also notice that the volatility of the HML factor is not higher for small stocks than for big stocks. If we consider the yearly return given in Tables 42 and 43 on Page 93, we observe that the BHML factor is significantly impacted between 2007 and 2011, especially in Europe and the United States. This is not the case for the SHML factor, except in Europe. 
Figure 7: Fama-French SHML, BHML and HML factors (1995 - 2013)
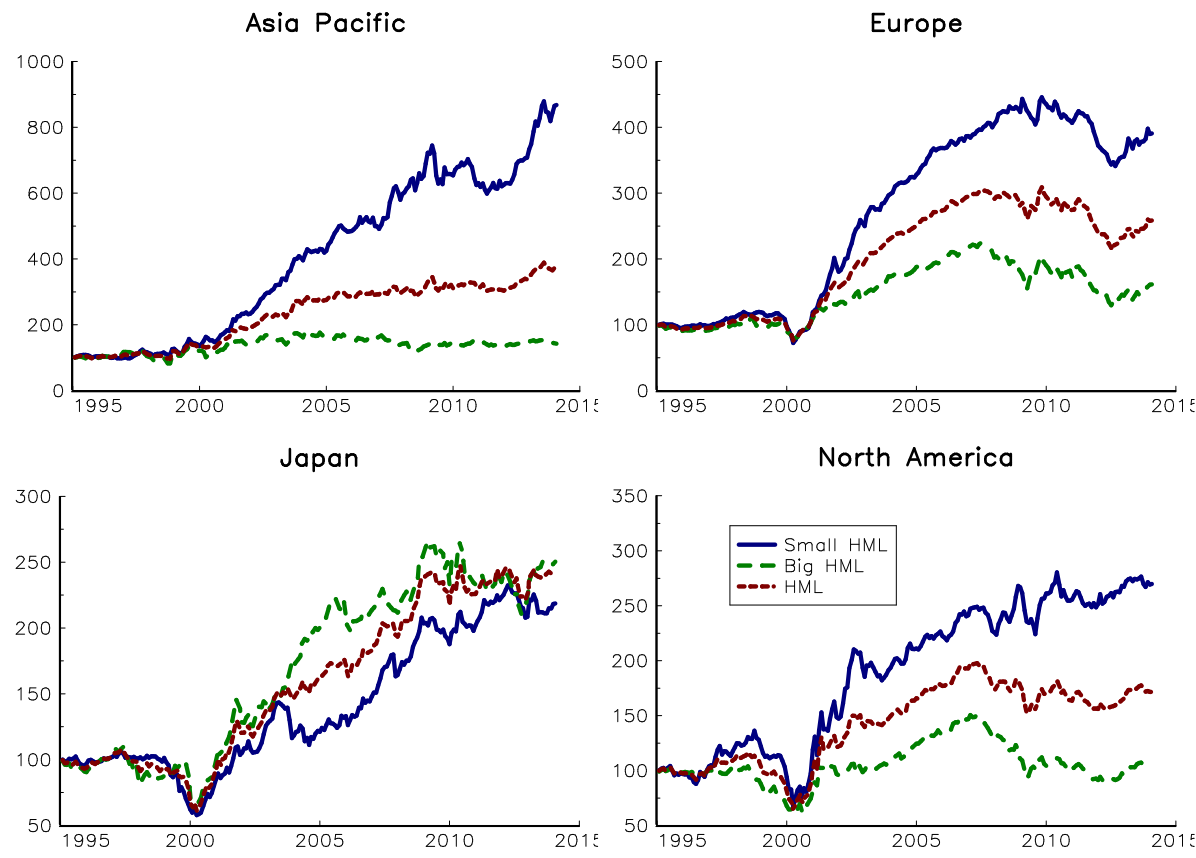

Table 12: Performance of the SHML, BHML and HML factors (1995 - 2013)

\begin{tabular}{|c|c|c|c|c|c|c|}
\hline Statistic & Factor & Asia Pacific & Europe & Japan & North America & US \\
\hline \multirow{3}{*}{$\mu(x)$} & SHML & 12.0 & 7.4 & 4.2 & 5.4 & 5.1 \\
\hline & BHML & 1.8 & 2.6 & 5.0 & 0.2 & -0.6 \\
\hline & HML & 7.1 & 5.2 & 4.8 & 2.9 & 2.4 \\
\hline & $\overline{\mathrm{SH}} \overline{\mathrm{M}} \mathrm{L}^{-}$ & $\overline{1} \overline{1} . \overline{7}$ & $\overline{10} . \overline{0}$ & $\overline{11} \overline{0}$ & $\overline{15.2}$ & $\overline{1} \overline{3} . \overline{4}$ \\
\hline \multirow[t]{3}{*}{$\sigma(x)$} & BHML & 15.2 & 11.0 & 13.3 & 11.2 & 11.9 \\
\hline & HML & 11.5 & 9.0 & 10.3 & 12.1 & 11.5 \\
\hline & $\overline{\mathrm{SHM}} \overline{\mathrm{M}} \mathrm{L}^{-}$ & $\overline{1} . \overline{0} 3$ & $-\overline{0} . \overline{4}$ & $0 . \overline{38}$ & $\overline{0.35}$ & $\overline{0 . \overline{3}} \overline{8}$ \\
\hline \multirow[t]{2}{*}{$\operatorname{SR}(x \mid r)$} & BHML & 0.12 & 0.24 & 0.38 & 0.02 & -0.05 \\
\hline & HML & 0.61 & 0.57 & 0.47 & 0.24 & 0.20 \\
\hline
\end{tabular}


Let us now investigate the second point related to the BHML factor. Note that this factor is the difference between the return of the big value and the big growth portfolios. Let $\overline{\mathrm{ME}}_{t}(\mathrm{BV})$ and $\overline{\mathrm{ME}}_{t}(\mathrm{BG})$ be the average market value of the stocks in these two portfolios. We then define the size ratio between the big value and the big growth portfolios as follows:

$$
\begin{aligned}
\mathcal{R}_{t}(\mathrm{BV} / \mathrm{BG})= & \mathbf{1}\left\{\overline{\mathrm{ME}}_{t}(\mathrm{BG}) \geq \overline{\mathrm{ME}}_{t}(\mathrm{BV})\right\} \cdot\left(\frac{\overline{\mathrm{ME}}_{t}(\mathrm{BV})}{\overline{\mathrm{ME}}_{t}(\mathrm{BG})}-1\right)- \\
& \mathbf{1}\left\{\overline{\mathrm{ME}}_{t}(\mathrm{BG})<\overline{\mathrm{ME}}_{t}(\mathrm{BV})\right\} \cdot\left(\frac{\overline{\mathrm{ME}}_{t}(\mathrm{BG})}{\overline{\mathrm{ME}}_{t}(\mathrm{BV})}-1\right)
\end{aligned}
$$

If the two portfolios present the same pattern of stock size, $\mathcal{R}_{t}(\mathrm{BV} / \mathrm{BG})$ is close to zero. If the BHML factor is tilted toward a small size factor, $\mathcal{R}_{t}(\mathrm{BV} / \mathrm{BG})$ is negative. This means that the value stocks of the big portfolio are smaller than the growth stocks of the big portfolio. We report this ratio in Figure 8. We notice that it is highly negative except in Europe during the period July 2006 - October 2008. In the case of the Japanese or US markets, this ratio may even reach $-80 \%$ in some periods, implying that value stocks are five times smaller than growth stocks. We can therefore conclude that the BHML factor is explained by a size factor and is not a pure value factor.

Figure 8: The size bias of the BHML factor
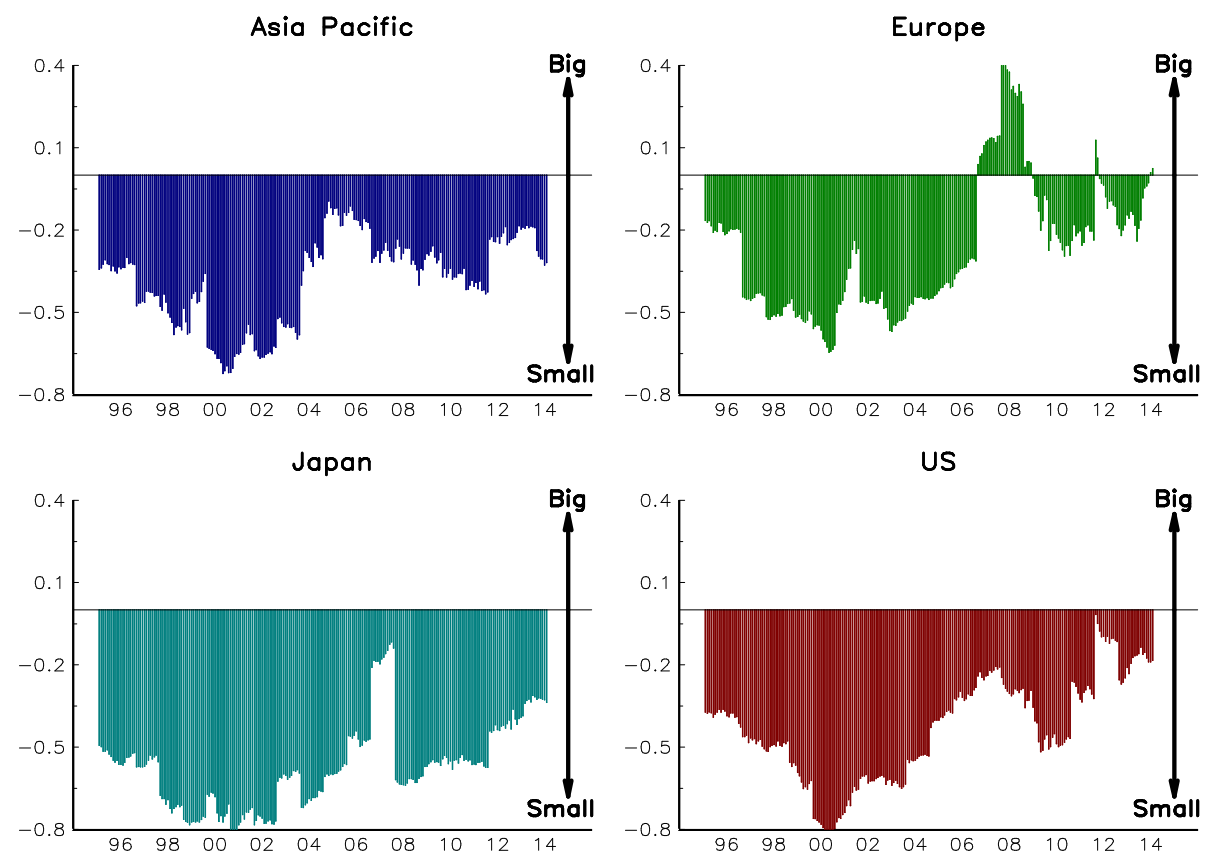

\subsubsection{Stock-based or fund-based risk factors}

Huij and Verbeek (2009) argue that factor proxies based on mutual fund returns rather than stock returns are more reliable, because academic factors "are based on hypothetical stock portfolios and do not incorporate transaction costs, trade impact, and trading restrictions". This implies that the factor premia may be different. 
Facts and Fantasies About Factor Investing

In what follows, we build SMB and HML factors for the period 2000-2014 from the Morningstar database. We retrieve monthly returns and assets under management for mutual funds invested in the US, Europe and Japan. For each universe, we differentiate the style of the different funds in order to obtain the traditional categories: small value (SV), small blend (SB), small growth (SG), large value (LV), large blend (LB) and large growth (LG). Consequently, we obtain six portfolios of mutual funds equivalent to the six portfolios of stocks defined by Fama and French (1993). Using the assets under management, we compute the return of the value-weighted portfolios, which are rebalanced on a monthly basis ${ }^{20}$. Finally, we obtain the same SMB and HML risk factors with mutual funds as those based on stocks ${ }^{21}$ :

$$
\mathrm{SMB}_{t}^{(\mathrm{MF})}=\frac{1}{3}\left(R_{t}(\mathrm{SV})+R_{t}(\mathrm{SB})+R_{t}(\mathrm{SG})\right)-\frac{1}{3}\left(R_{t}(\mathrm{LV})+R_{t}(\mathrm{LB})+R_{t}(\mathrm{LG})\right)
$$

and:

$$
\mathrm{HML}_{t}^{(\mathrm{MF})}=\frac{1}{2}\left(R_{t}(\mathrm{SV})+R_{t}(\mathrm{LV})\right)-\frac{1}{2}\left(R_{t}(\mathrm{SG})+R_{t}(\mathrm{LG})\right)
$$

In Figures 9 and 10, we report on Fama-French (FF) and mutual fund (MF) US risk factors. Where we observe a high coherency for the SMB risk factor, there are significant differences in the case of the HML risk factor. Indeed, the magnitude of the MF HML risk premium is much smaller than for the FF HML risk premium, even if the correlation between FF and MF HML risk factors is equal to $84.8 \%$ (see Table 13). In the case of Europe and $\mathrm{Japan}^{22}$, we find that the MF SMB risk premium is higher than the FF SMB risk premium. For the HML risk premium, results are reversed.

Table 13: Correlation between FF and MF risk factors (1999 - 2013)

\begin{tabular}{|c|ccc|}
\hline Factor & Europe & Japan & US \\
\hline SMB & 79.8 & 86.0 & 93.9 \\
HML & 55.5 & 54.3 & 84.8 \\
\hline
\end{tabular}

Remark 4 We can show that risk factors based on mutual funds are more pertinent to style analysis and performance measurement than the Fama-French risk factors (Huij and Verbeek, 2009; Cazalet and Roncalli, 2014).

\subsection{The momentum factor}

At the end of the eighties, several studies showed that stock returns are predictable based on past returns. For instance, De Bondt and Thaler (1985) found that long-horizon ${ }^{23}$ past loser stocks outperform long-horizon past winner stocks. Jegadeesh (1990) and Lehman (1990) report other evidence of return reversals, but with a short-term horizon. Stocks that

\footnotetext{
${ }^{20}$ This frequency differs from the traditional Fama-French methodology, which considers an annual rebalancing. The objective is to obtain portfolios which try to be as accurate as possible to represent style strategies.

${ }^{21}$ Contrary to the initial Fama-French factors, the European and Japanese risk factors are expressed in EUR and JPY respectively. The last step consists in hedging these factors to compare them to the FamaFrench risk factors expressed in USD.

${ }^{22}$ See Figures $41-44$ on Page 105.

${ }^{23}$ The term long-horizon is used here to designate time periods from three to five years.
} 
Figure 9: Comparison between FF and MF SMB risk factors (US, 1999-2014))

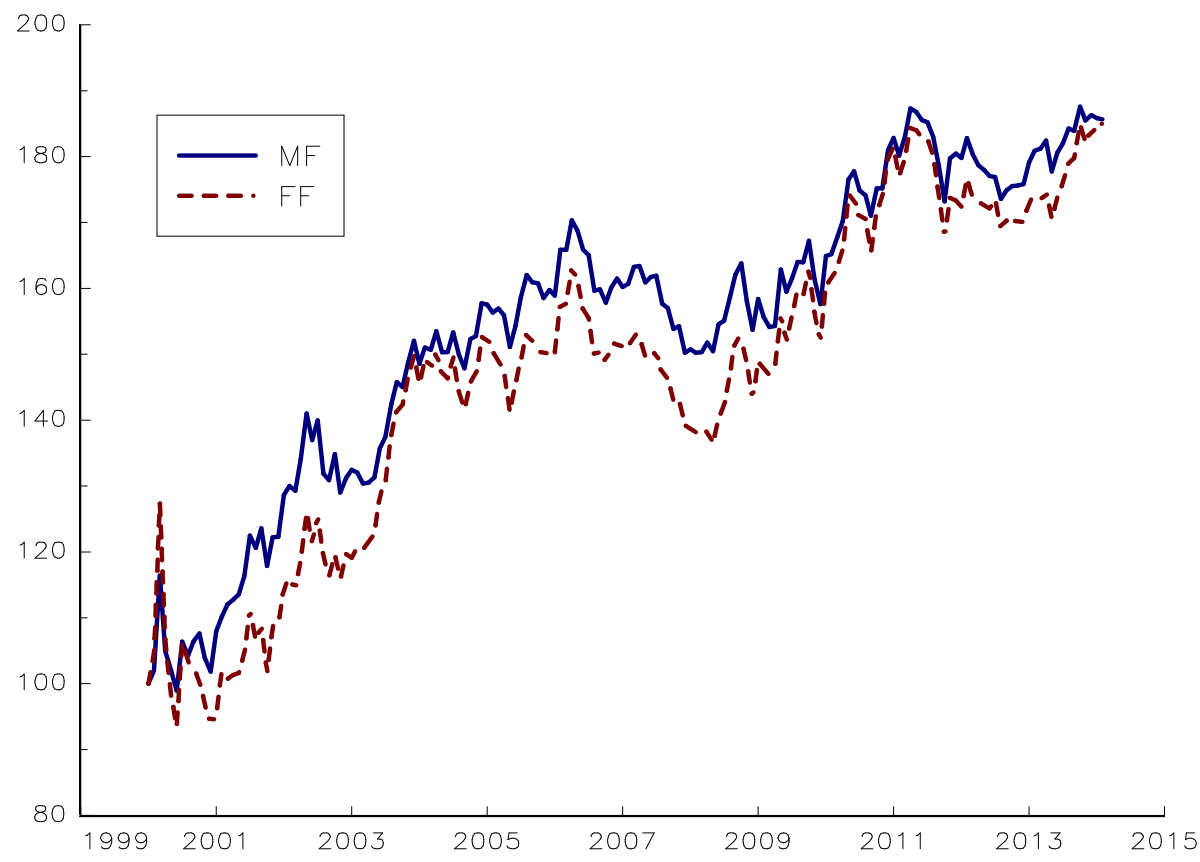

Figure 10: Comparison between FF and MF HML risk factors (US, 1999-2014))

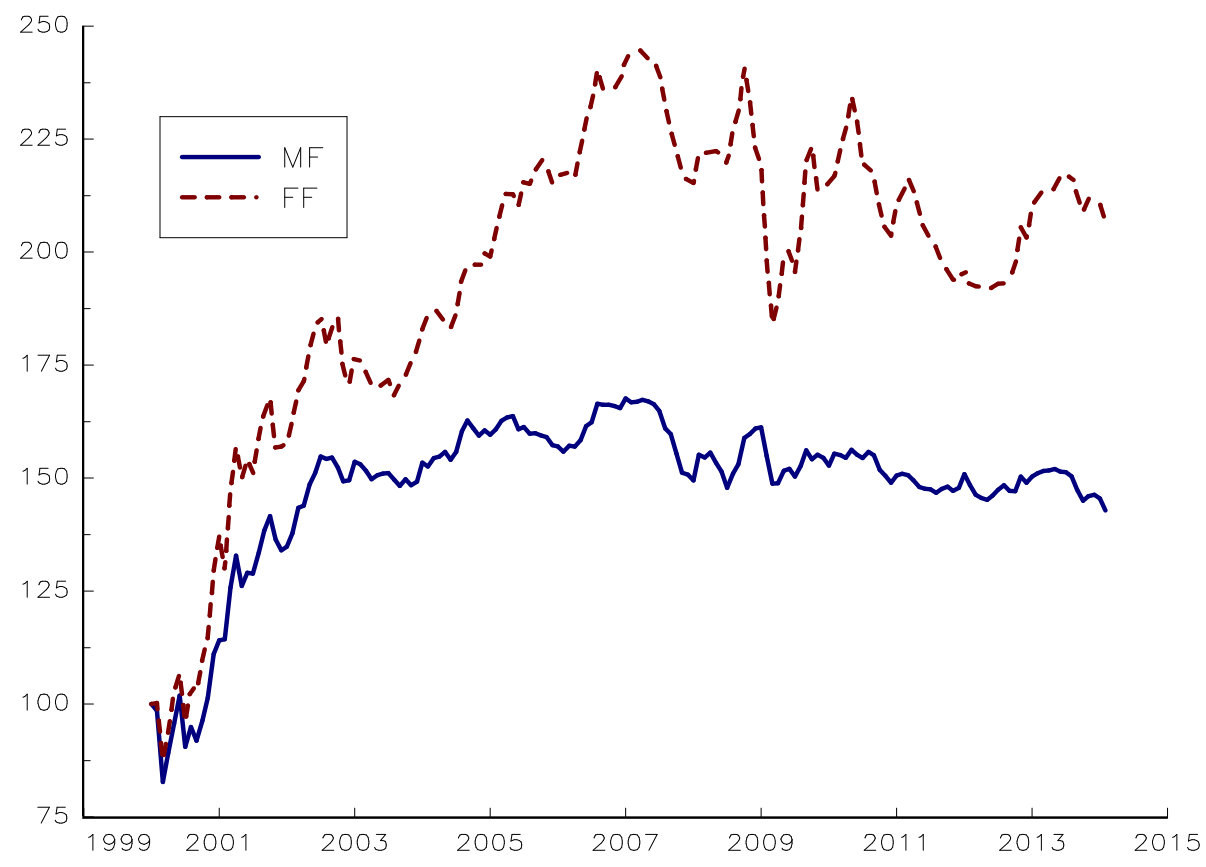


Facts and Fantasies About Factor Investing

have poorly performed in the previous week or month perform better in the next month. These two contrarian strategies have generated extensive literature to explain these reversal anomalies ${ }^{24}$. Although the contrarian investment style is very popular among mutual fund and hedge fund managers, it is difficult to implement, for two reasons:

- Short-run reversal strategies can be tricky to manage in a systematic way and imply a high turnover and significant transaction costs (Lesmond et al., 2004);

- It may be difficult to reconcile the holding period of a long-run reversal strategy (typically between three to five years) and the evaluation horizon of investors, who measure the performance of their portfolios over a shorter run (Benartzi and Thaler, 1995);

Another evidence of return predictability based on past returns is the momentum strategy of Jegadeesh and Titman (1993). They found that buying stocks that have performed well over the past three to twelve months and selling stocks that have performed poorly produces abnormal positive returns. This anomaly has been confirmed by a number of papers ${ }^{25}$. In a key paper, Carhart (1997) uses a four-factor model to evaluate the performance of equity mutual funds, adding the one-year momentum factor to the Fama-French three factor model. Thus, the model (4) becomes:

$$
\mathbb{E}\left[R_{i}\right]-R_{f}=\beta_{i}^{m}\left(\mathbb{E}\left[R_{m}\right]-R_{f}\right)+\beta_{i}^{s m b} \mathbb{E}\left[R_{s m b}\right]+\beta_{i}^{h m l} \mathbb{E}\left[R_{h m l}\right]+\beta_{i}^{w m l} \mathbb{E}\left[R_{w m l}\right]
$$

where $R_{w m l}$ is the return difference of winner and loser stocks of the past twelve months. Over the years, this has become a standard model in most studies on equity funds and is known as the Fama-French-Carhart risk factor model. In his paper, Carhart shows that these four common factors almost entirely explain persistence in the performance of equity mutual funds found by Hendricks et al. (1993).

In Table 14, we report some statistics for the WML factor computed by Fama and French (2012), which are also available on the website of Kenneth French ${ }^{26}$. As with the SMB and HML factors, we consider three periods: \#1 (January 1995 - March 2000), \#2 (April 2000 - March 2009) and \#3 (April 2009 - December 2013). We notice that the WML factor produces strong positive returns in Asia Pacific and Europe for all three periods. In the case of Japan and the United States, the WML portfolio performed well during the dot-com bubble, but has posted negative returns since 2009. We also notice that the WML factor has a higher volatility than the SMB or HML factors. This figure is confirmed by the yearly returns reported in Table 44 on Page 94. In fact, momentum strategies exhibit high negative skewness (Daniel et al., 2012). This can be illustrated by computing a histogram of monthly

\footnotetext{
${ }^{24}$ See for example Lo and MacKinlay (1990), Chopra et al. (1992), Jegadeesh and Titman (1995), Balvers and $\mathrm{Wu}$ (2006), Khandani and Lo (2011).

${ }^{25}$ See for example Chan et al. (1996), Haugen and Baker (1996), Rouwenhorst (1998), Lewellen (2002), Griffin et al. (2003), Chui et al. (2010), Asness et al. (2013).

${ }^{26}$ The construction of the WML factor follows the methodology used to define the HML factor. Using the same sorting approach, Fama and French (2012) considered six portfolios:

\begin{tabular}{l|ccc} 
& Loser & Average & Winner \\
\hline Small & SL & SA & SW \\
Big & BL & BA & BW
\end{tabular}
}

They then defined the WML factor as follows:

$$
\mathrm{WML}_{t}=\frac{1}{2}\left(R_{t}(\mathrm{SW})+R_{t}(\mathrm{BW})\right)-\frac{1}{2}\left(R_{t}(\mathrm{SL})+R_{t}(\mathrm{BL})\right)
$$


Facts and Fantasies About Factor Investing

Table 14: Performance of the WML factor

\begin{tabular}{|c|c|c|c|c|c|c|}
\hline Statistic & Period & Asia Pacific & Europe & Japan & North America & US \\
\hline \multirow[b]{2}{*}{$\mu(x)$} & $\# 1$ & 3.8 & 19.9 & 8.7 & 22.6 & 17.6 \\
\hline & $\# 2$ & 11.9 & 11.5 & -0.3 & 1.4 & 3.7 \\
\hline & $\# 3$ & 5.6 & 2.9 & -2.0 & -4.5 & -9.3 \\
\hline & $\# 1$ & 24.7 & $1 \overline{2} . \overline{8}$ & $\overline{2} 2.1^{-}$ & $\overline{1} \overline{8 . \overline{7}}$ & $\overline{1} \overline{4} . \overline{5}$ \\
\hline \multirow[t]{2}{*}{$\sigma(x)$} & $\# 2$ & 12.7 & 15.9 & 14.1 & 20.0 & 20.1 \\
\hline & $\# 3$ & 15.2 & 17.3 & 14.0 & 15.3 & 19.9 \\
\hline & $\overline{\#} 1$ & $\overline{0.15}{ }^{-}$ & $1.5 \overline{6}$ & $\overline{0} . \overline{4} 0^{-}$ & $\overline{1} . \overline{2} \overline{1}$ & $\overline{1} . \overline{2} \overline{2}$ \\
\hline \multirow{2}{*}{$\operatorname{SR}(x \mid r)$} & $\# 2$ & 0.93 & 0.72 & -0.02 & 0.07 & 0.19 \\
\hline & $\# 3$ & 0.37 & 0.17 & -0.14 & -0.30 & -0.47 \\
\hline
\end{tabular}

returns. In Figure 11, we observe some significant monthly losses of more than $20 \%$. This tail risk has been called "momentum crashes" by Daniel and Moskowitz (2013), and occurs when a quick crash market is followed by a strong rebound ${ }^{27}$. Daniel and Moskowitz (2013) deduced that the momentum strategy presents a short option-like profile. This result seems to be contradictory to those obtained by Fung and Hsieh (2001), Potters and Bouchaud (2005) and Bruder and Gaussel (2011). These authors show that momentum strategies exhibit a straddle convex profile, because trend followers face frequent small losses and rare large gains. In fact, it appears that momentum strategies on individual stocks are different from momentum strategies on asset classes. In particular, Daniel and Moskowitz (2013) found that the option profile of loser stocks is more important than the option profile of winner stocks ${ }^{28}$.

Contrary to the HML factor, there is less academic debate on the WML factor, certainly because Jegadeesh and Titman (1993) do not consider the WML factor as a risk premium, i.e. a compensation for risk ${ }^{29}$. Generally, momentum returns are explained by the theory of behavioral finance (Hirshleifer, 2001; Barberis and Thaler, 2003). In this case, this anomaly may be explained by either an under reaction to earnings announcements and news or a delayed reaction ${ }^{30}$.

As with the value premium, it is possible to investigate the link between the momentum premium and the size effect. In Table 15, we report the statistics of the WML factor for small and big stocks, which are built as follows:

$$
\begin{aligned}
\mathrm{SWML}_{t} & =R_{t}(\mathrm{SW})-R_{t}(\mathrm{SL}) \\
\mathrm{BWML}_{t} & =R_{t}(\mathrm{BW})-R_{t}(\mathrm{BL})
\end{aligned}
$$

We observe that the WML factor is stronger for small stocks than for big stocks. But, contrary to the BHML factor, the BWML factor posts a positive performance for all regions. Moreover, the momentum factor does not seem to present a size bias in the same way as the value factor. For instance, we have computed the size ratio between the big winners and the

\footnotetext{
${ }^{27}$ Using a longer period, Daniel and Moskowitz (2013) reported nine monthly losses larger than $30 \%$. The maximum was reached in August 1932 with a performance of $-79 \%$.

${ }^{28}$ See Appendix A.2 for more details.

${ }^{29}$ There are a few articles that support this assumption (Johnson, 2002; Sagi and Seasholes, 2007).

${ }^{30}$ See, for instance, Bernard and Thomas (1989), De Long et al. (1990), Barberis et al. (1998), Hong and Stein (1999), Hong et al. (2000), Jegadeesh and Titman (2001), Frazzini (2006), Chui et al. (2010).
} 
Figure 11: Distribution of WML monthly returns
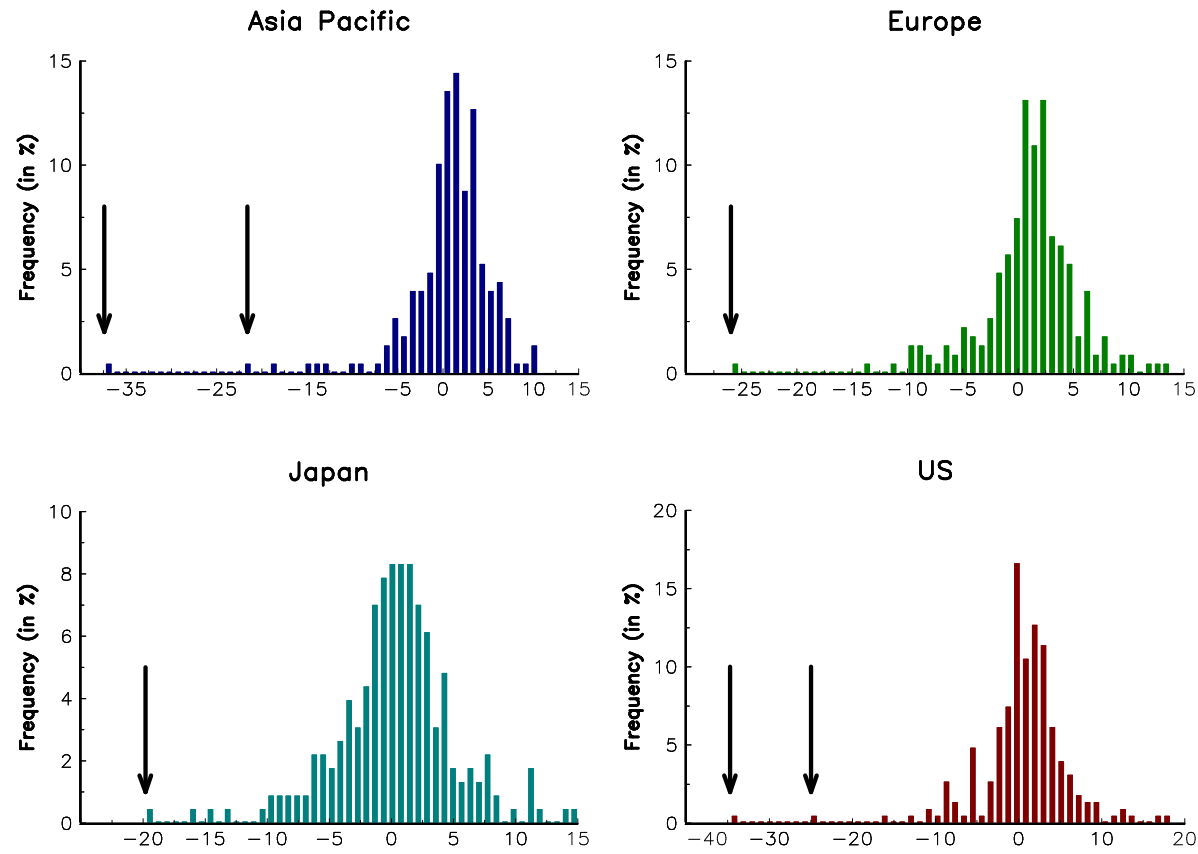

big losers as follows:

$$
\begin{aligned}
\mathcal{R}_{t}(\mathrm{BW} / \mathrm{BL})= & \mathbf{1}\left\{\overline{\mathrm{ME}}_{t}(\mathrm{BL}) \geq \overline{\mathrm{ME}}_{t}(\mathrm{BW})\right\} \cdot\left(\frac{\overline{\mathrm{ME}}_{t}(\mathrm{BW})}{\overline{\mathrm{ME}}_{t}(\mathrm{BL})}-1\right)- \\
& \mathbf{1}\left\{\overline{\mathrm{ME}}_{t}(\mathrm{BL})<\overline{\mathrm{ME}}_{t}(\mathrm{BW})\right\} \cdot\left(\frac{\overline{\mathrm{ME}}_{t}(\mathrm{BL})}{\overline{\mathrm{ME}}_{t}(\mathrm{BW})}-1\right)
\end{aligned}
$$

This ratio is close to zero on average (see Figure 13), implying that the BWML is not biased by a size effect.

\begin{tabular}{|c|c|c|c|c|c|c|}
\hline Statistic & Factor & Asia Pacific & Europe & Japan & North America & US \\
\hline \multirow[b]{2}{*}{$\mu(x)$} & SWML & 12.7 & 17.7 & 0.4 & 7.4 & 4.9 \\
\hline & BWML & 2.9 & 5.3 & 2.4 & 3.0 & 2.5 \\
\hline & WML & 8.0 & 11.5 & 1.7 & 5.3 & 3.8 \\
\hline & $-\overline{\mathrm{SW}} \overline{\mathrm{W}} \overline{\mathrm{M}} \overline{\mathrm{L}}$ & $\overline{1} \overline{6} . \overline{2}$ & $\overline{14} . \overline{1}$ & $\overline{15.3}$ & 19.0 & $\overline{1} \overline{9} . \overline{4}$ \\
\hline \multirow[t]{3}{*}{$\sigma(x)$} & BWML & 20.9 & 18.3 & 20.4 & 19.8 & 19.7 \\
\hline & WML & 17.3 & 15.5 & 16.6 & 18.7 & 18.8 \\
\hline & $-\overline{\mathrm{SW}} \overline{\mathrm{W}} \overline{\mathrm{M}} \overline{\mathrm{L}}$ & $\overline{0} \overline{\overline{7}} \overline{8}$ & 1.25 & $0 . \overline{03}$ & $0 . \overline{39}$ & $\overline{0.2 \overline{5}}$ \\
\hline \multirow[t]{2}{*}{$\operatorname{SR}(x \mid r)$} & BWML & 0.14 & 0.29 & 0.12 & 0.15 & 0.13 \\
\hline & WML & 0.46 & 0.74 & 0.10 & 0.28 & 0.20 \\
\hline
\end{tabular}

Table 15: Performance of the SWML, BWML and WML factors (1995 - 2013)

Remark 5 Value and momentum are two investment styles (Barberis and Schleifer, 2003), that are very popular among asset managers. However, it is difficult to find momentum 
Figure 12: The SWML, BWML and WML factors (1995 - 2013)
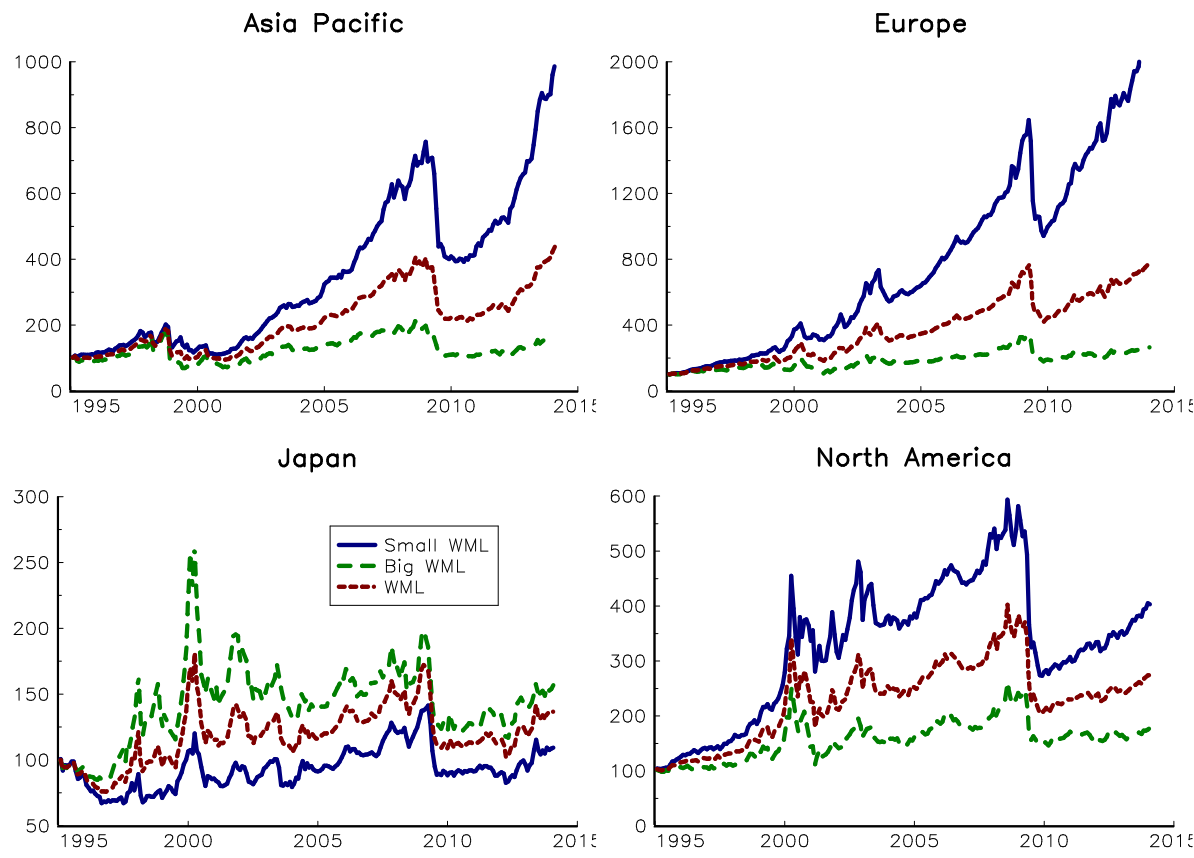

Figure 13: The size neutrality of the BWML factor

Asia Pacific
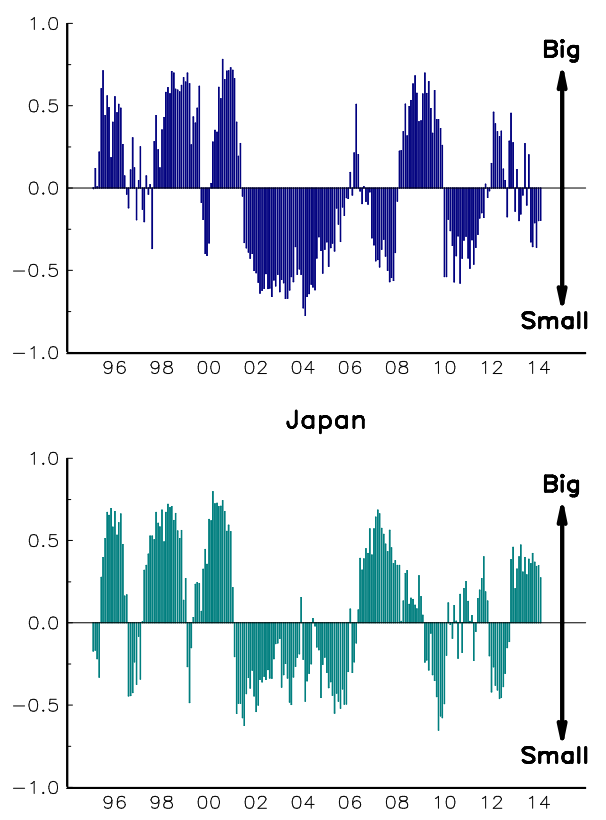

Europe
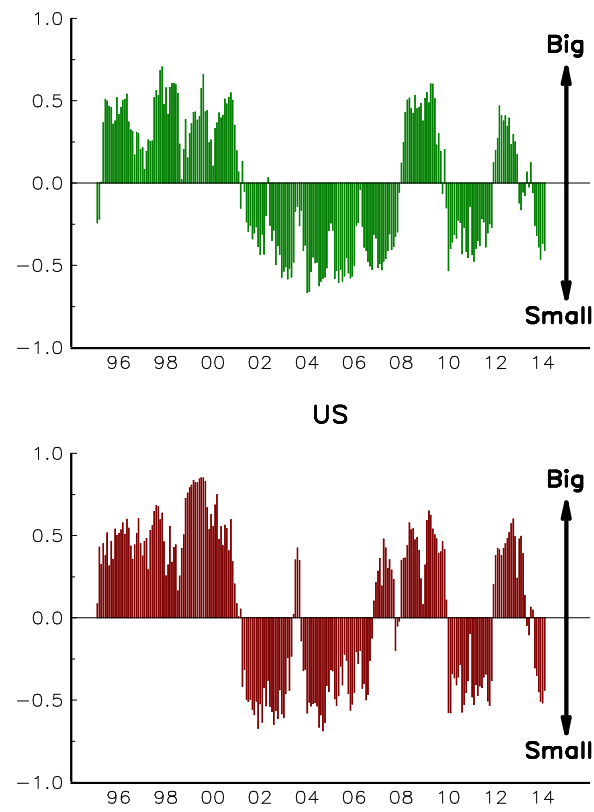
Facts and Fantasies About Factor Investing

investors, whereas it is easy to find many value investors in the mutual funds industry ${ }^{31}$. In the minds of asset managers, value investing is considered worthy because it is a hard task to find the fundamental value of stocks, whereas momentum investing is thought to be lazy. In fact, the reality of asset management is more complex. Many asset managers are trend followers without even recognizing it (Grinblatt and Titman, 1989). For instance, Grinblatt et al. (1995) found that $77 \%$ of mutual funds were momentum investors. This explains that the four-factor model of Carhart (1997) has replaced the three-factor version of Fama and French (1993) to evaluate the performance of mutual funds from an academic point of view $^{32}$. But despite all this evidence ${ }^{33}$, some professionals continue to be sceptical about momentum investing (Asness et al., 2014).

Figure 14: Comparison between the BWML and BHML factors

Asia Pacific
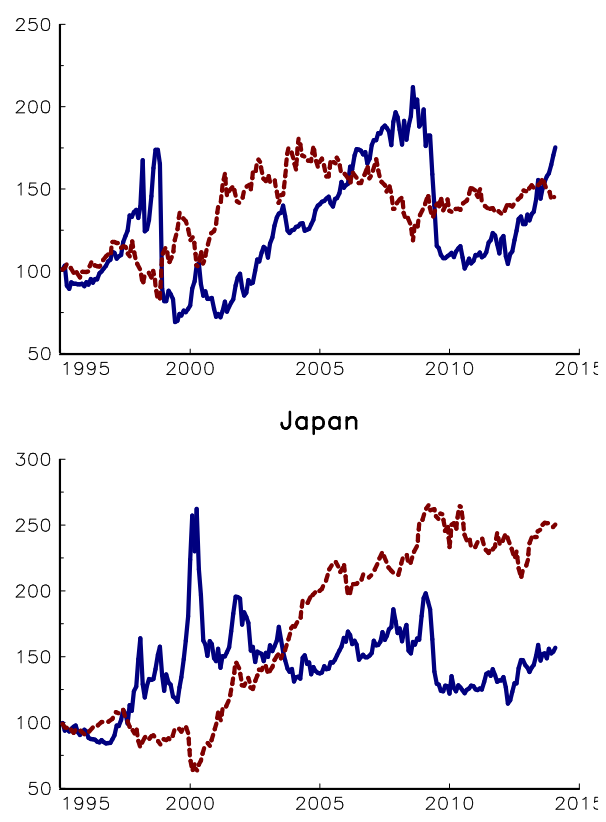

Europe
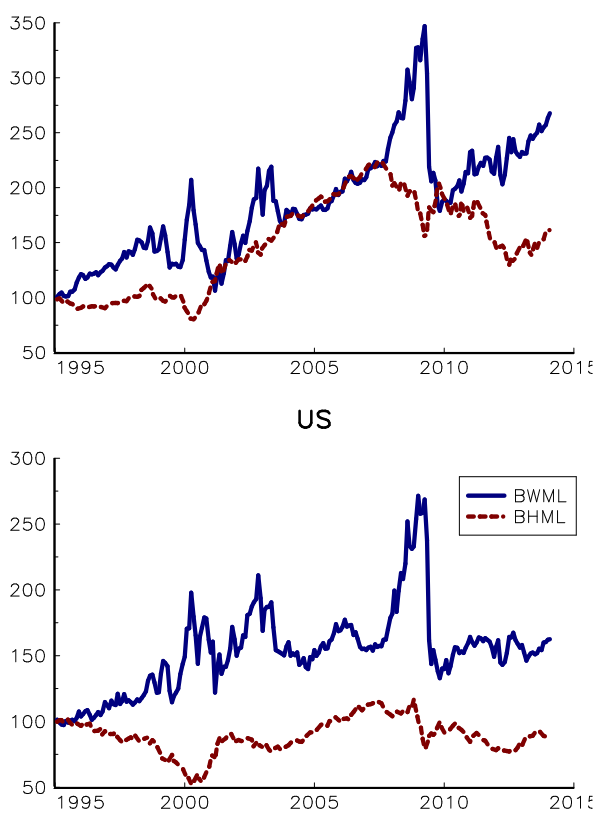

\subsection{Other risk factors}

The previous factors have been extensively documented in the equity market, but they may also be present in other asset classes. For instance, momentum investing is frequent in currencies (Okunev and White, 2003; Menkhoff et al., 2012) and commodities (Erb and Harvey, 2005; Gorton et al., 2013). Asness et al. (2013) define value strategies for currencies and bonds. Lin et al. (2011) and De Jong and Driessen (2012) estimate that a significant portion of corporate bond returns can be attributed to liquidity risk (Pastor and Stambaugh, 2003), which explains the size effect in equities.

\footnotetext{
${ }^{31}$ This is not the case in the hedge funds industry, where the trend following strategy is one of the main pillars of CTA funds.

${ }^{32}$ See, for instance, Cuthbertson et al. (2008), Bebchuk et al. (2009), Barras et al. (2010) and Fama and French (2010).

${ }^{33}$ In particular, the previous results show that momentum is more robust than value for large stocks, except in relation to Japan (see also Figure 14).
} 
Facts and Fantasies About Factor Investing

These factors can be supplemented by others (Ilmanen, 2011). We document some of them below. However, we have to be careful. In general, these factors have been recently discovered and/or have not been extensively studied. Therefore, they may be true risk premia, anomalies or stylized facts. For instance, Rozeff and Kinney (1976) described some seasonal effects, and in particular the January effect. They showed that stock returns for this month are higher than for other months. Other studies have confirmed the January effect. Nevertheless, Zhang and Jacobsen (2012) found that well-known monthly effects are in fact sample specific. This example is of particular interest because it illustrates a stylized fact, and can be an investment strategy (or an anomaly). But it is not a risk factor, which may explain the cross-section of asset returns and is a compensation for taking an economic risk.

More generally, it is a hard task to distinguish what is a stylized fact and what is a factor. Therefore, Harvey et al. (2014) show that statistical tests are insufficiently robust to distinguish between them:

"Hundreds of papers and hundreds of factors attempt to explain the cross-section of expected returns. Given this extensive data mining, it does not make any economic or statistical sense to use the usual significance criteria for a newly discovered factor, e.g., a $t$-ratio greater than 2. [...] Echoing a recent disturbing conclusion in the medical literature, we argue that most claimed research findings in financial economics are likely false."

In addition to this in-sample statistical bias, McLean and Pontiff (2014) also observe that stock return predictability declines considerably after the publication of the research, which can be attributed to both statistical bias and informed trading.

\subsubsection{Volatility}

There are different ways to look at volatility as a risk factor. The first approach is to consider that low volatility stocks outperform high volatility stocks. This low volatility anomaly has been intensively documented over a long period, even before the phenomenal success of minimum variance portfolios (Haugen and Baker, 1991). Ang et al. (2006) found more recently that the cross-section of stock returns can be explained by volatility. More precisely, they show that stocks with a high sensitivity to innovation in aggregate volatility and with high idiosyncratic volatility have low average returns. Finally, Frazzini and Pedersen (2014) extend the CAPM model by introducing leverage and margin constraints. In this framework, high beta assets have negative alpha, whereas low beta assets are associated with positive alpha. This finding led them to build a betting-against-beta risk factor. Even these three approaches to define a volatility risk factor are connected; they present some significant differences in terms of theoretical arguments and implementation.

Low volatility anomaly The roots of the low risk anomaly are well established. In the CAPM, there is a linear relationship between the expected return of asset $i$ and the expected return of the market portfolio ${ }^{34}$ :

$$
\mathbb{E}\left[R_{i}\right]=R_{f}+\beta_{i}^{m}\left(\mathbb{E}\left[R_{m}\right]-R_{f}\right)
$$

The return of asset $i$ can then be written as follows:

$$
R_{i}=R_{f}+\beta_{i}^{m}\left(R_{m}-R_{f}\right)+\varepsilon_{i}
$$

\footnotetext{
${ }^{34}$ Note that $R_{i}$ and $R_{m}$ are the asset and market returns, $R_{f}$ is the risk-free rate and the coefficient $\beta_{i}^{m}$ is the beta of asset $i$ with respect to the market portfolio.
} 
where $\varepsilon_{i}$ is the idiosyncratic risk. If we now consider a portfolio $x=\left(x_{1}, \ldots, x_{n}\right)$, we have:

$$
\begin{aligned}
R(x) & =\sum_{i=1}^{n} x_{i} R_{i} \\
& =R_{f}+\beta\left(x \mid x_{m}\right)\left(R_{m}-R_{f}\right)+x^{\top} \varepsilon
\end{aligned}
$$

where the beta of the portfolio $x$ is the weighted sum of asset betas:

$$
\beta\left(x \mid x_{m}\right)=\frac{x^{\top} \Sigma x_{m}}{x_{m}^{\top} \Sigma x_{m}}=\sum_{i=1}^{n} x_{i} \beta_{i}^{m}
$$

Finally, we obtain:

$$
\mu(x)=R_{f}+\beta\left(x \mid x_{m}\right)\left(\mu\left(x_{m}\right)-R_{f}\right)
$$

and:

$$
\sigma^{2}(x)=\beta^{2}\left(x \mid x_{m}\right) \sigma^{2}\left(x_{m}\right)+x^{\top} D x
$$

where $D$ is the covariance matrix of idiosyncratic risks. If the portfolio is well-diversified, we have $x^{\top} D x \simeq 0$, meaning that ${ }^{35} \sigma(x)=\beta\left(x \mid x_{m}\right) \sigma\left(x_{m}\right)$. Let $x_{1}$ and $x_{2}$ be two diversified portfolios. It follows that:

$$
\sigma\left(x_{2}\right)>\sigma\left(x_{1}\right) \Rightarrow \mu\left(x_{2}\right)>\mu\left(x_{1}\right)
$$

This implies that the expected return is an increasing function of the volatility of the portfolio. However, using the Wilshire 5000 universe, Haugen and Baker (1991) build a minimum variance portfolio that performs better than the market-cap portfolio. This result is confirmed by Clarke et al. (2006), who use a more recent and longer period. Nevertheless, they also found that minimum variance portfolios have both a size and value bias, and the excess return is reduced by imposing factor neutrality. This result was not shared by Blitz and van Vliet (2007). They create decile portfolios by ranking stocks by three-year volatility. They observed that the excess return of these portfolios is a decreasing function of their portfolio, but they found that it cannot be explained by the Fama-French factors. Using European stocks, Demey et al. were unable to confirm the result of Haugen and Baker. The minimum variance portfolio has a lower performance than the market-cap portfolio. Nevertheless, it has the highest Sharpe ratio ${ }^{36}$. One of the difficulties with the low volatility anomaly is that there is no benchmark consensus to calibrate this factor. One of the main advantages of Fama-French factors is the existence of a standardized approach and the availability of the data. This is not the case with the low volatility factor, because the weighting scheme depends significantly on the design of the minimum variance portfolio ${ }^{37}$. For instance, we know that its composition greatly depends on the covariance matrix estimator, the weight constraints and the rebalancing frequency (Jagannathan and Ma, 2003).

Idiosyncratic volatility anomaly Ang et al. (2006) define two volatility factors AVOL and IVOL, which explain the cross-section of stock returns. The first corresponds to the variation in aggregate volatility:

$$
\mathrm{AVOL}_{t}=\Delta \mathrm{VIX}_{t}
$$

where VIX $_{t}$ is the value of the VIX index from the CBOE. They show that differences between portfolios sorted by exposure to AVOL are significant. In particular, the first quintile

\footnotetext{
${ }^{35}$ Without loss of generality, we assume that $\beta\left(x \mid x_{m}\right)>0$.

${ }^{36}$ See also Blitz and van Vliet (2011) and Carvalho et al. (2012)

${ }^{37} \mathrm{~A}$ ranking-based approach can be viewed as a minimum variance approach with diagonal covariance matrix and weight constraints.
} 
Facts and Fantasies About Factor Investing

portfolio outperforms the last quintile portfolio. However, the estimated risk premium of this factor is low at $-1 \%$ per year in the United States. Moreover, it is sensitive to the sample. The second factor, IVOL, is the volatility of the idiosyncratic risk $\epsilon_{i}(t)$ corresponding to the residual of the Fama-French regression ${ }^{38}$ :

$$
R_{i}(t)=\alpha_{i}+\beta_{i}^{m} R_{m}(t)+\beta_{i}^{s m b} R_{s m b}(t)+\beta_{i}^{h m l} R_{h m l}(t)+\epsilon_{i}(t)
$$

By sorting stocks by exposure to IVOL, Ang et al. (2006) observed that the return difference between the first quintile portfolio and the last quintile portfolio was $1.06 \%$ per month in the United States. Later, Ang et al. (2009) extended their study to the G7 countries and found similar results, which cannot be attributed to size, value, momentum or liquidity factors ${ }^{39}$. On the contrary, Bali and Cakini (2008) reported that these results are very sensitive to the measure of idiosyncratic volatility, the weighting scheme and the stock universe. They concluded that there is no robust significant relationship between idiosyncratic volatility and expected returns ${ }^{40}$.

Low beta anomaly The last version of the volatility premium is called the low beta anomaly, whereby low beta stocks outperform high beta stocks (Baker et al., 2014). This anomaly can be linked to the empirical evidence of Black et al. (1972), which found that the slope of the security market line is lower than the theoretical slope given by the CAPM. Black (1972) explains this puzzle by the borrowing constraints of many investors. If the investor cannot leverage and targets an expected return higher than the expected return of the tangency portfolio, he will prefer high beta assets. This preference for high risky assets implies a higher risk-adjusted return for low risky assets. Building on this assumption, Frazzini and Pedersen (2014) proposed an elegant framework for understanding the low beta anomaly.

These authors considered an equilibrium model with two periods, $n$ risky assets whose prices and dividends are denoted by $P_{i}$ and $D_{i}$, and $m$ investors, who have a given amount of wealth $W_{j}$. Let $x_{j}$ and $\phi_{j}$ be the portfolio and the risk aversion of the investor $j$. At time $t$, investors maximize their utility function:

$$
x_{j}^{\star}=\arg \max x_{j}^{\top} \mathbb{E}\left[\tilde{P}+\tilde{D}-\left(1+R_{f}\right) P\right]-\frac{\phi_{j}}{2} x_{j}^{\top} \Sigma x_{j}
$$

with $P$ the vector of actual prices, $\tilde{P}$ the vector of future prices, $\tilde{D}$ the vector of future dividends, $\Sigma$ the covariance matrix of $\tilde{P}+\tilde{D}$ and $R_{f}$ the risk-free rate. Frazzini and Pedersen (2014) assume that investors face some borrowing constraints:

$$
m_{j}\left(x_{j}^{\top} P\right) \leq W_{j}
$$

They consider three cases:

1. If $m_{j}<1$, the investor must hold some of his wealth in cash.

2. If $m_{j}=1$, the investor cannot use leverage because of regulatory constraints or borrowing capacity.

3. If $m_{j}>1$, the investor is able to leverage his exposure to risky assets.

\footnotetext{
${ }^{38}$ This factor was previously proposed by Merton (1987), who developed an extension of the CAPM where expected returns of assets are an increasing function of their beta risk, size and idiosyncratic risk.

${ }^{39}$ See also Jiang et al. (2009).

${ }^{40} \mathrm{Fu}(2009)$ also suggests that the findings of Ang et al. (2006) were due to the poor performance of some small stocks with high idiosyncratic volatility.
} 
The equilibrium between demand and supply implies that:

$$
\sum_{j=1}^{m} x_{j}=x_{m}
$$

where $x_{m, i}$ is the number of shares outstanding of asset $i$ and $x_{m}=\left(x_{m, 1}, \ldots, x_{m, n}\right)$. In other words, $x_{m}$ is also the market capitalization portfolio. The existence of investor constraints will modify the traditional relationship between the risk premium and the beta of asset $i$ :

$$
\mathbb{E}\left[R_{i}\right]-R_{f}=\beta_{i}^{m}\left(\mathbb{E}\left[R\left(x_{m}\right)\right]-R_{f}\right)
$$

where $R_{m}$ is the return $R\left(x_{m}\right)$ of the market portfolio. Using the previous framework, Frazzini and Pedersen (2014) deduced that:

$$
x_{m}=\frac{1}{\phi} \Sigma^{-1}\left(\mathbb{E}[\tilde{P}+\tilde{D}]-\left(1+R_{f}+\psi\right) P\right)
$$

with $\phi=\left(\sum_{j=1}^{m} \phi_{j}^{-1}\right)^{-1}, \psi=\sum_{j=1}^{m} \phi \phi_{j}^{-1} \lambda_{j} m_{j}$ and $\lambda_{j}$ the Lagrange multiplier associated with the constraint (13). Let $\beta_{i}^{m}=\beta\left(e_{i} \mid x_{m}\right)$ be the beta of asset $i$ with respect to the market portfolio. Frazzini and Pedersen (2014) show that:

$$
\mathbb{E}\left[R_{i}\right]-R_{f}=\alpha_{i}+\beta_{i}^{m}\left(\mathbb{E}\left[R_{m}\right]-R_{f}\right)
$$

where $\alpha_{i}=\psi\left(1-\beta_{i}^{m}\right)$. If we compare this relationship with Equation (14), we notice the presence of a new term $\alpha_{i}$, which is Jensen's alpha. Finally, Frazzini and Pedersen (2010) concluded that "the alpha decreases in the beta" and "the Sharpe ratio is highest for an efficient portfolio with a beta less than 1 and decreases in $\beta_{i}^{m}$ for higher betas and increases with lower betas".

Example 2 We consider four assets where $\mu_{1}=5 \%, \mu_{2}=6 \%, \mu_{3}=8 \%, \mu_{4}=6 \%$, $\sigma_{1}=15 \%, \sigma_{2}=20 \%, \sigma_{3}=25 \%$ and $\sigma_{4}=20 \%$. The correlation matrix $C$ is equal to:

$$
C=\left(\begin{array}{cccc}
1.00 & & & \\
0.10 & 1.00 & & \\
0.20 & 0.60 & 1.00 & \\
0.40 & 0.50 & 0.50 & 1.00
\end{array}\right)
$$

The risk-free rate is set to $2 \%$.

This example is taken from Cazalet et al. (2014). Using the previous parameters, we computed the tangency portfolio $x^{\star}$ without any constraints and obtained the results given in Table 16. In this case, the expected return and the volatility of the tangency portfolio are $\mu\left(x^{\star}\right)=6.07 \%$ and $\sigma\left(x^{\star}\right)=13.77 \%$. Let $\beta_{i}(x)$ and $\pi_{i}(x)$ be the beta of asset $i$ and its implied risk premium ${ }^{41}$ with respect to market portfolio $x$. These two statistics are also reported in Table 16. We found that the implied risk premium $\pi_{i}\left(x^{\star}\right)$ is equal to the true risk premium $\mu_{i}-r$. Let us suppose that the market includes two investors. The first investor cannot leverage his risky portfolio, whereas the second investor must hold $50 \%$ of his wealth

\footnotetext{
${ }^{41}$ We have:

$$
\pi_{i}(x)=\beta_{i}(x) \cdot\left(\mu(x)-R_{f}\right)
$$
}

where $\mu(x)$ is the expected return of the portfolio $x$. 
Facts and Fantasies About Factor Investing

in cash. The market portfolio ${ }^{42} x_{m}$ is therefore different from the tangency portfolio $x^{\star}$ (see Table 17). It is more heavily weighted in high risk assets and less heavily weighted in low risk assets. This is why the implied risk premium is underestimated for low beta assets and overestimated for high beta assets. For instance, the implied risk premium of the first asset is $2.68 \%$. We can also compute the alpha. We found that it is positive for low beta assets $\left(\beta_{i}\left(x_{m}\right)<1\right)$ and negative for high beta assets $\left(\beta_{i}\left(x_{m}\right)>1\right)$. If we add the alpha return to the implied risk premium, we obtain the true risk premium.

Table 16: Tangency portfolio $x^{\star}$ without any constraints

\begin{tabular}{|c|rcc|}
\hline Asset & \multicolumn{1}{|c}{$x_{i}^{\star}$} & $\beta_{i}\left(x^{\star}\right)$ & $\pi_{i}\left(x^{\star}\right)$ \\
\hline 1 & $47.50 \%$ & 0.74 & $3.00 \%$ \\
2 & $19.83 \%$ & 0.98 & $4.00 \%$ \\
3 & $27.37 \%$ & 1.47 & $6.00 \%$ \\
4 & $5.30 \%$ & 0.98 & $4.00 \%$ \\
\hline
\end{tabular}

Table 17: Market portfolio $x_{m}$ with two investors

\begin{tabular}{|c|rrccc|}
\hline Asset & \multicolumn{1}{|c}{$x_{m, i}$} & \multicolumn{1}{c}{$\alpha_{i}$} & $\beta_{i}\left(x_{m}\right)$ & $\pi_{i}\left(x_{m}\right)$ & $\alpha_{i}+\pi_{i}\left(x_{m}\right)$ \\
\hline 1 & $42.21 \%$ & $0.32 \%$ & 0.62 & $2.68 \%$ & $3.00 \%$ \\
2 & $15.70 \%$ & $0.07 \%$ & 0.91 & $3.93 \%$ & $4.00 \%$ \\
3 & $36.31 \%$ & $-0.41 \%$ & 1.49 & $6.41 \%$ & $6.00 \%$ \\
4 & $5.78 \%$ & $0.07 \%$ & 0.91 & $3.93 \%$ & $4.00 \%$ \\
\hline
\end{tabular}

Frazzini and Pedersen (2014) consider normalized-beta and cash-neutral assets such that their beta is equal to one ${ }^{43}$ and their performance is the excess return over the risk-free rate. The return of these new assets is then equal to:

$$
\tilde{R}_{i}=\frac{R_{i}-R_{f}}{\beta_{i}\left(x_{m}\right)}
$$

We obtain:

$$
\begin{aligned}
\mathbb{E}\left[\tilde{R}_{i}\right] & =\frac{\mathbb{E}\left[R_{i}\right]-R_{f}}{\beta_{i}\left(x_{m}\right)} \\
& =\frac{\alpha_{i}}{\beta_{i}\left(x_{m}\right)}+\pi\left(x_{m}\right)
\end{aligned}
$$

Let us now consider a zero-beta portfolio $\tilde{x}$ with previous normalized assets, such that $\sum_{i=1}^{n} \tilde{x}_{i}=0$. The return of the portfolio is $R(\tilde{x})=\sum_{i=1}^{n} \tilde{x}_{i} \tilde{R}_{i}$ and we deduce that:

$$
\begin{aligned}
\mathbb{E}[R(\tilde{x})] & =\sum_{i=1}^{n} \tilde{x}_{i} \frac{\alpha_{i}}{\beta_{i}\left(x_{m}\right)}+\pi\left(x_{m}\right) \sum_{i=1}^{n} \tilde{x}_{i} \\
& =\sum_{i=1}^{n} \tilde{x}_{i} \frac{\alpha_{i}}{\beta_{i}\left(x_{m}\right)}
\end{aligned}
$$

Therefore, we can build betting-against-beta (or BAB) portfolios, i.e. zero-beta portfolios with positive alphas. It suffices to have positive weights on stocks with a beta lower than

\footnotetext{
${ }^{42}$ We have $\mu\left(x_{m}\right)=6.30 \%$ and $\sigma\left(x_{m}\right)=14.66 \%$.

${ }^{43}$ We leverage assets with a beta lower than one and de-leverage assets with a beta higher than one.
} 
Facts and Fantasies About Factor Investing

one and negative weights on stocks with a beta higher than one. In Table 18, we report the composition $\tilde{x}$, the expected return $\mathbb{E}[R(\tilde{x})]$ and the volatility of four BAB portfolios. For instance, the first portfolio goes long on the first asset and short on the third asset ${ }^{44}$. Its expected return is 79 bps, while its volatility is $26.45 \%$.

Table 18: Betting-against-beta portfolios

\begin{tabular}{|c|rrrr|}
\hline Portfolio & $\# 1$ & $\# 2$ & $\# 3$ & $\# 4$ \\
\hline$\tilde{x}_{1}$ & 1 & 0 & 1 & 5 \\
$\tilde{x}_{2}$ & 0 & 1 & 1 & 0 \\
$\tilde{x}_{3}$ & -1 & 0 & -3 & -5 \\
$\tilde{x}_{4}$ & 0 & -1 & 1 & 0 \\
\hline$\overline{\mathbb{E}}[\bar{R}(\tilde{x})]$ & $-\overline{0.79} \overline{\%}$ & $-\overline{0} . \overline{0} \overline{\%}$ & $-1.5 \overline{1} \%$ & $-\overline{3} . \overline{9} \overline{4} \overline{\%}$ \\
$\sigma(R(\tilde{x}))$ & $26.45 \%$ & $21.93 \%$ & $46.59 \%$ & $132.24 \%$ \\
\hline
\end{tabular}

Frazzini and Pedersen (2014) defined the betting-against-beta (or BAB) factor as the return difference between the low beta and high beta portfolios:

$$
\mathrm{BAB}_{t}=\frac{R_{t}\left(x_{\text {low-beta }}\right)-R_{f}}{\beta_{i}\left(x_{\text {low-beta }}\right)}-\frac{R_{t}\left(x_{\text {high-beta }}\right)-R_{f}}{\beta_{i}\left(x_{\text {high-beta }}\right)}
$$

To this end, they considered a universe of $n$ assets, which are sorted according to their estimated beta. The low beta (or high beta) portfolio is comprised entirely of assets with a beta below (above) the median value. The portfolios are rebalanced every month. Results ${ }^{45}$ for the different asset classes are reported in Figure 15 and Table 19. The excess return of these factors is positive, except for the French equities and the commodities. The median Sharpe ratio for the 30 asset classes used by Frazzini and Pedersen (2014) is close to 0.50.

Table 19: Performance of the BAB factor (1995-2013)

\begin{tabular}{|c|c|c|c|}
\hline Asset class & $\mu(x)$ & $\sigma(x)$ & $\mathrm{SR}(x \mid r)$ \\
\hline USD Equities & $9.04 \%$ & $14.96 \%$ & 0.60 \\
\hline JPY Equities & $2.65 \%$ & $13.12 \%$ & 0.20 \\
\hline DEM Equities & $6.38 \%$ & $17.98 \%$ & 0.36 \\
\hline FRF Equities & $-3.03 \%$ & $26.26 \%$ & -0.12 \\
\hline GBP Equities & $5.31 \%$ & $14.41 \%$ & 0.37 \\
\hline International Equities & $7.73 \%$ & $8.20 \%$ & 0.94 \\
\hline 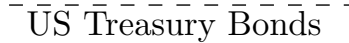 & $\overline{1.73} \%$ & $2 . \overline{95} \overline{\%}$ & $0 . \overline{5}$ \\
\hline US Corporate Bonds & $5.43 \%$ & $10.81 \%$ & 0.50 \\
\hline Currencies & $1.12 \%$ & $8.64 \%$ & 0.13 \\
\hline Commodities & $-4.78 \%$ & $17.76 \%$ & -0.27 \\
\hline All assēts & $5.3 \overline{6} \%$ & $\overline{4} . \overline{34} \overline{\%}$ & $1 . \overline{2} \overline{4}$ \\
\hline
\end{tabular}

Links between low volatility, idiosyncratic volatility and low beta anomalies At first sight, these three anomalies seems to be different, but they are strongly related. Indeed,

\footnotetext{
${ }^{44}$ The weights are respectively $160.5 \%$ and $-67.1 \%$.

${ }^{45}$ Data for the BAB factor are available on the website of Lasse H. Pedersen: http://www. Ihpedersen. com/data.
} 
Figure 15: Frazzini-Pedersen BAB factor (1995 - 2013)
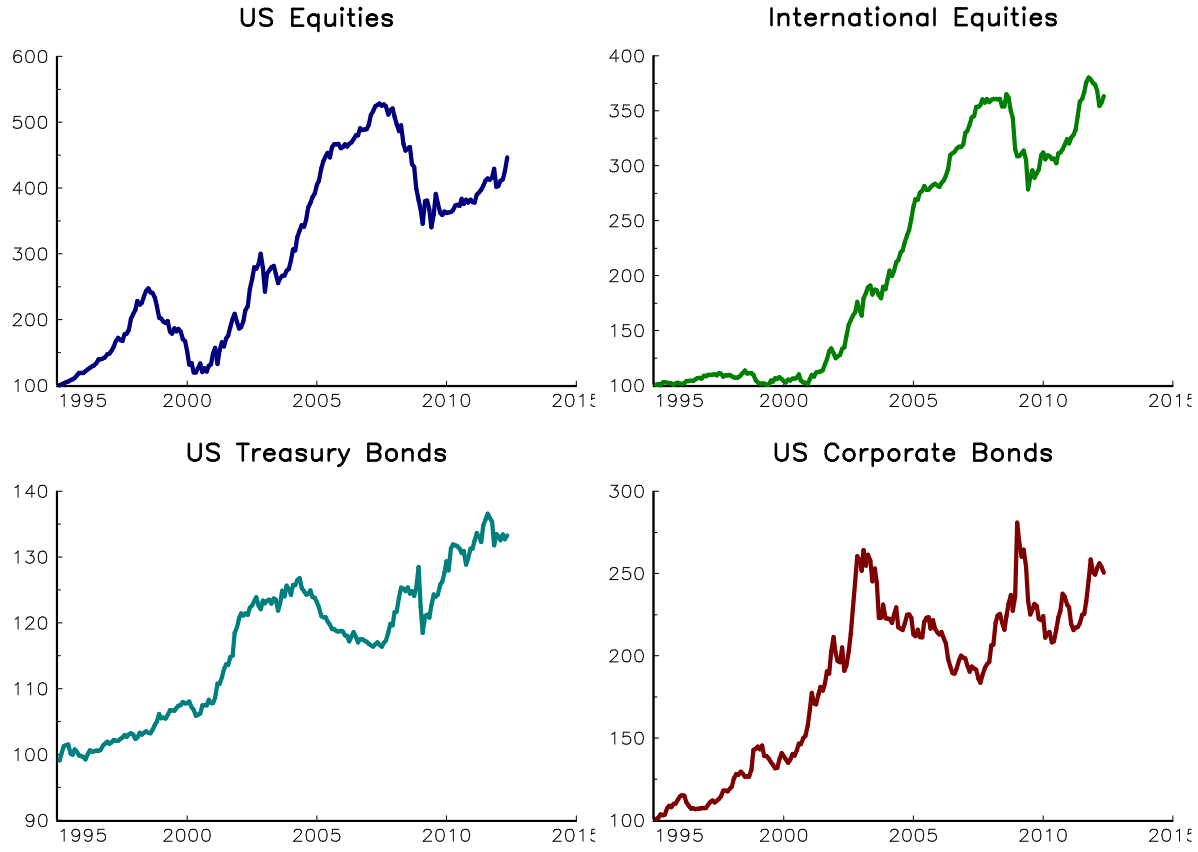

in the CAPM, the volatility $\sigma_{i}$ of asset $i$ can be decomposed into two components:

$$
\sigma_{i}^{2}=\left(\beta_{i}^{m}\right)^{2} \sigma_{m}^{2}+\tilde{\sigma}_{i}^{2}
$$

The first component is the systematic risk and depends on the beta $\beta_{i}$ of the asset, while the second component is the idiosyncratic volatility $\tilde{\sigma}_{i}$. All other things being equal, the total volatility is an increasing function of the beta and the idiosyncratic volatility ${ }^{46}$. In this case, the low volatility anomaly, the idiosyncratic volatility anomaly and the low beta anomaly seem to be the same thing. For instance, in Table VI on Page 285 reported by Ang et al. (2006), the results obtained with portfolios sorted by total volatility are very close to those based on portfolios sorted by idiosyncratic volatility ${ }^{47}$. Similarly, Clarke et al. (2010) and Scherer (2011) showed that the performance of minimum variance portfolios is linked to the low beta anomaly. In the CAPM, the covariance matrix $\Sigma$ of asset returns can be decomposed as:

$$
\Sigma=\beta \beta^{\top} \sigma_{m}^{2}+D
$$

where $\beta=\left(\beta_{1}, \ldots, \beta_{n}\right)$ is the vector of betas, $\sigma_{m}^{2}$ is the variance of the market portfolio and $D=\operatorname{diag}\left(\tilde{\sigma}_{1}^{2}, \ldots, \tilde{\sigma}_{n}^{2}\right)$ is the diagonal matrix of idiosyncratic variances. Using this expression, Clarke et al. (2010) and Scherer (2011) showed that the weights of the minimum

\footnotetext{
${ }^{46}$ Moreover, we observe empirically that the idiosyncratic volatility is also an increasing function of beta. In Figure 45 on Page 107, we consider all the stocks in the S\&P 500 Index for at least three years from 1995 to 2013 and report the empirical relationship between the beta and the idiosyncratic volatility obtained with the CAPM regression:

$$
R_{i}(t)=\alpha_{i}+\beta_{i}^{m} R_{m}(t)+\epsilon_{i}(t)
$$

We verified the positive relation between $\hat{\beta}_{i}^{m}$ and $\hat{\sigma}\left(\epsilon_{i}(t)\right)$. The same conclusion holds if we use the threefactor Fama-French regression (12) instead of the previous one-factor regression (see Figure 46).

${ }^{47}$ However, Ang et al. (2006) define idiosyncratic volatility with respect to the Fama-French model and not relative to the CAPM.
} 
variance portfolio are:

$$
x_{i}^{\star}=\frac{\sigma^{2}\left(x^{\star}\right)}{\tilde{\sigma}_{i}^{2}}\left(1-\frac{\beta_{i}}{\beta^{\star}}\right)
$$

where $\beta^{\star}$ is a threshold, which depends on the vector of betas and the idiosyncratic variances. If we consider this formula, we note that the minimum variance portfolio is exposed to assets with low idiosyncratic volatility and low beta. More precisely, if asset $i$ has a beta $\beta_{i}$ smaller than $\beta^{\star}$, the weight of this asset is positive $\left(x_{i}^{\star}>0\right)$. If $\beta_{i}>\beta^{\star}$, then $x_{i}^{\star}<0$. For the long-only minimum variance portfolio, Clarke et al. (2010) showed that the previous formula (16) remains valid, but with another threshold value $\beta^{\star}$. In this case, if $\beta_{i}>\beta^{\star}, x_{i}^{\star}=0$. This analysis highlights the results obtained by Hsu and Li (2013), who found that the performance of low volatility portfolios is mainly explained by MKT and BAB factors ${ }^{48}$.

Figure 16: Difference between the low beta and low volatility anomalies
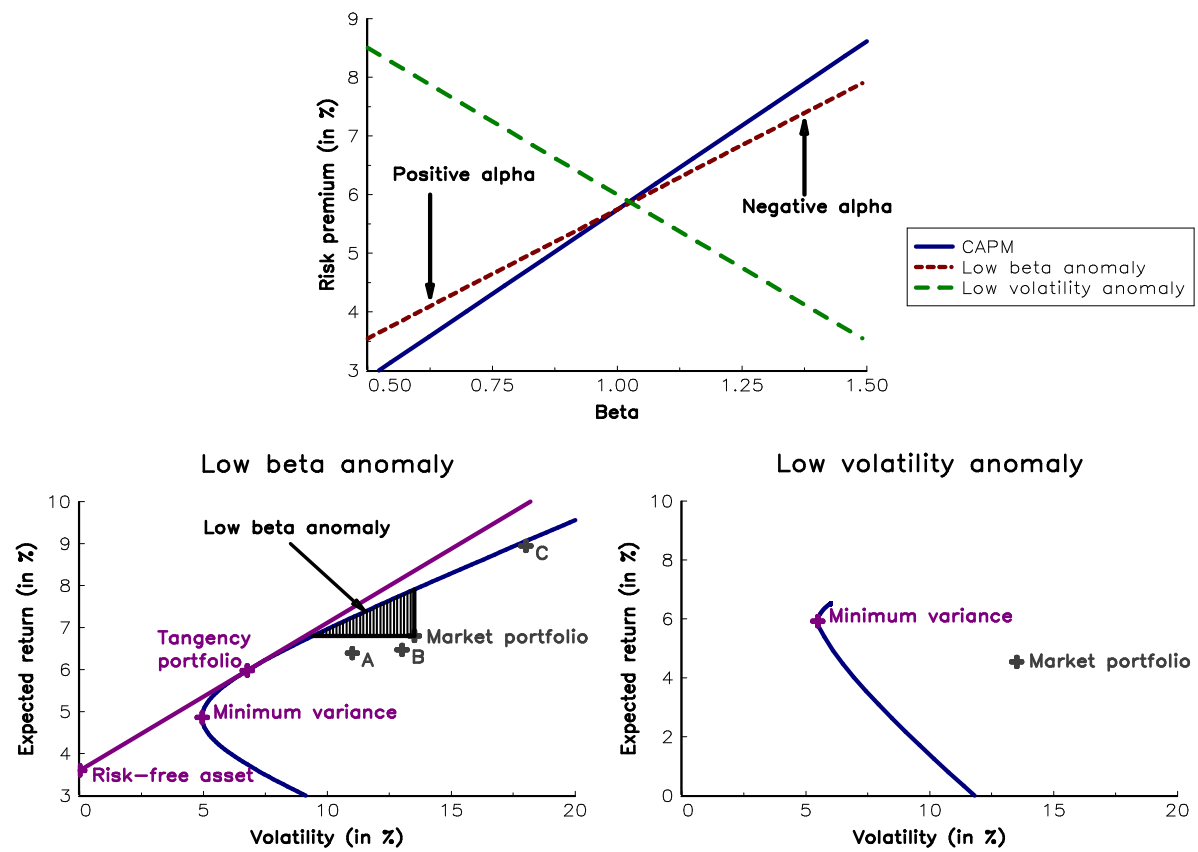

Remark 6 There is a big difference between the low beta anomaly and the low volatility anomaly. The low beta anomaly tells us that the risk premium of low beta stocks (or high beta stocks) is underestimated (or overestimated) in the CAPM model. In the asset management industry, the low volatility anomaly means that low volatility stocks perform better than high volatility stocks. These statements are illustrated in the first panel of Figure 16. Given the low beta anomaly, it is therefore possible to improve the risk-return profile of the market portfolio. However, the low beta anomaly does not assume that the minimum variance portfolio outperforms the tangency portfolio (see the second panel of Figure 16). In the case of the low volatility anomaly, the minimum variance portfolio is very close to the tangency portfolio, and outperforms the market portfolio. The two anomalies can only be reconciled when we use leveraged portfolios or when we consider that the market portfolio has no risk premium or a negative risk premium.

\footnotetext{
${ }^{48}$ Using the Carhart model, Hsu and Li (2013) note that low volatility portfolios are sensitive to the SMB and HML factors, but this effect disappears if we include the BAB factor.
} 
Facts and Fantasies About Factor Investing

\subsubsection{Liquidity}

Amihud and Mendelson (1986) found that the return on an asset is an increasing and concave function of its bid-ask spread. Pàstor and Stambaugh (2003) then suggested including a liquidity premium in the Fama-French-Carhart model:

$$
\begin{aligned}
\mathbb{E}\left[R_{i}\right]-R_{f}= & \beta_{i}^{m}\left(\mathbb{E}\left[R_{m}\right]-R_{f}\right)+\beta_{i}^{s m b} \mathbb{E}\left[R_{s m b}\right]+\beta_{i}^{h m l} \mathbb{E}\left[R_{h m l}\right]+ \\
& \beta_{i}^{w m l} \mathbb{E}\left[R_{w m l}\right]+\beta_{i}^{l i q} \mathbb{E}\left[R_{l i q}\right]
\end{aligned}
$$

To do this, they build an aggregate liquidity factor LIQ based on order flows or volume. More precisely, $\mathrm{LIQ}_{t}$ measures the shock or innovation of the aggregate liquidity ${ }^{49}$. This liquidity measure is consistent with the analysis of Amihud (2002), who found that "stock returns are negatively related over time to contemporaneous unexpected liquidity". To illustrate the relevance of this liquidity measure, Pàstor and Stambaugh (2003) estimated the liquidity beta $\beta_{i}^{l i q}$ by using the three-factor or four-factor model, and by including the liquidity factor $\mathrm{LIQ}_{t}$. At the end of each year, they then sort stocks by their (predicted) liquidity betas in order to form 10 portfolios and compute the alpha for each of the decile portfolios ${ }^{50}$. Their results are reported in Figure 17. We observe that the alpha is an increasing function of the sensitivity to liquidity. For instance, the expected return difference between the last decile portfolio $^{51}$ and the first decile portfolio is $7.5 \%$ according to the Carhart four-factor model. Another interesting finding of Pàstor and Stambaugh (2003) concerns momentum strategies. They found that a significant part of the performance of these strategies is explained by the liquidity factor.

The liquidity risk measure described above is different from the traditional liquidity measure, which defines the liquidity characteristic (or level) of the asset. On the one hand, the asset liquidity level is generally measured by its bid-ask spread or trading volume. In this case, the literature amply documents that less liquid assets outperform more liquid assets (Amihud and Mendelson, 1986; Ibbotson et al., 2013). On the other hand, the asset liquidity risk is a measure of the unexpected variation in total liquidity. This new way to measure liquidity is now commonly accepted (Acharya and Pedersen, 2005; Sadka, 2006; Hou and Sadka, 2011), and the empirical finding of Pàstor and Stambaugh (2003) has been confirmed by other studies (Lee 2011). The liquidity risk premium is also found in other asset classes. For instance, Lin et al. (2011) and Sadka (2010) showed that liquidity risk is priced into corporate bonds and hedge funds.

\footnotetext{
${ }^{49}$ Pàstor and Stambaugh (2003) define the liquidity measure for asset $i$ and period $t$ as the OLS estimate $\hat{\gamma}_{i}(t)$ in the regression:

$$
R_{i}(\tau+1)=\theta_{i}(t)+\phi_{i}(t) R_{i}(\tau)+\gamma_{i}(t) \operatorname{sgn}\left(\pi_{i}(\tau)\right) \cdot V_{i}(\tau)+\varepsilon_{i}(\tau) \quad \text { for } \tau \in t
$$
}

where $R_{i}(\tau)$ is the daily return, $\pi_{i}(\tau)=R_{i}(\tau)-R_{m}(\tau)$ is the daily excess return and $V_{i}(\tau)$ is the daily dollar volume for asset $i$ and time $\tau$. The linear regression is performed for all trading days belonging to period $t$, which is typically a month. The innovations in liquidity are the fitted residual $\hat{v}(t)$ of the following autoregressive regression:

$$
\Delta \hat{\gamma}(t)=a+b \Delta \hat{\gamma}(t-1)+c \hat{\gamma}(t-1)+v(t)
$$

where $\hat{\gamma}(t)=s(t) \cdot\left(n^{-1} \sum_{i=1}^{n} \hat{\gamma}_{i}(t)\right)$ is the scaled aggregate liquidity measure and $s(t)$ is a scaling factor proportional to the market value of stocks.

${ }^{50}$ Their study period is from August 1966 to December 1999 and concerns US Stocks traded on NYSE and AMEX.

${ }^{51}$ This corresponds to stocks with a high sensitivity to liquidity. 
Figure 17: Alphas of decile portfolios sorted on predicted liquidity betas

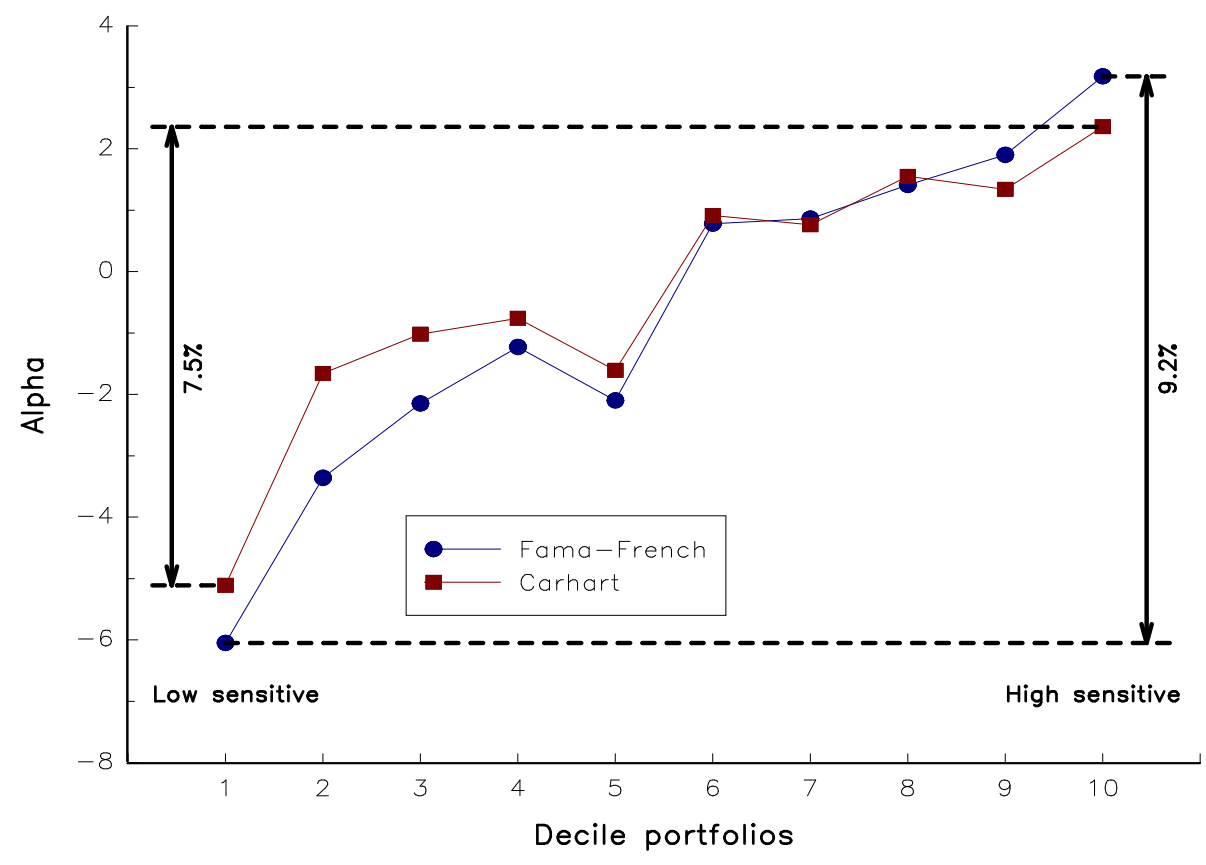

\subsubsection{Carry}

At the end of the 1970s, a number of academic papers concluded that the uncovered interest rate parity (UIP) is not verified ${ }^{52}$. This theory, formulated by Irving Fisher, states that the difference in interest rates between two countries is equal to the expected variation in exchange rates between the two countries. This theory is related to two other theories: covered interest rate parity (CIP) and the efficient market hypothesis (EMH). CIP implies that the forward premium is equal to the nominal interest rate differential, otherwise there will be arbitrage opportunities between the two currencies. Let $S_{t}$ be the spot exchange rate $^{53}$. We note $F_{t}, i_{t}$ and $i_{t}^{*}$ the forward exchange rate, the domestic interest rate and the foreign interest rate for the period $[t, t+1]$. We have $\mathrm{e}^{54}$ :

$$
F_{t}=\frac{1+i_{t}}{1+i_{t}^{*}} S_{t}
$$

Moreover, if the market is efficient, the forward exchange rate is equal to the expected value of the spot rate:

$$
\mathbb{E}_{t}\left[S_{t+1}\right]=F_{t}
$$

The UIP theory derives directly from these two statements. It follows that:

$$
\ln S_{t+1}-\ln S_{t}=\left(i_{t}-i_{t}^{*}\right)+\varepsilon_{t}
$$

\footnotetext{
${ }^{52}$ See, for instance, Cumby and Obstfeld (1981).

${ }^{53} \mathrm{It}$ is measured in terms of the number of domestic currency units per unit of foreign currency.

${ }^{54}$ The forward premium $f_{t}$ is generally defined as the difference between the forward and spot exchange rates (expressed in $\log )$ :

$$
\ln F_{t}-\ln S_{t} \simeq i_{t}-i_{t}^{*}
$$
}


Facts and Fantasies About Factor Investing

where $\varepsilon_{t}$ is a white noise process. This means that an investment that is long on currencies with high interest rates and short on currencies with short interest rates will face a negative return on average, which offsets the interest rate differential. This style of investment is called a currency carry trade. But, in practice, the relationship (19) is not verified. Meese and Rogoff (1983) found that the random walk model $\ln S_{t+1}-\ln S_{t}=\varepsilon_{t}$ performs better. In this case, a currency carry trade generates a positive performance. In Figure 18, we report the excess return of currency carry indices sponsored by Deutsche Bank ${ }^{55}$. The G10 Carry Index systematically invests in the three highest yielding G10 currencies through funding in the three lowest yielding G10 currencies. The portfolio is equally-weighted and the frequency of rebalancing is quarterly. The Balanced and Global Carry indices use the same rules with a universe of high liquid currencies (G10 and EM currencies) and five currencies instead of three currencies for building the long and short legs of the portfolio. The Balanced Carry Index is a constrained version of the Global Carry Index created by imposing at least two G10 currencies for the long and short legs. Some statistics are reported in Table 20. We observe that the long-run Sharpe ratio of this strategy is around 0.50. These results are in line with those reported by Brunnermeier et al. (2009) or Jurek (2014).

Figure 18: Performance of currency carry indices
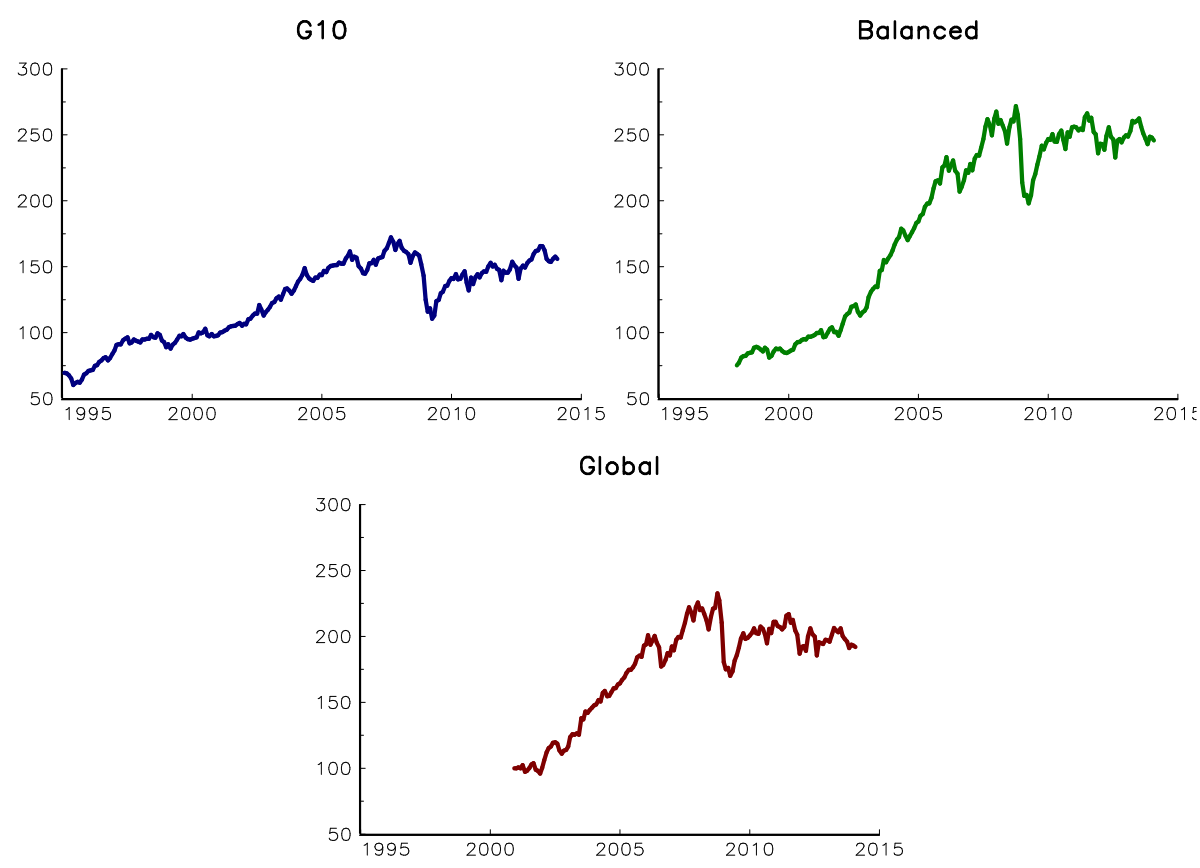

There are multiple interpretations of this forward premium puzzle (Fama, 1984). Lustig and Verdelhan $(2007,2011)$ considered that consumption risk explains a large part of carry trade performance, because "high interest rate currencies depreciate when US consumption growth is low and US investors want to be compensated for this risk". Bhansali (2007) interpreted the carry trade as another form of short volatility trade and Brunnermeier et al. (2009) showed that the strategy is related to funding liquidity constraints and crash risk. In a similar manner, Burnside et al. (2011) suggested that the currency carry strategy reflects

\footnotetext{
${ }^{55}$ The Bloomberg tickers are DBHTG10U Index (G10), DBHVBUSI Index (Balanced) and DBHVGUSI Index (Global). They have been live since December 2005.
} 
Facts and Fantasies About Factor Investing

Table 20: Performance of currency carry strategies (1995-2013)

\begin{tabular}{|c|ccc|}
\hline Universe & $\mu(x)$ & $\sigma(x)$ & SR $(x \mid r)$ \\
\hline G10 & $4.31 \%$ & $10.48 \%$ & 0.41 \\
Balanced & $7.44 \%$ & $10.87 \%$ & 0.68 \\
Global & $5.02 \%$ & $11.68 \%$ & 0.43 \\
\hline
\end{tabular}

a Peso problem ${ }^{56}$. However, Jurek (2014) found that excess returns on currency carry trades remain significant after hedging the tail risk, indicating that negative skewness is not the only risk factor priced in the carry premium. For instance, if we consider the previous G10 carry strategy, we observe two large drawdowns (-31.4\% between September 1992 and April 1995 , and $-37.1 \%$ between July 2007 and January 2009). The loss during the 2008 financial crisis represents 3.5 times the long-run volatility of the carry strategy. It is comparable to results obtained with the equity asset class $^{57}$.

Koijen et al. (2013) extended the carry strategy to other asset classes. They defined the carry of a futures (or forward) contract as the expected return if the spot price remains the same. Let $X_{t}$ be the capital allocated at time $t$ to finance a futures position on asset $S_{t}$. At time $t+1$, the excess return of this investment is ${ }^{58}$ :

$$
R_{t+1}(X)-R_{f}=C_{t}+\frac{\mathbb{E}_{t}\left[\Delta S_{t+1}\right]}{X_{t}}+\varepsilon_{t+1}
$$

where $\varepsilon_{t+1}=\left(S_{t+1}-\mathbb{E}_{t}\left[S_{t+1}\right]\right) / X_{t}$ is the unexpected price change and $C_{t}$ is the carry:

$$
C_{t}=\frac{S_{t}-F_{t}}{X_{t}}
$$

It follows that the expected excess return is the sum of the carry and the expected price change:

$$
\mathbb{E}_{t}\left[R_{t+1}(X)\right]-R_{f}=C_{t}+\frac{\mathbb{E}_{t}\left[\Delta S_{t+1}\right]}{X_{t}}
$$

The nature of these two components is different. The carry is an ex-ante observable quantity whereas the expected price change depends on the dynamic model of $S_{t}$. If we assume that the spot price does not change $(\mathcal{H})$, the expected excess return is equal to the carry. Under assumption $(\mathcal{H})$, a profitable strategy would be long on high carry assets and short on low carry assets. In the case of currencies, it follows from Equation (18):

$$
C_{t}=\frac{i_{t}^{*}-i}{1+i_{t}} \simeq i_{t}^{*}-i
$$

\footnotetext{
${ }^{56}$ See also Gabaix (2012).

${ }^{57}$ If we consider the maximum drawdown for the S\&P 500 during the same period, the ratio is 3.0 .

${ }^{58}$ Under the assumption that the futures price expires at the future spot price $\left(F_{t+1}=S_{t+1}\right)$, Koijen et al. (2013) showed that:
}

$$
\begin{aligned}
R_{t+1}(X)-R_{f} & =\frac{F_{t+1}-F_{t}}{X_{t}} \\
& =\frac{S_{t+1}-F_{t}}{X_{t}} \\
& =\frac{S_{t}-F_{t}}{X_{t}}+\frac{\mathbb{E}_{t}\left[S_{t+1}\right]-S_{t}}{X_{t}}+\frac{S_{t+1}-\mathbb{E}_{t}\left[S_{t+1}\right]}{X_{t}}
\end{aligned}
$$


We verify that the currency carry is equal to the interest rate differential. For equities, Koijen et al. (2013) show that:

$$
C_{t} \simeq \frac{\mathbb{E}_{t}\left[D_{t+1}\right]}{S_{t}}-R_{f}
$$

where $\mathbb{E}_{t}\left[D_{t+1}\right]$ is the risk-neutral expected dividend for time $t+1$. If we assume that dividends are constant, the carry is the difference between the dividend yield and the riskfree rate:

$$
C_{t} \simeq D Y_{t}-R_{f}
$$

In this case, the equity carry factor is long on stocks with high dividends and short on stocks with low dividends. Therefore, the equity carry strategy can be viewed as another form of a value strategy.

Carry strategies are present in lot of asset classes. For instance, Koijen et al. (2013) define them for bonds, credit, commodities and options. In the case of bonds, we generally distinguish two forms of carry trades. The first corresponds to the roll-down strategy. Given an investment horizon $\delta$, the carry of a bond with maturity $T$ is the return on buying this bond at time $t$ and selling it at time $t+\delta$, assuming that the yield curve has not change. In this case, the carry strategy consists of buying bonds with high carry for the investment horizon $\delta$. The second form of carry trade is the slope carry, which is defined as the difference between the ten-year and two-year yield-to-maturity rates:

$$
C_{t} \simeq R_{t}^{10 \mathrm{Y}}-R_{t}^{2 \mathrm{Y}}
$$

The empirical results of Koijen et al. (2013) suggest that the performance found in currencies is similar for other asset classes. They also conclude that "carry is a novel predictor of returns in these asset classes".

\subsubsection{Quality}

Benjamin Graham was known to be a value investor. Novy-Marx (2014) reported that Graham was also a quality investor, meaning that he believed in buying not only cheap stocks, but high quality cheap stocks. By making the difference between weak value stocks (or distressed stocks) and strong value stocks (or quality stocks), Piotroski (2000) argues that the success of the value strategy is explained by the strong performance of quality stocks. For instance, he shows that the annual return of a value strategy can be increased by $7.5 \%$ by using some filters based on accounting information. Although the figures produced by Piotroski may be overestimated (Guay, 2000), similar results were previously arrived at by Sloan (1996), who showed that exceptional components of earnings have a negative impact on market performance. Similarly, Novy-Marx (2013) showed that profitable firms earn significantly higher average returns than unprofitable firms. Because the returns of this strategy are negatively correlated to those of value strategies, combining the two strategies thus produces a higher risk-return profile. However, we notice that these various strategies can be viewed as different versions of the GARP ${ }^{59}$ investment style.

Contrary to other risk factors, the construction of a quality score is less straightforward, because it encompasses several dimensions. For instance, Piotroski (2000) considers three

\footnotetext{
${ }^{59}$ Growth at a reasonable price.
} 
Facts and Fantasies About Factor Investing

dimensions: profitability, leverage/liquidity and operating efficiency. More precisely, he combines nine fundamental binary signals into a composite score ${ }^{60}$ :

$$
\begin{aligned}
F_{-} S C O R E= & \underbrace{F_{-} R O A+F_{-} C F O+F_{-} \Delta R O A+F_{-} A C C R U A L}_{\text {Profitability }}+ \\
& \underbrace{F_{-} \Delta L E V E R+F_{-} \Delta L I Q U I D+F_{-} C E Q}_{\text {Leverage/liquidity }}+ \\
& \underbrace{F_{-} \Delta M A R G I N+F_{-} \Delta T U R N}_{\text {Operating efficiency }}
\end{aligned}
$$

In this case, quality stocks correspond to firms that are profitable without managing earnings though exceptional accruals, have a strong balance sheet ${ }^{61}$, and are efficient in terms of operating performance. Novy-Marx (2013) used a simple quality screen based on gross profitability as measured by the ratio of a firm's gross profits ${ }^{62}$ to its assets (or GPA). Although profitable firms today tend to be profitable firms tomorrow, he shows that this factor is underestimated by the market today. Novy-Marx (2014) extended his work by comparing several quality scores based on investment styles of stock-picking gurus (Graham, Grantham and Greenblatt) or academic research (Sloan's accruals, Piotroski's F-score, GPA score). He shows that combining a quality score with a value or a momentum strategy does a good job. In a recent study, Asness et al. (2013) proposed a more comprehensive quality score. They defined a quality security as "one that has characteristics that, all-else-equal, an investor should be willing to pay a higher price for: stocks that are safe, profitable, growing, and well managed". To identify these characteristics, they adopted the dividend discount model (DDM) used to compute the fair price of a stock:

$$
P=\frac{D}{r-g}
$$

where $D$ is the dividend, $r$ is the required return and $g$ is the growth rate expected for dividends. Let $\Pi$ be the profit of the firm. The authors can then express the price-to-book value as follows:

$$
\begin{aligned}
\frac{P}{B} & =\frac{D / B}{r-g} \\
& =\frac{(\Pi / B) \times(D / \Pi)}{r-g} \\
& =\frac{\text { Profitability } \times \text { Payout ratio }}{\text { Required Return }- \text { Growth }}
\end{aligned}
$$

As with Piotroski's approach, they used four dimensions to compute the composite score ${ }^{63}$. The first two dimensions are very close to the analysis of Piotroski (2000) and Novy-Marx (2013), whereas the last two dimensions are novel concepts. The profitability dimension

\footnotetext{
${ }^{60} \mathrm{ROA}$ and $\mathrm{CFO}$ are defined as net income before extraordinary items and cash flows from operations divided by total assets. LEVER and LIQUID are the ratios of total long-term debt to total assets and current assets to current liabilities. CEQ is the common equity issued by the firm. MARGIN and TURN are the gross margin divided by total sales and total sales divided by total assets. The binary signals are then computed as follows: $F_{-} R O A=\mathbf{1}\{R O A>0\}, F_{-} C F O=\mathbf{1}\{C F O>0\}, F_{-} \Delta R O A=\mathbf{1}\{\triangle R O A>0\}, F_{-} A C C R U A L=$ $1\{C F O>R O A\}, F \_\Delta L E V E R=1\{\Delta L E V E R<0\}, F_{-} \Delta L I Q U I D=1\{\Delta L I Q U I D>0\}, F \_C E Q=$ $\mathbf{1}\{C E Q=0\}, F_{-} \Delta M A R G I N=\mathbf{1}\{\Delta M A R G I N>0\}$ and $F_{-} \Delta T U R N=\mathbf{1}\{\Delta T U R N>0\}$.

${ }^{61}$ They decrease their financial leverage, increase their liquidity and do not raise external capital.

${ }^{62}$ Gross profits is revenue minus cost of goods sold.

${ }^{63}$ They used the Z-score technique to build it.
} 
Facts and Fantasies About Factor Investing

is based on GPA, ROA, ROE, CFO, gross margin and low ACCRUAL, while the growth dimension is based on the five-year difference of these six profitability factors. The safety (or required return) dimension is built using six other factors: low beta (BAB), low IVOL, low leverage, low bankruptcy risk and low ROE volatility. Finally, the payout dimension is defined using equity and debt net issuance and total net payout over profits. By using the quality score, Asness et al. (2013) showed that the price of quality is positive but limited. Based on this empirical result, they built a new risk factor, called quality minus junk (or QMJ), which is long on high quality stocks and short on low quality stocks. Its construction follows the same methodology as Fama and French (1993). Asness et al. (2013) considered six portfolios:

\begin{tabular}{l|ccc} 
& Junk & Median & Quality \\
\hline Small & SJ & SM & SQ \\
Big & BJ & BM & BQ
\end{tabular}

They then defined the QMJ factor as follows:

$$
\mathrm{QMJ}_{t}=\frac{1}{2}\left(R_{t}(\mathrm{SQ})+R_{t}(\mathrm{BQ})\right)-\frac{1}{2}\left(R_{t}(\mathrm{SJ})+R_{t}(\mathrm{BJ})\right)
$$

As in the case of the HML and WML factors, we can also define a QMJ factor for small and big stocks:

$$
\begin{aligned}
\mathrm{SQMJ}_{t} & =R_{t}(\mathrm{SQ})-R_{t}(\mathrm{SJ}) \\
\mathrm{BQMJ}_{t} & =R_{t}(\mathrm{BQ})-R_{t}(\mathrm{BJ})
\end{aligned}
$$

In Table 21 and Figure 19, we report the statistics and cumulative performance of the QMJ factors ${ }^{64}$. As with the HML factor, we notice that the cumulative returns are higher for small stocks, but are still significant for big stocks. Why are quality stocks better rewarded than junk stocks? According to Asness et al. (2013), this puzzling question has yet to be answered. By definition, the premium of the QMJ factor is not a compensation for taking more risk. In particular, Asness et al. (2013) showed that quality stocks protect investors from severe market downturns. A potential explanation remains market inefficiency and mispricing. In particular, Novy-Marx (2013) showed that a four-factor model based on the HML, WML and quality factors significantly captures the alpha of a wide range of anomalies.

Table 21: Statistics for the SQMJ, BQMJ and QMJ factors (1995 - 2013)

\begin{tabular}{|c|rrr:rrr|}
\hline \multirow{2}{*}{ Statistic } & \multicolumn{3}{|c|}{ US } & \multicolumn{3}{c|}{ Global } \\
& SQMJ & BQMJ & QMJ & SQMJ & BQMJ & QMJ \\
\hline$\mu(x)$ & 5.9 & 2.7 & 4.4 & 7.2 & 3.0 & 5.2 \\
$\sigma(x)$ & 13.5 & 10.4 & 10.8 & 10.0 & 8.6 & 8.5 \\
SR $(x \mid r)$ & 0.44 & 0.26 & 0.41 & 0.73 & 0.35 & 0.60 \\
\hline
\end{tabular}

\subsubsection{Slope of the yield curve}

In the case of fixed-income instruments, several risk factors have been documented. The cross-section and time-variation of bond returns can thus be explained by statistical factors (Litterman and Scheinkman, 1991), market factors (Fama and Bliss, 1987; Cochrane and Piazzesi, 2005) or economic factors (Ludvigson and Ng, 2009). Litterman and Scheinkman

\footnotetext{
${ }^{64}$ Data for the QMJ factor are available on the website of Andrea Frazzini: http://www.econ.yale.edu/ af 227/data_library.htm.
} 
Figure 19: Performance of the QMJ, SQMJ and BQMJ factors
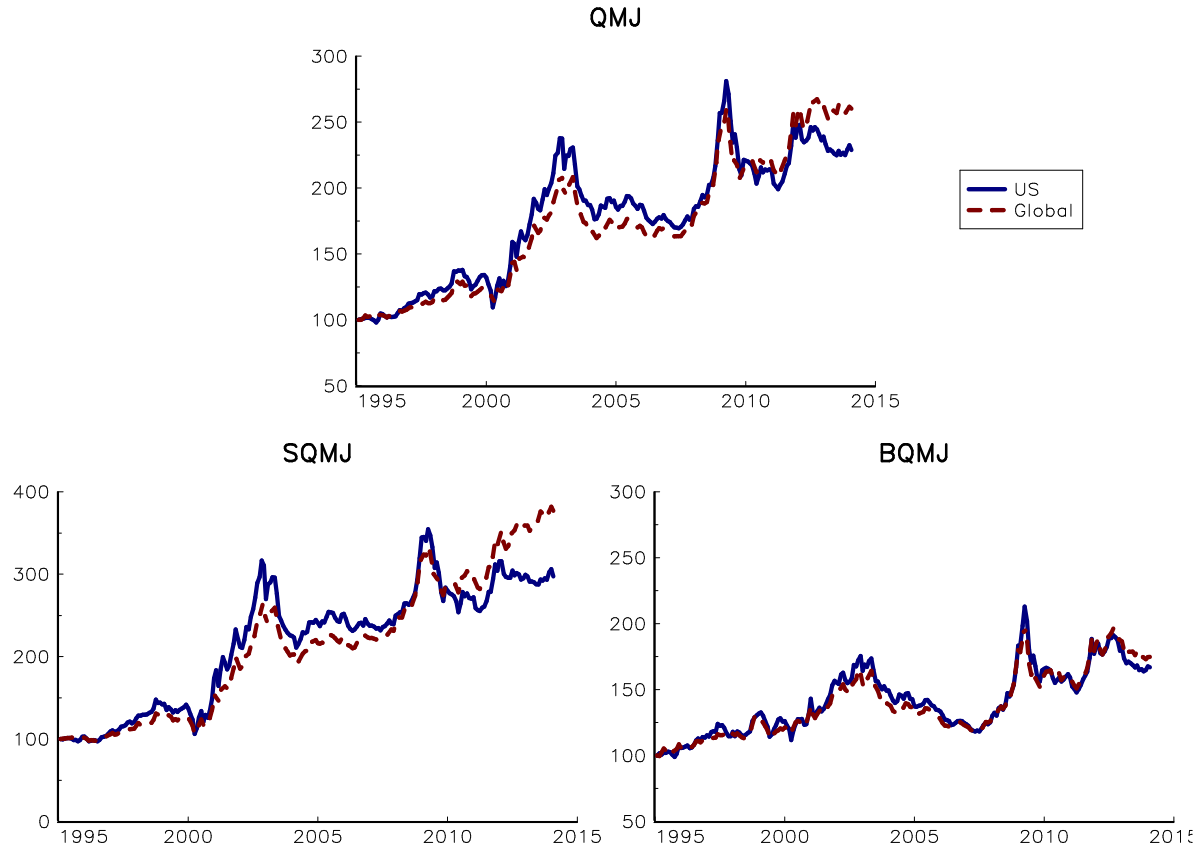

(1991) found that three factors explain a large part of the variation in bond prices. These factors are the level, slope and curvature of the yield curve and can be estimated using principal component analysis of bond yields. In Figure 20, we report the factor loadings computed by Roncalli (2013) for the US yield curve.

The first factor is a weighted average of the different zero-coupon rates with different maturities. In fact, this factor is highly correlated to the risk-free rate (or the instantaneous zero-coupon rate). The first factor can then be assimilated to the interest rate $R_{f}$, a term which is already present in the CAPM or Fama-French equations (1) and (4). The second factor is a long/short portfolio whose weights increase with respect to the maturity. Therefore, we can interpret this factor as the steepness or the slope of the yield curve. Generally, this factor is approximated by the difference between the yield of long-term government bonds (generally 10 years) and the one-month interest rate, and is denoted by TERM. This factor is largely used to explain bond returns, but also stock returns (Chen et al., 1986; Fama and French, 1993; Petkova, 2006). The third PCA factor, which is a proxy of the curvature or convexity of the yield curve, is less significant and stable than the other two risk factors. It is rarely used nowadays to explain the cross-section of stock and bond returns.

\subsubsection{Other risk factors}

As mentioned previously, there are a lot of other risk factors. Among this zoo of factors and new variables (Cochrane, 2011), we consider the following to merit our attention: the default risk factor, the coskewness factor and macroeconomic factors.

The default risk factor is used by Chan et al. (1985), Chen et al. (1986) and Fama and French (1993). It corresponds to the spread between the return on a portfolio of long-term 
Figure 20: PCA factors of the US yield curve (Jan. 2003 - Jun. 2012)

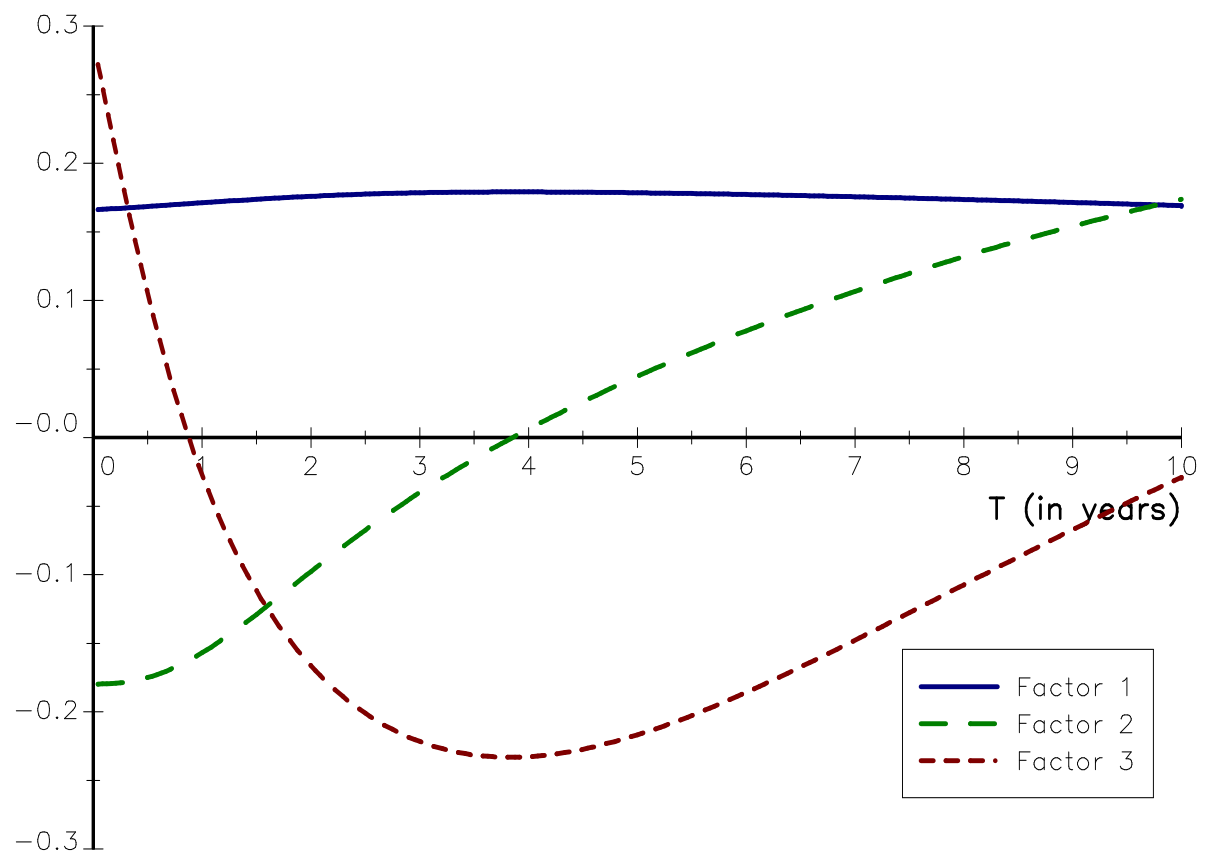

corporate bonds and the yield of long-term government bonds ${ }^{65}$. These papers found that the coefficient associated with default risk is generally significant in risk factor models ${ }^{66}$. These results are confirmed by more recent studies (Avramov et al., 2007).

Coskewness risk ${ }^{67}$ has been extensively documented by Harvey and Siddique (2000). They found that stocks with lower coskewness have higher expected returns. This result is confirmed by many other studies ${ }^{68}$. Moreover, this risk factor can be related to the downside risk of Ang et al. (2006).

The impact of macroeconomic factors on asset returns has a long history, dating back to Merton (1973) and Lucas (1978), who identified the link between consumption risks and expected returns. The relationship with real activity and inflation (expected and unexpected) was also studied by Fama (1981) and Chen et al. (1986). More recently, many papers have attempted to explain the time variation in expected asset returns in relation to macroeconomic risks. For instance, Lettau and Ludvigson (2001) suggested considering the aggregate consumption-wealth ratio (or $\mathrm{CAY}^{69}$ ), while Bansal and Yaron (2004) presented

\footnotetext{
${ }^{65}$ The link between corporate spreads and default risk is not straightforward however. For instance, Elton et al. (2001) found that expected defaults explain a small part of corporate spreads. On the contrary, using credit default swaps, Longstaff et al. (2005) concluded that a large part of corporate spreads is due to default risk.

${ }^{66}$ However, the concept of default risk is close to the concept of distress risk, meaning that there may be some connections with the SMB and HML factors (Vassalou and Xing, 2004).

${ }^{67} \mathrm{It}$ is measured as the covariance between the stock return and the square of the market portfolio return.

${ }^{68}$ See, for instance, Bakshi at al. (2003), Barone Adesi et al. (2004), Chung et al. (2006), Moreno and Rodríguez (2009) and Lambert and Hübner (2013).

${ }^{69}$ The authors present a general framework linking consumption $(\mathrm{C})$, asset holdings (A), and labor income (Y) with expected returns. Based on the theory, these three variables should share a common trend over the long term, but may deviate substantially from one another in the short run. The deviations from the share
} 
Facts and Fantasies About Factor Investing

a model that links consumption volatility and asset returns. However, as noted by Flannery and Protopapadakis (2002): "the hypothesis that macroeconomic developments exert important effects on equity returns has strong intuitive appeal but little empirical evidence". As a consequence, results differ from one paper to another. Moreover, academics consider macroeconomic risks to explain the time variation of expected returns, but there is little research available on the cross-section of expected returns, except for the works of Bansal et al. (2005).

\section{From risk factors to factor indexing}

Institutional investors have been looking at risk factors for quite some time when analyzing their portfolios in terms of factor bets. Today, some of these investors go even further and use risk factors as investment vehicles. In some ways, they consider their asset allocation to be a factor allocation process. For instance, one investor may prefer to allocate $30 \%$ to value and $20 \%$ to momentum factors instead of allocating $50 \%$ to equities directly. This new form of asset allocation is called factor investing.

Factor investing requires the availability of factor-based products like factor-based mutual funds and factor-based indexes. Factor-based mutual funds have long existed for SMB and HML factors, but not for the other factors. This led index providers to develop a large range of factor-based indexes, which have been largely and rapidly adopted by institutional investors. This success may be explained by the transparency of indexes, which use systematic rules to define the portfolio. However, transforming a non-investable risk factor into an investable risk-based index is not straightforward. The choice of implementation (asset universe, weighting scheme, rebalancing frequency) has an impact and accounts for why two indexes based on the same factor may behave differently.

Two other issues arise with factor indexes. In the academic literature, risk factors are designed as long/short portfolios. When these risk factors are transformed into investable products, the corresponding portfolio is generally long-only. This constraint is imposed because the cost of short selling may be high or because it is not possible to have a short position on some stocks (in particular small stocks). Another issue concerns the investment capacity of the factor-based products. Because they are used by large institutional investors, capacity constraints may be taken into account. We will see how these two issues may affect the original risk factor.

\subsection{How to transform risk factors into factor indexes?}

\subsubsection{Asset universe}

To produce risk factors, academics generally use a large asset universe provided by the Center for Research in Security Prices (CRSP) or Standard and Poor's (Compustat and Xpressfeed). This means that the universe contains a significant number of small-caps, which are not easy to trade, even for large institutional investors. For instance, NBIM $^{70}$ had about 1900 and 1300 American and Japanese stocks in its portfolio at the end of December 2013. We can

trend should outline agents' expectations of future returns on the market portfolio. Lettau and Ludvigson (2001) then estimated the long-term relationship between C, A and Y, focusing on the difference between the observed and estimated C, which they call CAY.

${ }^{70}$ NBIM, also known as the Government Pension Fund Global (GPFG) and formerly the Government Petroleum Fund, is the Norwegian sovereign wealth fund. According to the SWF institute, it is the world's largest sovereign fund with about $\$ 890$ billion in assets under management in July 2004 
Facts and Fantasies About Factor Investing

compare these figures with the number of stocks used by Fama and French to compute their HML factor ${ }^{71}$ :

\begin{tabular}{|l|ccccc|}
\hline & Asia Pacific & Europe & Japan & North America & US \\
\hline Big & 326 & 615 & 591 & 888 & 846 \\
Small & 2646 & 4093 & 1840 & 2982 & 2385 \\
\hline Total & 2972 & 4708 & 2431 & 3870 & 3231 \\
\hline
\end{tabular}

The difference is substantial. Indeed, it is not realistic to think that an institutional investor will manage its small-cap (and micro-cap) exposure according to a systematic and quantitative investment approach, because the liquidity risk is too high. In Table 49 on Page 97, we have shown the number of stocks in the MSCI World Index, which is a more realistic universe in which to perform systematic strategies. In this case, it is obvious that there will be a gap between risk factors exhibited by academics and risk factors built by professionals.

In Figure 21, we compare the performance of the risk factors MKT, SMB, HML and WML obtained by Fama and French (blue line) and those computed with the universe of the S\&P 500 Index (red line). Because we use the same methodology to build the factors as Fama and French (2013), the differences are due entirely to the stock universe selected. We observe that including small and micro-cap stocks has little impact on the MKT factor, but also curiously on the SMB factor. This is not the case with the HML and WML factors, confirming that they depend on the stock universe ${ }^{72}$.

Figure 21: Performance of risk factors with the S\&P 500 Index (1995 - 2013)
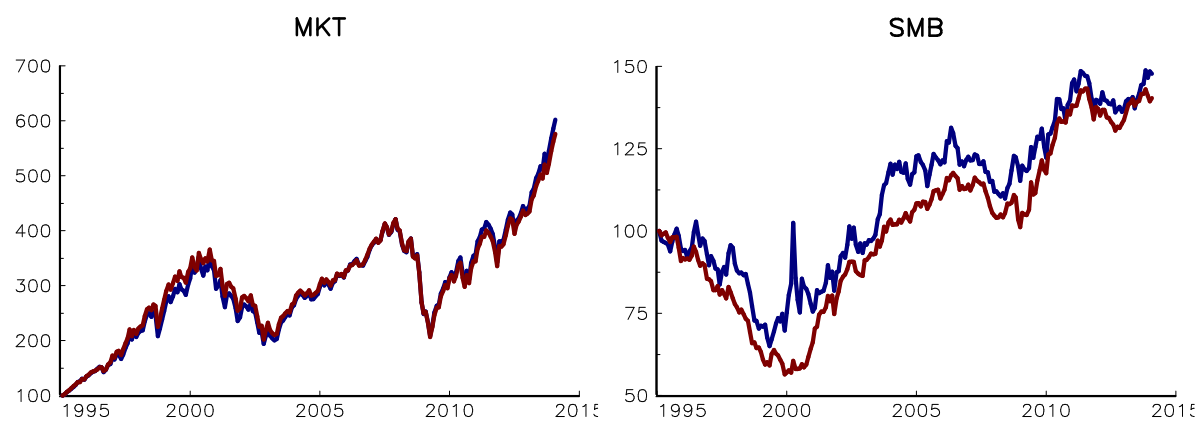

HML
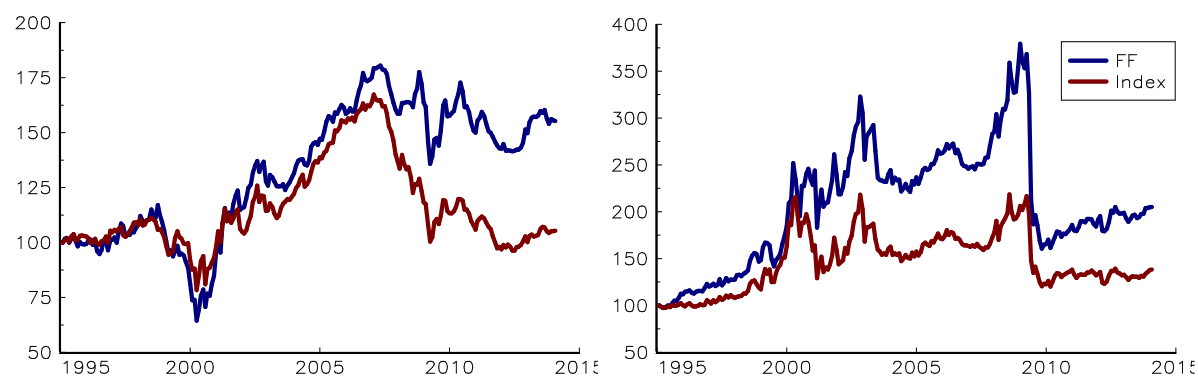

\footnotetext{
${ }^{71}$ These statistics are those of Kenneth French available on his website for the end of December 2013.

${ }^{72} \mathrm{We}$ observe the same patterns if we compare the results of Fama and French and those obtained with the MSCI Europe Index (see Figure 47 on Page 108). Of course, if we consider a universe with more stocks, the differences are reduced. For instance, results with the Topix Index are shown in Figure 48 on Page 108.
} 
Facts and Fantasies About Factor Investing

\subsubsection{Weighting scheme}

In this paragraph, we focus on two problems. The first one concerns the construction of the factor itself, in other words, how portfolio allocation is defined. In this case, the choice depends on several criteria: return maximization, investment capacity, etc. The second problem concerns the replication of the factor when a factor model is given.

Defining weightings Let $R_{i}$ be the rank of stock $i$ according to the factor characteristic. Fama and French define the weightings as follows:

$$
w_{i} \propto\left\{\begin{array}{cc}
-M E_{i} & \text { if } R_{i}<Q_{1} \\
+M E_{i} & \text { if } R_{i}>Q_{2}
\end{array}\right.
$$

where $Q_{1}$ and $Q_{2}$ are two numbers such that $Q_{1}<\bar{R}<Q_{2}$. It consists in deleting the stocks around the median and selecting the stocks in the bottom and top quantiles. Instead of the value-weighted portfolio, we can opt to use the equally-weighted portfolio:

$$
w_{i} \propto \begin{cases}-1 & \text { if } R_{i}<Q_{1} \\ +1 & \text { if } R_{i}>Q_{2}\end{cases}
$$

Asness et al. (2013) consider a rank-weighted scheme:

$$
w_{i} \propto\left\{\begin{array}{cc}
-\left|R_{i}-\bar{R}\right| & \text { if } R_{i}<Q_{1} \\
+\left|R_{i}-\bar{R}\right| & \text { if } R_{i}>Q_{2}
\end{array}\right.
$$

More complex schemes are also considered by index providers.

In Figure 22, we compare value-weighted (VW) and equally-weighted (EW) US factors obtained by Kenneth French ${ }^{73}$. In Table 22, we observe that they are highly correlated, especially for WML and HML factors. However, the global performance may differ considerably, as is the case for the SMB factor in Asia Pacific and Europe and the HML factor in Asia Pacific and the US. In addition to the weighting scheme, the behavior of the risk factors may also depend on the quantile values $Q_{1}$ and $Q_{2}$ of the selection process. To illustrate, let us consider two sets for parameters $Q_{1}$ and $Q_{2}$ for the S\&P 500 universe: $\left(Q_{1}=30 \%, Q_{2}=70 \%\right)$, which is the default parameter set used by Fama and French and $\left(Q_{1}=20 \%, Q_{2}=80 \%\right)$. Results are given in Figure 23. The parameter set has little impact on the VW and EW factors, but the performance of the rank-weighted (or RW) factor is sensitive to $Q_{1}$ and $Q_{2}$.

Table 22: Correlation (in \%) between VW and EW risk factors (1995 - 2013)

\begin{tabular}{|c|ccccc|}
\hline Factor & Asia Pacific & Europe & Japan & North America & US \\
\hline SMBL & 76 & 74 & 88 & 78 & 75 \\
HML & 89 & 90 & 86 & 92 & 89 \\
WML & 94 & 97 & 96 & 98 & 97 \\
\hline
\end{tabular}

Factor replication Suppose now that we have access to a risk factor model or that risk factors are given. Replicating the factor $\mathcal{F}_{j}$ is equivalent to estimating the weights $x$ of the portfolio under some objective function. For instance, it can involve minimizing the tracking

\footnotetext{
${ }^{73}$ See Figures 53, 54, 55 and 56 on Page 111 for the other regions.
} 
Figure 22: Comparison of VW and EW risk factors (US, 1995 - 2013)
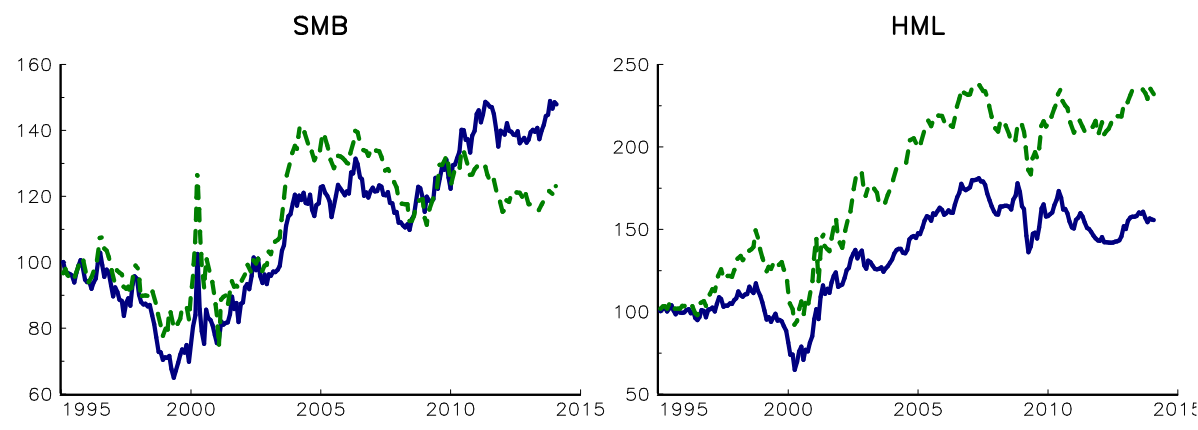

WML

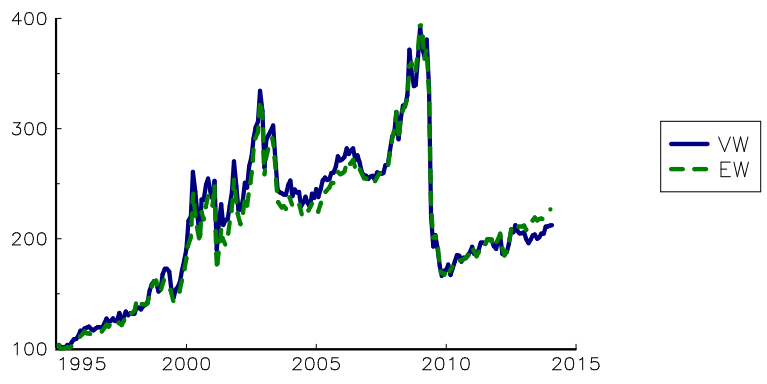

Figure 23: Impact of $\left(Q_{1}, Q_{2}\right)$ on HML and WML factors (S\&P 500, 1995 - 2013)

$$
Q_{1}=30 \%-Q_{2}^{H M L}=70 \%
$$

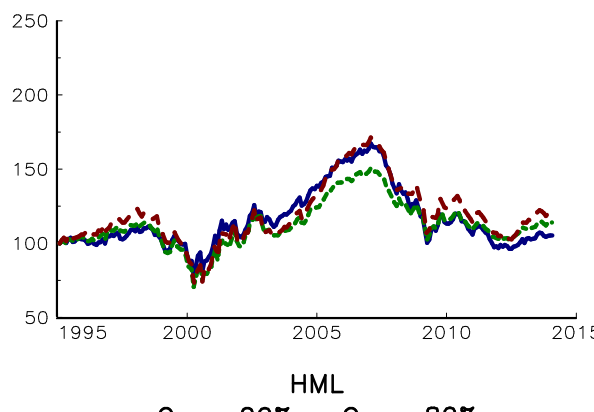

$Q_{1}=20 \%-Q_{2}=80 \%$

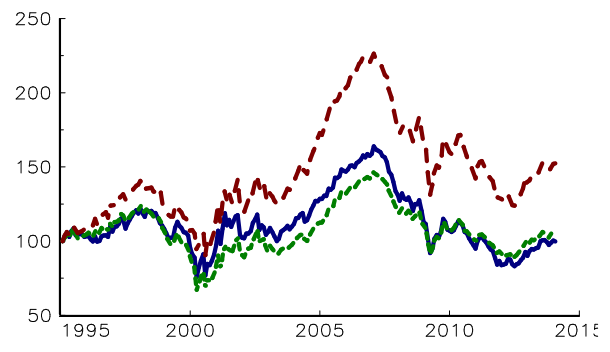

$Q_{1}=30 \%-Q_{2}=70 \%$

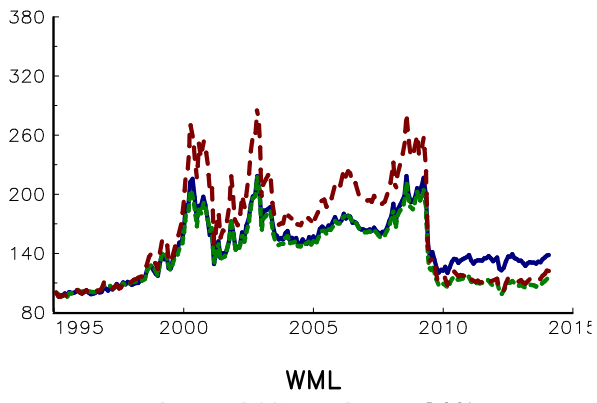

$Q_{1}=20 \%-Q_{2}=80 \%$

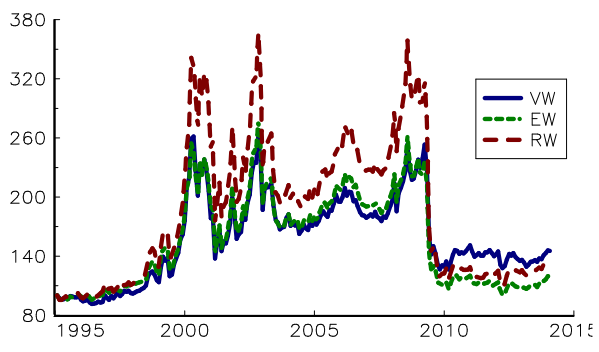


Facts and Fantasies About Factor Investing

Table 23: Minimizing tracking error volatility

\begin{tabular}{|c|c|c|c|c|c|c|}
\hline Portfolio & \multicolumn{3}{|c|}{$\# 1$} & \multicolumn{3}{|c|}{$\# 2$} \\
\hline Factor & 1 & 2 & 3 & 1 & 2 & 3 \\
\hline$x_{1}$ & 8.4 & 1.2 & 0.7 & 8.5 & 1.3 & 1.3 \\
\hline$x_{2}$ & 6.3 & 10.8 & -1.5 & 6.4 & 12.0 & -2.6 \\
\hline$x_{3}$ & 39.9 & 39.6 & 2.0 & 40.5 & 44.0 & 3.6 \\
\hline$x_{4}$ & 23.2 & -56.3 & 1.5 & 23.6 & -62.5 & 2.6 \\
\hline$x_{5}$ & 3.2 & -5.7 & 0.5 & 3.2 & -6.4 & 0.9 \\
\hline$x_{6}$ & 19.2 & -13.3 & -4.2 & 19.5 & -14.8 & -7.5 \\
\hline$-\overline{\beta_{1}}$ & $\overline{9} \overline{7} . \overline{0}$ & 1.5 & $0 . \overline{1}$ & $9 \overline{8} . \overline{5}$ & 1.7 & $\overline{0} . \overline{1}$ \\
\hline$\beta_{2}$ & 2.7 & 81.0 & 1.1 & 2.8 & 90.0 & 1.9 \\
\hline$\beta_{3}$ & 26.3 & 246.1 & 32.4 & 26.7 & 273.4 & 56.9 \\
\hline$\overline{\mathrm{R}} \overline{\mathrm{C}}_{1}^{\star}$ & $\overline{10} \overline{0} . \overline{0}$ & 0.0 & $0 . \overline{-}$ & $\overline{1} 0 \overline{0} . \overline{0}$ & 0.0 & $\overline{0} . \overline{0}$ \\
\hline $\mathrm{RC}_{2}^{\star}$ & 0.0 & 100.0 & 0.0 & 0.0 & 100.0 & 0.0 \\
\hline $\mathrm{RC}_{3}^{\star}$ & 0.0 & 0.0 & 100.0 & 0.0 & 0.0 & 100.0 \\
\hline $\bar{\sigma}\left(\overline{\mathcal{F}}_{j}^{\star} \mid \overline{\mathcal{F}}_{j}^{-}\right)$ & $\overline{3} . \overline{5}$ & 6.5 & $0 . \overline{8}$ & $\overline{3} . \overline{5}$ & 6.7 & $\overline{0} . \overline{9}$ \\
\hline$\sigma\left(\mathcal{F}_{j}^{\star}\right)$ & 19.7 & 13.5 & 0.6 & 20.0 & 15.0 & 1.0 \\
\hline
\end{tabular}

error between the true factor $\mathcal{F}_{j}$ and the replicated factor $\mathcal{F}_{j}^{\star}=\sum_{i=1}^{n} x_{i} R_{i}$. If we do not impose other constraints, we obtain an analytical solution ${ }^{74}$. For instance, if we consider Example 1 on Page 8, we obtain the results (expressed in \%) given in Table 23 (Portfolio \#1). If we impose the constraint that the replicating factors have the same volatility as the true factors, we obtain Portfolio \#2. For each portfolio, we report the asset weights, the betas and risk contributions with respect to the factors, the tracking error volatility $\sigma\left(\mathcal{F}_{j}^{\star} \mid \mathcal{F}_{j}\right)$ and also the volatility $\sigma\left(\mathcal{F}_{j}^{\star}\right)$ of the replicating factor. We notice that the weights are not necessarily in line with the sensitivities. Moreover, it appears that the first two replicated factors present a significant beta compared to the third factor. This result can easily be explained, because the volatility of the third factor is very low compared to the volatility of the first and second factors. One consequence is that it is better to define risk factors with comparable volatilities.

We can compare the tracking error method to other approaches used to estimate replicated risk factors. These approaches are generally classified them into three categories:

1. The sensitivity approach.

In this case, the portfolio weightings are related to the sensitivities: $x_{i}=f\left(B_{i, j}\right)$.

2. The beta approach.

The idea is to maximize the beta $\beta_{j}$ of the $j^{\text {th }}$ factor and to minimize the beta of the other factors.

3. The risk contribution approach.

This is similar to the previous approach, except that we consider risk contributions instead of betas.

Results $^{75}$ with these three approaches are shown in Table 24 . We notice that the portfolios vary greatly from one approach to another and may present higher tracking error volatilities than those obtained using the approach based on minimizing tracking error.

\footnotetext{
${ }^{74}$ See Appendix A.3 on Page 84.

${ }^{75}$ The portfolios are scaled in order to match the volatility of the original risk factors.
} 
Facts and Fantasies About Factor Investing

Table 24: Comparison of the three approaches

\begin{tabular}{|c|c|c|c|c|c|c|c|c|c|}
\hline Approach & \multicolumn{3}{|c|}{$\# 1$} & \multicolumn{3}{|c|}{$\# 2$} & \multicolumn{3}{|c|}{$\# 3$} \\
\hline Factor & 1 & 2 & 3 & 1 & 2 & 3 & 1 & 2 & 3 \\
\hline$x_{1}$ & 16.7 & 16.3 & $\overline{2.2}$ & 17.4 & 4.2 & 2.7 & $\overline{15.2}$ & 13.9 & 2.1 \\
\hline$x_{2}$ & 20.4 & 27.1 & -1.3 & 17.9 & 40.4 & -3.7 & 18.6 & 42.9 & -2.9 \\
\hline$x_{3}$ & 22.3 & 32.6 & 2.9 & 17.7 & 16.0 & 1.0 & 19.3 & 2.3 & 2.5 \\
\hline$x_{4}$ & 14.9 & -43.4 & -1.0 & 17.8 & -55.7 & 0.5 & 19.6 & -68.5 & -0.1 \\
\hline$x_{5}$ & 14.9 & -10.9 & 1.8 & 17.4 & -29.9 & 3.6 & 16.0 & -15.3 & 2.6 \\
\hline$x_{6}$ & 13.0 & -21.7 & -4.5 & 17.7 & 1.6 & -3.9 & 16.4 & 5.5 & -5.4 \\
\hline$\overline{\beta_{1}}$ & $\overline{97.1}$ & $\overline{2} \overline{5} . \overline{0}$ & $\overline{1} . \overline{5}$ & $\overline{9} \overline{7} . \overline{1}$ & 0.0 & 0.0 & $\overline{9} \overline{\overline{7}} . \overline{3}$ & -0.7 & ${ }^{-} \overline{0} . \overline{1}$ \\
\hline$\beta_{2}$ & 8.5 & 83.6 & 4.0 & 0.0 & 81.0 & 0.0 & 0.0 & 82.7 & 2.4 \\
\hline$\beta_{3}$ & 32.7 & 252.8 & 45.6 & 0.0 & 0.0 & 42.7 & 0.4 & 0.0 & 51.7 \\
\hline$\overline{\mathrm{R}} \overline{\mathrm{C}}_{1}^{\star}$ & 99.6 & $1 \overline{1} . \overline{0}$ & $\overline{9} . \overline{8}$ & $\overline{9} 9 . \overline{8}$ & 0.0 & 0.0 & $\overline{10} \overline{0} . \overline{0}$ & 0.0 & $\overline{0} . \overline{0}$ \\
\hline $\mathrm{RC}_{2}^{\star}$ & 0.3 & 91.2 & 25.3 & 0.0 & 100.5 & 0.0 & 0.0 & 100.0 & 0.0 \\
\hline $\mathrm{RC}_{3}^{\star}$ & 0.1 & -2.2 & 64.8 & 0.0 & 0.0 & 89.5 & 0.0 & 0.0 & 100.0 \\
\hline $\bar{\sigma}\left(\overline{\mathcal{F}}_{j}^{\star} \mid \overline{\mathcal{F}_{j}}\right)$ & 4.8 & $\overline{8} . \overline{6}$ & $\overline{1} . \overline{0}$ & $\overline{4} . \overline{8}$ & 9.2 & 1.1 & $\overline{4} . \overline{7}$ & 8.8 & $\overline{1} . \overline{0}$ \\
\hline$\sigma\left(\mathcal{F}_{j}^{\star}\right)$ & 20.0 & 15.0 & 1.0 & 20.0 & 15.0 & 1.0 & 20.0 & 15.0 & 1.0 \\
\hline
\end{tabular}

Remark 7 There is an issue concerning the dependence between risk factors. Indeed, there is no reason for the correlation matrix between the original risk factors to be preserved when we build replicated factors. For instance, if we consider the tracking error approach, the correlation matrix becomes:

$$
C=\left(\begin{array}{lll}
1.00 & & \\
0.02 & 1.00 & \\
0.02 & 0.32 & 1.00
\end{array}\right)
$$

whereas the original factors are independent ${ }^{76}$. This is a serious drawback, in particular when considering strategic asset allocation.

\subsubsection{Rebalancing frequency}

The choice of rebalancing frequency is another important topic when it comes to the design of factor indexes. The question is this: is it better to rebalance the portfolio every month, every quarter, every six months or every year? It is not an easy question to answer, because it depends on different parameters. For instance, increasing the frequency may have a considerable impact on the portfolio turnover and also on trading costs. This trade-off is particularly important for the WML factor. The rebalancing frequency also depends on the definition of risk factors. Some risk factors are structurally low-frequency. For example, this is the case of the HML factor, because the B/M statistic is not frequently revised.

\footnotetext{
${ }^{76}$ For the other approaches, the correlations are:

1. $\rho\left(\mathcal{F}_{1}^{\star}, \mathcal{F}_{2}^{\star}\right)=39 \%, \rho\left(\mathcal{F}_{1}^{\star}, \mathcal{F}_{3}^{\star}\right)=36 \%$ and $\rho\left(\mathcal{F}_{2}^{\star}, \mathcal{F}_{3}^{\star}\right)=70 \%$ for the sensitivity approach;

2. $\rho\left(\mathcal{F}_{1}^{\star}, \mathcal{F}_{2}^{\star}\right)=-3 \%, \rho\left(\mathcal{F}_{1}^{\star}, \mathcal{F}_{3}^{\star}\right)=5 \%$ and $\rho\left(\mathcal{F}_{2}^{\star}, \mathcal{F}_{3}^{\star}\right)=-40 \%$ for the beta approach;

3. $\rho\left(\mathcal{F}_{1}^{\star}, \mathcal{F}_{2}^{\star}\right)=-1 \%, \rho\left(\mathcal{F}_{1}^{\star}, \mathcal{F}_{3}^{\star}\right)=0 \%$ and $\rho\left(\mathcal{F}_{2}^{\star}, \mathcal{F}_{3}^{\star}\right)=9 \%$ for the risk contribution approach.
} 
Facts and Fantasies About Factor Investing

Table 25: Impact of the long-only constraint

\begin{tabular}{|c|c|c|c|c|c|c|c|c|c|}
\hline \multirow{2}{*}{$\begin{array}{l}\text { Approach } \\
\text { Factor }\end{array}$} & \multicolumn{3}{|c|}{ Tracking error } & \multicolumn{3}{|c|}{ Sensitivity } & \multicolumn{3}{|c|}{ Beta } \\
\hline & 1 & 2 & 3 & 1 & 2 & 3 & 1 & 2 & 3 \\
\hline$x_{1}$ & 8.5 & 0.0 & 0.8 & 16.7 & 13.4 & 1.4 & 17.4 & 0.0 & 0.0 \\
\hline$x_{2}$ & 6.4 & 0.0 & 0.0 & 20.4 & 22.4 & 0.0 & 17.9 & 40.3 & 0.0 \\
\hline$x_{3}$ & 40.5 & 57.0 & 2.9 & 22.3 & 26.9 & 2.0 & 17.7 & 18.2 & 1.7 \\
\hline$x_{4}$ & 23.6 & .0 & 0.0 & 14.9 & 0.0 & 0.0 & 17.8 & 0.0 & 0.0 \\
\hline$x_{5}$ & 3.2 & 0 & 0.5 & 14.9 & 0.0 & 1.2 & 17.4 & 0.0 & 2.8 \\
\hline$x_{6}$ & 19.5 & 0.0 & 0.0 & 13.0 & 0.0 & 0.0 & 17.7 & 0.0 & 0.0 \\
\hline$\overline{\beta_{1}}$ & $9 \overline{8} . \overline{5}$ & $68 . \overline{3}$ & $\overline{4} . \overline{7}$ & $\overline{9} \overline{7} .1$ & $\overline{6} \overline{8} . \overline{9}$ & 4.6 & $\overline{97} . \overline{1}$ & $\overline{6} \overline{6} . \overline{2}$ & $\overline{4} . \overline{2}$ \\
\hline$\beta_{2}$ & 2.8 & 34.2 & 1.9 & 8.5 & 31.3 & 1.4 & 0.0 & 31.1 & 0.4 \\
\hline$\beta_{3}$ & 26.7 & 193.7 & 13.1 & 32.7 & 91.3 & 12.9 & 0.0 & 1.5 & 11.6 \\
\hline$\overline{\mathrm{R}} \overline{\mathrm{C}}_{1}^{\star}$ & $\overline{10} \overline{0} . \overline{0}$ & $\overline{83} . \overline{9}$ & $8 \overline{9} . \overline{2}$ & $\overline{9} 9 . \overline{6}$ & $\overline{8} \overline{7} . \overline{7}$ & 90.7 & $-\overline{99} . \overline{8}$ & $\overline{8} \overline{1} . \overline{9}$ & $\overline{7} \overline{8} . \overline{7}$ \\
\hline $\mathrm{RC}_{2}^{\star}$ & 0.0 & 12.1 & 7.0 & 0.3 & 12.7 & 2.4 & 0.0 & 14.6 & -1.1 \\
\hline $\mathrm{RC}_{3}^{\star}$ & 0.0 & 2.1 & 4.1 & 0.1 & -0.5 & 6.1 & 0.0 & 0.0 & 8.7 \\
\hline $\bar{\sigma}\left(\overline{\mathcal{F}}_{j}^{\star-} \mid-\overline{\mathcal{F}_{j}}\right)$ & $\overline{3} . \overline{5}$ & $\overline{17} . \overline{2}$ & $\overline{1} . \overline{3}$ & 4.8 & $\overline{1} \overline{7} . \overline{6}$ & 1.3 & $\overline{4} . \overline{8}$ & $\overline{1} \overline{7} . \overline{6}$ & $\overline{1} . \overline{3}$ \\
\hline$\sigma\left(\mathcal{F}_{j}^{\star}\right)$ & 20.0 & 15.0 & 1.0 & 20.0 & 15.0 & 1.0 & 20.0 & 15.0 & 1.0 \\
\hline
\end{tabular}

\subsection{From long/short to long-only solutions}

Most products based on risk factors generally use a long-only portfolio, for three main reasons:

- The first reason is that factor investing primarily interests institutional investors, who distinguish between core and alternative investments. For their core investments, they use mainly long-only portfolios. In this perspective, factor investing is considered to be a new way to allocate their equity and bond portfolios ${ }^{77}$. This explains why the demand for long-only factor indexes is higher than that for long/short factor products ${ }^{78}$

- The second reason is the feasibility of factor indexes. A short portfolio is more complicated and costly to manage. It requires the use of derivatives and OTC products. Moreover, managing short sales in a systematic way can be dangerous.

- Some investors believe that a portfolio with a beta exposure and long/short strategies may be equivalent to a portfolio with long-only exposures.

However, by imposing long-only exposures, the nature of the risk factors may be significantly modified. To illustrate this problem, let us consider our previous example and replicate the factors in a long-only framework. The results are shown in Table 25 for three approaches: tracking error, sensitivity and beta. For the first factor, we obtain the same portfolio, because the long-only constraint is not restrictive. For the second and third factors, solutions are very different. They present a significant residual risk, they are concentrated and their tracking error volatility increases substantially. But the main drawback concerns the dependence between the replicated factors. For instance, we obtain the following correlation matrix in the case of the tracking error approach:

$$
C=\left(\begin{array}{lll}
1.00 & & \\
0.93 & 1.00 & \\
0.95 & 0.99 & 1.00
\end{array}\right)
$$

\footnotetext{
${ }^{77}$ Even if factor investing is also one important aspect of hedge fund strategies.

${ }^{78}$ In this case, investors prefer to consider active management.
} 
Facts and Fantasies About Factor Investing

Table 26: Correlation matrix of risk factors (US, 1995 - 2013)

\begin{tabular}{|c|c|c|c|c|c|c|c|}
\hline Factor & MKT & SMB & HML & WML & $\mathrm{SMB}^{+}$ & $\mathrm{HML}^{+}$ & $\mathrm{WML}^{+}$ \\
\hline Volatility & 15.9 & 12.1 & 11.5 & 18.8 & $\begin{array}{ll} & 20.4 \\
\end{array}$ & 17.7 & 18.4 \\
\hline MKT & 100 & & & & 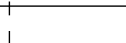 & & \\
\hline SMB & 25 & 100 & & & ? & & \\
\hline HML & -23 & -36 & 100 & & ! & & \\
\hline WML & -28 & 8 & -15 & 100 & i & & \\
\hline$\overline{\mathrm{S}} \overline{\mathrm{MB}} \overline{\mathrm{B}}^{+-}$ & $\overline{8} 7^{-}$ & $\overline{6} \overline{6}$ & -18 & $-\overline{2} 2 \overline{-}$ & $\overline{100}$ & & \\
\hline $\mathrm{HML}^{+}$ & 87 & 33 & 19 & -34 & 90 & 100 & \\
\hline $\mathrm{WML}^{+}$ & 89 & 53 & -29 & 7 & 92 & 81 & 100 \\
\hline
\end{tabular}

The replicated factors are now highly correlated ${ }^{79}$. Therefore, the long-only constraint introduces a new structure between the factors and imposes a solution, which is very different from the original risk model.

The other possibility for dealing with the problem is to notice that most risk factors found by academics are obtained by defining a long/short portfolio:

$$
\mathcal{F}_{j}=\mathcal{F}_{j}^{+}-\mathcal{F}_{j}^{-}
$$

In this case, we can just consider the long-only counterpart component $\mathcal{F}_{j}^{+}$. For instance, using the previous notations, we define the following three risk factors in the case of the Fama-French-Carhart model:

$$
\begin{aligned}
\mathrm{SMB}_{t}^{+} & =\frac{1}{3}\left(R_{t}(\mathrm{SV})+R_{t}(\mathrm{SN})+R_{t}(\mathrm{SG})\right) \\
\mathrm{HML}_{t}^{+} & =\frac{1}{2}\left(R_{t}(\mathrm{SV})+R_{t}(\mathrm{BV})\right) \\
\mathrm{WML}_{t}^{+} & =\frac{1}{2}\left(R_{t}(\mathrm{SW})+R_{t}(\mathrm{BW})\right)
\end{aligned}
$$

In Figure 24, we compare the performance of long/short risk factors to that of corresponding long-only risk factors using the data of Kenneth French ${ }^{80}$. The impact of the short portfolio is high, implying that the first component of these long-only risk factors is a beta or market component (see Figure 25). These results are not specific to the US market, but we observe the same conclusions for the other markets ${ }^{81}$.

The fact that the first risk factor $\mathcal{F}_{1}$ is the market factor for equities has an impact on the behavior of long-only portfolios compared with long/short portfolios. Let us consider a portfolio composed by $100 \%$ of market risk and $\alpha \%$ of long/short risk factors. We can compare this portfolio to a pure long-only portfolio composed by $(100-\alpha) \%$ of market risk and $\alpha \%$ of long-only risk factors. Whereas there is a large gap between long/short and long-only portfolios from a theoretical point of view, empirical results show that the two

\footnotetext{
${ }^{79}$ For the other approaches, the correlations are:

1. $\rho\left(\mathcal{F}_{1}^{\star}, \mathcal{F}_{2}^{\star}\right)=95 \%, \rho\left(\mathcal{F}_{1}^{\star}, \mathcal{F}_{3}^{\star}\right) 96 \%$ and $\rho\left(\mathcal{F}_{2}^{\star}, \mathcal{F}_{3}^{\star}\right)=95 \%$ for the sensitivity approach;

2. $\rho\left(\mathcal{F}_{1}^{\star}, \mathcal{F}_{2}^{\star}\right)=90 \%, \rho\left(\mathcal{F}_{1}^{\star}, \mathcal{F}_{3}^{\star}\right)=91 \%$ and $\rho\left(\mathcal{F}_{2}^{\star}, \mathcal{F}_{3}^{\star}\right)=77 \%$ for the beta approach.
}

${ }^{80}$ In order to facilitate the comparison, we use a logarithmic scale.

${ }^{81}$ See Pages 109-110. 
Figure 24: Performance of long/short and long-only risk factors (US, 1995 - 2013)

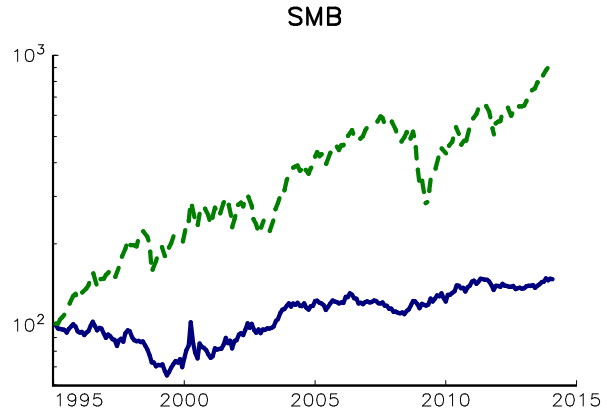

HML
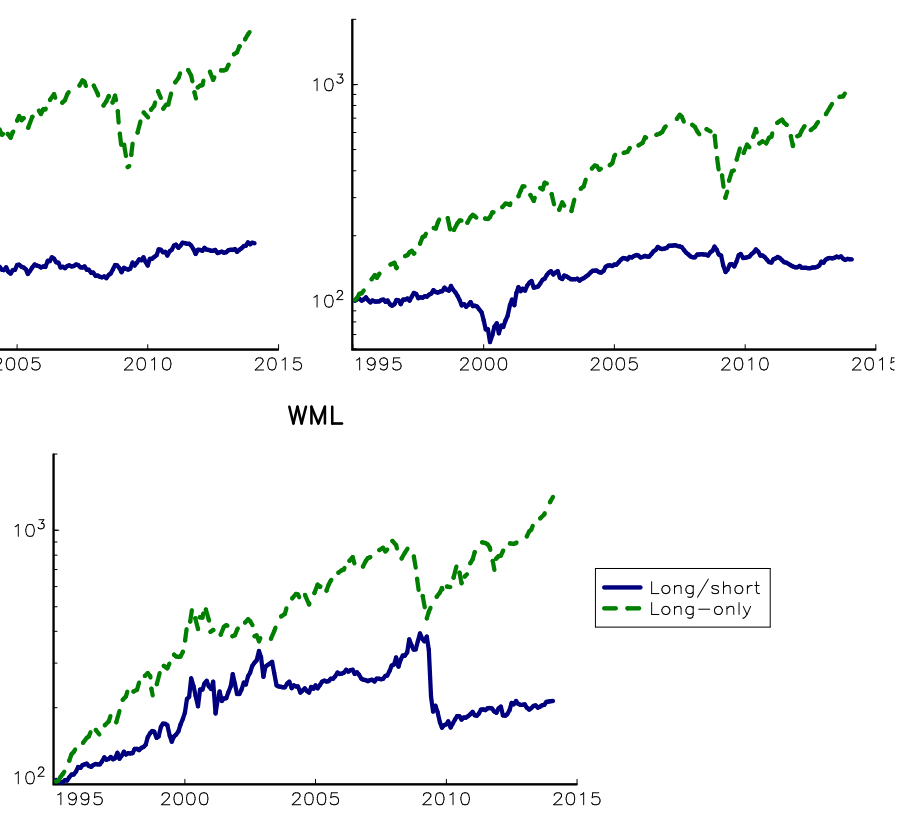

Figure 25: Performance of long-only risk factors (US, 1995 - 2013)

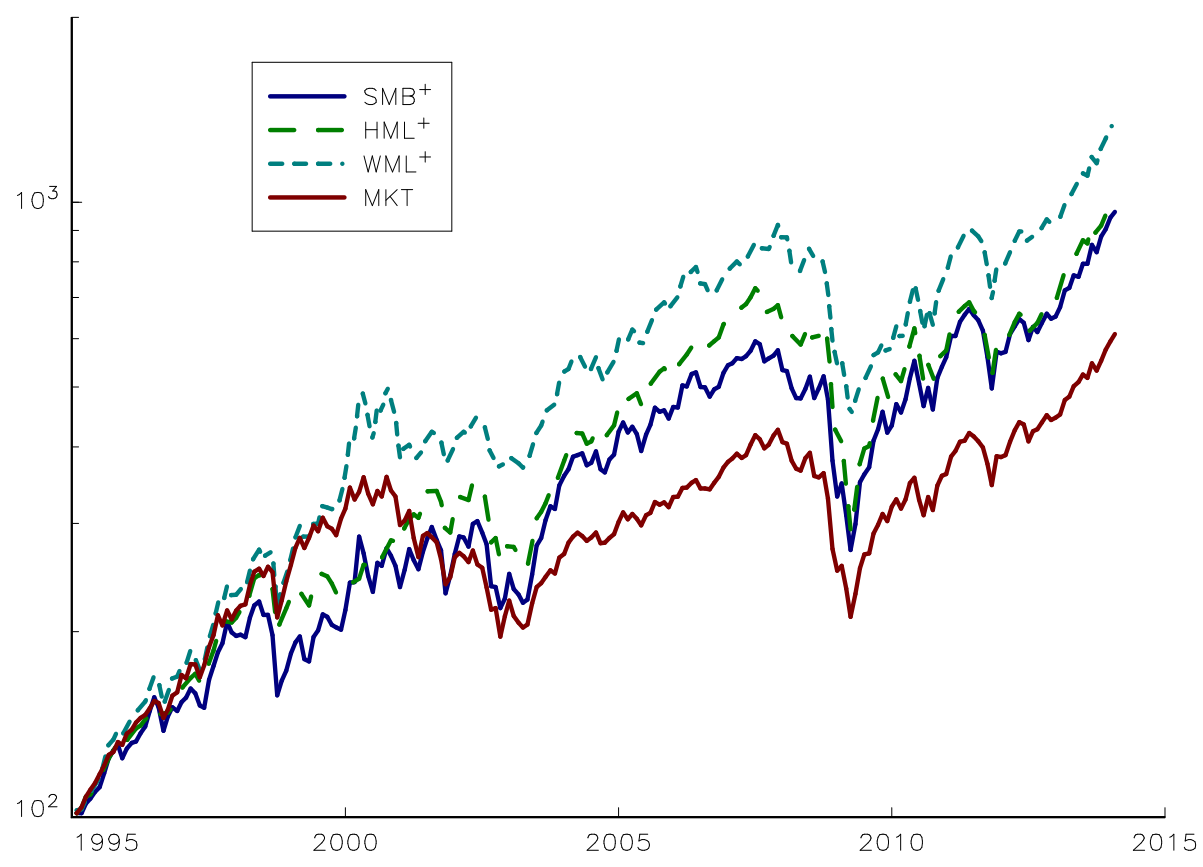


Facts and Fantasies About Factor Investing

Table 27: Statistics (in \%) of long/short and long-only portfolios (US, 1995 - 2013)

\begin{tabular}{|c|c|c|c|c|c|c|c|c|c|}
\hline Portfolio & $\# 0$ & $\# 1$ & $\# 2$ & $\# 3$ & $\# 4$ & $\# 5$ & $\# 6$ & $\# 7$ & $\# 8$ \\
\hline SMB & 0.0 & 10.0 & 20.0 & 0.0 & 20.0 & 30.0 & 0.0 & 50.0 & 100.0 \\
\hline HML & 0.0 & 10.0 & 20.0 & 20.0 & 20.0 & 30.0 & 0.0 & 50.0 & 100.0 \\
\hline WML & 0.0 & 10.0 & 0.0 & 20.0 & 20.0 & 30.0 & $\begin{array}{l}1 \quad 60.0 \\
1\end{array}$ & 50.0 & 100.0 \\
\hline$\mu\left(x^{ \pm}\right)$ & 9.9 & 11.2 & 11.1 & 12.0 & 12.5 & 13.7 & 13.5 & 16.0 & 21.0 \\
\hline$\mu\left(x^{+}\right)$ & & 11.0 & 11.2 & 11.5 & 12.1 & 13.2 & I 12.8 & 13.5 & 13.5 \\
\hline$\mu\left(x^{+} \mid x^{ \pm}\right)$ & & -0.2 & 0.0 & -0.5 & -0.4 & -0.5 & -0.8 & -2.5 & -7.5 \\
\hline$\sigma\left(x^{ \pm}\right)$ & 15.9 & 15.6 & 16.2 & 14.8 & 15.5 & 15.9 & 16.7 & 17.3 & 24.5 \\
\hline$\sigma\left(x^{+}\right)$ & & 16.2 & 16.5 & 16.1 & 16.9 & 17.7 & 17.0 & 18.1 & 18.1 \\
\hline$\sigma\left(x^{+} \mid x^{ \pm}\right)$ & & 1.7 & 1.0 & 3.5 & 3.5 & 5.2 & 8.6 & 8.0 & 18.1 \\
\hline$\rho\left(x^{+}, x^{ \pm}\right)$ & & 99.5 & 99.8 & 97.8 & 98.0 & 95.8 & $\begin{array}{l}\text { I } 86.9 \\
\end{array}$ & 89.8 & 67.8 \\
\hline
\end{tabular}

portfolios may be highly correlated. In Table 27 , we consider different portfolios based on the risk factors MKT, SMB, HML and WML. For instance, the composition of the long/short portfolio \#1 is $100 \%$ of the MKT factor, $10 \%$ of the SMB factor, $10 \%$ of the HML factor and $10 \%$ of the WML factor, whereas the composition of the long-only portfolio \#1 is $70 \%$ of the MKT factor, $10 \%$ of the $\mathrm{SMB}^{+}$factor, $10 \%$ of the $\mathrm{HML}^{+}$factor and $10 \%$ of the $\mathrm{WML}^{+}$ factor. In each case, we report the composition in SMB, HML and WML risk factors, the annual returns $\mu\left(x^{ \pm}\right)$and $\mu\left(x^{+}\right)$of the long/short $x^{ \pm}$and long-only $x^{+}$portfolios, the excess return $\mu\left(x^{+} \mid x^{ \pm}\right)$of the long-only portfolio compared to the long/short portfolio, the annual volatilities $\mu\left(x^{ \pm}\right)$and $\mu\left(x^{+}\right)$of the long/short and long-only portfolios, the tracking error volatility $\sigma\left(x^{+} \mid x^{ \pm}\right)$and the correlation $\rho\left(x^{+}, x^{ \pm}\right)$between the long/short and long-only portfolios. When risk factor exposure is lower, the tracking error volatility between the long/short and long-only portfolios is relatively low and the correlation is high (over 95\%). This is not the case when the portfolio is highly exposed to the risk factors or when the long/short portfolio is leveraged ${ }^{82}$. For instance, the tracking error volatility is greater than $8 \%$ in the cases $\# 6, \# 7$ and \#8. For the other regions, results are similar ${ }^{83}$. However, these figures should be interpreted with caution. The role of shorting depends on the nature of the risk factor. For instance, shorting increases the profit of momentum strategies, but long portfolios continue to capture significant profits (Israel and Moskowitz, 2012). Moreover, with long-only momentum portfolios, investors avoid momentum crashes described by Daniel and Moskowitz (2013). However, the nature of some risk factors or anomalies changes in a long-only format. This is the case of the Betting-Against-Beta (or $\mathrm{BAB})$ risk factor, because it is difficult to reconcile the theory with a long-only format ${ }^{84}$.

\subsection{Capacity constraints of long-term investors}

The empirical works on risk factors generally assume that the investor has no transaction costs or capacity constraints. However, the profitability of the risk factors may be influenced by these trading frictions, in particular when the turnover is high. For instance, Lesmond et al. (2004) find that momentum profits are eroded by trading costs due to turnover costs,

\footnotetext{
${ }^{82}$ These results suggest that some risk factors can be used in two different ways: long-only risk factors can be considered in core portfolios, whereas long/short risk factors are more appropriate to define alpha or alternative portfolios.

${ }^{83}$ See Tables 54, 55, 56 and 57 on Page 98.

${ }^{84}$ The expected return of an asset remains an increasing function of the asset's beta.
} 
Facts and Fantasies About Factor Investing

but also by the illiquidity of the assets traded ${ }^{85}$. Korajczyk and Sadka (2004) estimate that break-even fund sizes that lead long-only momentum strategies to zero abnormal returns, are between $\$ 2$ and $\$ 5$ billion (relative to December 1999 market capitalization). These results contrast with those recently found by Frazzini et al. (2012):

"Assessing standard long/short strategies commonly used in the literature we find that size, value, and momentum survive transactions costs at fairly substantial sizes, but that short-term reversals do not. Break-even fund sizes for the Fama and French long/short factors of size, value, and momentum are 103, 83, and 52 billion dollars among U.S. securities, respectively, and 156, 190, and 89 billion dollars globally. Short-term reversal strategies, on the other hand, do not survive transactions costs at sizes greater than $\$ 9$ billion in the U.S. or $\$ 13$ billion globally. Moreover, a combination of value and momentum has even higher capacity (\$100 billion U.S., $\$ 177$ billion globally) due to netting of trades across negatively correlated positions."

Novy-Marx and Velikov (2014) confirm that most anomalies with low turnover continue to generate statistically significant alpha. They also observe that the asset universe and weighting scheme have an impact on profitability. For instance, they estimate that transaction costs for equally-weighted risk factors are two to three times higher than those for value-weighted risk factors.

The previous results help us to understand the possible magnitude of transaction costs and market impact. However, the issue for long-term investors is not really the break-even size. Indeed, these attempt to estimate transaction costs in a relative manner. The questions are therefore: do trading costs eliminate the alpha of the strategy and what proportion of alpha disappears by taking into account transaction costs? For instance, a strategy which has a gross annual return of $5 \%$ remains profitable if transaction costs are $1 \%$. This first strategy is dominated by a second strategy which has a gross annual return of $10 \%$ and remains profitable if transaction costs are $5 \%$. Indeed, the net return is respectively $4 \%$ and $5 \%$. However, a long-term investor does not reason like that, but instead will look at why the costs in absolute way terms, and not with respect to the gross expected return. This explains why institutional investors have been shifting a large portion of their investment from active to passive management over the last 20 years. They do not want to pay high fees or costs even if the (promised) expected return is attractive. Therefore, it is unlikely that they will invest in the two previous strategies, because transaction costs are too high. Generally, institutional investors have implicit annual transaction cost thresholds. Beyond this limit, they do not consider the strategy, even if expected returns are much higher than transaction costs. This is particularly true for core investments. In Figure 26, we show the relationship between turnover and transaction costs. We assume that they include brokerage fees (BF) and possibly tax fees (TF). In a liquid universe (S\&P 500, MSCI Europe), investors generally assume that brokerage fees are equal to $1 \mathrm{bp}$ for long-only portfolios, and between 5 and $10 \mathrm{bps}$ for long/short portfolios. In the case of MSCI Europe, we have to add tax fees due to financial transaction tax (FTT) on buy-side orders ${ }^{86}$. These transaction costs do not include market impacts, which may be substantial in the case of a large universe of stocks or when the managed assets are high.

\footnotetext{
${ }^{85}$ They found that the momentum strategy is "heavily weighted toward high cost stocks".

${ }^{86}$ We estimate that it costs between 15 and 20 bps in average.
} 
Figure 26: Relationship between turnover and transaction costs

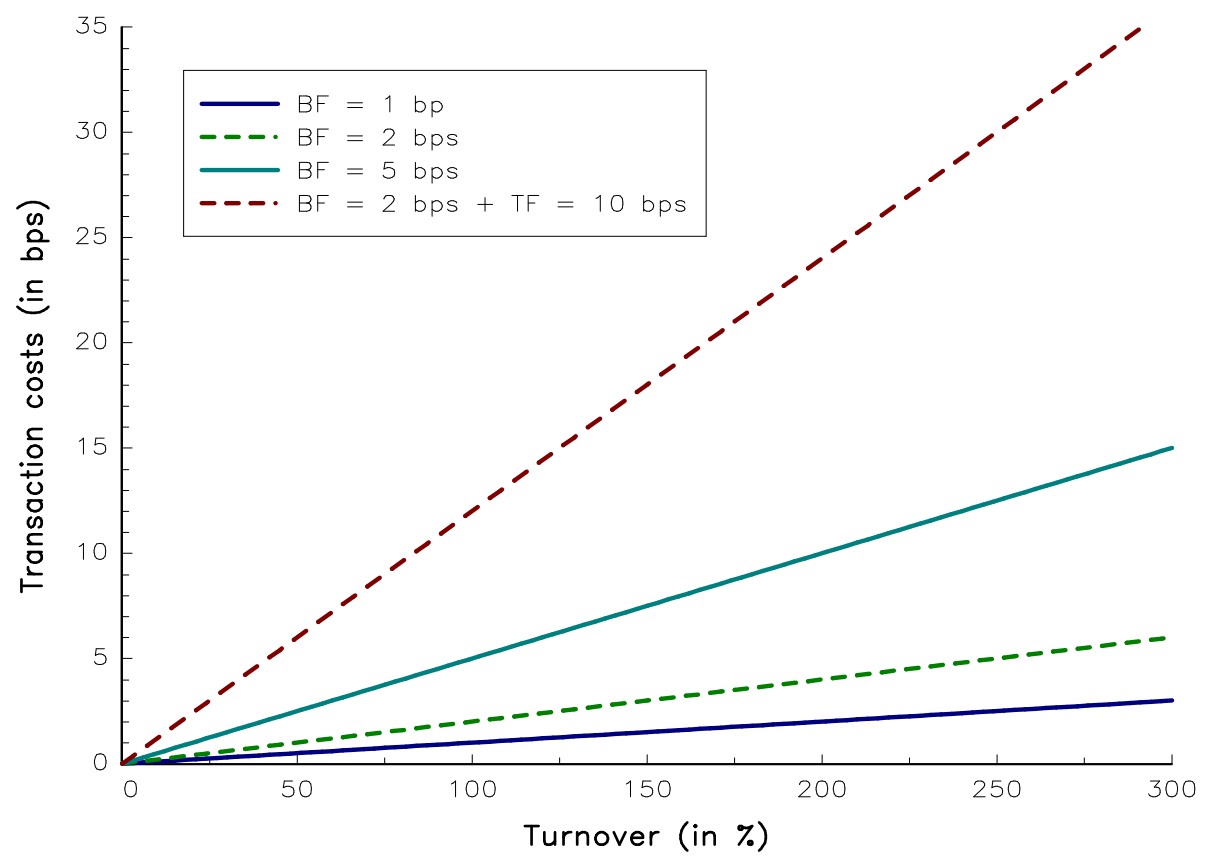

\section{Portfolio allocation with risk factors}

One of the big challenges with factor investing is portfolio construction. Generally, we oppose allocation based on asset classes and allocation based on risk factors. This is particularly true for strategic asset allocation (or long-term investing). Supporters of factor investing think that strategic asset allocation based on asset classes is an issue, because:

1. It is difficult to estimate their risk premia;

2. Correlations between asset classes vary over time and are not stable;

3. We don't know if it is the right level of aggregation.

The first point concerns the relationship between economic risks and the return on financial assets (Eychenne et al., 2011). From a theoretical point of view, it is recognized that monetary policy has a big impact on the return on the risk-free assets, but not on the return on other assets. The experience of the last few years shows that this is no longer the case. The second point concerns the time-dependency between asset returns, in particular within and between equities and bonds. For instance, the decoupling theory, which stated that emerging economies would continue to grow, has been largely invalidated. The 2008 financial crisis illustrated that diversified assets, which presented a low correlation with equities during normal periods, may be highly correlated with them during a crisis. The third point questions the top-down approach of the allocation. Because asset classes are exposed to independent risk premia, supporters of factor investing think that strategic asset allocation based on risk factors is easier and more robust. In what follows, we will show that it is not straightforward and some difficulties appear in practice. 


\subsection{A magical world}

The main benefit of factor investing is the diversification effect. By their very nature, risk factors are mutually independent. This implies that the Sharpe ratio of an equally-weighted portfolio of $m$ risk factors is equal to the square root of the number of factors times the average Sharpe ratio of risk factors:

$$
\mathrm{SR}(x)=\sqrt{m} \times \overline{\operatorname{SR}(\mathcal{F})}
$$

This relationship is shown in Figure 27. In this context, we can obtain a very high Sharpe ratio by combining a large number of risk factors. For instance, if $m$ is equal to 9 , the average Sharpe ratio is multiplied by a factor of three!

Figure 27: The arithmetic of the Sharpe ratio

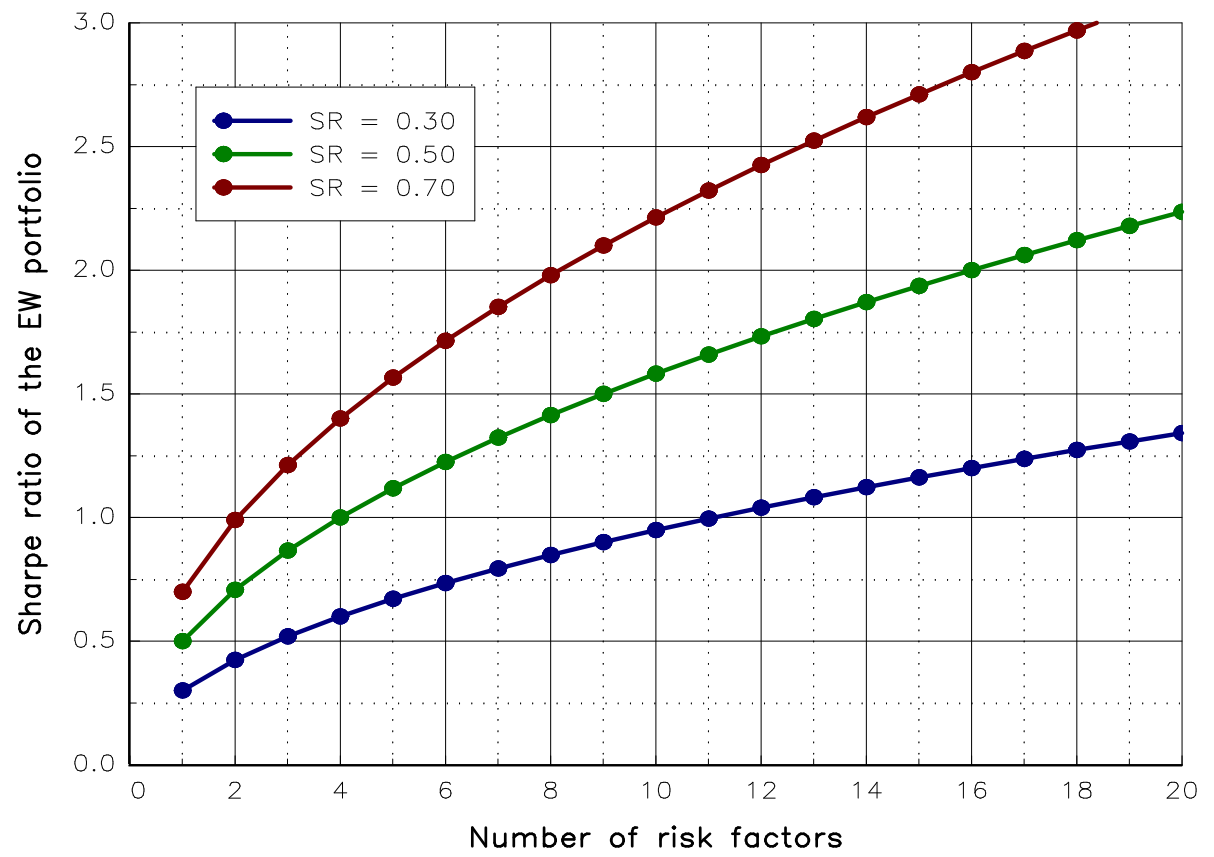

To illustrate the strength of this result, we consider a universe of five factors: SMB, HML, WML, BAB and QMJ. For each region, we consider an equally-weighted portfolio of these 5 long/short risk factors. The leverage of the portfolio is calibrated in order to obtain an ex-ante volatility equal to $10 \%$ and the portfolio is rebalanced every month ${ }^{87}$. Results are reported in Table 28. If we compare these figures with those obtained by the market portfolio, we notice that the risk/return profile is highly improved (more return and less volatility). Moreover, the maximum drawdown is divided by a factor of three with respect to the maximum drawdown of the MKT factor. We also notice that the diversification across the regions is higher for the $5 \mathrm{~F}$ portfolio than for the MKT portfolio. For instance,

\footnotetext{
${ }^{87} \mathrm{We}$ can express the monthly return of the $5 \mathrm{~F}$ portfolio as follows:

$$
R(x)=R_{f}+\ell \cdot R^{ \pm}(x)
$$

where $R^{ \pm}(x)$ is the return of the unfunded long/short 5F portfolio and $\ell$ is the level of leverage in order to achieve a $10 \%$ volatility target. $\ell$ is respectively equal to 1.8 for Asia Pacific, 1.6 for Europe, 1.6 for Japan, 1.5 for North America and 1.4 for US.
} 
Facts and Fantasies About Factor Investing

Table 28: Performance of the 5F and MKT portfolios (1995 - 2013)

\begin{tabular}{|c|c|c|c|c|c|c|c|c|c|c|}
\hline \multirow[t]{2}{*}{ Statistic } & \multicolumn{2}{|c|}{ Asia Pacific } & \multicolumn{2}{|c|}{ Europe } & \multicolumn{2}{|c|}{ Japan } & \multicolumn{2}{|c|}{ North America } & \multicolumn{2}{|c|}{ US } \\
\hline & $5 \mathrm{~F}$ & MKT & $5 \mathrm{~F}$ & MKT & $5 \mathrm{~F}$ & MKT & $5 \mathrm{~F}$ & MKT & $5 \mathrm{~F}$ & MKT \\
\hline & & & 14.3 & & 6.8 & 0.6 & 11.2 & & 0 & 9.9 \\
\hline & & & & & & & & & & .9 \\
\hline $\operatorname{SR}(x \mid r)$ & 04 & 0.29 & 4 & 0. & 0.40 & -0.12 & & & ). & 0.45 \\
\hline $\operatorname{MDD}(x)$ & 21.6 & 60.2 & 19.9 & 58.9 & 21.4 & 58.1 & 17.7 & 50.9 & 21.4 & 50.4 \\
\hline
\end{tabular}

the empirical correlation matrix between MKT factors is as follows:

$$
C=\left(\begin{array}{ccccc}
1.00 & & & & \\
0.78 & 1.00 & & & \\
0.56 & 0.51 & 1.00 & & \\
0.77 & 0.84 & 0.50 & 1.00 & \\
0.76 & 0.83 & 0.49 & 1.00 & 1.00
\end{array}\right)
$$

We verify that these correlations are higher than those obtained with $5 \mathrm{~F}$ portfolios:

$$
C=\left(\begin{array}{ccccc}
1.00 & & & & \\
0.48 & 1.00 & & & \\
0.56 & 0.38 & 1.00 & & \\
0.43 & 0.74 & 0.34 & 1.00 & \\
0.43 & 0.74 & 0.38 & 0.98 & 1.00
\end{array}\right)
$$

For example, the cross-correlation between the Europe and US MKT factors is $83 \%$, whereas it is $74 \%$ between the Europe and US $5 \mathrm{~F}$ portfolios. This implies that if we consider a balanced allocation between the four regions (Asia Pacific, Europe, Japan and North America), the diversification benefit ${ }^{88}$ is higher for the $5 \mathrm{~F}$ portfolio than for the MKT portfolio (see Table 29 and Figure 29).

Table 29: Performance of equally-weighted 5F and MKT global portfolios (1995 - 2013)

\begin{tabular}{|c|cc|}
\hline Statistic & $5 \mathrm{~F}$ & MKT \\
\hline$\mu(x)$ & 13.8 & 7.7 \\
$\sigma(x)$ & 10.0 & 16.0 \\
$\operatorname{SR~}(x \mid r)$ & 1.10 & 0.31 \\
$\operatorname{MDD}(x)$ & 23.3 & 53.4 \\
\hline
\end{tabular}

Remark 8 The cash of the previous $5 F$ portfolios is invested in the risk-free asset. We can also assume that it is invested in the market risk factor. In this case, the monthly returns are equal to:

$$
R(x)=R_{m}+\ell \cdot R^{ \pm}(x)
$$

Results are given in Table 30. We observe that the Sharpe ratio is improved in comparison to the previous $5 F$ portfolio, except for Asia Pacific and Japan. Moreover, the drawdown of the MKT risk factor is reduced by $10 \%$ on average. Long/short risk factors can then be used in two different ways:

\footnotetext{
${ }^{88}$ In Figure 28, we report the eigenvalues of the risk factors for the global portfolios. We verify that the first eigenvalue is low and close to $20 \%$. We also observe that the explained variance decreases slowly with the number of principal components, meaning that the diversification gain may be high.
} 
Figure 28: Eigenvalues of the risk factors

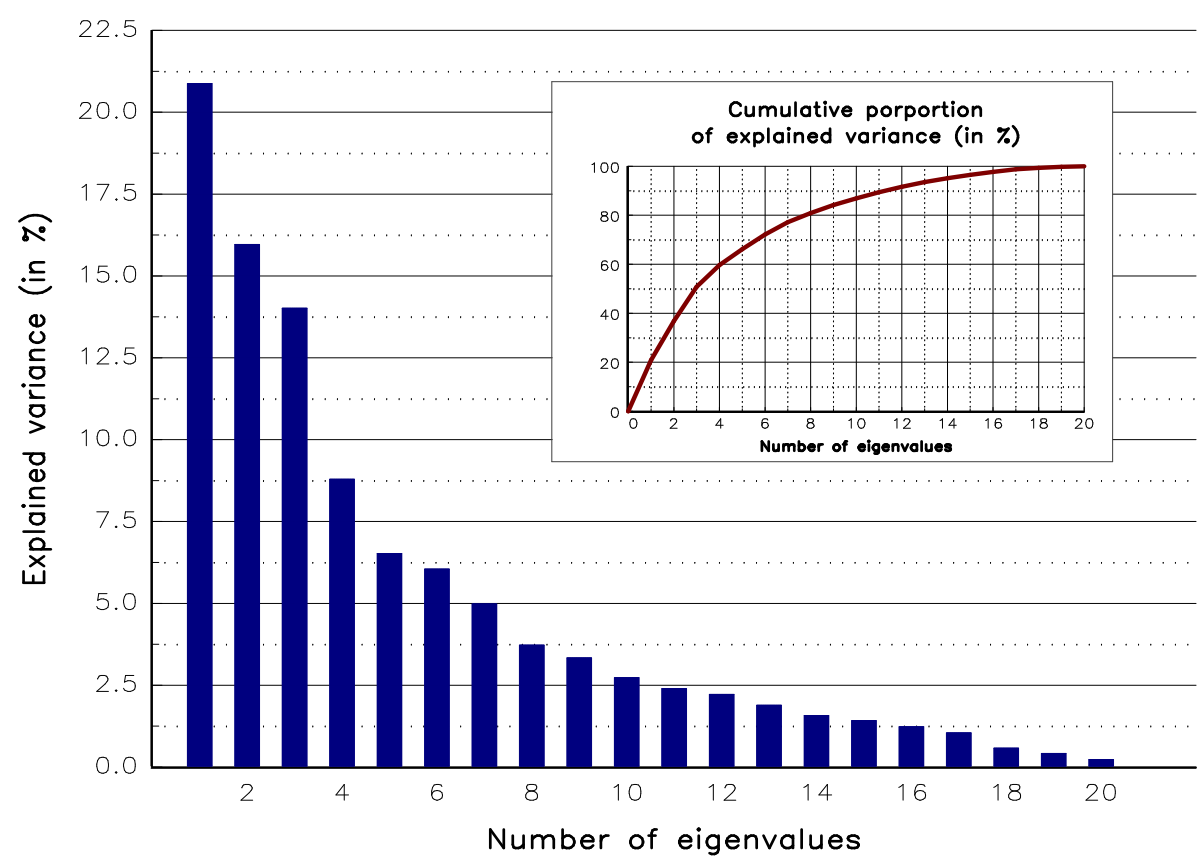

Figure 29: Performance of equally-weighted 5F and MKT global portfolios

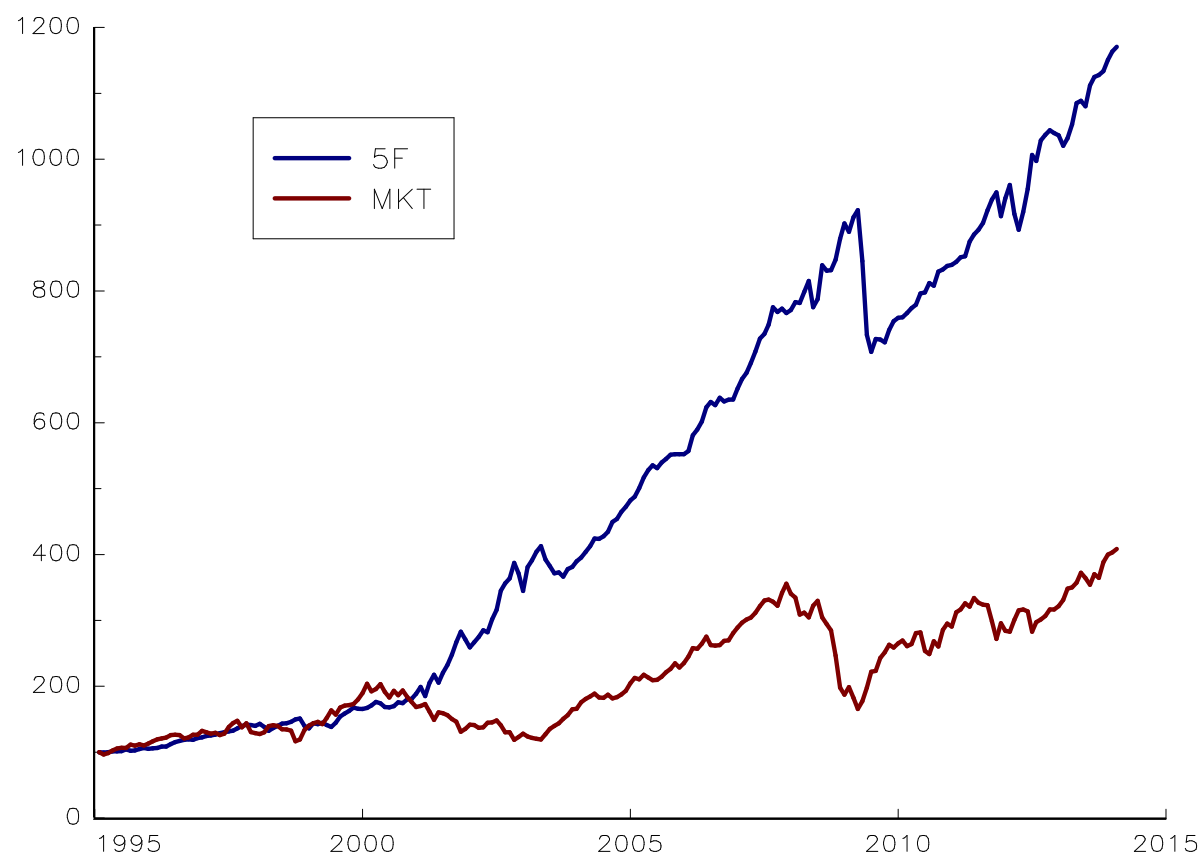


Facts and Fantasies About Factor Investing

1. They can be considered to build an absolute return portfolio with a limited drawdown;

2. They can also be used to complement a market exposure in order to significantly improve the Sharpe ratio of the market portfolio ${ }^{89}$.

Table 30: Performance of the MKT + 5F portfolios $(1995$ - 2013)

\begin{tabular}{|c|cccccc|}
\hline Statistic & Asia Pacific & Europe & Japan & North America & US & Global \\
\hline$\mu(x)$ & 20.9 & 22.2 & 5.2 & 19.9 & 18.5 & 20.1 \\
$\sigma(x)$ & 21.1 & 16.8 & 17.8 & 14.6 & 14.0 & 14.2 \\
SR $(x \mid r)$ & 0.85 & 1.16 & 0.13 & 1.18 & 1.12 & 1.22 \\
MDD $(x)$ & 55.3 & 53.6 & 55.9 & 49.6 & 46.1 & 45.5 \\
\hline
\end{tabular}

The implementation of long/short strategies are not obvious for institutional investors, because they require the use of leverage. Let us now consider the constrained case with no short or leveraged exposures. In table 31, we report the performance of the equally-weighted long-only $5 \mathrm{~F}$ portfolio. This portfolio improves the risk/return profile in comparison to a long exposure to market risk factors. For instance, the Sharpe ratio is increased by $66 \%$ and $114 \%$ for Asia Pacific and Europe. For North America and US, the level of the Sharpe ratio is equivalent to this, obtained by the long/short $5 \mathrm{~F}$ portfolio. Nevertheless, we notice that the long-only $5 \mathrm{~F}$ does not reduce the drawdown observed for the market portfolio. Despite this drawback, a diversified long-only strategy based on risk factors remains attractive as shown by the backtest of the global portfolio in Figure 30 .

Table 31: Performance of the long-only 5F portfolios (1995 - 2013)

\begin{tabular}{|c|cccccc|}
\hline Statistic & Asia Pacific & Europe & Japan & North America & US & Global \\
\hline$\mu(x)$ & 13.4 & 15.5 & 3.1 & 15.8 & 14.3 & 11.3 \\
$\sigma(x)$ & 21.9 & 16.9 & 18.1 & 15.2 & 16.3 & 15.6 \\
SR $(x \mid r)$ & 0.48 & 0.75 & 0.02 & 0.86 & 0.71 & 0.54 \\
$\operatorname{MDD}(x)$ & 60.5 & 58.1 & 58.1 & 52.5 & 55.3 & 54.5 \\
\hline
\end{tabular}

\subsection{Optimal allocation}

In this paragraph, we will develop the optimal solution of risk factor portfolios. For this, we will consider the Markowitz framework for strategic asset allocation. We will show that the optimal portfolio differ if we consider long/short or long-only risk factors.

\subsubsection{Long/short portfolios}

Following Roncalli (2013), we can write the Markowitz approach as a quadratic utility optimization problem:

$$
x^{\star}(\phi)=\arg \max x^{\top} \mu(\mathcal{F})-\frac{\phi}{2} x^{\top} \Omega x
$$

\footnotetext{
${ }^{89}$ In this case, the main benefit is to increase the performance, but not to reduce the volatility or the risk of the long portfolio. Contrary to some accepted ideas, a long/short exposure on risk factors can then not be used to hedge an exposure on the market.
} 
Figure 30: Performance of long-only 5F and MKT global portfolios

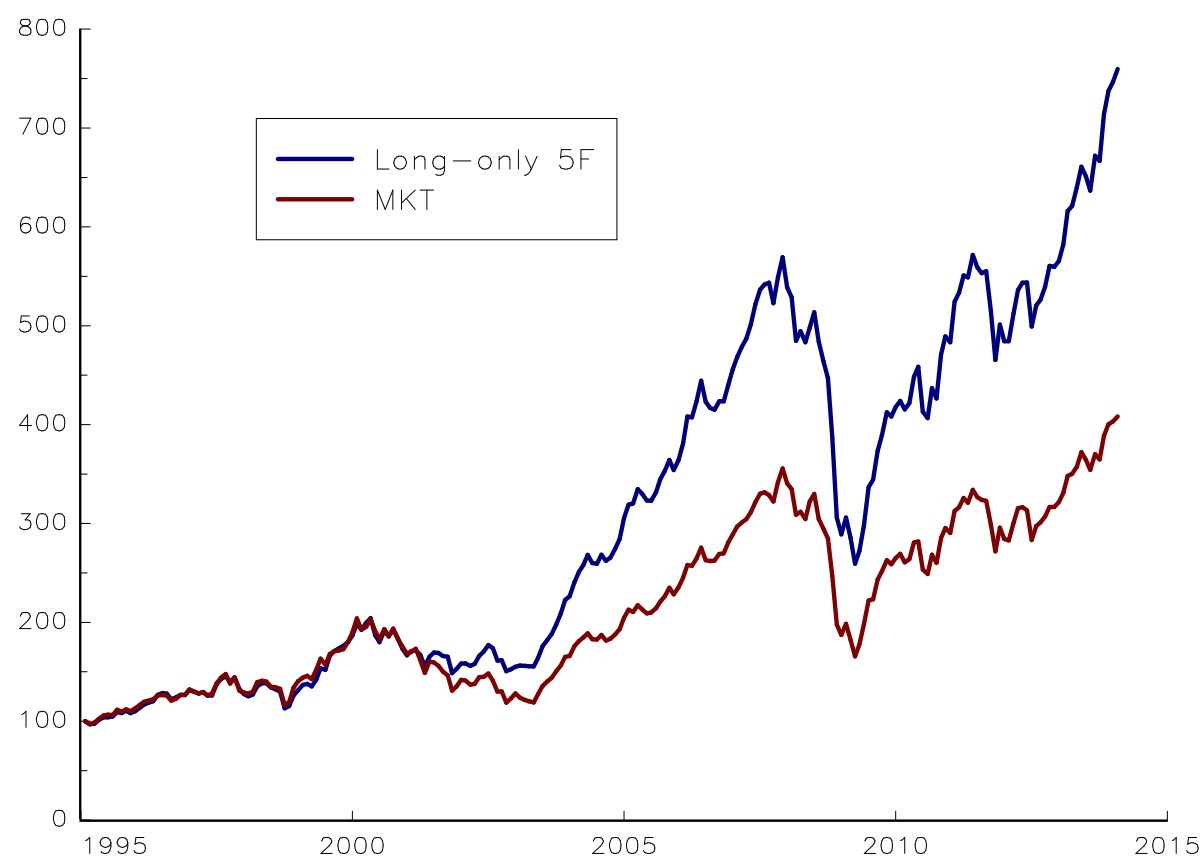

where $x=\left(x_{1}, \ldots, x_{m}\right)$ are the weights of long/short risk factors in the portfolio, $\mu(\mathcal{F})$ is the expected return on risk factors and $\Omega$ is the associated covariance matrix. $\phi$ can be interpreted as a risk-aversion parameter. We deduce that the solution satisfying the first-order condition is ${ }^{90}$ :

$$
x^{\star}(\phi)=\frac{1}{\phi} \Omega^{-1} \mu(\mathcal{F})
$$

We assume that the nature of the long/short risk factors implies that they are independent, meaning that $\Omega=\operatorname{diag}\left(\sigma^{2}\left(\mathcal{F}_{1}\right), \ldots, \sigma^{2}\left(\mathcal{F}_{m}\right)\right)$. Moreover, in the case of a long/short portfolio, $\phi$ is a free parameter to scale the leverage of the portfolio. This implies that the optimal solution has the following form:

$$
x_{j}^{\star} \propto \frac{\mu\left(\mathcal{F}_{j}\right)}{\sigma^{2}\left(\mathcal{F}_{j}\right)}
$$

The optimal weight for the $j^{\text {th }}$ factor is therefore proportional to its expected return divided by its variance. In Figure 31, we have reported the level curves $\kappa=\sigma^{-2} \mu$. Along a given curve, we have no preference for one point over another. For instance, a risk factor with $\mu\left(\mathcal{F}_{j}\right)=1 \%$ and $\sigma=10 \%$ has the same allocation as another risk factor with $\mu\left(\mathcal{F}_{j}\right)=4 \%$ and $\sigma=20 \%$. If we consider two risk factors belonging to two distinct level curves $\kappa_{1}$ and $\kappa_{2}$, the ratio of their weights is $\kappa_{1} / \kappa_{2}$. For example, the weight of a risk factor with $\mu\left(\mathcal{F}_{j}\right)=4 \%$ and $\sigma=9 \%$ is approximately 5 times the weight of a risk factor with $\mu\left(\mathcal{F}_{j}\right)=1 \%$ and $\sigma=10 \%$.

Remark 9 Portfolio (21) may be different than portfolio (20), because the cross-correlations may not be equal to zero. It is particularly true from an ex-post analysis. However, we have

\footnotetext{
${ }^{90}$ In fact, the optimal weights correspond to the positive part of the expression, because a short exposure on a risk factor does not make sense. This constraint is equivalent to select risk factors with a positive risk premium.
} 
to be careful by considering a correlated matrix of risk factors, because these risk factors are generally built in order to be independent.

Figure 31: Level curves of optimal portfolios

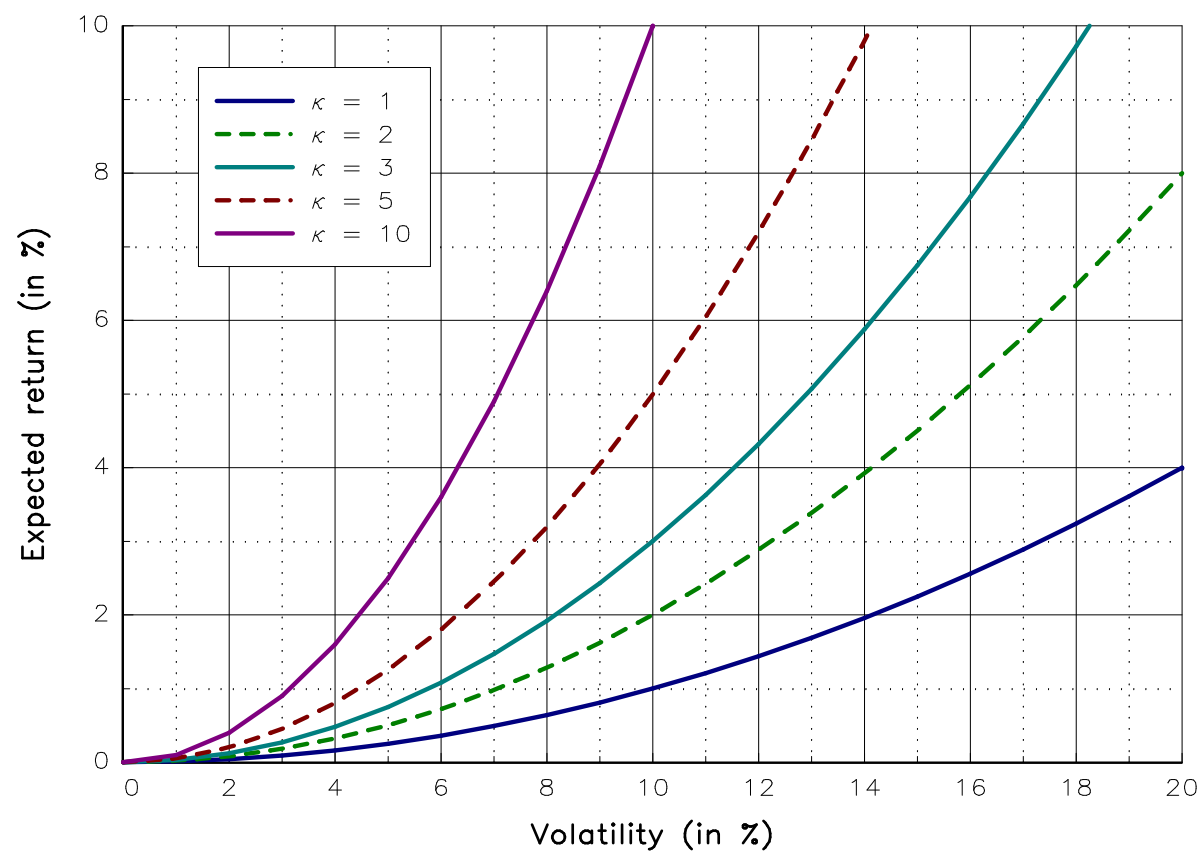

There are two special cases which are very interesting:

1. If we assume that expected returns and volatilities are the same for all the factors, the optimal allocation corresponds to the equally-weighted (or EW) portfolio:

$$
x_{j}^{\star}=\frac{1}{m}
$$

2. If we assume that the risk factors have the same Sharpe ratio, the optimal allocation is then the equal risk contribution (or ERC) portfolio defined by Maillard et al. (2010):

$$
x_{j}^{\star} \propto \frac{1}{\sigma\left(\mathcal{F}_{j}\right)}
$$

In Table 32, we compare the EW, ERC and MVO global portfolios ${ }^{91}$. We notice that the Sharpe ratio increases if we relax an extra assumption, but there is no relationship between the drawdown and the set of assumptions. On page 100, we have reported other results regarding the different regions. We show that they are heterogeneous, and it is difficult to conclude that one method dominates largely the others.

\footnotetext{
${ }^{91}$ We have the following correspondence: EW corresponds to Equation (22), ERC corresponds to Equation (23), $\mathrm{MVO}^{\star}$ corresponds to Equation (21) and MVO corresponds to Equation (20).
} 
Facts and Fantasies About Factor Investing

Table 32: Performance and weights of long/short 5F global portfolios (1995 - 2013)

\begin{tabular}{|cc|cccc|}
\hline & & EW & ERC & MVO $^{\star}$ & MVO \\
\hline \multirow{5}{*}{ Statistic } & $\mu(x)$ & 13.8 & 14.0 & 14.7 & 15.3 \\
& $\sigma(x)$ & 10.0 & 10.0 & 10.0 & 10.0 \\
& SR $(x \mid r)$ & 1.10 & 1.11 & 1.19 & 1.24 \\
& MDD $(x)$ & 23.3 & 19.8 & 19.7 & 21.9 \\
\hline \multirow{5}{*}{ Weight } & SMB & 20.0 & 25.1 & 0.0 & 0.0 \\
& HML & 20.0 & 22.6 & 31.1 & 46.3 \\
& WML & 20.0 & 12.8 & 13.7 & 20.6 \\
& BAB & 20.0 & 18.2 & 31.9 & 26.6 \\
& QMJ & 20.0 & 21.4 & 23.4 & 6.5 \\
\hline
\end{tabular}

\subsubsection{Long-only portfolios}

In the case of long-only risk factors, the optimization problem becomes:

$$
\begin{aligned}
& x^{\star}=\arg \max x^{\top}\left(\mu\left(\mathcal{F}^{+}\right)-r \mathbf{1}\right)-\frac{\phi}{2} x^{\top} \Omega_{+} x \\
& \text { u.c. } \quad\left\{\begin{array}{l}
\mathbf{1}^{\top} x=1 \\
x \geq \mathbf{0}
\end{array}\right.
\end{aligned}
$$

where $\mu\left(\mathcal{F}^{+}\right)$and $\Omega_{+}$are the vector of expected returns and the covariance matrix of longonly risk factors $\mathcal{F}^{+}$. In Appendix A.6.2 on Page 87, we show that the tangency portfolio has the following form:

$$
x_{j}^{\star} \propto \frac{\max \left(\mu\left(\mathcal{F}_{j}^{+}\right)-r-\beta_{j} \lambda^{\star}, 0\right)}{\left(\tilde{\sigma}_{j}^{+}\right)^{2}}
$$

where $\beta_{j}$ is the beta of the long-only risk factor $\mathcal{F}_{j}^{+}$with respect to the market factor and $\tilde{\sigma}_{j}^{+}=\sqrt{\sigma^{2}\left(\mathcal{F}_{j}^{+}\right)-\beta_{j}^{2} \sigma^{2}\left(R_{m}\right)}$ is the idiosyncratic volatility of the long-only risk factor $\mathcal{F}_{j}^{+}$. $\lambda^{\star}$ is a constant parameter, which corresponds to a weighted average of risk premia. This implies that $\beta_{j} \lambda^{\star}$ is a risk premium penalization for the long-only risk factor $\mathcal{F}_{j}^{+}$. Because we have $\mu\left(\mathcal{F}_{j}^{+}\right)-r=\alpha_{j}^{+}+\beta_{j}\left(\mu_{m}-r\right)$ where $\alpha_{j}^{+}$is the alpha of the long-only risk factor $\mathcal{F}_{j}^{+}$, we deduce that the risk premium component coming from alpha is better than the risk premium component coming from beta. Another important parameter is the idiosyncratic volatility. Finally, we deduce that optimal long-only risk factors share the following characteristics:

- High alpha;

- Low beta if the market risk premium is low, but high beta if the market risk premium is high;

- Low idiosyncratic volatility.

In practice, optimal solutions are concentrated. For instance, if we consider the global portfolio, the optimal solution is composed only by WML and BAB long-only risk factors. This is why we have to consider some weight constraints in order to diversify the portfolio.

Remark 10 In the previous analysis, we assumed that the objective of the investor is to maximize the Sharpe ratio of its risk factor portfolio. However, the investor may pursue another objective. For instance, the investor may have an objective in terms of tracking 
error if he would like to replace or complement a passive market portfolio by an allocation between risk factors. In this case, we show that the optimal portfolio has the following form ${ }^{92}$ :

$$
x_{j}^{\star} \propto \frac{\alpha_{j}^{+}+\left(1-\beta_{j}\right) r+\tilde{\lambda}_{j}^{\star}}{\left(\tilde{\sigma}_{j}^{+}\right)^{2}}
$$

where $\tilde{\lambda}_{j}^{\star}$ is the gain or cost on the risk factor $\mathcal{F}_{k}^{+}$due to long-only constraints. The allocation in the market risk factor is the complementary allocation of the other risk factors.

\subsection{Robustness}

One of the main arguments in favor of factor investing concerns long-term allocation. We know that strategic asset allocation based on asset classes is not easy, because it is difficult to estimate their risk premia, and correlations between asset classes are time-varying and not stable. Supporters of factor investing argue that asset classes are exposed to independent risk factors, which are rewarded on the long-run, meaning that strategic asset allocation based on risk factors is more easy and robust. We will see that these arguments should be interpreted with caution.

Figure 32: Comparison of long/short and long-only solutions

$$
\begin{aligned}
& \text { Long/short solution } \\
& x_{j}^{\star} \propto \frac{\max \left(\mathrm{RP}_{j}, 0\right)}{\mathrm{VOL}_{j}^{2}}
\end{aligned}
$$

\begin{tabular}{l} 
Long-only solution (SR) \\
$x_{j}^{\star} \propto \frac{\max \left(\mathrm{RP}_{j}-\beta_{j} \lambda^{\star}, 0\right)}{\mathrm{IVOL}_{j}^{2}}$ \\
\hline
\end{tabular}

Long-only solution (TE)
$x_{j}^{\star} \propto \frac{\mathrm{RP}_{j}-\beta_{j} \mathrm{RP}_{m}+\tilde{\lambda}_{j}^{\star}}{\mathrm{IVOL}_{j}^{2}}$

The comparison of long/short and long-only solutions shows that they present some similarities. The weight of the $j^{\text {th }}$ factor is an increasing function of its risk premium $\mathrm{RP}_{j}$ and a decreasing function of its risk. In the case of the long/short portfolio, the risk of the factor is measured by its volatility $\mathrm{VOL}_{j}$ whereas it is equal to its idiosyncratic volatility $\mathrm{IVOL}_{j}$ in the case of the long-only portfolio. Moreover, we see that the long-only risk premium is penalized with respect to the beta $\beta_{j}$ of the risk factor. If we compare the two long-only solutions ${ }^{93}$, we also observe that the TE solution is more sensitive to the alpha and less sensitive to the beta premium than the SR solution.

Example 3 We consider a universe of three long/short risk factors $\mathcal{F}_{1}, \mathcal{F}_{2}$ and $\mathcal{F}_{3}$ plus the market risk factor. The alpha of long-only risk factors is respectively equal to $2 \%, 3 \%$ and $3 \%$ whereas the idiosyncratic volatility is equal to $7 \%, 10 \%$ and $12 \%$. The beta of long-only risk factors with respect to the market risk factor takes the following values: 1.10, 0.90 and 1.00. We assume that the short leg of the risk factors present the same characteristics than the long leg of risk factors (same alpha, same beta and same idiosyncratic volatility). The

\footnotetext{
${ }^{92}$ See Appendix A.6.3 on Page 88.

${ }^{93}$ The solution which maximizes the Sharpe ratio is noted SR whereas the solution which controls the tracking error is noted TE.
} 
Facts and Fantasies About Factor Investing

other parameters are the volatility of the market risk factor, the market risk premium and the risk-free rate. We assume that they are equal to $20 \%, 6 \%$ and $2 \%$.

We report the results ${ }^{94}$ for the previous example in column \#0 of the following tables. For instance, the long/short solution is given in Table 33. The optimal weights are $44.54 \%$ for the risk factor $\mathcal{F}_{1}, 32.73 \%$ for the risk factor $\mathcal{F}_{2}$ and $22.73 \%$ for the risk factor $\mathcal{F}_{3}$. The Sharpe ratio of this portfolio is then equal to 0.68 . In Table 34, the long-only solution corresponds to the portfolio which maximizes the Sharpe ratio. In this case, the optimal solution becomes $(0 \%, 64.39 \%, 35.61 \%)$. The weight of the long-only risk factor $\mathcal{F}_{1}^{+}$is equal to zero, because it has a lower alpha than the two other long-only risk factors $\mathcal{F}_{2}^{+}$and $\mathcal{F}_{3}^{+}$. We also notice that this optimal portfolio has an alpha and a tracking error volatility with respect to the market risk factor equal to $2.74 \%$ and $7.83 \%$, implying that the information ratio is equal to 0.35 . In Tables 35 and 36 , we assume that the benchmark is the market risk factor, and we consider the tracking error optimization problem with two values for the parameter $\phi . \phi=1$ corresponds to the case where we target a tracking error volatility higher than $6 \%$, and $\phi=20$ constraints the optimal solution to have a tracking error volatility lower than 3\%. We observe that optimal TE solutions are more diversified compared to the maximum Sharpe ratio solution. For instance, if $\phi$ is equal to 1 , the optimal solution is $(21.44 \%, 29.83 \%, 48.73 \%)$ implying a tracking error volatility equal to $6.74 \%$. If $\phi$ is equal to 20 , the optimal solution becomes $(23.65 \%, 13.41 \%, 10.42 \%)$ meaning that the optimal portfolio is composed by $52.52 \%$ of the market risk.

Table 33: Long/short solution

\begin{tabular}{|c|c|c|c|c|c|c|c|}
\hline Set & $\# 0$ & $\# 1$ & $\# 2$ & $\# 3$ & $\# 4$ & $\# 5$ & $\# 6$ \\
\hline 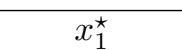 & 454 & U. & 346 & 44.54 & 44.54 & 44.5 & 66.2 \\
\hline & & 39 & & & & & 0. \\
\hline & .73 & 20 & 39.8 & 22.73 & 22.73 & 22.73 & 33.79 \\
\hline$\overline{\left(x^{\star}\right.}$ & $0.6 \overline{8}$ & $0 . \overline{78}$ & $\overline{0} . \overline{7} 9$ & $\overline{0} . \overline{6} \overline{8}$ & $0.6 \overline{8}$ & $0 . \overline{68}$ & $\overline{0} . \overline{5} 4$ \\
\hline
\end{tabular}

Table 34: Long-only solution (SR)

\begin{tabular}{|c|c|c|c|c|c|c|c|}
\hline Set & \#0 & $\# 1$ & $\# 2$ & $\# 3$ & $\# 4$ & $\# 5$ & \#6 \\
\hline$x_{1}^{\star}$ & 0.00 & 0.00 & 0.00 & 0.00 & 33.40 & 0.00 & 30.50 \\
\hline$x_{2}^{\star}$ & 64.39 & 87.44 & 47.81 & 72.74 & 40.16 & 74.19 & 0.00 \\
\hline$x_{3}^{\star}$ & 35.61 & 12.56 & 52.19 & 27.26 & 26.44 & 25.81 & 69.50 \\
\hline$\overline{\mathrm{S}} \overline{\mathrm{R}}\left(x^{\bar{\star}} \mid r \overline{)}\right.$ & $0 . \overline{3}$ & $0 . \overline{37}$ & $\overline{0} . \overline{3} 4^{-}$ & $\overline{0} . \overline{3} \overline{5}$ & $0.5 \overline{8}$ & $0 . \overline{15}$ & $\overline{0} . \overline{3} 1$ \\
\hline$\mu\left(x^{\star} \mid b\right)$ & 2.74 & 3.52 & 2.81 & 2.13 & 2.64 & 3.00 & 2.82 \\
\hline$\sigma\left(x^{\star} \mid b\right)$ & 7.83 & 9.04 & 6.42 & 9.09 & 5.63 & 8.18 & 8.63 \\
\hline $\operatorname{IR}\left(x^{\star} \mid b\right)$ & 0.35 & 0.39 & 0.44 & 0.23 & 0.47 & 0.37 & 0.33 \\
\hline
\end{tabular}

To illustrate the sensitivity of optimal solutions to the parameters, we consider some changes to their initial values. For each parameter set, we only change the value of one

\footnotetext{
${ }^{94}$ The optimal weights of the $j^{\text {th }}$ risk factor is denoted $x_{j}^{\star}$. In the case of the TE optimization problem, the benchmark is the market risk factor and its weight is equal to $x_{b}^{\star}$. SR $\left(x^{\star} \mid r\right)$ is the Sharpe ratio of the optimal portfolio $x^{\star}$ with respect to the risk-free asset. $\mu\left(x^{\star} \mid b\right), \sigma\left(x^{\star} \mid b\right)$ and $\operatorname{IR}\left(x^{\star} \mid b\right)$ represent respectively the excess return, the tracking error volatility and the information ratio of the optimal portfolio $x^{\star}$ when the benchmark $b$ is the market risk factor. All these statistics are expressed as \% except the Sharpe ratio and the information ratio, which are expressed as decimals.
} 
Facts and Fantasies About Factor Investing

parameter with respect to the initial parameter set \#0:

\begin{tabular}{|c|ccccccc|}
\hline Set & $\# 0$ & $\# 1$ & $\# 2$ & $\# 3$ & $\# 4$ & $\# 5$ & $\# 6$ \\
\hline$\alpha_{2}^{+}$ & & $4 \%$ & & & & & $0 \%$ \\
$\tilde{\sigma}_{3}^{+}$ & & & $8 \%$ & & & & \\
$\beta_{2}$ & & & & 0.70 & & & \\
$\sigma_{m}$ & & & & & $10 \%$ & & \\
$\mu_{m}$ & & & & & & $2 \%$ & \\
\hline
\end{tabular}

For instance, the parameter set \#1 corresponds to the initial parameter set \#0 except that the alpha of the second long-only risk factor is equal to $4 \%$. For the parameter set \#2, we change the value of the idiosyncratic volatility of the third risk factor. Then, we change the values of the beta $\beta_{2}$ of the second risk factor, the volatility $\sigma_{m}$ of the market risk factor and the market risk premium $\mu_{m}$. Finally, we set the alpha of the second long-only risk factor to zero in the parameter set \#6. We notice that the optimal long/short solution does not change very much except in the case of the last parameter set. The long-only SR solution is more sensitive. In particular, we notice that it depends on the parameter of the market risk factor. Indeed, the volatility of the market risk premium has an impact on the level of the risk premia weighted average $\lambda^{\star}$. An increase of $\lambda^{\star}$ favors more the alpha component than the beta component of the risk premia. In a similar way, a change in the market risk premium has an impact on the individual risk premia, because the risk factors don't have the same beta. Curiously, the long-only TE solution is even more sensitive than the long-only SR solution when $\phi$ is low (see Table 35).

Table 35: Long-only solution (TE, $\phi=1)$

\begin{tabular}{|c|c|c|c|c|c|c|c|}
\hline Set & $\# 0$ & $\# 1$ & $\# 2$ & $\# 3$ & $\# 4$ & $\# 5$ & $\# 6$ \\
\hline$x_{1}^{\star}$ & 21.44 & 0.00 & 0.00 & 42.64 & 21.08 & 0.00 & 42.64 \\
\hline$x_{2}^{\star}$ & 29.83 & 82.26 & 14.29 & 0.00 & 30.15 & 58.06 & 0.00 \\
\hline$x_{3}^{\star}$ & 48.73 & 17.74 & 85.71 & 57.36 & 48.78 & 41.94 & 57.36 \\
\hline & 0.00 & 0.00 & 0.00 & 0.00 & 0.00 & 0.00 & 0.00 \\
\hline$\overline{\mathrm{S}} \overline{\mathrm{R}}\left(x^{\frac{0}{\star}}\lceil r)\right.$ & $-\overline{3} \overline{2} \overline{2}$ & $\overline{0.37^{-}}$ & $\overline{0} . \overline{3} 3-$ & $\overline{0} . \overline{3} \overline{0}$ & $0.5 \overline{6}$ & $\overline{0.15}$ & $\overline{0} . \overline{3} 0^{-}$ \\
\hline$\mu\left(x^{\star} \mid b\right)$ & 2.75 & 3.49 & 2.94 & 2.74 & 2.75 & 3.00 & 2.74 \\
\hline$\sigma\left(x^{\star} \mid b\right)$ & 6.74 & 8.65 & 7.01 & 7.55 & 6.75 & 7.77 & 7.55 \\
\hline $\operatorname{IR}\left(x^{\star} \mid b\right)$ & 0.41 & 0.40 & 0.42 & 0.36 & 0.41 & 0.39 & 0.36 \\
\hline
\end{tabular}

Table 36: Long-only solution (TE, $\phi=20)$

\begin{tabular}{|c|c|c|c|c|c|c|c|}
\hline Set & $\# 0$ & $\# 1$ & \#2 & $\# 3$ & $\# 4$ & \#5 & \#6 \\
\hline$x_{1}^{\star}$ & 23.65 & 24.02 & 23.65 & 24.63 & 24.26 & 20.01 & 22.64 \\
\hline$x_{2}^{\star}$ & 13.41 & 18.23 & 13.41 & 8.79 & 13.11 & 15.19 & 0.00 \\
\hline$x_{3}^{\star}$ & 10.42 & 10.42 & 23.44 & 10.42 & 10.42 & 10.42 & 10.42 \\
\hline$x_{b}^{\star}$ & 52.52 & 47.33 & 39.50 & 56.16 & 52.21 & 54.38 & 66.94 \\
\hline$\overline{\mathrm{S}} \overline{\mathrm{R}}\left(x^{\bar{\star}}\lceil r \bar{r}\right.$ & $0 . \overline{2} \overline{6}$ & $0 . \overline{27}$ & $\overline{0} . \overline{2} 8^{-}$ & $\overline{0} \overline{2} \overline{5}$ & 0.50 & $\overline{0.06}$ & $\overline{0} . \overline{2} \overline{4}$ \\
\hline$\mu\left(x^{\star} \mid b\right)$ & 1.23 & 1.55 & 1.62 & 1.06 & 1.24 & 1.17 & 0.86 \\
\hline$\sigma\left(x^{\star} \mid b\right)$ & 2.48 & 2.78 & 2.85 & 2.30 & 2.49 & 2.42 & 2.07 \\
\hline $\operatorname{IR}\left(x^{\star} \mid b\right)$ & 0.50 & 0.56 & 0.57 & 0.46 & 0.50 & 0.48 & 0.41 \\
\hline
\end{tabular}

These results show that factor investing does not completely solve the problem of the strategic asset allocation based on asset classes. In this last case, the difficulties concern 
Facts and Fantasies About Factor Investing

the estimation and the stability of the risk premium of each asset class and the crosscorrelations between asset classes. In the case of the strategic asset allocation based on risk factors, the difficulties are transferred to the estimation and the stability of the alpha, beta and idiosyncratic volatility of each risk factors. This is particularly true when we consider long-only solutions. In these last cases, the allocation also depends on the characteristic of the market risk factor. Another issue concerns the dependence of the solution to the universe of risk factors. It is easy to show that the inclusion or the deletion of a risk factor may highly impact the solution. In summary, the superiority of risk factors on asset classes can not be demonstrated in terms of optimal allocation. This explains why practitioners consider heuristic allocation approaches when they want to build a multi-factor portfolio. These methods have the advantage to average the 'bad times' induced by each risk factor (Ang, 2014).

\section{Conclusion}

In this article, we have shown that factor investing is not as simple as it is sometimes presented by practitioners. Because there are many risk factors and anomalies published in academic journals, the investor may have the feeling to be lost in this "zoo of factors", to borrow an expression of John Cochrane. Some actual research challenges the increased number of risk factors. For instance, Harvey et al. (2014) propose to adapt the usual $t$-statistic for testing the significance of a newly discovered risk factor. In a similar way, Novy-Marx (2014) warns about the standard approach to define factors and anomalies:

"Standard predictive regressions fail to reject the hypothesis that the party of the U.S. President, the weather in Manhattan, global warming, El Niño, sunspots, or the conjunctions of the planets, are significantly related to anomaly performance. These results are striking, and quite surprising. In fact, some readers may be inclined to reject some of this paper's conclusions solely on the grounds of plausibility. I urge readers to consider this option carefully, however, as doing do so entails rejecting the standard methodology on which the return predictability literature is built."

From a professional point of view, only a few number of risk factors and anomalies are reliable. Among these relevant factors, we find for example SMB, HML or WML. But, even with a reduced set of less than 10 factors, there are again a lot of questions to answer in order to understand what the nature, the behavior and the risk of these factors are. Academics have done extensive studies on these questions and their work can help to find the answers, but some questions still remain open, in particular the level of the risk premia.

The concept of factor investing is based on risk factors, but not exclusively. The first dimension is to transform these academic findings into investible products. However, there are different issues to take into account in order to obtain a factor-mimicking portfolio. They concern the definition of the asset universe, the weighting scheme and the transaction costs. In this paper, we have shown that these choices have a big impact on the design of factor indexes. Another important issue concerns the long/short or long-only characteristic to give for these products. While academic studies are exclusively based on long/short portfolios, long-only products are more frequent in the investment industry. This leads to a gap between the theory and the practice of investment, and this gap is more important for certain factors, like BAB or WML. The second dimension of factor investing concerns the allocation between the risk factors. At first sight, factor allocation seems to be easy, at least less difficult than the allocation between asset classes, because risk factors are uncorrelated. 
Facts and Fantasies About Factor Investing

In fact, the allocation process is simplified in the case of long/short solutions, but remains a difficult exercise when we consider long-only risk factors. In this case, the optimal solution depends on the alpha, beta and idiosyncratic volatility of each risk factor, and also on the risk and the return of the market portfolio. The robustness of factor allocation depends then on the stability of these estimated parameters.

The objective of our paper was to provide an answer to the different issues that we have previously listed. Most of the time, the answers are partial because factor investing is a complex topic. Another goal of the paper was to show that academic research may help to verify or contradict some accepted ideas on the subject of factor investing. We have listed some of them below:

\begin{tabular}{|c|c|}
\hline Some facts & Some fantasies \\
\hline $\begin{array}{l}\text { - Common risk factors explain more } \\
\text { variance than idiosyncratic risks in } \\
\text { diversified portfolios. } \\
\text { - Some risk factors are more rele- } \\
\text { vant than others, for instance SMB, } \\
\text { HML and WML. } \\
\text { - Risk premia are time-varying and } \\
\text { low-frequency mean-reverting. The } \\
\text { length of a cycle is between } 3 \text { and } \\
10 \text { years. } \\
\text { - The explanatory power of risk fac- } \\
\text { tors other than the market risk fac- } \\
\text { tor has declined over the last few } \\
\text { years, because Beta has been back } \\
\text { since } 2003 . \\
\text { - Long-only and long/short risk fac- } \\
\text { tors have not the same behavior. } \\
\text { This is for example the case of BAB } \\
\text { and WML factors. } \\
\text { - Risk factors are local, not global. It } \\
\text { means that risk factors are not ho- } \\
\text { mogeneous. For instance, the value } \\
\text { factors in US and Japan cannot be } \\
\text { compared (distressed stocks versus } \\
\text { quality stocks). } \\
\text { - Factor investing is not a new invest- } \\
\text { ment style. It has been largely used } \\
\text { by asset managers and hedge fund } \\
\text { managers for a long time. }\end{array}$ & $\begin{array}{l}\text { - Risk factors are not dependent on size. } \\
\text { It is a fantasy. Some risk factors present } \\
\text { a size bias, like the HML risk factor. } \\
\text { - HML is much more rewarded than } \\
\text { WML. } \\
\text { - WML exhibits a CTA option profile. } \\
\text { This is wrong. The option profile of a } \\
\text { CTA is a long straddle whereas WML } \\
\text { presents some similarities to a short call } \\
\text { exposure. } \\
\text { - Long-only risk factors are more risky } \\
\text { than long/short risk factors. This is not } \\
\text { always the case. For instance, the risk of } \\
\text { the long/short WML factor is very high. } \\
\text { - HML is riskier than WML. It is gener- } \\
\text { ally admitted in finance that contrar- } \\
\text { ian strategies are riskier than trend- } \\
\text { following strategies. However, this is not } \\
\text { always the case, such as with the WML } \\
\text { factor, which is exposed to momentum } \\
\text { crashes. } \\
\text { - Strategic asset allocation with risk fac- } \\
\text { tors is easier than strategic asset alloca- } \\
\text { tion with asset classes. This is not easy, } \\
\text { in particular in a long-only framework. } \\
\text { Estimating the alpha, beta and idiosyn- } \\
\text { cratic volatility of a long-only risk factor } \\
\text { remains an issue, implying that portfolio } \\
\text { allocation is not straightforward. }\end{array}$ \\
\hline
\end{tabular}

In fact, like other recent hot topics in asset management (smart beta, risk parity or liabilitydriven investment), understanding the facts and the commonly held fictions is the primary pillar to handle the complexity of factor investing. 
Facts and Fantasies About Factor Investing

\section{References}

[1] Acharya V.V. and Pedersen L.H. (2005), Asset Pricing with Liquidity Risk, Journal of Financial Economics, 77(2), pp. 375-410.

[2] Ali A., Hwang L.S. and Trombley M.A. (2003), Arbitrage Risk and the Book-tomarket Anomaly, Journal of Financial Economics, 69(2), pp. 355-373.

[3] Aminud Y. (2002), Illiquidity and Stock Returns: Cross-Section and Time-Series Effects, Journal of Financial Markets, 5(1), pp. 31-56.

[4] Aminud Y. and Mendelson H. (1986), Asset Pricing and The Bid-Ask Spread, Journal of Financial Economics, 17(2), pp. 223-249.

[5] Aminud Y. and Mendelson H. (1989), The Effects of Beta, Bid-Ask Spread, Residual Risk, and Size on Stock Returns, Journal of Finance, 44(2), pp. 479-486.

[6] Ang A. (2014), Asset Management - A Systematic Approach to Factor Investing, Oxford University Press.

[7] Ang A., Chen J. and Xing Y. (2006), Downside Risk, Review of Financial Studies, 19(4), pp. 1191-1239.

[8] Ang A., Goetzmann W. and Schaefer S. (2009), Evaluation of Active Management of the Norwegian GPFG, Norway: Ministry of Finance.

[9] Arnott R.D., Hsu J.C. and Moore P. (2005), Fundamental Indexation, Financial Analysts Journal, 61(2), pp. 83-99.

[10] Asness C.S., Frazzini A., Israel R. and Moskowitz T.J. (2014), Fact, Fiction and Momentum Investing, SSRN, www.ssrn.com/abstract=2312432.

[11] Asness C.S., Frazzini A. and Pedersen L.H. (2013), Quality Minus Junk, SSRN, www . ssrn. com/abstract $=2435323$.

[12] Asness C.S., Moskowitz T.J. and Pedersen L.H. (2013), Value and Momentum Everywhere, Journal of Finance, 68(3), pp. 929-985.

[13] Avramov D., Jostova G. and Philipov A. (2007), Understanding Changes in Corporate Credit Spreads, Financial Analysts Journal, 63(2), pp. 90-105.

[14] Baker M., Bradley B. and Taliaferro R. (2014), The Low-Risk Anomaly: A Decomposition into Micro and Macro Effects, Financial Analysts Journal, 70(2), pp. 43-58.

[15] Bakshi G., Kapadia N. and Madan D. (2003), Stock Return Characteristics, Skew Laws, and the Differential Pricing of Individual Equity Options, Review of Financial Studies, 16(1), pp. 101-143.

[16] Balvers R.J. and Wu Y. (2006), Momentum and Mean Reversion Across National Equity Markets, Journal of Empirical Finance, 13(1), pp. 24-48.

[17] Bansal R., Dittmar R.F. and Lundblad C.T. (2005), Consumption, Dividends, and the Cross Section of Equity Returns, Journal of Finance, 60(4), pp. 1639-1672.

[18] Bansal R. and Yaron A. (2004), Risks for the Long Run: A Potential Resolution of Asset Pricing Puzzles, Journal of Finance, 59(4), pp. 1481-1509. 
Facts and Fantasies About Factor Investing

[19] Banz R.W. (1981), The Relationship between Return and Market Value of Common Stocks, Journal of Financial Economics, 9(1), pp. 3-18.

[20] Barberis N. and Shleifer A. (2003), Style Investing, Journal of Financial Economics, 68(2), pp. 161-199.

[21] Barberis N., Shleifer A. and Vishny R. (1998), A Model of Investor Sentiment, Journal of Financial Economics, 49(3), pp. 307-343.

[22] Barberis N. and Thaler R.H. (2003), A Survey of Behavioral Finance, in G.M. Constantinides, M. Harris and R.M. Stulz (Eds), Handbook of the Economics of Finance, 1(B), Elsevier, pp. 1053-1128.

[23] Barone Adesi G., Gagliardini P. and Urga G. (2004), Testing Asset Pricing Models with Coskewness, Journal of Business \& Economic Statistics, 22(4), pp. 474-485.

[24] Barras L., Scaillet O. and Wermers R. (2010), False Discoveries in Mutual Fund Performance: Measuring Luck in Estimated Alphas, Journal of Finance, 65(1), pp. 179-216.

[25] BASU S. (1977), Investment Performance of Common Stocks in Relation to Their PriceEarnings Ratios: A Test of The Efficient Market Hypothesis, Journal of Finance, 32(3), pp. 663-682.

[26] BASU S. (1983), The Relationship between Earnings' Yield, Market Value and Return for NYSE Common Stocks: Further Evidence, Journal of Financial Economics, 12(1), pp. 129-156.

[27] Bauer R., Cosemans M. and Schotman P.C. (2010), Conditional Asset Pricing and Stock Market Anomalies in Europe, European Financial Management, 16(2), pp. 165190 .

[28] Bebchuk L., Cohen A. and Ferrell A. (2009), What Matters in Corporate Governance?, Review of Financial Studies, 22(2), pp. 783-827.

[29] Berk J.B. (1995), A Critique of Size-related Anomalies, Review of Financial Studies, $8(2)$, pp. $275-286$.

[30] Berk J.B. (2000), Sorting Out Sorts, Journal of Finance, 55(1), pp. 407-427.

[31] Bernard V.L. and Thomas J.K. (1989), Post-Earnings-Announcement Drift: Delayed Price Response or Risk Premium?, Journal of Accounting Research, 27(1), pp. 1-36.

[32] Bhansali V. (2007), Volatility and the Carry Trade, Journal of Fixed Income, 17(3), pp. $72-84$.

[33] Black F. (1972), Capital Market Equilibrium with Restricted Borrowing, Journal of Business, 45(3), pp. 444-455.

[34] Black F. (1993), Beta and Return, Journal of Portfolio Management, 20(1), pp. 8-18.

[35] Black F. (1995), Estimating Expected Return, Financial Analysts Journal, 51(1), pp. 168-171.

[36] Black F., Jensen M.C. and Scholes M.S. (1972), The Capital Asset Pricing Model: Some Empirical Tests, in M.C. Jensen (Ed.), Studies in the Theory of Capital Markets, Praeger Publishers Inc., pp. 79-121. 
Facts and Fantasies About Factor Investing

[37] Blitz D.C. and van Vliet P. (2007), The Volatility Effect, Journal of Portfolio Management, 34(1), pp. 102-113.

[38] Blitz D.C. and van Vliet P. (2011), Benchmarking Low-Volatility Strategies, Journal of Index Investing, 2(1), pp. 44-49.

[39] Breen W.J. and Korajczyk R.A. (1993), On Selection Biases in Book-to-market Based Tests of Asset Pricing Models, Northwestern University Working Paper, 167.

[40] Bruder B. and Gaussel N. (2011), Risk-Return Analysis of Dynamic Investment Strategies, Lyxor White Paper Series, 7, www.lyxor.com.

[41] Brunnermeier M.K., Nagel S. and Pedersen L.H. (2009), Carry Trades and Currency Crashes, NBER Macroeconomics Annual 2008, 23(1), pp. 313-347.

[42] Burnside C., Eichenbaum M., Kleshchelski I. and Rebelo S. (2011), Do Peso Problems Explain the Returns to the Carry Trade?, Review of Financial Studies, 24(3), pp. 853-891.

[43] Campbell J.Y., Hilscher J. and Szilagyi J. (2008), In Search of Distress Risk, Journal of Finance, 63(6), pp. 2899-2939.

[44] Campbell J.Y. and Shiller R.J. (1991), Yield Spreads and Interest Rate Movements: A Bird's Eye View, Review of Economic Studies, 58(3), pp. 495-514.

[45] Carhart M.M. (1997), On Persistence in Mutual Fund Performance, Journal of Finance, $52(1)$, pp. $57-82$.

[46] Carvalho R. Leote de, Lu X. and Moulin P. (2012), Demystifying Equity Risk-Based Strategies: A Simple Alpha plus Beta Description, Journal of Portfolio Management, 38(3), pp. 56-70.

[47] Cazalet Z., Grison P. and Roncalli T. (2014), The Smart Beta Indexing Puzzle, Journal of Index Investing, 5(1), pp. 97-119.

[48] Cazalet Z. and Roncalli T. (2014), Style Analysis and Mutual Fund Performance Measurement Revisited, Lyxor Research Paper.

[49] Chan K.C. and Chen N.F. (1991), Structural and Return Characteristics of Small and Large Firms, Journal of Finance, 46(4), pp. 1467-1784.

[50] Chan K.C., Chen N.F. and Hsien D.A. (1985), An Exploratory Investigation of the Firm Size Effect, Journal of Financial Economics, 14(3), pp. 451-471.

[51] Chan L.K.C., Hamao Y. and Lakonishok J. (1991), The Fundamentals and Stock Returns in Japan, Journal of Finance, 46(5), pp. 1739-1764.

[52] Chan L.K.C., Jegadeesh N. and Lakonishok J. (1996), Momentum strategies, Journal of Finance, 51(5), pp. 1681-1713.

[53] Chambers D., Dimson E. and Ilmanen A.S. (2011), The Norway Model, SSRN, www. ssrn. com/abstract $=1936806$.

[54] Chopra N., Lakonishok J. and Ritter J.R. (1992), Measuring Abnormal Performance: Do Stocks Overreact?, Journal of Financial Economics, 31(2), pp. 235-268. 
Facts and Fantasies About Factor Investing

[55] Chordia T. and Shivakumar L. (2006), Earnings and Price Momentum, Journal of Financial Economics, 80(3), pp. 627-656.

[56] Chui A.C., Titman S. and Wei K.J. (2010), Individualism and Momentum Around The World, Journal of Finance, 65(1), pp. 361-392.

[57] Chung Y.P., Johnson H. and Schill M.J. (2006), Asset Pricing When Returns Are Nonnormal: Fama-French Factors versus Higher-Order Systematic Comoments, Journal of Business, 79(2), pp. 923-940.

[58] Clarke R.G., De Silva H. and Thorley S. (2006), Minimum-variance Portfolios in the US Equity Market, Journal of Portfolio Management, 33(1), pp. 10-24.

[59] Clarke R.G., De Silva H. and Thorley S. (2011), Minimum-variance Portfolio Composition, Journal of Portfolio Management, 37(2), pp. 31-45.

[60] Cochrane J.H. (2011), Presidential Address: Discount Rates, Journal of Finance, 66(4), pp. 1047-1108.

[61] Cochrane J.H. and Piazzesi M. (2005), Bond Risk Premia, American Economic Review, 95(1), pp. 138-160.

[62] Cooper M.J., Gutierrez R.C. and Hameed A. (2004), Market States and Momentum, Journal of Finance, 59(3), pp. 1345-1365.

[63] Cumby R.E. and Obstfeld M. (1981), A Note on Exchange-Rate Expectations and Nominal Interest Differentials: A Test of the Fisher Hypothesis, Journal of Finance, 36(3), pp. 697-703.

[64] Cuthbertson K., Nitzsche D. and O’Sullivan N. (2008), UK Mutual Fund Performance: Skill or Luck?, Journal of Empirical Finance, 15(4), pp. 613-634.

[65] Cremers M., Petajisto A. and Zitzewitz E. (2013), Should Benchmark Indices Have Alpha? Revisiting Performance Evaluation, Critical Finance Review, 2(1), pp. $1-48$.

[66] Daniel K.D., Hirshleifer D. and Subrahmanyam A. (2001), Overconfidence, Arbitrage, and Equilibrium Asset Pricing, Journal of Finance, 56(3), pp. 921-965.

[67] Daniel K.D., Jagannathan R. and Kim S. (2012), Tail Risk in Momentum Strategy Returns, NBER, 18169.

[68] Daniel K.D. and Moskowitz T.J. (2013), Momentum Crashes, SSRN, www.ssrn. com/abstract $=2371227$.

[69] Daniel K.D. and Titman S. (1997), Evidence on the Characteristics of Cross Sectional Variation in Stock Returns, Journal of Finance, 52(1), pp. 1-33.

[70] Daniel K.D., Titman S. and Wei K.C. (2001), Explaining the Cross-Section of Stock Returns in Japan: Factors or Characteristics?, Journal of Finance, 56(2), pp. 743-766.

[71] Davis J.L., Fama E.F. and French K.R. (2000), Characteristics, Covariances, and Average Returns: 1929 to 1997, Journal of Finance, 55(1), pp. 389-406.

[72] De Bondt W.F. and Thaler R. (1985), Does The Stock Market Overreact?, Journal of Finance, 40(3), pp. 793-805. 
Facts and Fantasies About Factor Investing

[73] De Jong F. and Driessen J. (2012), Liquidity Risk Premia in Corporate Bond Markets, Quarterly Journal of Finance, 2(2), pp. 1-34.

[74] De Long J.B., Shleifer A., Summers L.H. and Waldmann R.J. (1990), Positive Feedback Investment Strategies and Destabilizing Rational Speculation, Journal of Finance, 45(2), pp. 379-395.

[75] De Moor L. and Sercu P. (2013), The Smallest Firm Effect: An International Study, Journal of International Money and Finance, 32(1), pp. 129-155.

[76] Demey P., Maillard S. and Roncalli T. (2010), Risk-Based Indexation, SSRN, www. ssrn. com/abstract $=1582998$.

[77] Drew M.E., Naughton T. and Veeraraghavan M. (2003), Firm Size, Book-toMarket Equity and Security Returns: Evidence from the Shanghai Stock Exchange, Australian Journal of Management, 28(2), pp. 119-139.

[78] Elton E.J., Gruber M.J., Agrawal D. and Mann C. (2001), Explaining the Rate Spread on Corporate Bonds, Journal of Finance, 56(1), pp. 247-277.

[79] Erb C.B. and Harvey C.R. (2006), The Strategic and Tactical Value of Commodity Futures, Financial Analysts Journal, 62(2), pp. 69-97.

[80] Fama E.F. (1981), Stock Returns, Real Activity, Inflation, and Money, American Economic Review, 71(4), pp. 545-565.

[81] Fama E.F. (1984), Forward and Spot Exchange Rates, Journal of Monetary Economics, 14(3), pp. 319-338.

[82] Fama E.F. (1998), Market Efficiency, Long-term Returns, and Behavioral Finance, Journal of Financial Economics, 49(3), pp. 283-306.

[83] FAma E.F. and Bliss R.R. (1987), The Information in Long-maturity Forward Rates, American Economic Review, 77(4), pp. 680-692.

[84] Fama E.F. and French K.R. (1992), The Cross-Section of Expected Stock Returns, Journal of Finance, 47(2), pp. 427-465.

[85] Fama E.F. and French K.R. (1993), Common Risk Factors in the Returns on Stocks and Bonds, Journal of Financial Economics, 33(1), pp. 3-56.

[86] Fama E.F. and French K.R. (1995), Size and Book-to-market Factors in Earnings and Returns, Journal of Finance, 50(1), pp. 131-155.

[87] Fama E.F. and French K.R. (1996), Multifactor Explanations of Asset Pricing Anomalies, Journal of Finance, 51(1), pp. 55-84.

[88] Fama E.F. and French K.R. (1996), The CAPM is Wanted, Dead or Alive, Journal of Finance, 51(5), pp. 1947-1958.

[89] Fama E.F. and French K.R. (1998), Value versus Growth: The International Evidence, Journal of Finance, 53(6), pp. 1975-1999.

[90] Fama E.F. and French K.R. (2004), The Capital Asset Pricing Model: Theory and Evidence, Journal of Economic Perspectives, 18(3), pp. 25-46. 
Facts and Fantasies About Factor Investing

[91] Fama E.F. and French K.R. (2010), Luck Versus Skill in the Cross-section of Mutual Fund Returns, Journal of Finance, 65(5), pp. 1915-1947.

[92] Fama E.F. and French K.R. (2012), Size, Value, and Momentum in International Stock Returns, Journal of Financial Economics, 105(3), pp. 457-472.

[93] Fama E.F. and MacBeth J.D. (1973), Risk, Return, and Equilibrium: Empirical Tests, Journal of Political Economy, 81(3), pp. 607-636.

[94] Ferson W.E., Sarkissian S. and Simin T.T. (2003), Spurious Regressions in Financial Economics?, Journal of Finance, 58(4), pp. 1393-1414.

[95] Ferson W.E., Sarkissian S. and Simin T.T. (2003), Spurious Regressions in Financial Economics?, Journal of Finance, 58(4), pp. 1393-1414.

[96] Ferson W.E., Sarkissian S. and Simin T.T. (2003), Is Stock Return Predictability Spurious?, Journal of Investment Management, 1(3), pp. 1-10.

[97] Ferson W.E., Sarkissian S. and Simin T.T. (2008), Asset Pricing Models with Conditional Betas and Alphas: The Effects of Data Snooping and Spurious Regression, Journal of Financial and Quantitative Analysis, 43(2), pp. 331-353.

[98] Flannery M.J. and Protopapadakis A.A. (2002), Macroeconomic Factors Do Influence Aggregate Stock Returns, Review of Financial Studies, 15(3), pp. 751-782.

[99] Foye J., Mramor D. and Pahor M. (2013), A Respecified Fama French Three-Factor Model for the New European Union Member States, Journal of International Financial Management $\mathcal{E}$ Accounting, 24(1), pp. 3-25.

[100] Frazzini A. (2006), The Disposition Effect and Underreaction to News, Journal of Finance, 61(4), pp. 2017-2046.

[101] Frazzini A., Israel R. and Moskowitz T.J. (2012), Trading Costs of Asset Pricing Anomalies, SSRN, www.ssrn. com/abstract $=2294498$.

[102] Frazzini A. and Pedersen L.H. (2013), Betting Against Beta, Journal of Financial Economics, 111(1), pp. 1-25.

[103] Fung W. and Hsien D.A. (2001), The Risk in Hedge Fund Strategies: Theory and Evidence from Trend Followers, Review of Financial studies, 14(2), pp. 313-341.

[104] Idzorek T.M. and Kowara M. (2013), Factor-Based Asset Allocation vs. AssetClass-Based Asset Allocation, Financial Analyst Journal, 69(3), pp. 19-29.

[105] Gabaix X. (2012), Variable Rare Disasters: An Exactly Solved Framework for Ten Puzzles in Macro-Finance, Quarterly Journal of Economics, 127(2), pp. 645-700.

[106] Gaunt C. (2004), Size and Book to Market Effects and the Fama French Three Factor Asset Pricing Model: Evidence from the Australian Stockmarket, Accounting $\&$ Finance, 44(1), pp. 27-44.

[107] Gomes J.F., Kogan L. and Zhang L. (2003), Equilibrium Cross Section of Returns, Journal of Political Economy, 111(4), pp. 693-732.

[108] Gorton G.B., Hayashi F. and Rouwenhorst K.G. (2013), The Fundamentals of Commodity Futures Returns, Review of Finance, 17(1), pp. 35-105. 
Facts and Fantasies About Factor Investing

[109] Graham B. (1973), The Intelligent Investor, Harpers \& Row.

[110] Greenblatt J. (2010), The Little Book That Beats the Market, Wiley.

[111] Griffin J.M. (2002), Are the Fama and French Factors Global or Country Specific?, Review of Financial Studies, 15(3), pp. 783-803.

[112] Griffin J.M., Ji X. and Martin J.S. (2003), Momentum Investing and Business Cycle Risk: Evidence from Pole to Pole, Journal of Finance, 58(6), pp. 2515-2547.

[113] Griffin J.M. and Lemmon M.L. (2002), Book-to-market Equity, Distress Risk, and Stock Returns, Journal of Finance, 57(5), pp. 2317-2336.

[114] Grinblatt M. and Titman S. (1989), Mutual Fund Performance: An Analysis of Quarterly Portfolio Holdings, Journal of Business, 62, pp. 393-416.

[115] Grinblatt M., Titman S. and Wermers R. (1995), Momentum Investment Strategies, Portfolio Performance, and Herding: A Study of Mutual Fund Behavior, American Economic Review, 85(5), pp. 1088-1105.

[116] Guay W. (2000), Discussion of Value Investing: The Use of Historical Financial Statement Information to Separate Winners from Losers, Journal of Accounting Research, 38 , pp. $43-51$.

[117] Harvey C.R., Liu Y. and Zhu H. (2014), ... and the Cross-Section of Expected Returns, SSRN, www.ssrn.com/abstract=2249314

[118] Harvey C.R. and Siddique A. (2000), Conditional Skewness in Asset Pricing Tests, Journal of Finance, 55(3), pp. 1263-1295.

[119] Haugen R.A. (1994), The New Finance: The Case Against Efficient Markets, Prentice Hall.

[120] Haugen R.A. and Baker N.L. (1991), The Efficient Market Inefficiency of Capitalization-Weighted Stock Portfolios, Journal of Portfolio Management, 17(3), pp. $35-40$.

[121] Haugen R.A. and Baker N.L. (1996), Commonality in the Determinants of Expected Stock Returns, Journal of Financial Economics, 41(3), pp. 401-439.

[122] Hawawini G. and Keim D.B. (2000), The Cross Section of Common Stock Returns: A Review of the Evidence and Some New Findings, in Keim, D.B. and Ziemba, W.T. (eds), Security Market Imperfections in Worldwide Equity Markets, Cambridge University Press, 9, pp. 3-43.

[123] Hendricks D., Patel J. and Zeckhauser R. (1993), Hot Hands in Mutual Funds: Short-Run Persistence of Relative Performance, 1974-1988, Journal of Finance, 48(1), pp. 93-130.

[124] Heston S.L., Rouwenhorst K.G. and Wessels R.E. (1999), The Role of Beta and Size in the Cross-Section of European Stock Returns, European Financial Management, $5(1)$, pp. 9-27.

[125] Hirshleifer D. (2001), Investor Psychology and Asset Pricing, Journal of Finance, 56(4), pp. 1533-1597. 
Facts and Fantasies About Factor Investing

[126] Hong H. and Stein J.C. (1999), A Unified Theory of Underreaction, Momentum Trading, and Overreaction in Asset Markets, Journal of Finance, 54(6), pp. 2143-2184.

[127] Hong H., Lim T. and Stein J.C. (2000), Bad News Travels Slowly: Size, Analyst Coverage, and the Profitability of Momentum Strategies, Journal of Finance, 55(1), pp. 265-295.

[128] Horowitz J.L., Loughran T. and Savin N.E. (2000), Three Analyses of the Firm Size Premium, Journal of Empirical Finance, 7(2), pp. 143-153.

[129] Hou K., Karolyi G.A. and Kho B.C. (2011), What Factors Drive Global Stock Returns?, Review of Financial Studies, 24(8), pp. 2527-2574.

[130] Hsu J. and Li F. (2013), Low-Volatility Investing, Journal of Index Investing, 4(2), pp. $67-72$.

[131] Huij J. and Verbeek M. (2009), On The Use of Multifactor Models to Evaluate Mutual Fund Performance, Financial Management, 38(1), pp. 75-102.

[132] Ibbotson R.G., Chen Z., Kim D.Y.J. and Hu W.Y. (2013), Liquidity as an Investment Style, Financial Analysts Journal, 69(3), pp. 30-44.

[133] Ilmanen A. (2011), Expected Returns: An Investor's Guide to Harvesting Market Rewards, Wiley.

[134] Israel R. and Moskowitz T.J. (2013), The Role of Shorting, Firm Size, and Time on Market Anomalies, Journal of Financial Economics, 108(2), pp. 275-301.

[135] Jagannathan R. and Ma T. (2003), Risk Reduction in Large Portfolios: Why Imposing the Wrong Constraints Helps, Journal of Finance, 58(4), pp. 1651-1684.

[136] Jagannathan R. and McGrattan E.R. (1995), The CAPM Debate, Reserve Bank of Minneapolis Quarterly Review, 19(4), pp. 2-17.

[137] Jegadeesh N. (1990), Evidence of Predictable Behavior of Security Returns, Journal of Finance, 45(3), pp. 881-898.

[138] Jegadeesh N. and Titman S. (1993), Returns to Buying Winners and Selling Losers: Implications for Stock Market Efficiency, Journal of Finance, 48(1), pp. 65-91.

[139] Jegadeesh N. and Titman S. (1995), Overreaction, Delayed Reaction, and Contrarian Profits, Review of Financial Studies, 8(4), pp. 973-993.

[140] Jegadeesh N. and Titman S. (2001), Profitability of Momentum Strategies: An Evaluation of Alternative Explanations, Journal of Finance, 56(2), pp. 699-720.

[141] Jensen G.R., Johnson R.R. and Mercer J.M. (1997), New Evidence on Size and Price-to-Book Effects in Stock Returns, Financial Analysts Journal, 53(6), pp. 34-42.

[142] Jensen M.C. (1968), The Performance of Mutual Funds in the Period 1945-1964, Journal of Finance, 23(2), pp. 389-416.

[143] Jensen M.C. and Benington G.A. (1970), Random Walks and Technical Theories: Some Additional Evidence, Journal of Finance, 25(2), pp. 469-482.

[144] Johnson T.C. (2002), Rational Momentum Effects, Journal of Finance, 57(2), pp. 585-608. 
[145] Jurek J.W. (2014), Crash-Neutral Currency Carry Trades, Journal of Financial Economics, forthcoming.

[146] Khandani A.E. and Lo A.W. (2011), What Happened to the Quants in August 2007? Evidence from Factors and Transactions Data, Journal of Financial Markets, 14(1), pp. $1-46$.

[147] Kapadia N. (2011), Tracking Down Distress Risk, Journal of Financial Economics, 102(1), pp. 167-182.

[148] Knez P.J. and Ready M.J. (1997), On The Robustness of Size and Book-to-Market in Cross-Sectional Regressions, Journal of Finance, 52(4), pp. 1355-1382.

[149] Korajczyk R.A. and Sadka R. (2004), Are Momentum Profits Robust to Trading Costs?, Journal of Finance, 59(3), pp. 1039-1082.

[150] Kothari S.P., Shanken J. and Sloan R.G. (1995), Another Look at the Crosssection of Expected Stock Returns, Journal of Finance, 50(1), pp. 183-224.

[151] Lakonishok J., Shleifer A. and Vishny R.W. (1994), Contrarian Investment, Extrapolation, and Risk, Journal of Finance, 49(5), pp. 1541-1578.

[152] Lambert M. and Hübner G. (2013), Comoment Risk and Stock Returns, Journal of Empirical Finance, 23, pp. 191-205.

[153] Lambert M. and Hübner G. (2014), Size Matters, Book Value Does Not! The Fama-French Empirical CAPM Revisited, Working Paper, ???.

[154] La Porta R., Lakonishok J, Shleifer A. and Vishny R.W. (1997), Good News for Value Stocks: Further Evidence on Market Efficiency, Journal of Finance, 52(2), pp. 859-874.

[155] LeE K.H. (2011), The World Price of Liquidity Risk, Journal of Financial Economics, 99(1), pp. 136-161.

[156] Lehmann B.N. (1990), Fads, Martingales and Market Efficiency, Quarterly Journal of Economics, 105(1), pp. 1-28.

[157] Lesmond D.A., Schill M.J. and Zhou C. (2004), The Illusory Nature of Momentum Profits, Journal of Financial Economics, 71(2), pp. 349-380.

[158] Lettau M. and Ludvigson S. (2001), Consumption, Aggregate Wealth, and Expected Stock Returns, Journal of Finance, 56(3), pp. 815-849.

[159] Levy R.A. (1967), Relative Strength as A Criterion for Investment Selection, Journal of Finance, 22(4), pp. 595-610.

[160] Lewellen J. (2002), Momentum and Autocorrelation in Stock Returns, Review of Financial Studies, 15(2), pp. 533-564.

[161] Lin H., Wang J. and Wu C. (2011), Liquidity Risk and Expected Corporate Bond Returns, Journal of Financial Economics, 99(3), pp. 628-650.

[162] Litterman R.B. and Scheinkman J.A. (1991), Common Factors Affecting Bond Returns, Journal of Fixed Income, 1(1), pp. 54-61. 
Facts and Fantasies About Factor Investing

[163] Lischewski J. and Voronkova S. (2012), Size, Value and Liquidity. Do They Really Matter on an Emerging Stock Market?, Emerging Markets Review, 13(1), pp. 8-25.

[164] Lo A.W. and MacKinlay A.C. (1990), When are Contrarian Profits due to Stock Market Overreaction?, Review of Financial Studies, 3(2), pp. 175-205.

[165] Lo A.W. and MacKinlay A.C. (1990), Data-snooping Biases in Tests of Financial Asset Pricing Models, Review of Financial Studies, 3(3), pp. 431-467.

[166] Longstaff F.A., Mithal S. and Neis E. (2005), Corporate Yield Spreads: Default Risk or Liquidity? New Evidence from the Credit Default Swap Market, Journal of Finance, 60(5), pp. 2213-2253.

[167] Lou X. and Sadka R. (2011), Liquidity Level or Liquidity Risk? Evidence from the Financial Crisis, Financial Analysts Journal, 67(3), pp. 51-62.

[168] LuCAS R.E. (1978), Asset Prices in an Exchange Economy, Econometrica, 46(6), pp. 1429-1445.

[169] Ludvigson S.C. and Ng S. (2009), Macro Factors in Bond Risk Premia, Review of Financial Studies, 22(12), pp. 5027-5067.

[170] Lustig H. and Verdelhan A. (2007), The Cross Section of Foreign Currency Risk Premia and Consumption Growth Risk, American Economic Review, 97(1), pp. 89-117.

[171] Lustig H. and Verdelhan A. (2011), The Cross Section of Foreign Currency Risk Premia and Consumption Growth Risk: Reply, American Economic Review, 101(7), pp. 3477-3500.

[172] MacKinlay A.C. (1995), Multifactor Models Do Not Explain Deviations from The CAPM, Journal of Financial Economics, 38(1), pp. 3-28.

[173] Markowitz H. (1952), Portfolio Selection, Journal of Finance, 7(1), pp. 77-91.

[174] McLean R.D. and Pontiff J. (2014), Does Academic Research Destroy Stock Return Predictability?, SSRN, www.ssrn.com/abstract $=2156623$.

[175] Meese R.A. and Rogoff K. (1983), Empirical Exchange Rate Models of the Seventies. Do They Fit out of Sample?, Journal of International Economics, 14(1), pp. $3-24$.

[176] Menkhoff L., Sarno L., Schmeling M. and Schrimpf A. (2012), Currency Momentum Strategies, Journal of Financial Economics, 106(3), pp. 660-684.

[177] Merton R.C. (1973), An Intertemporal Capital Asset Pricing Model, Econometrica, 41(5), pp. 867-887.

[178] Merton R.C. (1987), A Simple Model of Capital Market Equilibrium with Incomplete Information, Journal of Finance, 42(3), pp. 483-510.

[179] Meucci A. (2007), Risk Contributions from Generic User-defined Factors, Risk, 20(6), pp. 84-88.

[180] Nagel S. (2005), Short Sales, Institutional Investors and the Cross-section of Stock Returns, Journal of Financial Economics, 78(2), pp. 277-309. 
Facts and Fantasies About Factor Investing

[181] Moreno D. and Rodríguez R. (2009), The Value of Coskewness in Mutual Fund Performance Evaluation, Journal of Banking $\&$ Finance, 33(9), pp. 1664-1676.

[182] Novy-Marx R. (2013), The Other Side of Value: The Gross Profitability Premium, Journal of Financial Economics, 108(1), pp. 1-28.

[183] Novy-Marx R. (2014), The Quality Dimension of Value Investing, University of Rochester, Working Paper.

[184] Novy-Marx R. (2014), Predicting Anomaly Performance with Politics, The Weather, Global Warming, Sunspots, and The Stars, Journal of Financial Economics, 112(2), pp. 137-146.

[185] Okunev J. and White D. (2003), Do Momentum-based Strategies Still Work in Foreign Currency Markets?, Journal of Financial and Quantitative Analysis, 38(2), pp. 425-448.

[186] Pastor L. and Stambaugh R.F. (2001), Liquidity Risk and Expected Stock Returns, Journal of Political Economy, 111(3), pp. 642-685.

[187] Petkova R. (2006), Do the Fama-French Factors Proxy for Innovations in Predictive Variables?, Journal of Finance, 61(2), pp. 581-612.

[188] Petkova R. and Zhang L. (2005), Is Value Riskier than Growth?, Journal of Financial Economics, 78(1), pp. 187-202.

[189] Phalippou L. (2007), Can Risk-based Theories Explain The Value Premium?, Review of finance, 11(2), pp. 143-166.

[190] Piotroski J.D. (2000), Value Investing: The Use of Historical Financial Statement Information to Separate Winners from Losers, Journal of Accounting Research, 38, pp. $1-41$.

[191] Piotroski J.D. and So E.C. (2012), Identifying Expectation Errors in Value/Glamour Strategies: A Fundamental Analysis Approach, Review of Financial Studies, 25(9), pp. 2841-2875.

[192] Potters M. and Bouchaud J.-P. (2005), Trend Followers Lose More Often Than They Gain, Wilmott magazine, 26, pp. 58-63.

[193] Roll R. (1977), A Critique of the Asset Pricing Theory's Tests Part I: On Past and Potential Testability of the Theory, Journal of Financial Economics, 4(2), pp. 129-176.

[194] Roncalli T. (2013), Introduction to Risk Parity and Budgeting, Chapman \& Hall/CRC Financial Mathematics Series.

[195] Roncalli T. and Weisang G. (2012), Risk Parity Portfolios with Risk Factors, $S S R N$, www.ssrn.com/abstract $=2155159$.

[196] Rosenberg B. (1974), Extra-Market Components of Covariance in Security Returns, Journal of Financial and Quantitative Analysis, 9(2), pp. 263-274.

[197] Rosenberg B. and McKibben W. (1973), The Prediction of Systematic and Specific Risk in Common Stocks, Journal of Financial and Quantitative Analysis, 8(2), pp. 317-333. 
Facts and Fantasies About Factor Investing

[198] Rosenberg B., Reid K. and Lanstein R. (1985), Persuasive Evidence of Market Inefficiency, Journal of Portfolio Management, 11(3), pp. 9-16.

[199] Ross S. (1976), The Arbitrage Theory of Capital Asset Pricing, Journal of Economic Theory, 13(3), pp. 341-360.

[200] Rozeff M.S. and Kinney W.R. (1976), Capital Market Seasonality: The Case of Stock Returns, Journal of Financial Economics, 3(4), pp. 379-402.

[201] Rouwenhorst K.G. (1998), International Momentum Strategies, Journal of Finance, 53(1), pp. 267-284.

[202] SADKA R. (2006), Momentum and Post-Earnings-Announcement Drift Anomalies: The Role of Liquidity Risk, Journal of Financial Economics, 80(2), pp. 309-349.

[203] SAdka R. (2010), Liquidity Risk and The Cross-Section of Hedge-Fund Returns, Journal of Financial Economics, 80(2), pp. 309-349.

[204] Sagi J.S. and Seasholes M.S. (2007), Firm-specific Attributes and the Cross-section of Momentum, Journal of Financial Economics, 84(2), pp. 389-434.

[205] Scherer B. (2011), A Note on the Returns from Minimum Variance Investing, Journal of Empirical Finance, 18(4), pp. 652-660.

[206] Sharpe W.F. (1964), Capital Asset Prices: A Theory of Market Equilibrium under Conditions of Risk, Journal of Finance, 19(3), pp. 425-442.

[207] SlOAn R.G. (1996), Do Stock Prices Fully Reflect Information in Accruals and Cash Flows about Future Earnings?, Accounting Review, 71(3), pp. 289-315.

[208] Stambaugh R.F., Yu J. and Yuan Y. (2012), The short of It: Investor Sentiment and Anomalies, Journal of Financial Economics, 104(2), pp. 288-302.

[209] Tobin J. (1958), Liquidity Preference as Behavior Towards Risk, Review of Economic Studies, 25(2), pp. 65-86.

[210] Vassalou M. and Xing Y. (2004), Default Risk in Equity Returns, Journal of Finance, 59(2), pp. 831-868.

[211] White H. (2000), A Reality Check for Data Snooping, Econometrica, 68(5), pp. 10971126.

[212] Zhang C.Y. and Jacobsen B. (2012), Are Monthly Seasonals Real? A Three Century Perspective, Review of Finance, 17(5), pp. 1743-1785.

[213] Zhang L. (2005), The Value Premium, Journal of Finance, 60(1), pp. 67-103. 


\section{A Mathematical results}

\section{A.1 Derivation of the arbitrage pricing theory}

We recall that:

$$
R_{i}-\mathbb{E}\left[R_{i}\right]=\sum_{j=1}^{m} \beta_{i}^{j}\left(\mathcal{F}_{j}-\mathbb{E}\left[\mathcal{F}_{j}\right]\right)+\varepsilon_{i}
$$

We consider an arbitrage portfolio $x \neq \mathbf{0}_{n}$ such as $\sum_{i=1}^{n} x_{i} \beta_{i}^{j}=0$ and $\sum_{i=1}^{n} x_{i}=0$. We obtain:

$$
\begin{aligned}
R(x) & =\sum_{i=1}^{n} x_{i} R_{i} \\
& =\sum_{i=1}^{n} x_{i}\left(\mathbb{E}\left[R_{i}\right]+\sum_{j=1}^{m} \beta_{i}^{j}\left(\mathcal{F}_{j}-\mathbb{E}\left[\mathcal{F}_{j}\right]\right)+\varepsilon_{i}\right) \\
& =\sum_{i=1}^{n} x_{i} \mathbb{E}\left[R_{i}\right]+\sum_{i=1}^{n} \sum_{j=1}^{m} x_{i} \beta_{i}^{j}\left(\mathcal{F}_{j}-\mathbb{E}\left[\mathcal{F}_{j}\right]\right)+\sum_{i=1}^{n} x_{i} \varepsilon_{i}
\end{aligned}
$$

If the portfolio is well-diversified, it follows that $\sum_{i=1}^{n} x_{i} \varepsilon_{i} \rightarrow 0$ and $\sum_{i=1}^{n} x_{i} \beta_{i}^{j}\left(\mathcal{F}_{j}-\mathbb{E}\left[\mathcal{F}_{j}\right]\right) \rightarrow$ 0 , meaning that:

$$
R(x)=\sum_{i=1}^{n} x_{i} \mathbb{E}\left[R_{i}\right]=\mu(x)
$$

We deduce that the return of the portfolio is certain which implies that $\sigma(x)=0$. Arbitrage theory tells us that the return of the portfolio is then the risk-free rate:

$$
R(x)=R_{f}
$$

Finally, we obtain the following set of constraints:

$$
\left\{\begin{array}{l}
\sum_{i=1}^{n} x_{i} \beta_{i}^{j}=0 \\
\sum_{i=1}^{n} x_{i}=0 \\
\sum_{i=1}^{n} x_{i}\left(\mathbb{E}\left[R_{i}\right]-R_{f}\right)=0
\end{array}\right.
$$

This set of equations has a solution if there exists a vector $\left(\pi_{1}, \ldots, \pi_{m}\right)$ such as ${ }^{95}$ :

$$
\mathbb{E}\left[R_{i}\right]=R_{f}+\sum_{j=1}^{m} \beta_{i}^{j} \pi_{j}
$$

$$
\begin{aligned}
& { }^{95} \text { We have } A x=0 \text { and } B x=\mathbf{0}_{m+1} \text { with: } \\
& \qquad A=\left(\begin{array}{lll}
\mathbb{E}\left[R_{1}\right]-R_{f} & \cdots & \mathbb{E}\left[R_{n}\right]-R_{f}
\end{array}\right)
\end{aligned}
$$

and:

$$
B=\left(\begin{array}{ccc}
1 & \cdots & 1 \\
\beta_{1}^{1} & & \beta_{n}^{1} \\
& \ddots & \\
\beta_{1}^{m} & & \beta_{n}^{m}
\end{array}\right)
$$

Using linear algebra, we can show that $A$ belongs to the subspace of $B$. We deduce that:

$$
A=\pi^{\top} B
$$

where $\pi=\left(\pi_{0}, \pi_{1}, \ldots, \pi_{m}\right)$. It is easy to show that $\pi_{0}=0$. 
For a fully-invested portfolio $x$, this relationship becomes:

$$
\begin{aligned}
\mu(x) & =\mathbb{E}\left[\sum_{i=1}^{n} x_{i} R_{i}\right] \\
& =R_{f}+\sum_{j=1}^{m}\left(\sum_{i=1}^{n} x_{i} \beta_{i}^{j}\right) \pi_{j} \\
& =R_{f}+\sum_{j=1}^{m} \beta^{j}(x) \pi_{j}
\end{aligned}
$$

where $\beta^{j}(x)=\sum_{i=1}^{n} x_{i} \beta_{i}^{j}$ is the sensitivity of the portfolio $x$ with respect to the factor $j$. Let us now consider a portfolio which is only sensitive to the factor $j$ :

$$
\left\{\begin{array}{l}
\beta^{k}(x)=0 \quad \text { if } k \neq j \\
\beta^{j}(x)=1
\end{array}\right.
$$

It follows that:

$$
\mu\left(\mathcal{F}_{j}\right)=\mathbb{E}\left[\mathcal{F}_{j}\right]=R_{f}+\pi_{k}
$$

We can interpret $\pi_{k}=\mu\left(\mathcal{F}_{j}\right)-R_{f}$ as the risk premium of the factor $j$. We conclude that:

$$
\pi_{i}=\mathbb{E}\left[R_{i}\right]-R_{f}=\sum_{j=1}^{m} \beta_{i}^{j}\left(\mu\left(\mathcal{F}_{j}\right)-r\right)
$$

\section{A.2 Option profile of momentum strategies}

Potters and Bouchaud (2005) show that losses are more frequent than gains in a trendfollowing strategy on indexes. The explanation is simple. In most cases, a trend-following strategy loses money, because there are a lot of bad signals, but these losses are limited. Sometimes, asset classes exhibit a big trend. In this case, the trend-following strategy gains a lot of money. Because this situation is less frequent, it follows that trend-following strategies loses frequently a limited amount of money, but gains occasionally a large amount of money. This means that the option profile of a CTA strategy is a long exposure on a straddle payoff.

The trend-following strategy described above is different than the momentum strategy of the WML factor. Indeed, a CTA strategy exhibits a zero-beta correlation with respect to the market risk factor in the long run. However, it is not true in the short run, because a CTA strategy presents locally a high positive or negative beta. The behavior of the WML factor is completely different. By construction, it has a zero-beta correlation with the market all of the time. Empirical results show that the WML factor exhibits a gain most of the time. However, it may suffer a lot when the market rebounds after a serious crash. In this case, past loser stocks post much better returns than past winner stocks. This situation is called a 'momentum crash' by Daniel and Moskowitz (2013). The option profile of WML is therefore very different than the option profile of CTA. Investors in the WML strategy generally receive a premium and sometimes pay the payoff whereas investors in the CTA strategy generally pay a premium and sometimes receive the payoff. Figure 33 summarizes these two option profiles. 
Figure 33: Option profile of CTA and WML strategies

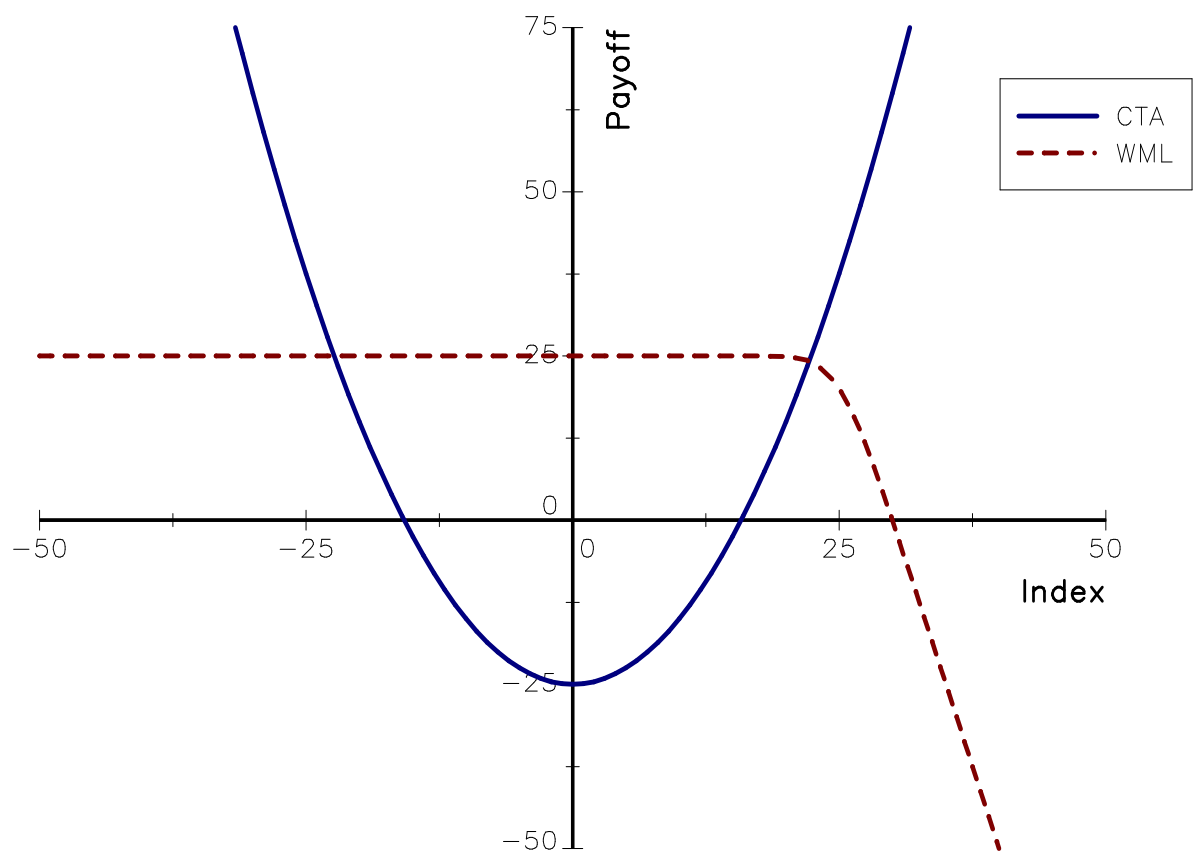

\section{A.3 Optimal solution of the factor replication problem}

Let $\mathcal{F}_{j}^{\star}=x^{\top} R$ be the replicating factor. We have:

$$
\mathcal{F}_{j}^{\star}=x^{\top} \alpha+x^{\top} B \mathcal{F}+x^{\top} \varepsilon
$$

It follows that:

$$
\begin{aligned}
\sigma^{2}\left(\mathcal{F}_{j}^{\star}\right) & =x^{\top} B \Omega B^{\top} x+x^{\top} D x \\
& =\beta(x)^{\top} \Omega \beta(x)+x^{\top} D x
\end{aligned}
$$

and:

$$
\sigma^{2}\left(\mathcal{F}_{j}\right)=e_{j}^{\top} \Omega e_{j}
$$

We also deduce that:

$$
\begin{aligned}
\operatorname{cov}\left(\mathcal{F}_{j}^{\star}, \mathcal{F}_{j}\right) & =\mathbb{E}\left[\left(x^{\top} B(\mathcal{F}-\mu(\mathcal{F}))+x^{\top} \varepsilon\right)(\mathcal{F}-\mu(\mathcal{F}))^{\top} e_{j}\right] \\
& =\beta(x)^{\top} \Omega e_{j}
\end{aligned}
$$

The expression of the tracking error variance is then:

$$
\sigma^{2}\left(\mathcal{F}_{j}^{\star}-\mathcal{F}_{j}\right)=\beta(x)^{\top} \Omega \beta(x)+x^{\top} D x+e_{j}^{\top} \Omega e_{j}-2 \beta(x)^{\top} \Omega e_{j}
$$

The first-order condition of the minimization program is:

$$
B \Omega B^{\top} x+D x-B \Omega e_{j}=0
$$

We deduce that the optimal solution is:

$$
x^{\star}=\left(B \Omega B^{\top}+D\right)^{-1} B \Omega e_{j}
$$




\section{A.4 Parameterization of the risk model with long-only factors}

If we assume that each factor is the result of a long/short portfolio for $m \geq 2$, we have:

$$
\mathcal{F}_{j}=\mathcal{F}_{j}^{+}-\mathcal{F}_{j}^{-}
$$

In this case, we obtain:

$$
\begin{aligned}
R_{i} & =\alpha_{i}+\beta_{i}^{1} \mathcal{F}_{1}+\sum_{j=2}^{m} \beta_{i}^{j}\left(\mathcal{F}_{j}^{+}-\mathcal{F}_{j}^{-}\right)+\varepsilon_{i} \\
& =\alpha_{i}+\beta_{i}^{1} \mathcal{F}_{1}+\sum_{j=2}^{m} \beta_{i}^{j} \mathcal{F}_{j}^{+}-\sum_{j=2}^{m} \beta_{i}^{j} \mathcal{F}_{j}^{-}+\varepsilon_{i}
\end{aligned}
$$

We can rewrite the previous model as follows:

$$
R_{i}=\alpha_{i}+\beta_{i}^{1} \mathcal{F}_{1}+\sum_{j=2}^{m} \beta_{i}^{j} \mathcal{F}_{j}^{+}+\eta_{i}
$$

where the residual risk is equal to:

$$
\eta_{i}=\varepsilon_{i}-\sum_{j=2}^{m} \beta_{i}^{j} \mathcal{F}_{j}^{-}
$$

It is obvious that imposing the long-only constraint has a big impact on residual risks $\eta_{i}$.

Another approach consists in reformulating the first factor:

$$
\begin{aligned}
R_{i} & =\alpha_{i}+\beta_{i}^{1}\left(\mathcal{F}_{1}-\sum_{j=2}^{m} \frac{\beta_{i}^{j}}{\beta_{i}^{1}} \mathcal{F}_{j}^{-}\right)+\sum_{j=2}^{m} \beta_{i}^{j} \mathcal{F}_{j}^{+}+\varepsilon_{i} \\
& =\alpha_{i}+\beta_{i}^{1} \tilde{\mathcal{F}}_{1}+\sum_{j=2}^{m} \beta_{i}^{j} \mathcal{F}_{j}^{+}+\varepsilon_{i}
\end{aligned}
$$

In this case, we observe that the original risk factors are transformed into new risk factors. The long/short risk factors are replaced by their long-only counterpart components, whereas the first factor is replaced by a synthetic factor.

\section{A.5 Sharpe ratio of portfolios invested in long/short risk factors}

We recall that $\mathcal{F} \sim \mathcal{N}(\mu(\mathcal{F}), \Omega)$. Let $x$ be a portfolio of risk factors. The portfolio return is:

$$
R(x)=x^{\top} \mathcal{F}
$$

We deduce that $R(x) \sim \mathcal{N}\left(x^{\top} \mu(\mathcal{F}), x^{\top} \Omega x\right)$. Because the risk factors are long/short, the Sharpe ratio of the factor portfolio is:

$$
\operatorname{SR}(x)=\frac{x^{\top} \mu(\mathcal{F})}{\sqrt{x^{\top} \Omega x}}
$$


If we assume that the long/short risk factors are uncorrelated $\left(\mathcal{H}_{1}\right)$, we obtain:

$$
\begin{aligned}
& \operatorname{SR}(x)=\sum_{j=1}^{m} \frac{x_{j} \mu\left(\mathcal{F}_{j}\right)}{\sqrt{\sum_{k=1}^{m} x_{k}^{2} \sigma^{2}\left(\mathcal{F}_{k}\right)}} \\
& =\sum_{j=1}^{m} \frac{x_{j} \sigma\left(\mathcal{F}_{j}\right) \mu\left(\mathcal{F}_{j}\right)}{\sqrt{\sum_{k=1}^{m} x_{k}^{2} \sigma^{2}\left(\mathcal{F}_{k}\right)} \sigma\left(\mathcal{F}_{j}\right)} \\
& =\sum_{j=1}^{m} w_{j} \operatorname{SR}\left(\mathcal{F}_{j}\right)
\end{aligned}
$$

with:

$$
w_{j}=\frac{x_{j} \sigma\left(\mathcal{F}_{j}\right)}{\sqrt{\sum_{k=1}^{m} x_{k}^{2} \sigma^{2}\left(\mathcal{F}_{k}\right)}}
$$

We notice that $\sum_{j=1}^{m} w_{j}>1$. For some special cases of portfolios, we can find an explicit expression of the Sharpe ratio:

1. In the case of the equally-weighted portfolios, the weights becomes:

$$
w_{j}=\frac{\sigma\left(\mathcal{F}_{j}\right)}{\sqrt{\sum_{k=1}^{m} \sigma^{2}\left(\mathcal{F}_{k}\right)}}
$$

Moreover, if we assume that the factors have the same volatility, we obtain $w_{j}=1 / \sqrt{m}$ and:

$$
\mathrm{SR}(x)=\sqrt{m} \cdot \overline{\mathrm{SR}(\mathcal{F})}
$$

where $\overline{\operatorname{SR}(\mathcal{F})}$ is the average Sharpe ratio.

2. In the case of the ERC portfolio, the weights becomes ${ }^{96}$ :

$$
w_{j}=\frac{1}{\sqrt{m}}
$$

Moreover, if we assume that the factors have the same volatility, we retrieve the formula for the EW portfolio:

$$
\mathrm{SR}(x)=\sqrt{m} \cdot \overline{\operatorname{SR}(\mathcal{F})}
$$

\section{A.6 Portfolio optimization with long-only risk factors}

\section{A.6.1 The framework}

We assume that the long/short risk factor is expressed as:

$$
\mathcal{F}_{j}=\mathcal{F}_{j}^{+}-\mathcal{F}_{j}^{-}
$$

and:

$$
\begin{aligned}
& \mathcal{F}_{j}^{+}-r=\alpha_{j}^{+}+\beta_{j}\left(R_{m}-r\right)+\varepsilon_{j}^{+} \\
& \mathcal{F}_{j}^{-}-r=\alpha_{j}^{-}+\beta_{j}\left(R_{m}-r\right)+\varepsilon_{j}^{-}
\end{aligned}
$$

\footnotetext{
${ }^{96}$ We have:
}

$$
x_{j}=\frac{\sigma^{-1}\left(\mathcal{F}_{j}\right)}{\sum_{k=1}^{m} \sigma^{-1}\left(\mathcal{F}_{k}\right)}
$$


We generally assume that $\alpha_{j}^{+}>\alpha_{j}^{-}$. This implies that:

$$
\mathcal{F}_{j}=\left(\alpha_{j}^{+}-\alpha_{j}^{-}\right)+\left(\varepsilon_{j}^{+}-\varepsilon_{j}^{-}\right)
$$

We notice that:

$$
\mu\left(\mathcal{F}_{j}^{+}\right)=r+\alpha_{j}^{+}+\beta_{j}\left(\mu_{m}-r\right)
$$

and:

$$
\sigma\left(\mathcal{F}_{j}^{+}\right)=\sqrt{\beta_{j}^{2} \sigma_{m}^{2}+\left(\tilde{\sigma}_{j}^{+}\right)^{2}}
$$

The Sharpe ratio of the long-only risk factor is:

$$
\operatorname{SR}\left(\mathcal{F}_{j}^{+} \mid r\right)=\frac{\alpha_{j}^{+}+\beta_{j}\left(\mu_{m}-r\right)}{\sqrt{\beta_{j}^{2} \sigma_{m}^{2}+\left(\tilde{\sigma}_{j}^{+}\right)^{2}}}
$$

It is the sum of two components: one coming from the alpha and one coming from the market risk premium.

\section{A.6.2 The maximum Sharpe ratio portfolio}

We assume that the investor optimizes the Sharpe ratio of its portfolio:

$$
\begin{aligned}
x^{\star} & =\arg \max \frac{x^{\top}\left(\mu\left(\mathcal{F}^{+}\right)-r \mathbf{1}\right)}{\sqrt{x^{\top} \Omega_{+} x}} \\
\text { u.c. } & \left\{\begin{array}{l}
\mathbf{1}^{\top} x=1 \\
x \geq \mathbf{0}
\end{array}\right.
\end{aligned}
$$

The constraint $x \geq \mathbf{0}$ is not an issue for the optimization problem, because it is only used to determine the risk factors which are present in the long-only portfolio. Indeed, we can always delete a risk factor to reduce the universe and obtain a solution with all selected risk factors. The solution of the MSR portfolio is ${ }^{97}$ :

$$
x^{\star}=\frac{\Omega_{+}^{-1}\left(\mu\left(\mathcal{F}^{+}\right)-r \mathbf{1}\right)}{\mathbf{1}^{\top} \Omega_{+}^{-1}\left(\mu\left(\mathcal{F}^{+}\right)-r \mathbf{1}\right)}
$$

We know that ${ }^{98}$ :

$$
\Omega_{+}^{-1}=D^{-1}-\frac{\sigma_{m}^{2}}{1+\sigma_{m}^{2} \kappa} \tilde{\beta} \tilde{\beta}^{\top}
$$

with $\tilde{\beta}_{j}=\beta_{j} /\left(\tilde{\sigma}_{j}^{+}\right)^{2}$ and $\kappa=\tilde{\beta}^{\top} \beta$. It follows that:

$$
x^{\star} \propto\left(D^{-1}-\frac{\sigma_{m}^{2}}{1+\sigma_{m}^{2} \kappa} \tilde{\beta} \tilde{\beta}^{\top}\right)\left(\alpha^{+}+\beta\left(\mu_{m}-r\right)\right)
$$

We deduce that:

$$
\begin{aligned}
x_{j}^{\star} & \propto \frac{\alpha_{j}^{+}+\beta_{j}\left(\mu_{m}-r\right)}{\left(\tilde{\sigma}_{j}^{+}\right)^{2}}-\frac{\sigma_{m}^{2}}{1+\sigma_{m}^{2} \kappa} \sum_{k=1}^{m} \tilde{\beta}_{j} \tilde{\beta}_{k}\left(\alpha_{k}^{+}+\beta_{k}\left(\mu_{m}-r\right)\right) \\
& =\frac{\alpha_{j}^{+}+\beta_{j}\left(\mu_{m}-r\right)}{\left(\tilde{\sigma}_{j}^{+}\right)^{2}}-\left(\frac{\sigma_{m}^{2}}{1+\sigma_{m}^{2} \kappa}\right) \frac{\beta_{j}}{\left(\tilde{\sigma}_{j}^{+}\right)^{2}} \sum_{k=1}^{m} \beta_{k} \frac{\left(\alpha_{k}^{+}+\beta_{k}\left(\mu_{m}-r\right)\right)}{\left(\tilde{\sigma}_{k}^{+}\right)^{2}} \\
& =\frac{1}{\left(\tilde{\sigma}_{j}^{+}\right)^{2}}\left(\alpha_{j}^{+}+\beta_{j}\left(\mu_{m}-r-\lambda\right)\right)
\end{aligned}
$$

\footnotetext{
${ }^{97}$ See Roncalli (2013) on Page 14.

${ }^{98}$ See Roncalli (2013) on Page 167.
} 
with:

$$
\lambda=\left(\frac{\sigma_{m}^{2}}{1+\sigma_{m}^{2} \kappa}\right) \sum_{k=1}^{m} \beta_{k} \frac{\left(\alpha_{k}^{+}+\beta_{k}\left(\mu_{m}-r\right)\right)}{\left(\tilde{\sigma}_{k}^{+}\right)^{2}}
$$

We can interpret $\lambda$ as a weighted average of risk premia.

In the case of the long-only portfolio, we can show that:

$$
x_{j}^{\star} \propto \frac{1}{\left(\tilde{\sigma}_{j}^{+}\right)^{2}} \max \left(\alpha_{j}^{+}+\beta_{j}\left(\mu_{m}-r-\lambda^{\star}\right), 0\right)
$$

with:

$$
\begin{aligned}
\lambda^{\star} & =\left(\frac{\sigma_{m}^{2}}{1+\sigma_{m}^{2} \kappa^{\star}}\right) \sum_{k \in \mathcal{L} \mathcal{O}} \beta_{k} \frac{\left(\alpha_{k}^{+}+\beta_{k}\left(\mu_{m}-r\right)\right)}{\left(\tilde{\sigma}_{k}^{+}\right)^{2}} \\
\kappa^{\star} & =\sum_{\alpha_{k}^{+}+\beta_{k}\left(\mu_{m}-r\right)>\beta_{k} \lambda^{\star}} \tilde{\beta}_{k} \beta_{k} \\
\mathcal{L O} & =\left\{k \in\{1, \ldots, m\}: \frac{\mu\left(\mathcal{F}_{k}^{+}\right)-r}{\beta_{k}}>\lambda^{\star}\right\}
\end{aligned}
$$

Contrary to Solution (24), Solution (25) is endogenous because $\lambda^{\star}$ can be computed only if we know the set of positive weights.

\section{A.6.3 The tracking error optimized portfolio}

We now consider that the risk factors are composed by the $m$ long-only risk factors and the market risk factor. The optimization problem becomes:

$$
x^{\star}=\arg \max (x-b)^{\top}\left[\begin{array}{c}
\mu\left(\mathcal{F}^{+}\right) \\
\mu_{m}
\end{array}\right]-\frac{\phi}{2}(x-b)^{\top}\left[\begin{array}{cc}
\tilde{\Omega}_{+} & \beta \sigma_{m}^{2} \\
\beta^{\top} \sigma_{m}^{2} & \sigma_{m}^{2}
\end{array}\right](x-b)
$$

By its very nature, $b=\mathbf{e}_{m+1}$ because the MKT factor corresponds to the last risk factor. Without any constraints, we know that the optimal solution is ${ }^{99}$ :

$$
x^{\star}=\frac{1}{\phi}\left[\begin{array}{cc}
\tilde{\Omega}_{+} & \beta \sigma_{m}^{2} \\
\beta^{\top} \sigma_{m}^{2} & \sigma_{m}^{2}
\end{array}\right]^{-1}\left[\begin{array}{c}
\mu\left(\mathcal{F}^{+}\right) \\
\mu_{m}
\end{array}\right]+\mathbf{e}_{m+1}
$$

Using blockwise inversion, it follows that:

$$
\left[\begin{array}{cc}
\tilde{\Omega}_{+} & \beta \sigma_{m}^{2} \\
\beta^{\top} \sigma_{m}^{2} & \sigma_{m}^{2}
\end{array}\right]^{-1}=\left[\begin{array}{cc}
D^{-1} & -D^{-1} \beta \\
-\beta^{\top} D^{-1} & \sigma_{m}^{-2}+\beta^{\top} D^{-1} \beta
\end{array}\right]
$$

We deduce that:

$$
\begin{aligned}
x_{j}^{\star} & =\frac{\mu\left(\mathcal{F}_{j}^{+}\right)-\beta_{j} \mu_{m}}{\phi\left(\tilde{\sigma}_{j}^{+}\right)^{2}} \\
& =\phi^{-1} \frac{\alpha_{j}^{+}+\left(1-\beta_{j}\right) r}{\left(\tilde{\sigma}_{j}^{+}\right)^{2}}
\end{aligned}
$$

\footnotetext{
${ }^{99}$ See Roncalli (2013) on Page 19.
} 
for $j=1, \ldots, m$ and:

$$
\begin{aligned}
x_{m+1}^{\star} & =\frac{\left(\sigma_{m}^{-2}+\beta^{\top} D^{-1} \beta\right) \mu_{m}-\beta^{\top} D^{-1} \mu\left(\mathcal{F}^{+}\right)+\phi}{\phi} \\
& =1-\phi^{-1}\left(\sum_{k=1}^{m} \tilde{\beta}_{k} \mu\left(\mathcal{F}_{k}^{+}\right)-\left(\frac{1+\sigma_{m}^{2} \kappa}{\sigma_{m}^{2}}\right) \mu_{m}\right)
\end{aligned}
$$

If we impose the constraint that the optimal portfolio is long-only, meaning that $\sum_{j=1}^{m+1} x_{j}=$ 1 and $x_{j} \geq 0$, the solution becomes:

$$
x_{j}^{\star}=\phi^{-1} \frac{\left(\mu\left(\mathcal{F}_{j}^{+}\right)-\beta_{j} \mu_{m}+\lambda_{j}^{\star}-\beta_{j} \lambda_{m+1}^{\star}\right)}{\left(\tilde{\sigma}_{j}^{+}\right)^{2}}
$$

for $j=1, \ldots, m$ and:

$$
x_{m+1}^{\star}=1-\phi^{-1}\left(\sum_{k=1}^{m} \tilde{\beta}_{k}\left(\mu\left(\mathcal{F}_{k}^{+}\right)+\lambda_{k}^{\star}\right)-\left(\frac{1+\sigma_{m}^{2} \kappa}{\sigma_{m}^{2}}\right)\left(\mu_{m}+\lambda_{m+1}^{\star}\right)\right)
$$

where $\lambda_{j}^{\star}$ is the sum of the Lagrange coefficient $\lambda_{0}$ associated to the equality constraint $\sum_{j=1}^{m+1} x_{j}=1$ and the Lagrange coefficient $\lambda_{j}$ associated to the positivity constraint $x_{j} \geq 0$.

Remark 11 By definition of the Kuhn-Tucker conditions, $\lambda_{j}$ is positive whereas $\lambda_{0}$ can be either negative or positive. 


\section{B Additional results}

\section{B.1 Tables}

Table 37: Average of $\Delta R^{2}$ (in \%) with the SMB factor

\begin{tabular}{|c|ccccc|}
\hline Year & Asia Pacific & Europe & Japan & North America & US \\
\hline 1995 & 10.6 & 12.1 & 9.2 & 13.5 & 12.7 \\
1996 & 10.2 & 12.4 & 8.9 & 17.3 & 16.0 \\
1997 & 10.8 & 15.3 & 10.3 & 18.2 & 14.4 \\
1998 & 10.6 & 17.3 & 13.2 & 18.1 & 14.1 \\
1999 & 9.8 & 17.6 & 13.9 & 15.3 & 13.1 \\
2000 & 10.0 & 18.9 & 16.7 & 22.8 & 20.9 \\
2001 & 9.4 & 16.7 & 16.2 & 20.3 & 20.3 \\
2002 & 8.7 & 14.4 & 15.5 & 18.4 & 18.6 \\
2003 & 9.4 & 12.1 & 12.6 & 17.1 & 17.5 \\
2004 & 9.7 & 10.5 & 13.0 & 17.4 & 17.8 \\
2005 & 7.5 & 8.1 & 10.0 & 9.3 & 11.2 \\
2006 & 7.6 & 7.2 & 11.7 & 9.5 & 11.3 \\
2007 & 8.5 & 6.7 & 13.4 & 8.7 & 9.9 \\
2008 & 6.9 & 5.8 & 13.8 & 7.6 & 8.5 \\
2009 & 4.6 & 4.4 & 13.7 & 5.0 & 5.1 \\
2010 & 4.4 & 4.8 & 12.2 & 4.9 & 5.5 \\
2011 & 4.0 & 4.2 & 11.1 & 4.2 & 4.8 \\
2012 & 3.7 & 3.9 & 10.6 & 3.7 & 4.4 \\
2013 & 4.0 & 3.9 & 9.1 & 4.0 & 4.3 \\
\hline
\end{tabular}


Facts and Fantasies About Factor Investing

Table 38: Average of $\Delta R^{2}$ (in \%) with the HML factor

\begin{tabular}{|c|ccccc|}
\hline Year & Asia Pacific & Europe & Japan & North America & US \\
\hline 1995 & 1.8 & 3.5 & 1.0 & 4.2 & 4.9 \\
1996 & 2.1 & 3.7 & 1.0 & 5.4 & 6.4 \\
1997 & 2.5 & 3.3 & 1.1 & 7.4 & 6.5 \\
1998 & 3.1 & 2.3 & 2.5 & 5.5 & 4.6 \\
1999 & 3.7 & 2.3 & 2.6 & 3.8 & 4.7 \\
2000 & 3.6 & 9.1 & 7.8 & 13.3 & 15.3 \\
2001 & 3.9 & 10.3 & 8.6 & 13.6 & 18.2 \\
2002 & 3.7 & 8.8 & 9.2 & 12.3 & 16.8 \\
2003 & 3.9 & 7.6 & 8.8 & 12.0 & 16.7 \\
2004 & 3.9 & 6.6 & 8.6 & 12.8 & 17.2 \\
2005 & 4.1 & 3.3 & 3.7 & 8.4 & 11.4 \\
2006 & 3.8 & 2.0 & 2.5 & 3.8 & 4.3 \\
2007 & 4.2 & 1.6 & 2.6 & 3.0 & 3.9 \\
2008 & 3.0 & 1.0 & 3.0 & 2.4 & 3.0 \\
2009 & 1.5 & 0.7 & 2.8 & 2.2 & 2.7 \\
2010 & 1.5 & 0.9 & 3.4 & 2.0 & 2.8 \\
2011 & 1.4 & 1.0 & 2.9 & 1.7 & 2.6 \\
2012 & 1.2 & 1.1 & 2.9 & 1.6 & 2.4 \\
2013 & 1.4 & 1.2 & 3.0 & 1.4 & 2.1 \\
\hline
\end{tabular}

Table 39: Yearly return of the MKT - RF factor (in \%)

\begin{tabular}{|r|rrrcr|}
\hline Year & Asia Pacific & Europe & Japan & North America & \multicolumn{1}{c|}{ US } \\
\hline 1995 & 14.9 & 19.3 & -2.5 & 35.7 & 36.8 \\
1996 & 22.9 & 21.9 & -16.1 & 22.3 & 21.1 \\
1997 & -20.6 & 19.9 & -28.7 & 30.8 & 31.2 \\
1998 & -6.7 & 25.5 & 7.5 & 22.9 & 24.3 \\
1999 & 46.6 & 19.7 & 81.7 & 23.3 & 25.2 \\
2000 & -15.6 & -9.9 & -32.9 & -7.8 & -11.6 \\
2001 & -8.1 & -20.0 & -28.9 & -10.7 & -11.4 \\
2002 & -7.0 & -14.0 & -7.8 & -21.3 & -21.1 \\
2003 & 50.5 & 42.7 & 41.0 & 32.5 & 31.8 \\
2004 & 28.6 & 23.6 & 17.3 & 13.1 & 11.9 \\
2005 & 13.4 & 11.9 & 27.2 & 7.9 & 6.1 \\
2006 & 33.8 & 37.0 & 1.0 & 15.6 & 15.4 \\
2007 & 36.5 & 14.1 & -4.9 & 7.8 & 5.7 \\
2008 & -51.1 & -45.7 & -26.0 & -37.9 & -36.7 \\
2009 & 77.4 & 35.5 & 5.2 & 31.9 & 28.3 \\
2010 & 22.4 & 6.1 & 16.2 & 18.3 & 17.5 \\
2011 & -15.2 & -13.0 & -10.3 & -0.7 & 0.5 \\
2012 & 24.6 & 21.1 & 6.5 & 15.6 & 16.4 \\
2013 & 6.2 & 28.5 & 26.7 & 32.3 & 35.2 \\
\hline
\end{tabular}


Facts and Fantasies About Factor Investing

Table 40: Yearly return of the SMB factor (in \%)

\begin{tabular}{|r|rrrrr|}
\hline Year & Asia Pacific & Europe & Japan & North America & \multicolumn{1}{c|}{ US } \\
\hline 1995 & -10.3 & -8.3 & -3.5 & -3.1 & -5.7 \\
1996 & 4.0 & -1.9 & -8.6 & -3.1 & -2.0 \\
1997 & -9.3 & -12.3 & -33.1 & -8.8 & -4.8 \\
1998 & -15.8 & -13.6 & 8.9 & -19.6 & -19.3 \\
1999 & 12.9 & 11.7 & -8.9 & 9.8 & 13.4 \\
2000 & -20.1 & -7.0 & 1.1 & -3.1 & -4.8 \\
2001 & -3.6 & -0.7 & 5.1 & 16.3 & 20.4 \\
2002 & 1.4 & 6.5 & 2.1 & 0.6 & 3.9 \\
2003 & 13.5 & 8.8 & 14.3 & 17.6 & 22.2 \\
2004 & -6.2 & 7.5 & 17.0 & 5.7 & 5.0 \\
2005 & -9.6 & 5.0 & 10.7 & 0.0 & -1.8 \\
2006 & 7.1 & 6.1 & -20.4 & 0.6 & 0.5 \\
2007 & -0.3 & -8.0 & -7.3 & -5.8 & -7.8 \\
2008 & -22.4 & -10.2 & 6.3 & -0.7 & 7.0 \\
2009 & 20.4 & 8.6 & 0.3 & 9.6 & 7.9 \\
2010 & 9.4 & 9.7 & 4.5 & 15.7 & 12.9 \\
2011 & -10.6 & -8.7 & 9.3 & -6.1 & -5.0 \\
2012 & -9.1 & 1.0 & 1.3 & -0.6 & 0.5 \\
2013 & -1.0 & 6.2 & -3.1 & 2.0 & 6.0 \\
\hline
\end{tabular}

Table 41: Yearly return of the HML factor (in \%)

\begin{tabular}{|c|rrrcr|}
\hline Year & Asia Pacific & Europe & Japan & North America & \multicolumn{1}{c|}{ US } \\
\hline 1995 & 1.0 & -5.0 & -3.5 & -2.0 & 0.8 \\
1996 & 7.1 & 1.6 & 9.0 & 5.2 & 1.4 \\
1997 & -2.4 & 12.2 & -12.8 & 11.4 & 9.6 \\
1998 & 11.3 & 0.6 & 1.7 & -13.6 & -10.2 \\
1999 & 11.5 & -17.0 & -32.5 & -25.3 & -26.7 \\
2000 & 23.7 & 33.0 & 60.1 & 48.9 & 37.3 \\
2001 & 18.0 & 33.0 & 20.2 & 11.7 & 14.8 \\
2002 & 18.3 & 26.9 & 14.4 & 18.2 & 12.6 \\
2003 & 13.7 & 15.6 & 9.2 & 4.6 & 3.2 \\
2004 & 8.3 & 9.2 & 8.6 & 9.0 & 8.7 \\
2005 & 1.5 & 8.0 & -0.3 & 7.0 & 8.6 \\
2006 & 2.1 & 7.9 & 14.5 & 11.6 & 12.7 \\
2007 & 4.5 & -0.6 & 5.9 & -12.4 & -11.6 \\
2008 & 9.0 & -3.1 & 21.3 & 0.2 & 2.0 \\
2009 & -5.1 & 1.7 & -3.8 & -1.7 & -1.8 \\
2010 & -1.1 & -5.3 & -0.3 & -1.1 & -2.1 \\
2011 & -1.9 & -14.1 & 5.5 & -4.5 & -6.8 \\
2012 & 14.9 & 1.4 & -1.6 & 5.6 & 6.8 \\
2013 & 5.0 & 7.9 & 2.3 & 0.7 & 0.4 \\
\hline
\end{tabular}


Facts and Fantasies About Factor Investing

Table 42: Yearly return of the SHML factor (in \%)

\begin{tabular}{|r|rrrrr|}
\hline Year & Asia Pacific & Europe & Japan & North America & \multicolumn{1}{c|}{ US } \\
\hline 1995 & 2.9 & -3.1 & -0.7 & -3.6 & 2.4 \\
1996 & -3.3 & 2.4 & 3.9 & 8.6 & 10.6 \\
1997 & 11.0 & 14.3 & -1.6 & 19.4 & 22.7 \\
1998 & 8.1 & 4.2 & -3.5 & -7.2 & -3.1 \\
1999 & 16.5 & -22.8 & -39.0 & -28.6 & -29.8 \\
2000 & 30.4 & 33.4 & 49.3 & 57.5 & 40.0 \\
2001 & 29.6 & 50.1 & 21.3 & 14.1 & 15.6 \\
2002 & 34.6 & 45.2 & 19.4 & 31.3 & 29.4 \\
2003 & 23.2 & 13.1 & -6.5 & 0.9 & 6.1 \\
2004 & 12.1 & 10.3 & 2.6 & 6.5 & 5.8 \\
2005 & 10.4 & 11.0 & 1.7 & 5.2 & 9.7 \\
2006 & 0.2 & 4.4 & 19.5 & 11.8 & 12.2 \\
2007 & 22.7 & 6.6 & 11.7 & -9.6 & -15.5 \\
2008 & 19.4 & 8.3 & 20.9 & 16.9 & 11.4 \\
2009 & -6.8 & -2.9 & -3.7 & -0.1 & 1.0 \\
2010 & -7.8 & -4.4 & 4.7 & -0.7 & 0.1 \\
2011 & 1.9 & -10.3 & 9.6 & 0.5 & -3.4 \\
2012 & 18.8 & -1.4 & -1.6 & 4.5 & 5.5 \\
2013 & 15.8 & 7.3 & -1.3 & -0.9 & -2.5 \\
\hline
\end{tabular}

Table 43: Yearly return of the BHML factor (in \%)

\begin{tabular}{|r|rrrcr|}
\hline Year & Asia Pacific & Europe & Japan & North America & \multicolumn{1}{c|}{ US } \\
\hline 1995 & -1.2 & -6.9 & -6.3 & -0.5 & -0.8 \\
1996 & 18.1 & 0.8 & 14.2 & 1.7 & -7.2 \\
1997 & -14.7 & 10.1 & -23.4 & 3.6 & -2.7 \\
1998 & 13.5 & -3.4 & 6.8 & -19.9 & -17.0 \\
1999 & 6.5 & -11.0 & -27.0 & -22.3 & -23.9 \\
2000 & 14.7 & 31.7 & 70.9 & 38.9 & 34.0 \\
2001 & 6.9 & 16.7 & 18.5 & 8.6 & 13.6 \\
2002 & 3.6 & 9.7 & 9.2 & 5.5 & -3.1 \\
2003 & 4.6 & 18.0 & 26.2 & 8.3 & 0.3 \\
2004 & 4.2 & 8.0 & 14.3 & 11.4 & 11.8 \\
2005 & -7.0 & 5.0 & -2.6 & 8.6 & 7.5 \\
2006 & 3.8 & 11.4 & 9.7 & 11.3 & 13.0 \\
2007 & -11.7 & -7.5 & 0.1 & -15.1 & -7.5 \\
2008 & -1.2 & -13.6 & 21.4 & -14.6 & -7.0 \\
2009 & -3.8 & 5.8 & -4.2 & -3.5 & -5.0 \\
2010 & 5.7 & -6.5 & -5.3 & -1.5 & -4.4 \\
2011 & -5.8 & -17.9 & 1.5 & -9.3 & -10.2 \\
2012 & 10.9 & 4.0 & -1.8 & 6.6 & 8.0 \\
2013 & -5.1 & 8.4 & 5.9 & 2.3 & 3.2 \\
\hline
\end{tabular}


Facts and Fantasies About Factor Investing

Table 44: Yearly return of the WML factor (in \%)

\begin{tabular}{|r|rrrrr|}
\hline Year & Asia Pacific & Europe & Japan & North America & \multicolumn{1}{c|}{ US } \\
\hline 1995 & 2.3 & 24.9 & -15.4 & 13.1 & 14.6 \\
1996 & 20.2 & 19.2 & -6.5 & 4.5 & 5.5 \\
1997 & 25.9 & 11.4 & 53.9 & 11.6 & 9.5 \\
1998 & -30.2 & 17.4 & -16.6 & 24.1 & 22.2 \\
1999 & 2.6 & 30.9 & 66.8 & 51.3 & 29.0 \\
2000 & -15.9 & -23.5 & -30.8 & -9.7 & 16.9 \\
2001 & 27.8 & 22.2 & 16.0 & -8.3 & -10.4 \\
2002 & 40.7 & 53.1 & -6.2 & 29.5 & 28.1 \\
2003 & 11.8 & -11.5 & -15.1 & -10.7 & -17.8 \\
2004 & 18.1 & 7.7 & 7.3 & 2.2 & -0.3 \\
2005 & 9.7 & 17.8 & 21.3 & 19.7 & 15.3 \\
2006 & 26.3 & 13.1 & -3.8 & -4.0 & -6.5 \\
2007 & 13.6 & 20.2 & 10.0 & 22.0 & 22.8 \\
2008 & 3.4 & 27.5 & 15.3 & 5.9 & 18.3 \\
2009 & -39.5 & -37.6 & -33.0 & -42.0 & -52.7 \\
2010 & 4.8 & 30.3 & -3.3 & 6.6 & 5.7 \\
2011 & 14.3 & 9.5 & 3.5 & 5.1 & 8.4 \\
2012 & 19.6 & 3.6 & 2.3 & 0.9 & -1.1 \\
2013 & 38.0 & 20.7 & 16.1 & 12.9 & 6.2 \\
\hline
\end{tabular}

Table 45: Yearly return of the equity BAB factors (in \%)

\begin{tabular}{|r|rrrrrr|}
\hline Year & USD & JPY & DEM & FRF & GBP & \multicolumn{1}{c|}{ INT } \\
\hline 1995 & 21.2 & -10.6 & 8.1 & -3.7 & -1.2 & 0.8 \\
1996 & 25.6 & 1.2 & -0.9 & 1.9 & 10.0 & 8.2 \\
1997 & 49.7 & 3.9 & -13.0 & -16.6 & -7.5 & -2.2 \\
1998 & -13.6 & -9.9 & 3.5 & 7.9 & -6.3 & -5.4 \\
1999 & -33.3 & 11.9 & -5.7 & -16.0 & 7.2 & 1.2 \\
2000 & 19.3 & -3.7 & -13.6 & -78.8 & 4.5 & 6.6 \\
2001 & 20.0 & 9.8 & 4.9 & 14.1 & 13.6 & 15.7 \\
2002 & 43.3 & 10.8 & 73.5 & 47.6 & 34.4 & 41.5 \\
2003 & 13.6 & -9.5 & 7.1 & 22.7 & 30.3 & 14.1 \\
2004 & 33.9 & 16.4 & 51.0 & 49.8 & 38.6 & 31.7 \\
2005 & 13.5 & 14.5 & 8.0 & -10.0 & 5.7 & 5.5 \\
2006 & 9.5 & -4.0 & 27.5 & 14.1 & 28.3 & 16.7 \\
2007 & -2.7 & -1.6 & 7.8 & 27.2 & -7.0 & 8.7 \\
2008 & -30.4 & 22.3 & -7.9 & -10.7 & -51.2 & -14.3 \\
2009 & 5.0 & -15.8 & -14.5 & -16.1 & 12.7 & -1.0 \\
2010 & 4.1 & 4.3 & 2.8 & 2.0 & 6.7 & 6.4 \\
2011 & 8.8 & 21.1 & 10.3 & 26.1 & 7.3 & 13.2 \\
\hline
\end{tabular}


Facts and Fantasies About Factor Investing

Table 46: Yearly return of the other BAB factors (in \%)

\begin{tabular}{|r|rrrrr|}
\hline Year & US TB & US CB & \multicolumn{1}{c}{ Cur. } & Com. & \multicolumn{1}{c|}{ All } \\
\hline 1995 & 0.1 & 14.5 & 3.1 & 0.7 & 2.6 \\
1996 & 2.6 & -5.2 & 30.2 & -27.8 & 9.3 \\
1997 & 0.8 & 14.8 & -19.3 & -4.3 & 1.7 \\
1998 & 2.9 & 14.2 & -20.9 & -8.8 & -1.6 \\
1999 & 2.4 & -4.3 & 10.0 & -25.8 & 2.5 \\
2000 & 0.6 & 29.5 & -5.6 & -21.4 & 4.2 \\
2001 & 11.8 & 10.8 & 0.7 & 0.1 & 12.6 \\
2002 & 1.6 & 34.3 & 2.0 & -15.7 & 21.4 \\
2003 & 2.0 & -15.8 & 25.7 & 10.6 & 8.4 \\
2004 & -2.7 & -4.7 & -0.5 & 17.1 & 11.6 \\
2005 & -3.5 & 1.2 & 6.2 & -8.5 & 2.4 \\
2006 & -1.3 & -9.5 & 1.1 & 17.4 & 9.3 \\
2007 & 4.4 & 6.6 & 5.7 & 5.7 & 8.7 \\
2008 & -2.6 & 30.1 & -5.7 & 19.3 & -7.2 \\
2009 & 8.0 & -21.6 & -3.8 & -23.9 & 0.1 \\
2010 & 3.5 & 4.0 & 5.3 & 21.3 & 4.2 \\
2011 & 0.0 & 15.5 & 1.7 & -9.7 & 5.6 \\
\hline
\end{tabular}

Table 47: Yearly return of the currency carry strategy (in \%)

\begin{tabular}{|r|rrr|}
\hline Year & \multicolumn{1}{|c}{ G10 } & Balanced & Global \\
\hline 1995 & 4.0 & & \\
1996 & 28.1 & & \\
1997 & 3.1 & & \\
1998 & -6.2 & 8.0 & \\
1999 & 9.5 & 1.5 & \\
2000 & 3.0 & 13.5 & \\
2001 & 9.2 & 11.3 & 12.2 \\
2002 & 12.1 & 16.8 & 11.0 \\
2003 & 14.7 & 30.4 & 21.2 \\
2004 & 3.7 & 12.6 & 12.4 \\
2005 & 7.7 & 18.2 & 15.3 \\
2006 & -0.2 & 2.6 & 0.8 \\
2007 & 4.8 & 13.1 & 12.4 \\
2008 & -28.8 & -23.3 & -21.7 \\
2009 & 22.8 & 24.1 & 18.2 \\
2010 & 1.2 & 1.7 & 1.0 \\
2011 & -0.4 & -6.4 & -9.1 \\
2012 & 9.3 & 6.0 & 6.7 \\
2013 & -1.8 & -3.4 & -4.6 \\
\hline
\end{tabular}


Facts and Fantasies About Factor Investing

Table 48: Yearly return of the QMJ factor (in \%)

\begin{tabular}{|r|rrr:rrr|}
\hline \multirow{2}{*}{ Year } & \multicolumn{1}{|c}{ US } & & \multicolumn{3}{c|}{ Global } \\
& SQMJ & BQMJ & QMJ & SQMJ & BQMJ & QMJ \\
\hline 1995 & 0.5 & 6.0 & 3.3 & 0.4 & 5.5 & 2.9 \\
1996 & 10.0 & 7.9 & 9.0 & 7.1 & 5.9 & 6.6 \\
1997 & 16.0 & 0.3 & 8.0 & 11.0 & 3.3 & 7.1 \\
1998 & 11.2 & 15.6 & 13.5 & 9.1 & 10.4 & 9.8 \\
1999 & -8.6 & -7.4 & -7.8 & -6.7 & -5.1 & -5.8 \\
2000 & 40.4 & 8.0 & 24.0 & 28.7 & 8.3 & 18.5 \\
2001 & 14.9 & 16.3 & 16.1 & 20.0 & 12.5 & 16.4 \\
2002 & 36.6 & 9.5 & 22.7 & 33.5 & 8.4 & 20.4 \\
2003 & -22.4 & -13.9 & -18.2 & -19.1 & -13.9 & -16.5 \\
2004 & 6.1 & -5.9 & 0.0 & 6.3 & -4.3 & 0.9 \\
2005 & 3.7 & -4.4 & -0.4 & 1.4 & -5.4 & -2.0 \\
2006 & -3.3 & -6.4 & -4.8 & 1.8 & -2.4 & -0.3 \\
2007 & 5.7 & 8.1 & 6.9 & 9.4 & 8.9 & 9.2 \\
2008 & 37.4 & 38.5 & 38.1 & 33.0 & 34.8 & 34.0 \\
2009 & -19.7 & -9.1 & -14.4 & -11.5 & -8.3 & -9.8 \\
2010 & -6.6 & -8.6 & -7.6 & -0.2 & -4.8 & -2.5 \\
2011 & 22.0 & 21.4 & 21.8 & 22.8 & 20.7 & 21.8 \\
2012 & -5.7 & -6.1 & -5.8 & 2.1 & -4.5 & -1.2 \\
2013 & 0.0 & -3.9 & -1.9 & 5.0 & -2.5 & 1.2 \\
\hline
\end{tabular}


Facts and Fantasies About Factor Investing

Table 49: Number of stocks

\begin{tabular}{|l|rrrr|}
\hline Country & AFP & NBIM & AP4 & MSCI World \\
Australia & 660 & 270 & 0 & 69 \\
Austria & 56 & 35 & 8 & 8 \\
Belgium & 91 & 57 & 11 & 11 \\
Canada & 541 & 285 & 92 & 95 \\
Denmark & 85 & 40 & 15 & 13 \\
Finland & 83 & 64 & 19 & 12 \\
France & 397 & 212 & 69 & 70 \\
Germany & 596 & 202 & 54 & 52 \\
Greece & 132 & 29 & 0 & 0 \\
Hong Kong & 516 & 164 & 39 & 39 \\
Ireland & 38 & 22 & 5 & 3 \\
Israel & 97 & 61 & 0 & 9 \\
Italy & 129 & 129 & 27 & 25 \\
Japan & 1988 & 1284 & 303 & 311 \\
Luxembourg & 0 & 11 & 0 & 4 \\
Netherlands & 109 & 65 & 25 & 28 \\
New Zealand & 69 & 24 & 6 & 6 \\
Norway & 120 & 0 & 11 & 10 \\
Portugal & 38 & 24 & 5 & 5 \\
Singapore & 353 & 106 & 25 & 29 \\
Spain & 82 & 73 & 22 & 21 \\
Sweden & 203 & 126 & 146 & 29 \\
Switzerland & 135 & 130 & 28 & 37 \\
United Kingdom & 1103 & 440 & 104 & 109 \\
United States & 3594 & 1910 & 463 & 617 \\
Total & 11215 & 5752 & 1477 & 1612 \\
\hline
\end{tabular}

The second column AFP corresponds to the average number of stocks used by Asness et al. (2014) to build their QMJ factor. The third column NBIM reports the number of stocks hold by NBIM at the end of December 2013. The fourth column AP4 reports the number of direct listed participations of AP4 at the end of June 2014. The last column gives the repartition of stocks by country at the end of June 2014 .

Table 50: Correlation matrix of risk factors (Asia Pacific, 1995 - 2013)

\begin{tabular}{|c|rrrr:rrr|}
\hline Factor & MKT & SMB & HML & WML & $\mathrm{SMB}^{+}$ & $\mathrm{HML}^{+}$ & $\mathrm{WML}^{+}$ \\
\hline Volatility & 21.5 & 10.6 & 11.5 & 17.3 & 24.9 & 24.9 & 23.3 \\
\hline MKT & 100 & & & & & & \\
SMB & 11 & 100 & & & & & \\
HML & 8 & -4 & 100 & & & & \\
WML & -28 & 6 & -36 & 100 & & & \\
\hdashline$\overline{\mathrm{M}} \bar{B}^{+}-$ & $-\overline{9} 3$ & $4 \overline{7}$ & $1 \overline{1}$ & $-\overline{2} 5$ & 100 & & \\
$\mathrm{HML}^{+}$ & 94 & 25 & 38 & -36 & 94 & 100 & \\
$\mathrm{WML}^{+}$ & 92 & 34 & 2 & 4 & 94 & 88 & 100 \\
\hline
\end{tabular}


Facts and Fantasies About Factor Investing

Table 51: Correlation matrix of risk factors (Europe, 1995 - 2013)

\begin{tabular}{|c|rrrr:rrc|}
\hline Factor & MKT & \multicolumn{1}{c}{ SMB } & HML & WML & SMB $^{+}$ & $\mathrm{HML}^{+}$ & $\mathrm{WML}^{+}$ \\
\hline Volatility & 18.1 & 8.0 & 9.0 & 15.5 & 18.4 & 19.5 & 17.9 \\
\hline MKT & 100 & & & & & & \\
SMB & -18 & 100 & & & & & \\
HML & 19 & -12 & 100 & & & & \\
WML & -34 & 10 & -28 & 100 & & & \\
\hdashline$\overline{\mathrm{SM}} \bar{B}^{+-}$ & $-\overline{9} 2$ & $2 \overline{1}$ & 16 & $-3 \overline{1}$ & 100 & & \\
$\mathrm{HML}^{+}$ & 96 & -4 & 40 & -39 & 95 & 100 & \\
$\mathrm{WML}^{+}$ & 91 & 5 & 8 & 4 & 91 & 87 & 100 \\
\hline
\end{tabular}

Table 52: Correlation matrix of risk factors (Japan, 1995 - 2013)

\begin{tabular}{|c|c|c|c|c|c|c|c|}
\hline Factor & MKT & SMB & HML & $\overline{\text { WML }}$ & $\mathrm{SMB}^{+}$ & $\mathrm{HML}^{+}$ & $\mathrm{WML}^{+}$ \\
\hline Volatility & 18.5 & 10.9 & 10.3 & 16.6 & $\begin{array}{ll}1 & 21.8 \\
\end{array}$ & 20.2 & 20.3 \\
\hline MKT & 100 & & & & | & & \\
\hline SMB & 6 & 100 & & & i & & \\
\hline HML & -20 & 5 & 100 & & 1 & & \\
\hline WML & -11 & -15 & -27 & 100 & 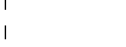 & & \\
\hline$\overline{\mathrm{S}} \overline{\mathrm{M}} \overline{\mathrm{B}}^{+-}$ & $\overline{8} 7^{-}$ & $5 \overline{4}$ & -8 & $-\overline{1} \overline{9}$ & 100 & & \\
\hline $\mathrm{HML}^{+}$ & 90 & 34 & 15 & -23 & 95 & 100 & \\
\hline $\mathrm{WML}^{+}$ & 91 & 24 & -21 & 22 & 88 & 86 & 100 \\
\hline
\end{tabular}

Table 53: Correlation matrix of risk factors (North America, 1995 - 2013)

\begin{tabular}{|c|c|c|c|c|c|c|c|}
\hline Factor & MKT & SMB & HML & WML & $\mathrm{SMB}^{+}$ & $\mathrm{HML}^{+}$ & $\mathrm{WML}^{+}$ \\
\hline Volatility & 15.8 & 11.3 & 12.1 & 18.7 & $\begin{array}{ll} & 20.6 \\
\end{array}$ & 17.2 & 20.3 \\
\hline MKT & 100 & & & & 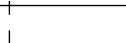 & & \\
\hline SMB & 24 & 100 & & & I & & \\
\hline HML & -23 & -38 & 100 & & I & & \\
\hline WML & -16 & 23 & -24 & 100 & I & & \\
\hline$\overline{\mathrm{S}} \overline{\mathrm{M}} \overline{\mathrm{B}}^{+-}$ & $\overline{8} 8^{-}$ & $\overline{6} \overline{6}$ & $-\overline{-}-\overline{0}$ & $-\overline{5}$ & $\overline{1} \overline{00}$ & & \\
\hline $\mathrm{HML}^{+}$ & 92 & 33 & 8 & -22 & 89 & 100 & \\
\hline $\mathrm{WML}^{+}$ & 84 & 56 & -37 & 34 & 90 & 78 & 100 \\
\hline
\end{tabular}

Table 54: Statistics (in \%) of long/short and long-only portfolios (Asia Pacific, 1995 - 2013)

\begin{tabular}{|c|r:rrrrr:rrr|}
\hline Portfolio & \multicolumn{1}{|c}{$\# 0$} & \multicolumn{1}{|c}{$\# 1$} & \multicolumn{1}{c}{$\# 2$} & \multicolumn{1}{c}{$\# 3$} & \multicolumn{1}{c}{$\# 4$} & \multicolumn{1}{c}{$\# 5$} & \multicolumn{1}{c}{$\# 6$} & \multicolumn{1}{c}{$\# 7$} & \multicolumn{1}{c}{$\# 8$} \\
\hline SMB & 0.0 & 10.0 & 20.0 & 0.0 & 20.0 & 30.0 & 0.0 & 50.0 & 100.0 \\
HML & 0.0 & 10.0 & 20.0 & 20.0 & 20.0 & 30.0 & 0.0 & 50.0 & 100.0 \\
WML & 0.0 & 10.0 & 0.0 & 20.0 & 20.0 & 30.0 & 60.0 & 50.0 & 100.0 \\
\hline$\mu\left(x^{ \pm}\right)$ & 9.1 & 10.7 & 10.0 & 13.0 & 12.3 & 13.8 & 15.5 & 16.7 & 23.5 \\
$\mu\left(x^{+}\right)$ & & 9.7 & 9.1 & 10.7 & 10.1 & 10.5 & 12.1 & 10.7 & 10.7 \\
$\mu\left(x^{+} \mid x^{ \pm}\right)$ & & -1.1 & -0.9 & -2.3 & -2.1 & -3.2 & -3.4 & -6.1 & -12.8 \\
$\sigma\left(x^{ \pm}\right)$ & 21.6 & 21.4 & 22.2 & 21.1 & 21.4 & 21.6 & 21.2 & 22.6 & 27.6 \\
$\sigma\left(x^{+}\right)$ & & 22.0 & 22.5 & 22.1 & 22.6 & 23.4 & 22.2 & 23.7 & 23.7 \\
$\sigma\left(x^{+} \mid x^{ \pm}\right)$ & & 1.4 & 1.0 & 2.8 & 2.8 & 4.1 & 7.2 & 6.4 & 15.3 \\
$\rho\left(x^{+}, x^{ \pm}\right)$ & & 99.8 & 99.9 & 99.3 & 99.4 & 98.6 & 94.6 & 96.3 & 83.2 \\
\hline
\end{tabular}


Facts and Fantasies About Factor Investing

Table 55: Statistics (in \%) of long/short and long-only portfolios (Europe, 1995 - 2013)

\begin{tabular}{|c|r:rrrrr:rrr|}
\hline Portfolio & \multicolumn{1}{|c}{$\# 0$} & \multicolumn{1}{|c}{$\# 1$} & \multicolumn{1}{c}{$\# 2$} & \multicolumn{1}{c}{$\# 3$} & \multicolumn{1}{c}{$\# 4$} & \multicolumn{1}{c}{$\# 5$} & \multicolumn{1}{c}{$\# 6$} & \multicolumn{1}{c}{$\# 7$} & \multicolumn{1}{c}{$\# 8$} \\
\hline SMB & 0.0 & 10.0 & 20.0 & 0.0 & 20.0 & 30.0 & 0.0 & 50.0 & 100.0 \\
HML & 0.0 & 10.0 & 20.0 & 20.0 & 20.0 & 30.0 & 0.0 & 50.0 & 100.0 \\
WML & 0.0 & 10.0 & 0.0 & 20.0 & 20.0 & 30.0 & 60.0 & 50.0 & 100.0 \\
\hline$\mu\left(x^{ \pm}\right)$ & 9.2 & 11.2 & 10.3 & 13.1 & 13.2 & 15.2 & 17.5 & 19.2 & 29.0 \\
$\mu\left(x^{+}\right)$ & & 10.3 & 9.8 & 11.3 & 11.3 & 12.4 & 13.7 & 12.8 & 12.8 \\
$\mu\left(x^{+} \mid x^{ \pm}\right)$ & & -0.9 & -0.5 & -1.9 & -1.8 & -2.8 & -3.8 & -6.4 & -16.3 \\
$\sigma\left(x^{ \pm}\right)$ & 18.1 & 17.7 & 18.3 & 17.7 & 17.5 & 17.4 & 17.4 & 17.8 & 21.6 \\
$\sigma\left(x^{+}\right)$ & & 17.9 & 18.2 & 18.0 & 17.9 & 18.0 & 17.6 & 18.0 & 18.1 \\
$\sigma\left(x^{+} \mid x^{ \pm}\right)$ & & 1.1 & 1.0 & 2.2 & 2.2 & 3.3 & 5.6 & 5.8 & 14.1 \\
$\rho\left(x^{+}, x^{ \pm}\right)$ & & 99.8 & 99.9 & 99.2 & 99.3 & 98.3 & 94.8 & 94.8 & 76.2 \\
\hline
\end{tabular}

Table 56: Statistics (in \%) of long/short and long-only portfolios (Japan, 1995 - 2013)

\begin{tabular}{|c|r:rrrrr:rrr|}
\hline Portfolio & \multicolumn{1}{|c}{$\# 0$} & \multicolumn{1}{|c}{$\# 1$} & \multicolumn{1}{c}{$\# 2$} & \multicolumn{1}{c}{$\# 3$} & \multicolumn{1}{c}{$\# 4$} & \multicolumn{1}{c}{$\# 5$} & \multicolumn{1}{c}{$\# 6$} & \multicolumn{1}{c}{$\# 7$} & \multicolumn{1}{c}{$\# 8$} \\
\hline SMB & 0.0 & 10.0 & 20.0 & 0.0 & 20.0 & 30.0 & 0.0 & 50.0 & 100.0 \\
HML & 0.0 & 10.0 & 20.0 & 20.0 & 20.0 & 30.0 & 0.0 & 50.0 & 100.0 \\
WML & 0.0 & 10.0 & 0.0 & 20.0 & 20.0 & 30.0 & 60.0 & 50.0 & 100.0 \\
\hline$\mu\left(x^{ \pm}\right)$ & 0.5 & 1.4 & 1.5 & 2.3 & 2.2 & 3.0 & 2.1 & 4.5 & 7.6 \\
$\mu\left(x^{+}\right)$ & & 1.2 & 1.2 & 1.7 & 1.7 & 2.2 & 2.0 & 2.4 & 2.4 \\
$\mu\left(x^{+} \mid x^{ \pm}\right)$ & & -0.2 & -0.3 & -0.6 & -0.5 & -0.8 & -0.1 & -2.1 & -5.2 \\
$\sigma\left(x^{ \pm}\right)$ & 18.6 & 18.4 & 18.6 & 18.1 & 18.3 & 18.5 & 20.1 & 19.4 & 24.4 \\
$\sigma\left(x^{+}\right)$ & & 18.7 & 19.0 & 18.7 & 19.2 & 19.8 & 19.3 & 20.1 & 20.1 \\
$\sigma\left(x^{+} \mid x^{ \pm}\right)$ & & 1.5 & 1.2 & 2.9 & 2.9 & 4.4 & 6.8 & 6.2 & 14.3 \\
$\rho\left(x^{+}, x^{ \pm}\right)$ & & 99.7 & 99.8 & 98.8 & 98.9 & 97.6 & 94.0 & 95.1 & 81.0 \\
\hline
\end{tabular}

Table 57: Statistics (in \%) of long/short and long-only portfolios (North America, 1995 2013)

\begin{tabular}{|c|r:rrrrr:rrr|}
\hline Portfolio & \multicolumn{1}{|c}{$\# 0$} & \multicolumn{1}{|c}{$\# 1$} & \multicolumn{1}{c}{$\# 2$} & \multicolumn{1}{c}{$\# 3$} & \multicolumn{1}{c}{$\# 4$} & \multicolumn{1}{c}{$\# 5$} & \multicolumn{1}{c}{$\# 6$} & \multicolumn{1}{c}{$\# 7$} & \multicolumn{1}{c}{$\# 8$} \\
\hline SMB & 0.0 & 10.0 & 20.0 & 0.0 & 20.0 & 30.0 & 0.0 & 50.0 & 100.0 \\
HML & 0.0 & 10.0 & 20.0 & 20.0 & 20.0 & 30.0 & 0.0 & 50.0 & 100.0 \\
WML & 0.0 & 10.0 & 0.0 & 20.0 & 20.0 & 30.0 & 60.0 & 50.0 & 100.0 \\
\hline$\mu\left(x^{ \pm}\right)$ & 10.2 & 11.5 & 11.3 & 12.6 & 12.9 & 14.1 & 14.5 & 16.6 & 21.8 \\
$\mu\left(x^{+}\right)$ & & 11.1 & 10.9 & 11.8 & 11.9 & 12.8 & 13.4 & 13.0 & 13.0 \\
$\mu\left(x^{+} \mid x^{ \pm}\right)$ & & -0.5 & -0.4 & -0.9 & -0.9 & -1.4 & -1.1 & -3.6 & -8.8 \\
$\sigma\left(x^{ \pm}\right)$ & 15.9 & 15.7 & 16.1 & 15.2 & 15.9 & 16.4 & 17.9 & 18.2 & 25.8 \\
$\sigma\left(x^{+}\right)$ & & 16.4 & 16.6 & 16.3 & 17.1 & 18.1 & 17.9 & 18.5 & 18.5 \\
$\sigma\left(x^{+} \mid x^{ \pm}\right)$ & & 1.4 & 1.3 & 3.0 & 2.9 & 4.3 & 6.6 & 7.1 & 17.4 \\
$\rho\left(x^{+}, x^{ \pm}\right)$ & & 99.7 & 99.7 & 98.4 & 98.8 & 97.4 & 93.2 & 92.5 & 73.6 \\
\hline
\end{tabular}


Facts and Fantasies About Factor Investing

Table 58: Performance of EW long/short 5F portfolios (1995 - 2013)

\begin{tabular}{|cc|cccccc|}
\hline & & Asia Pacific & Europe & Japan & North America & US & Global \\
\hline \multirow{5}{*}{ Statistic } & $\mu(x)$ & 13.2 & 14.3 & 6.8 & 11.2 & 10.0 & 13.8 \\
& $\sigma(x)$ & 10.0 & 10.0 & 10.0 & 10.0 & 10.0 & 10.0 \\
& $\operatorname{SR}(x \mid r)$ & 1.04 & 1.14 & 0.40 & 0.83 & 0.71 & 1.10 \\
& $\operatorname{MDD}(x)$ & 21.6 & 19.9 & 21.4 & 17.7 & 21.4 & 23.3 \\
\hline
\end{tabular}

Table 59: Performance and weights of ERC long/short 5F portfolios (1995 - 2013)

\begin{tabular}{|cc|cccccc|}
\hline & & Asia Pacific & Europe & Japan & North America & US & Global \\
\hline \multirow{5}{*}{ Statistic } & $\mu(x)$ & 13.1 & 13.8 & 7.2 & 11.5 & 10.4 & 14.0 \\
& $\sigma(x)$ & 10.0 & 10.0 & 10.0 & 10.0 & 10.0 & 10.0 \\
& SR $(x \mid r)$ & 1.03 & 1.10 & 0.44 & 0.86 & 0.75 & 1.11 \\
& MDD $(x)$ & 22.6 & 16.5 & 20.0 & 16.5 & 18.1 & 19.8 \\
\hline \multirow{5}{*}{ Weights } & SMB & 21.6 & 25.1 & 22.6 & 22.7 & 21.4 & 25.1 \\
& HML & 20.0 & 22.5 & 24.0 & 21.3 & 22.6 & 22.6 \\
& WML & 13.3 & 13.1 & 14.8 & 13.8 & 13.9 & 12.8 \\
& BAB & 21.1 & 16.1 & 17.2 & 18.2 & 18.0 & 18.2 \\
& QMJ & 24.1 & 23.2 & 21.5 & 24.0 & 24.1 & 21.4 \\
\hline
\end{tabular}

Table 60: Performance and weights of MVO^ long/short 5F portfolios (1995 - 2013)

\begin{tabular}{|cc|cccccc|}
\hline & & Asia Pacific & Europe & Japan & North America & US & Global \\
\hline \multirow{5}{*}{ Statistic } & $\mu(x)$ & 15.4 & 15.7 & 9.0 & 10.8 & 10.0 & 14.7 \\
& $\sigma(x)$ & 10.0 & 10.0 & 10.0 & 10.0 & 10.0 & 10.0 \\
& SR $(x \mid r)$ & 1.26 & 1.28 & 0.61 & 0.80 & 0.71 & 1.19 \\
& MDD $(x)$ & 21.5 & 20.3 & 18.6 & 22.0 & 24.9 & 19.7 \\
\hline \multirow{5}{*}{ Weights } & SMB & 0.0 & 0.0 & 0.0 & 5.8 & 11.8 & 0.0 \\
& HML & 26.3 & 25.4 & 57.7 & 14.9 & 14.8 & 31.1 \\
& WML & 13.1 & 19.2 & 7.6 & 11.3 & 9.2 & 13.7 \\
& BAB & 34.0 & 32.0 & 10.2 & 35.1 & 32.1 & 31.9 \\
& QMJ & 26.5 & 23.3 & 24.4 & 32.9 & 32.0 & 23.4 \\
\hline
\end{tabular}

Table 61: Performance and weights of MVO long/short 5F portfolios (1995 - 2013)

\begin{tabular}{|cc|ccrccc|}
\hline \multirow{5}{*}{ Statistic } & Asia Pacific & Europe & Japan & North America & US & Global \\
& $\mu(x)$ & 16.2 & 16.2 & 9.1 & 12.3 & 11.8 & 15.3 \\
& $\sigma(x)$ & 10.0 & 10.0 & 10.0 & 10.0 & 10.0 & 10.0 \\
& SR $(x \mid r)$ & 1.33 & 1.33 & 0.63 & 0.95 & 0.89 & 1.24 \\
& MDD $(x)$ & 23.8 & 25.2 & 18.1 & 22.1 & 21.8 & 21.9 \\
\hline \multirow{5}{*}{ Weights } & SMB & 0.0 & 0.0 & 0.0 & 33.0 & 36.9 & 0.0 \\
& HML & 38.7 & 35.3 & 64.6 & 0.0 & 0.8 & 46.3 \\
& WML & 20.5 & 23.8 & 13.5 & 0.2 & 0.0 & 20.6 \\
& BAB & 29.5 & 40.9 & 1.3 & 29.8 & 24.2 & 26.6 \\
& QMJ & 11.4 & 0.0 & 20.6 & 37.0 & 38.1 & 6.5 \\
\hline
\end{tabular}




\section{B.2 Figures}

Figure 34: Fama-French SMB factor (1995 - 2013)
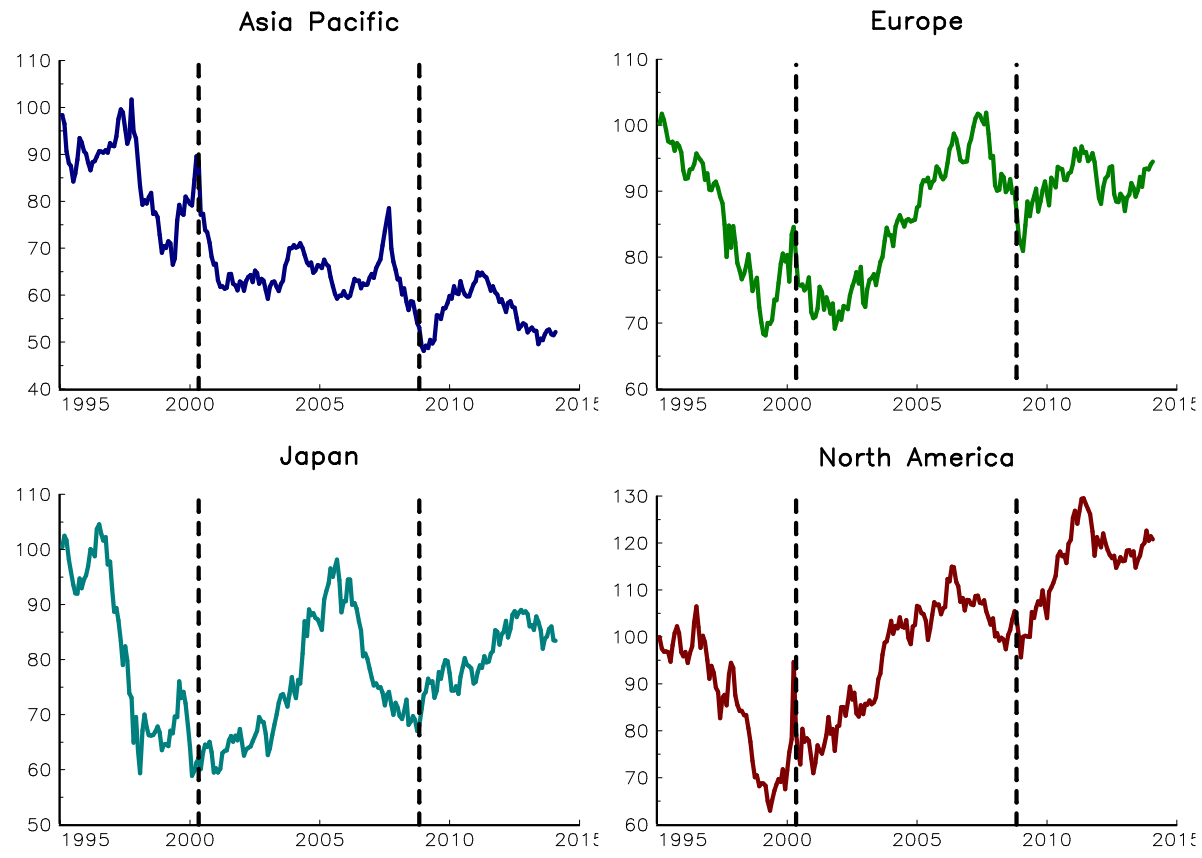
Figure 35: Fama-French HML factor (1995 - 2013)
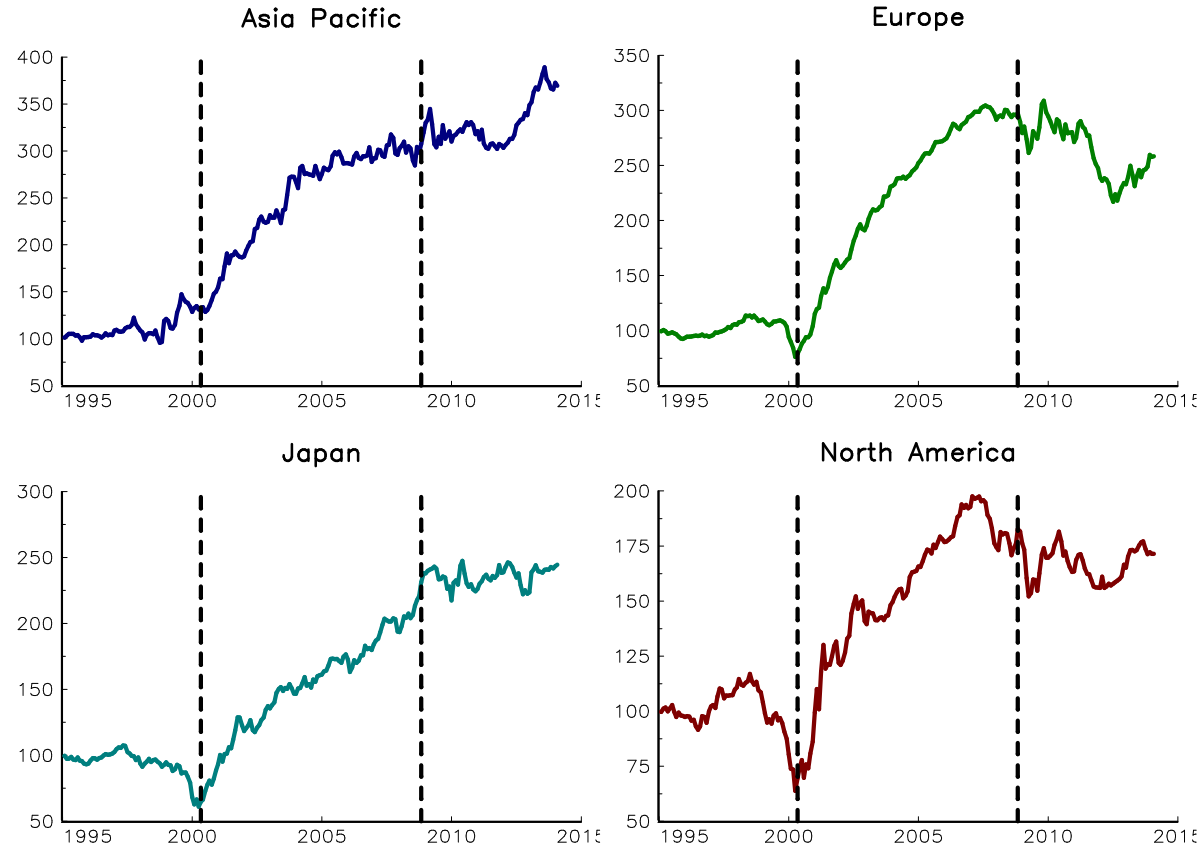

Figure 36: Dynamics of the $R^{2}$ coefficient in Asia Pacific (in \%)
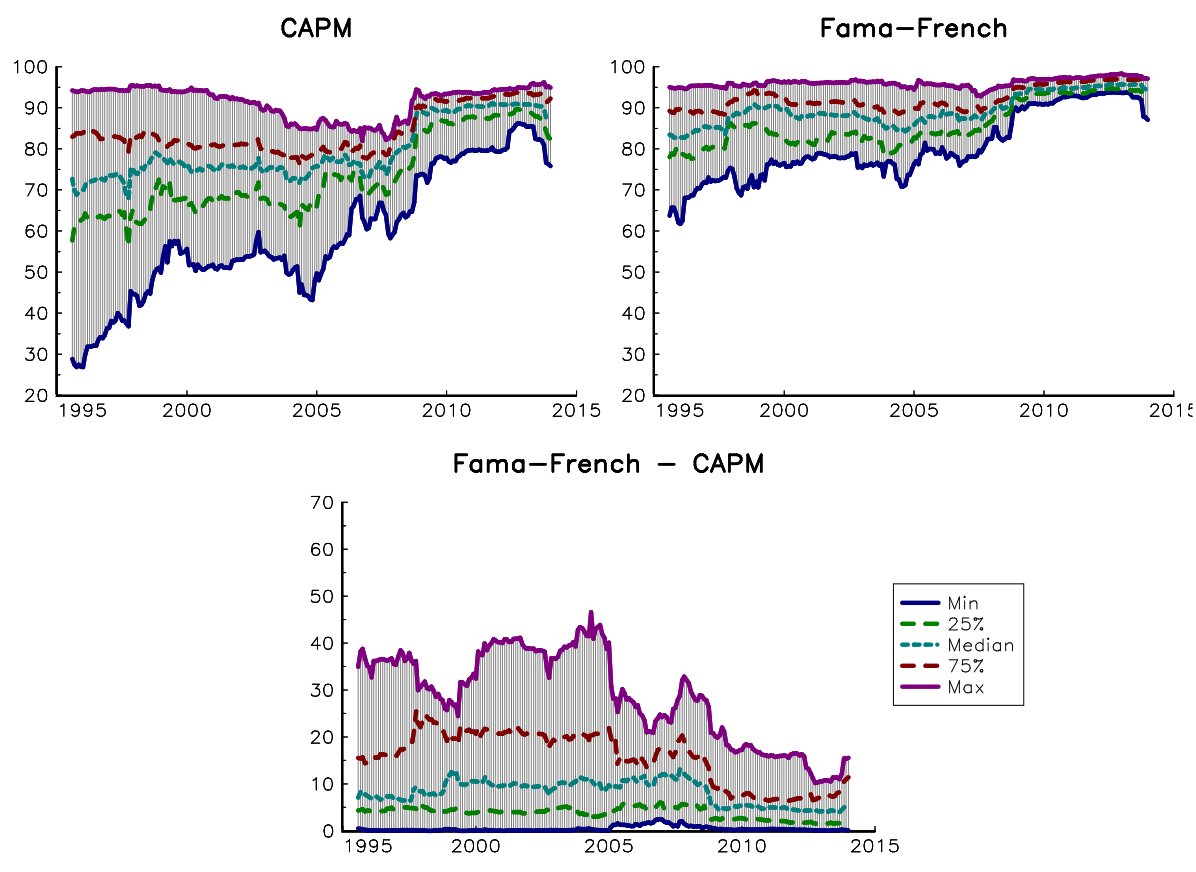
Figure 37: Dynamics of the $R^{2}$ coefficient in Europe (in \%)
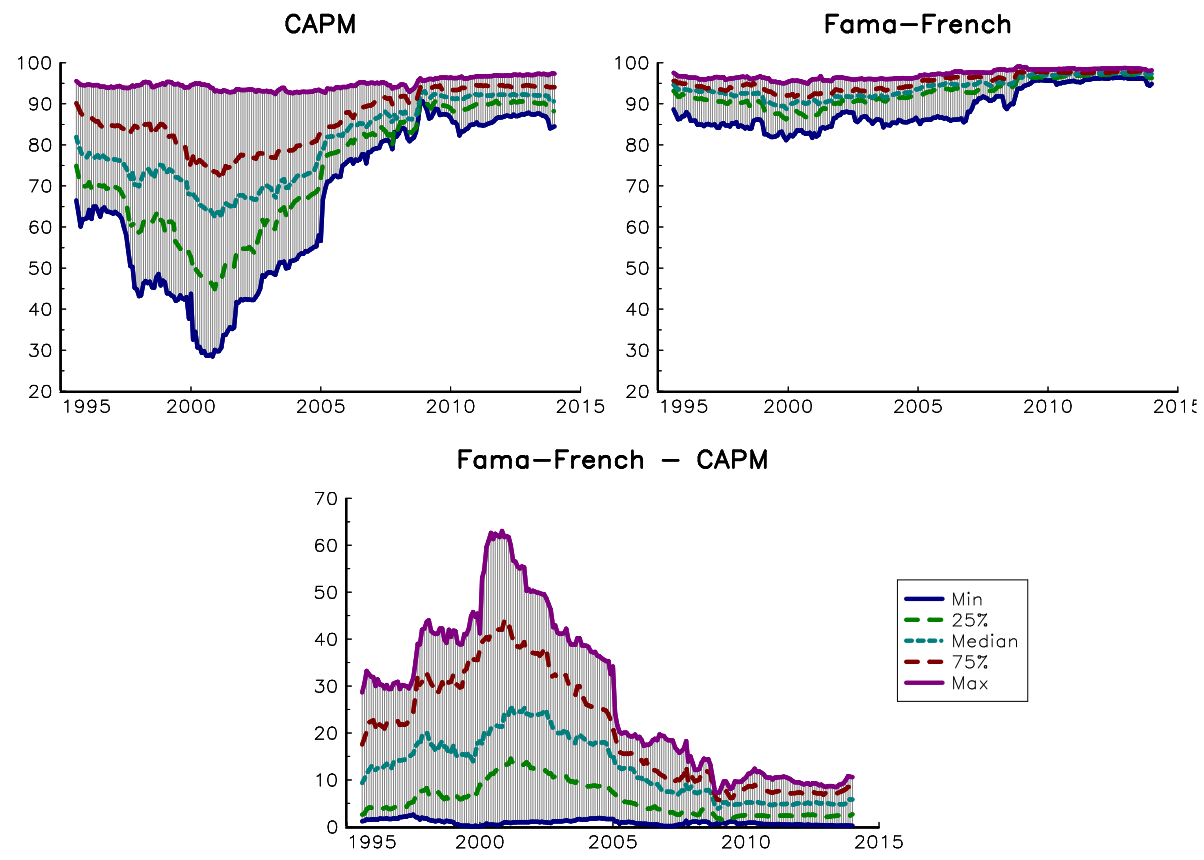

Figure 38: Dynamics of the $R^{2}$ coefficient in Japan (in \%)
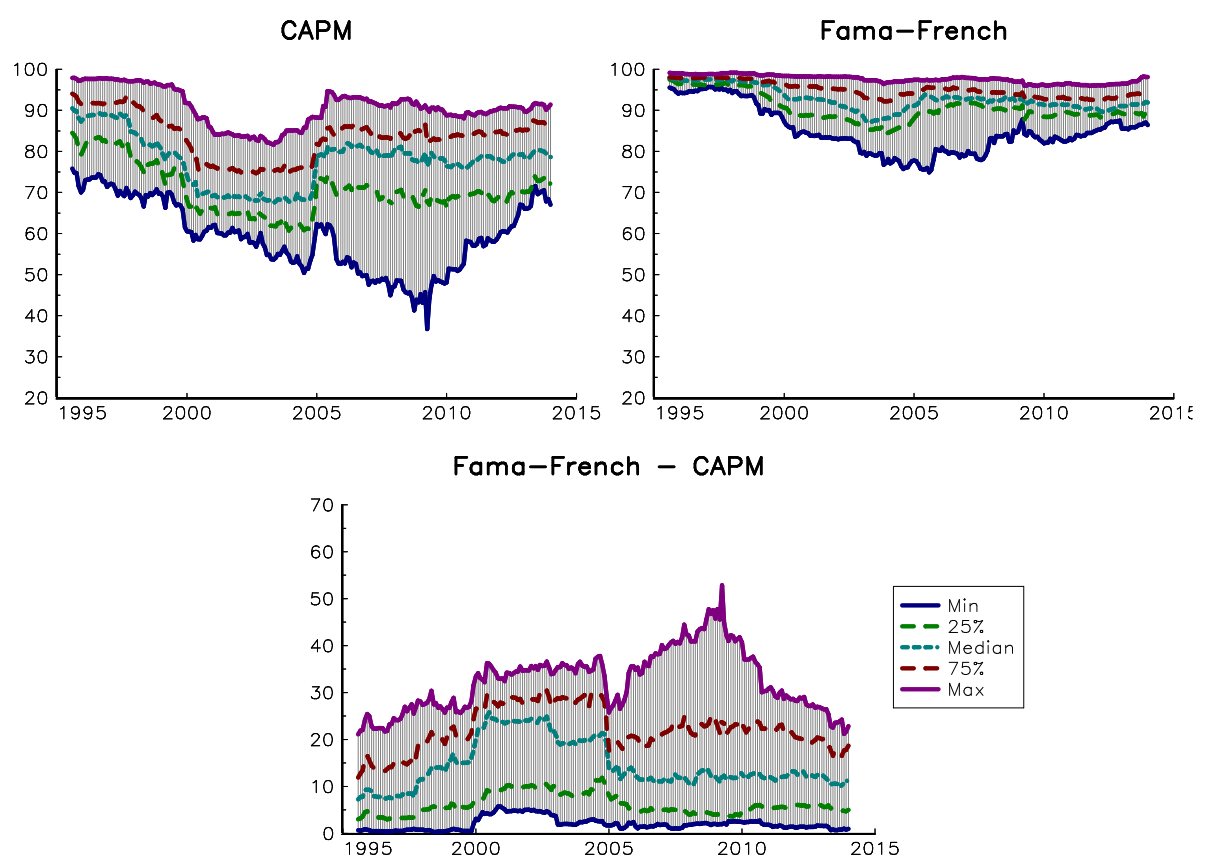
Figure 39: Dynamics of the $R^{2}$ coefficient in North America (in \%)
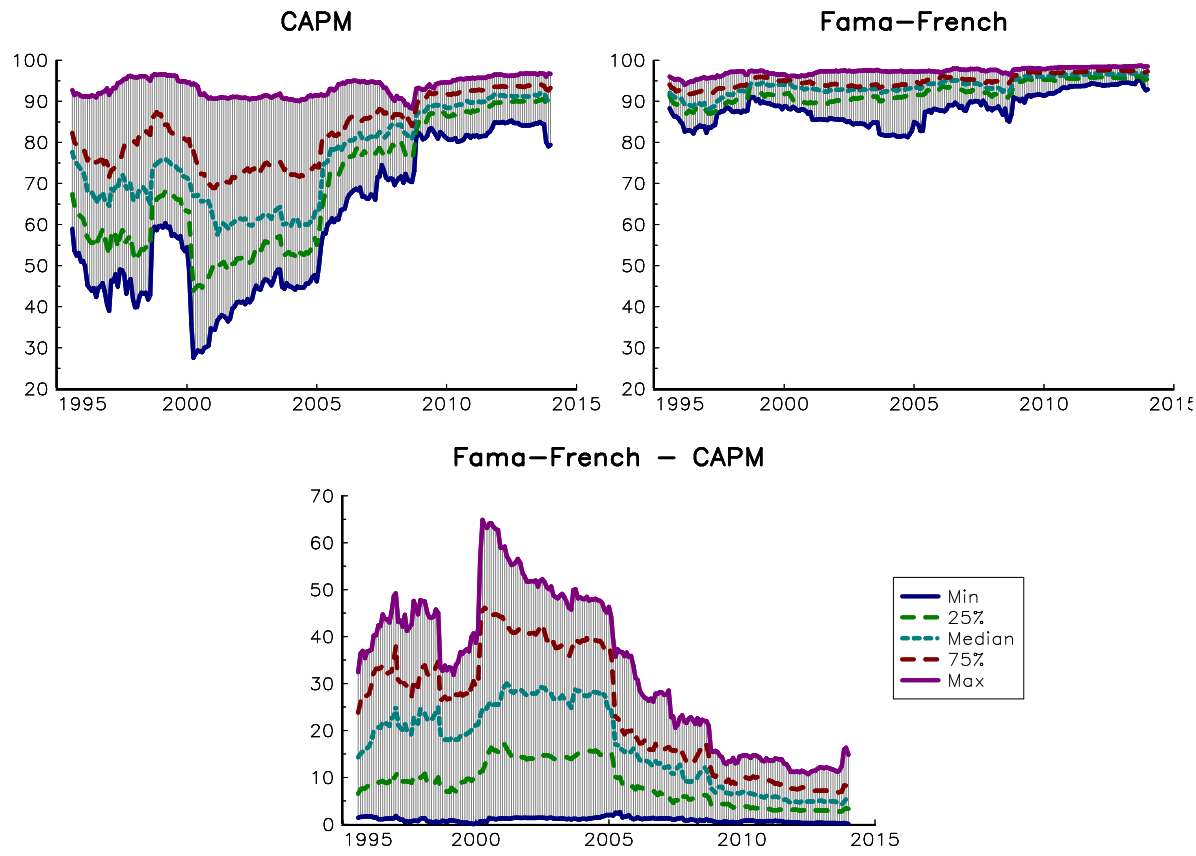

Figure 40: Comparison between WML and HML factors

Asia Pacific
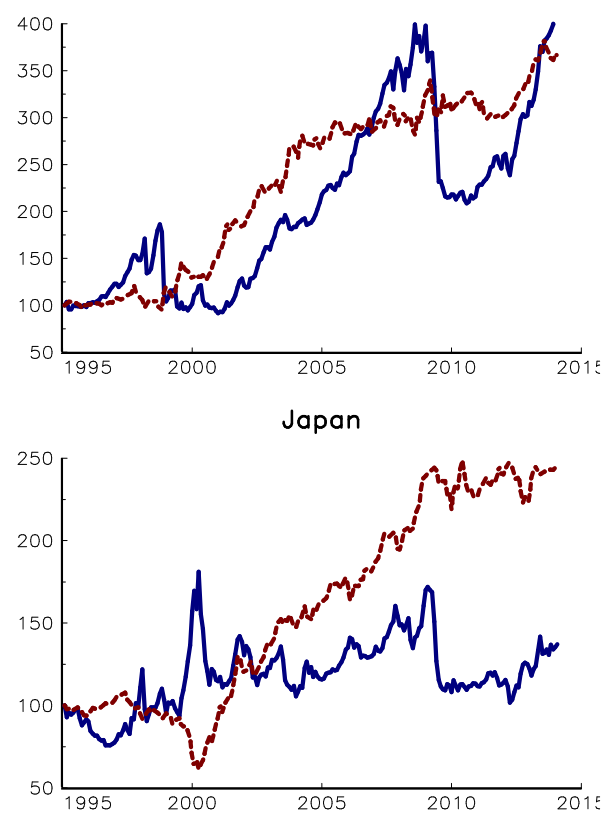

Europe
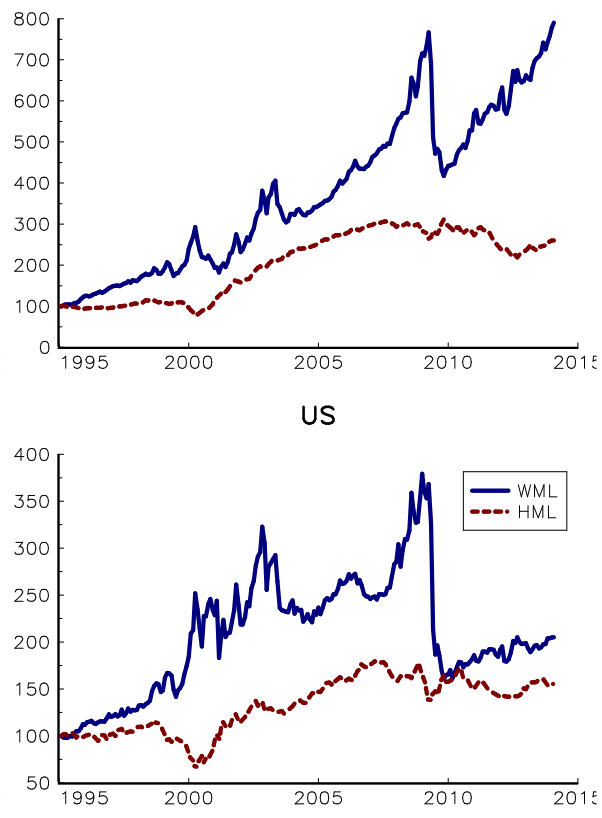
Figure 41: Comparison between FF and MF SMB risk factors (Europe, 2002-2014)

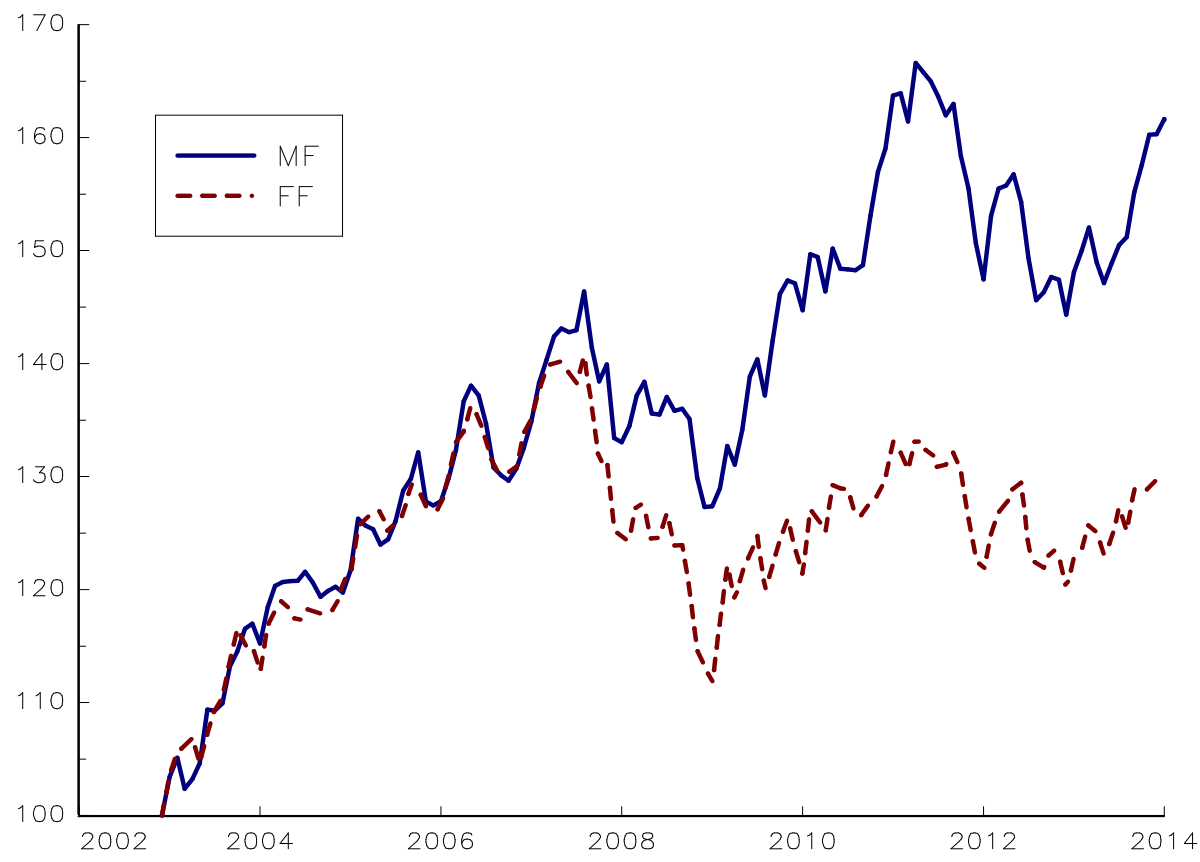

Figure 42: Comparison between FF and MF HML risk factors (Europe, 1999-2014)

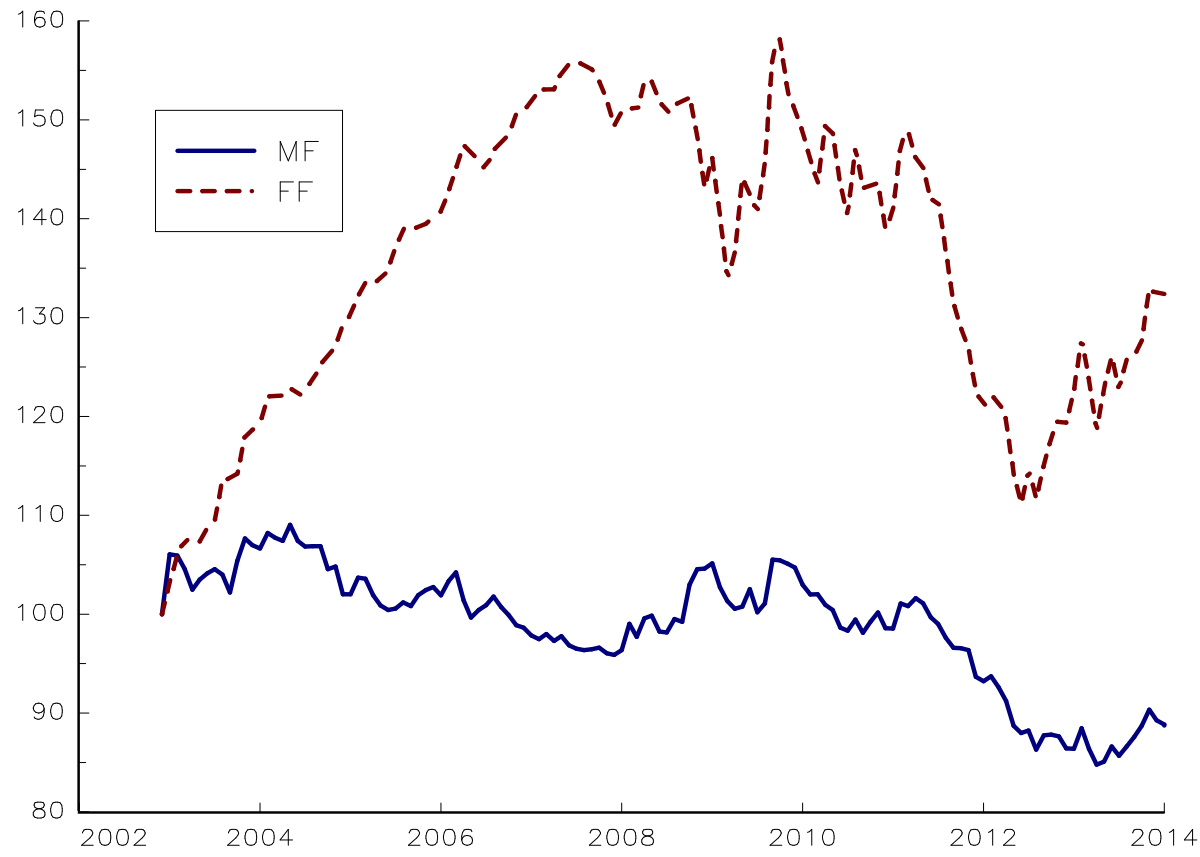


Figure 43: Comparison between FF and MF SMB risk factors (Japan, 2002-2014)

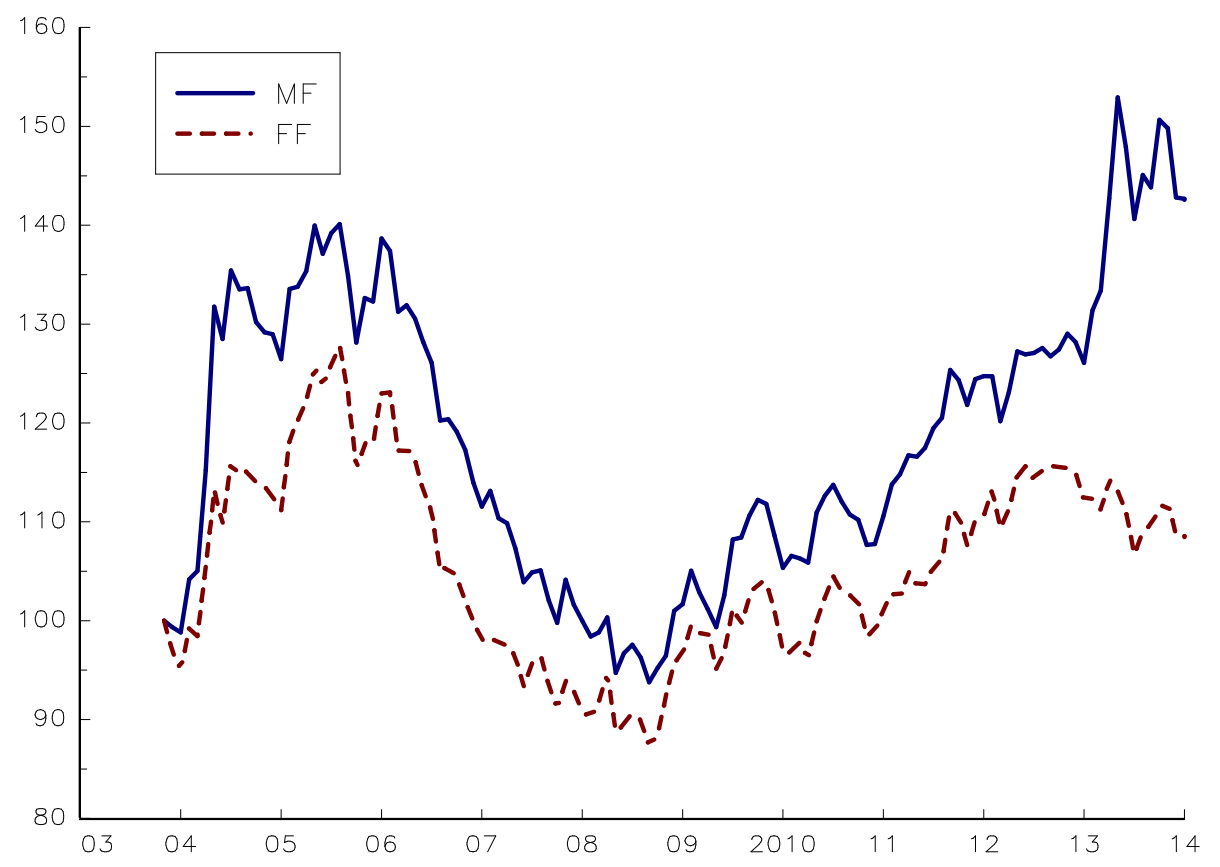

Figure 44: Comparison between FF and MF HML risk factors (Japan, 1999-2014)

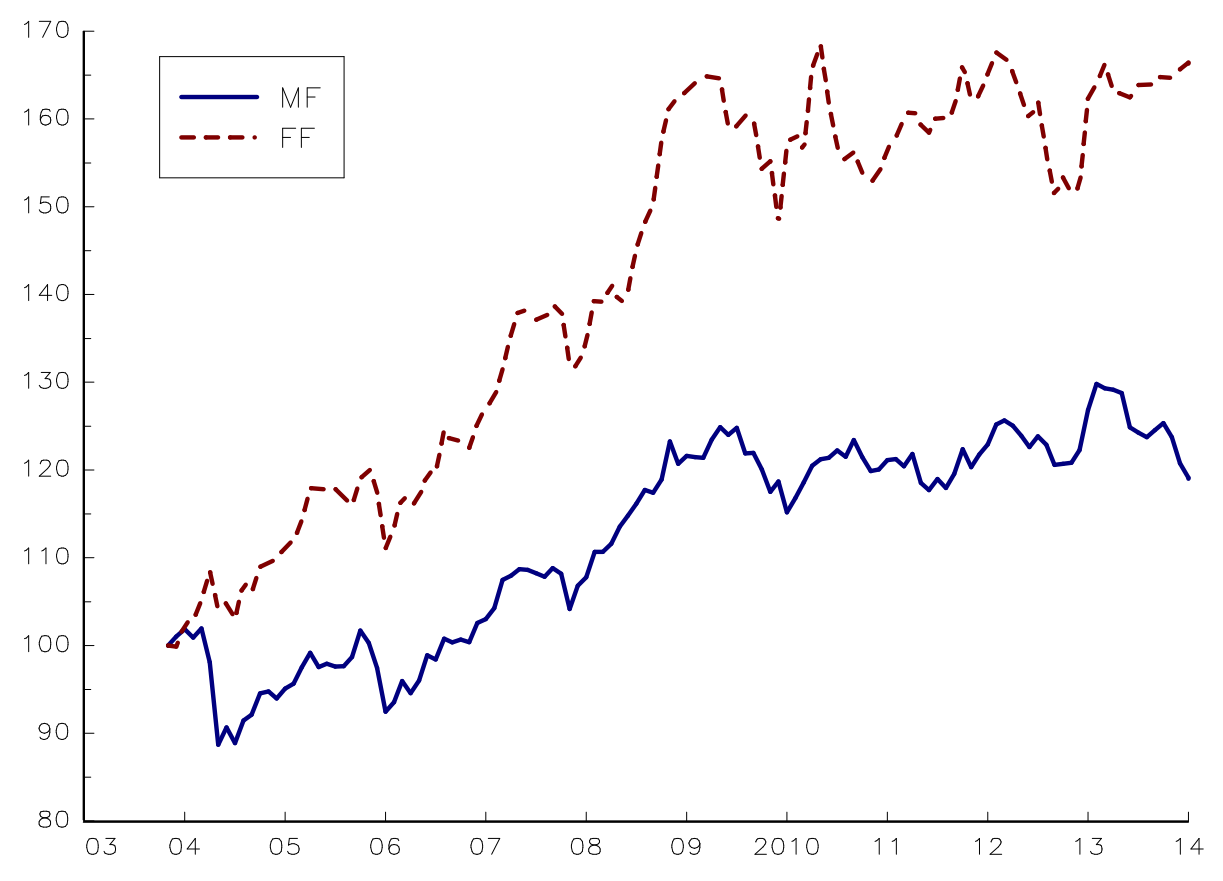


Figure 45: Relation between $\beta_{i}^{m}$ and $\operatorname{IVOL}_{i}(\mathrm{CAPM})$

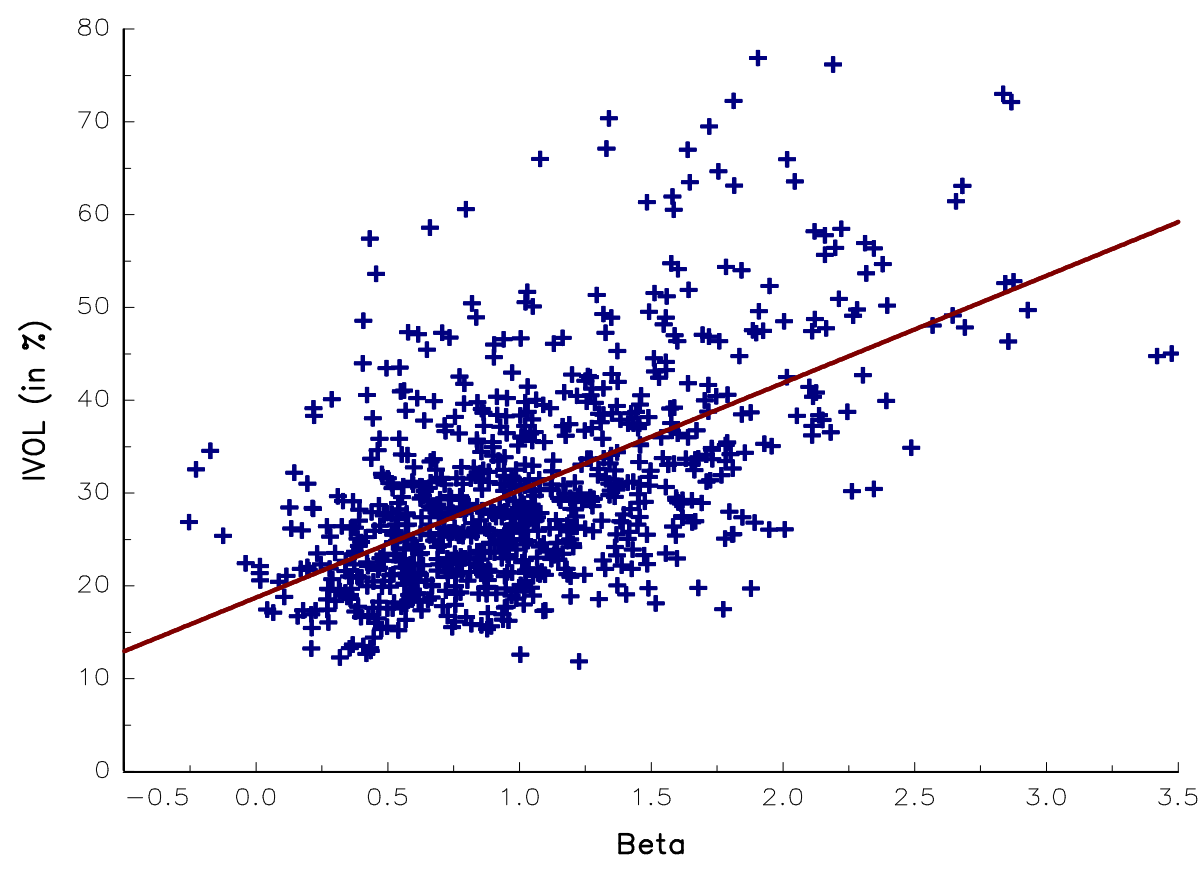

Figure 46: Relation between $\beta_{i}^{m}$ and $\mathrm{IVOL}_{i}$ (Fama-French)

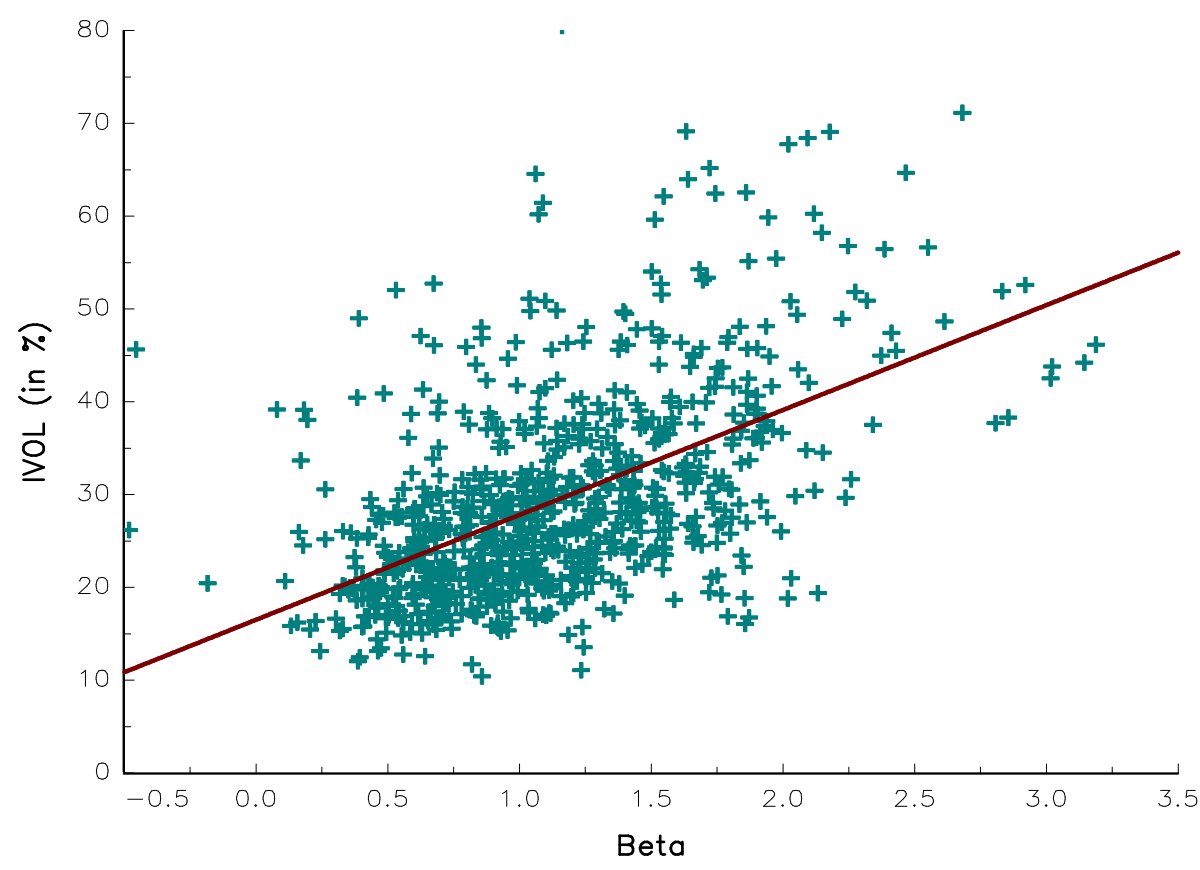


Figure 47: Performance of risk factors with the MSCI Europe Index (2004 - 2013)
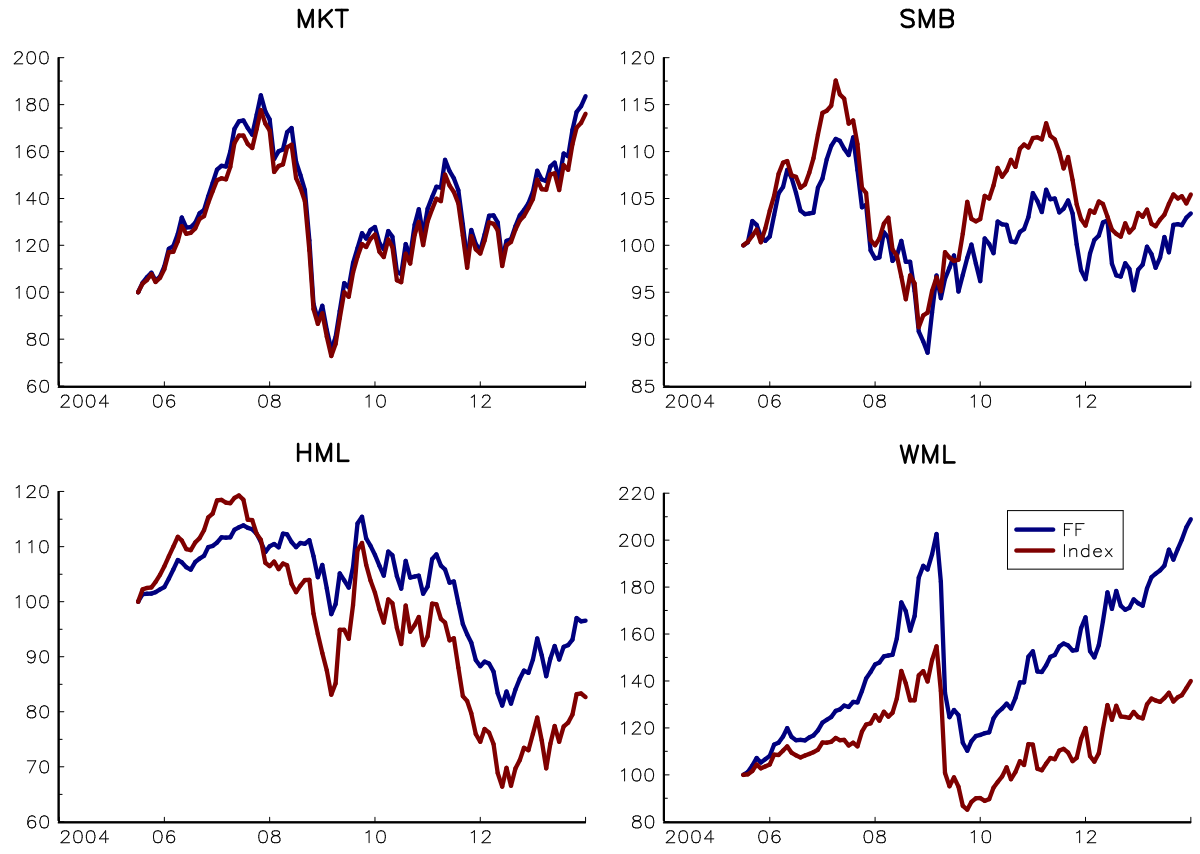

Figure 48: Performance of risk factors with the Topix Index (2004 - 2013)
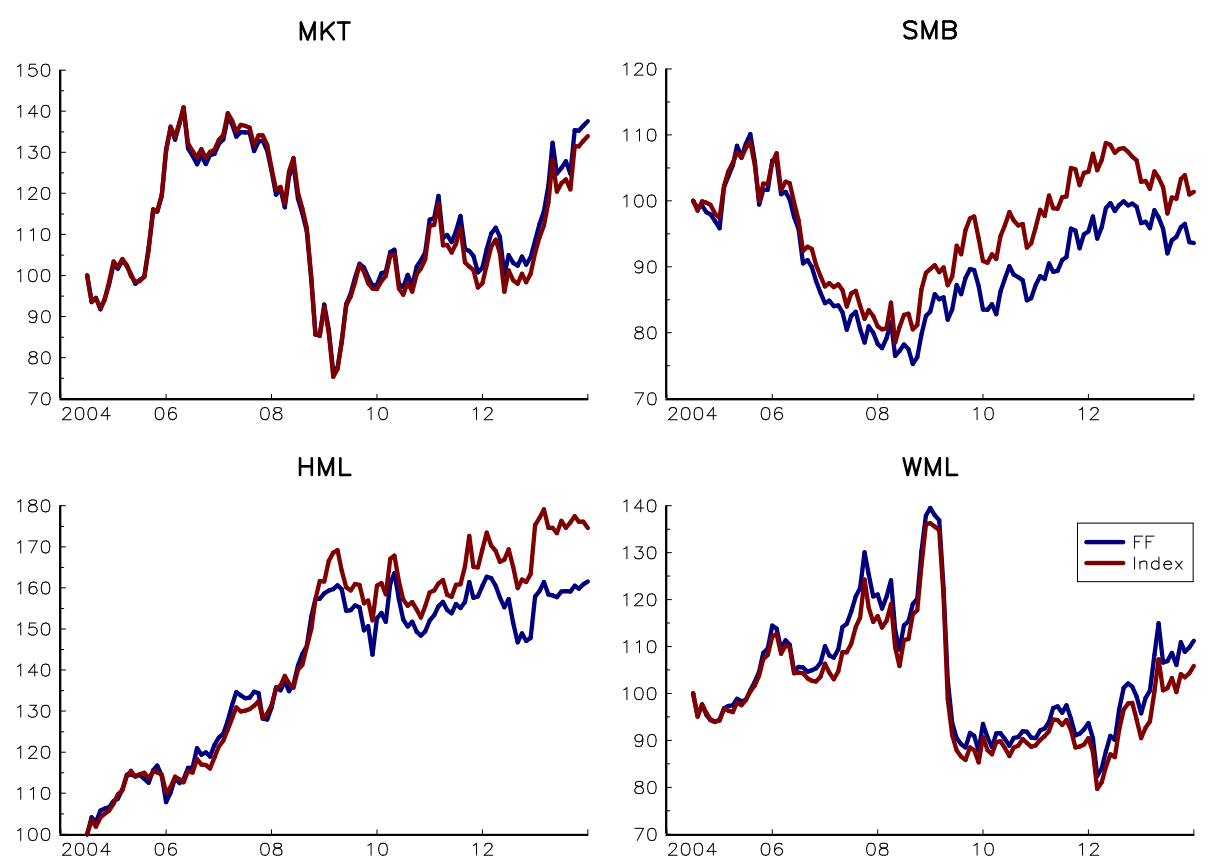
Figure 49: Performance of long-only risk factors (Asia Pacific, 1995 - 2013)
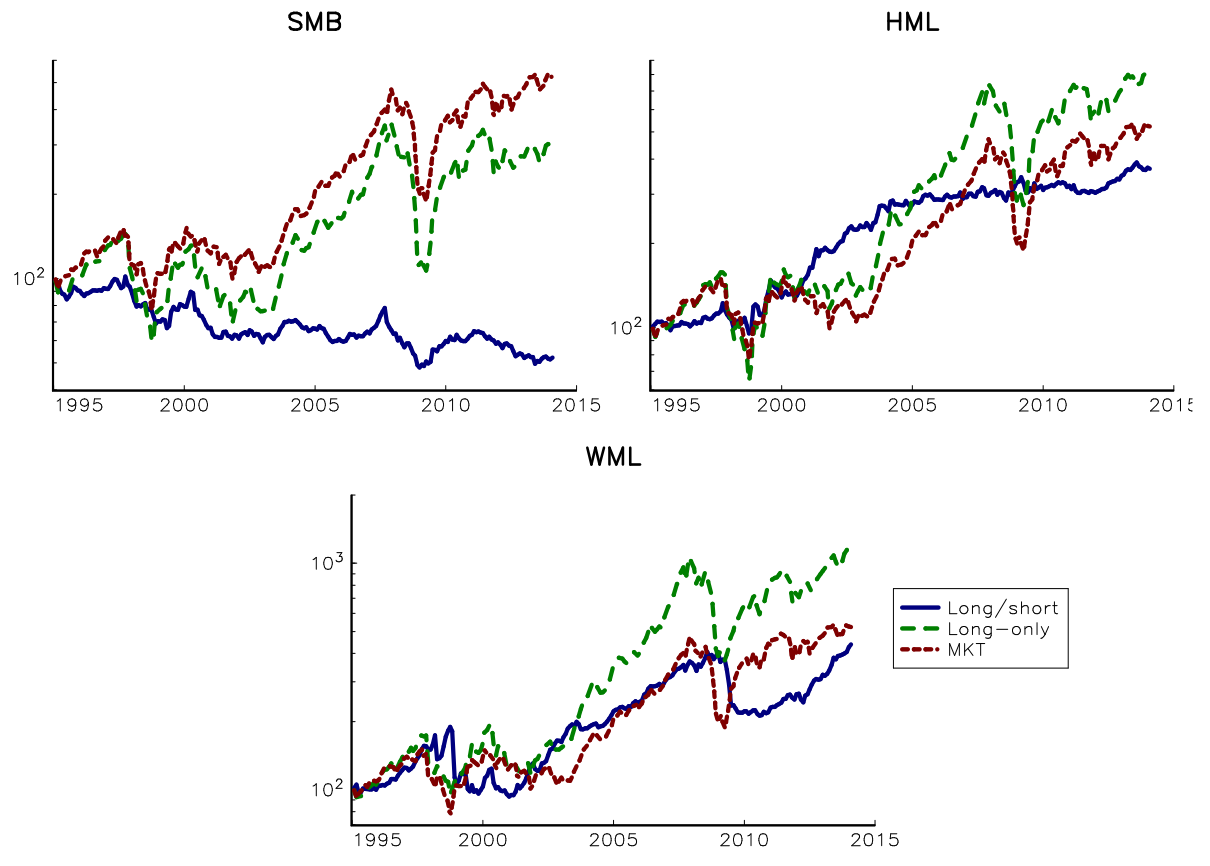

Figure 50: Performance of long-only risk factors (Europe, 1995 - 2013)
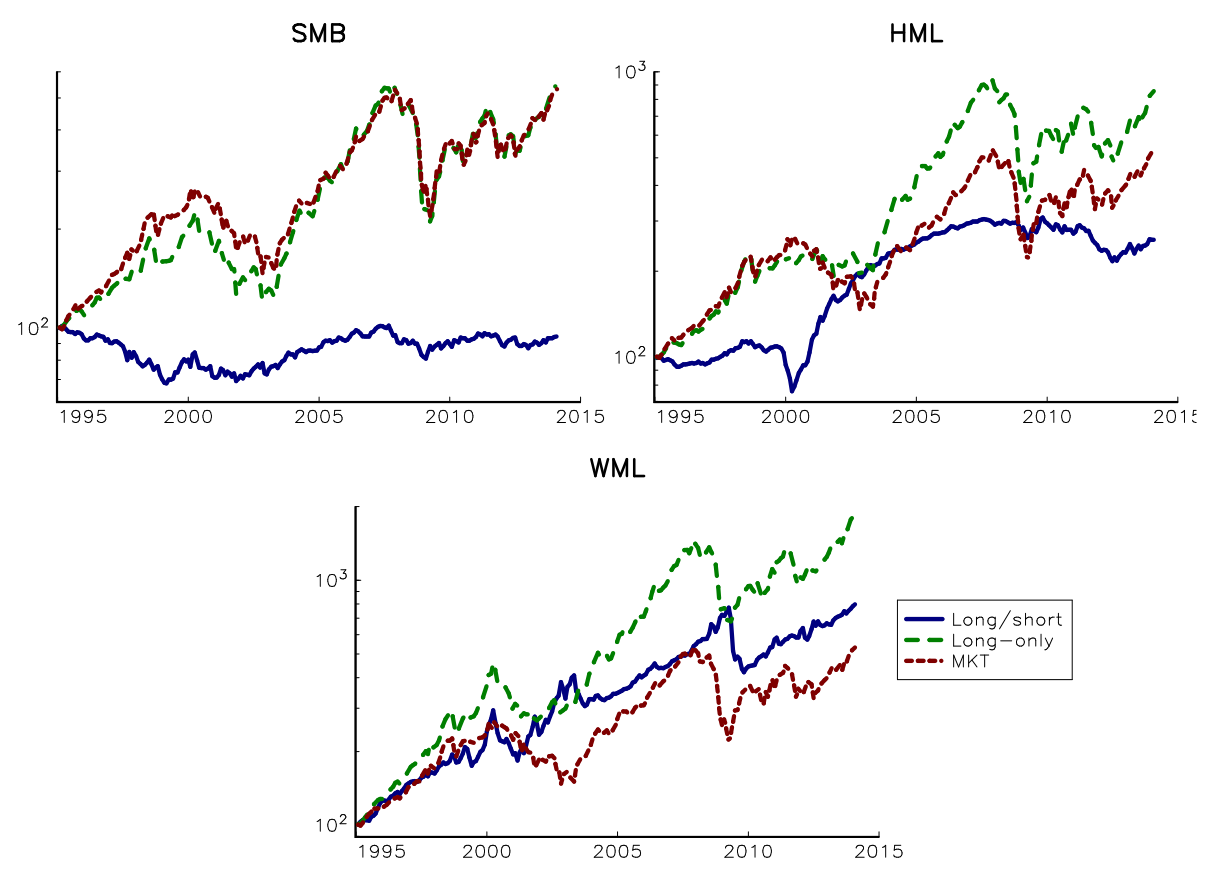
Figure 51: Performance of long-only risk factors (Japan, 1995 - 2013)
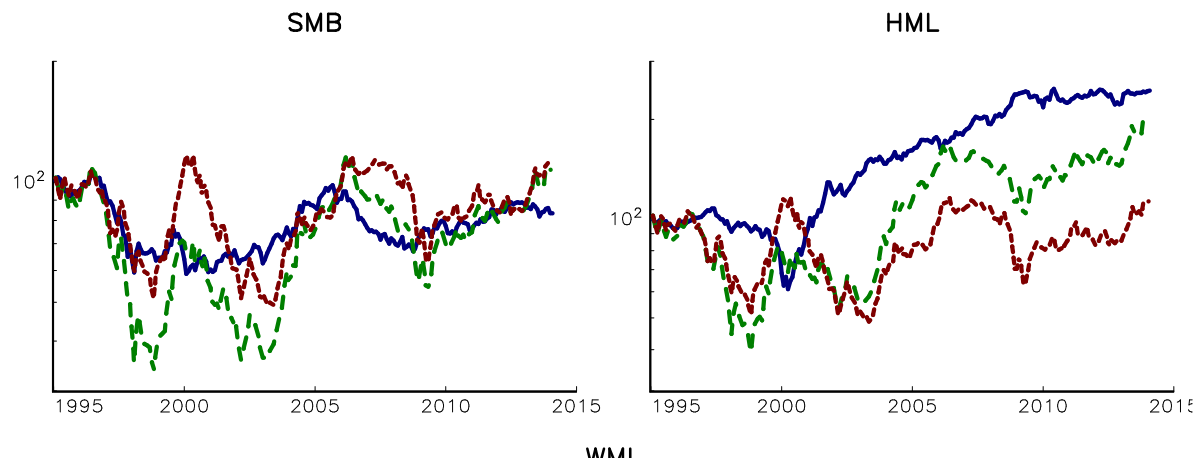

WML

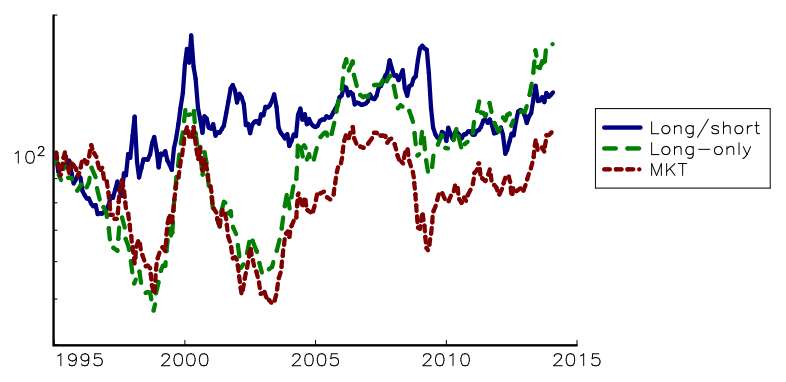

Figure 52: Performance of long-only risk factors (North America, 1995 - 2013)
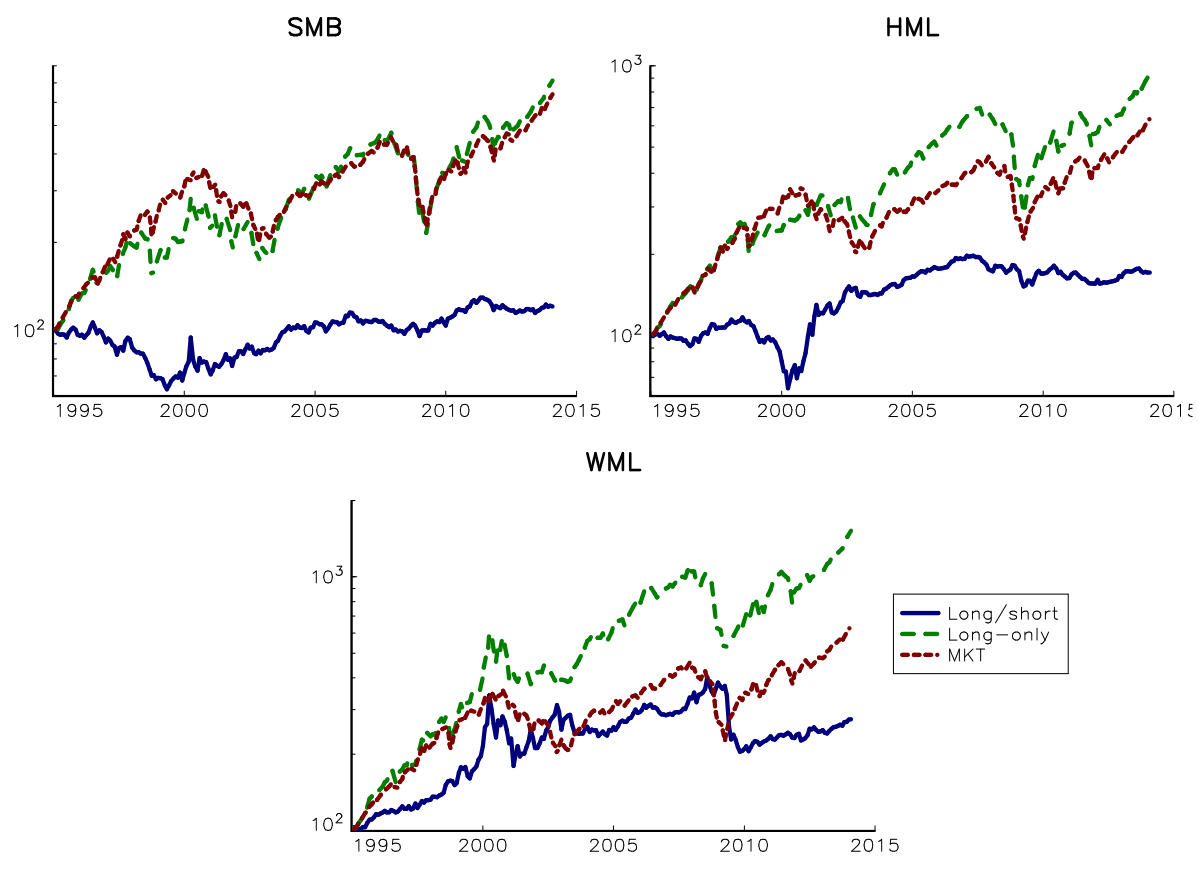
Figure 53: Comparison of VW and EW risk factors (Asia Pacific, 1995 - 2013)
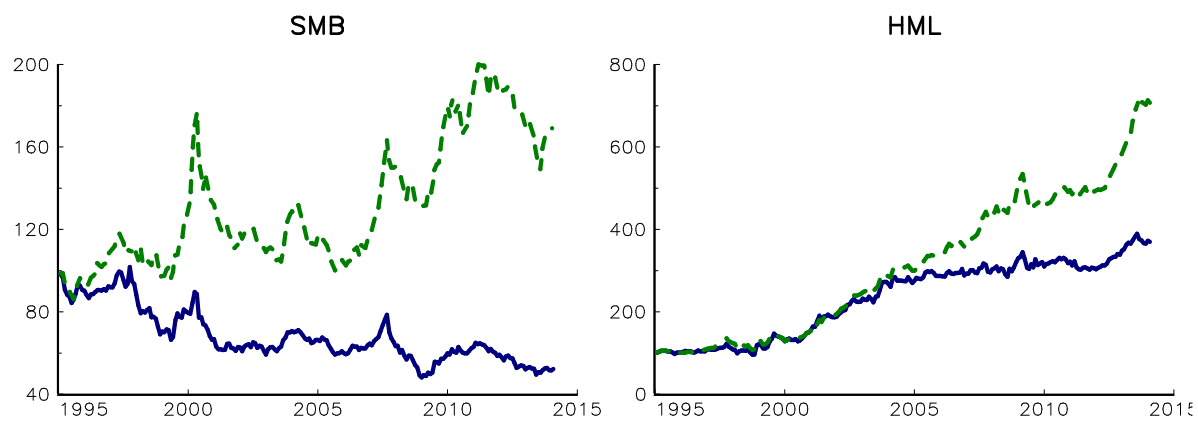

WML

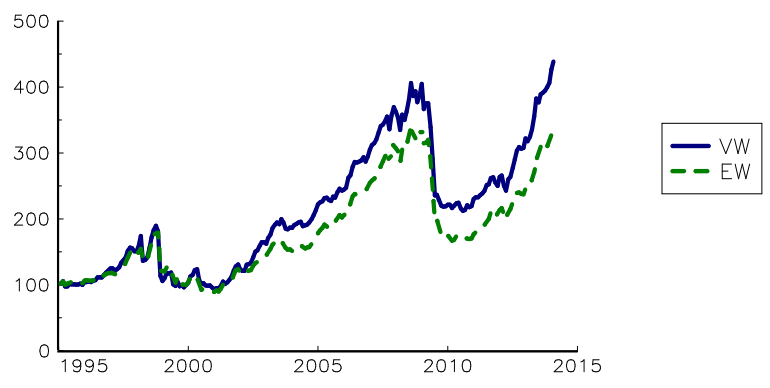

Figure 54: Comparison of VW and EW risk factors (Europe, 1995 - 2013)
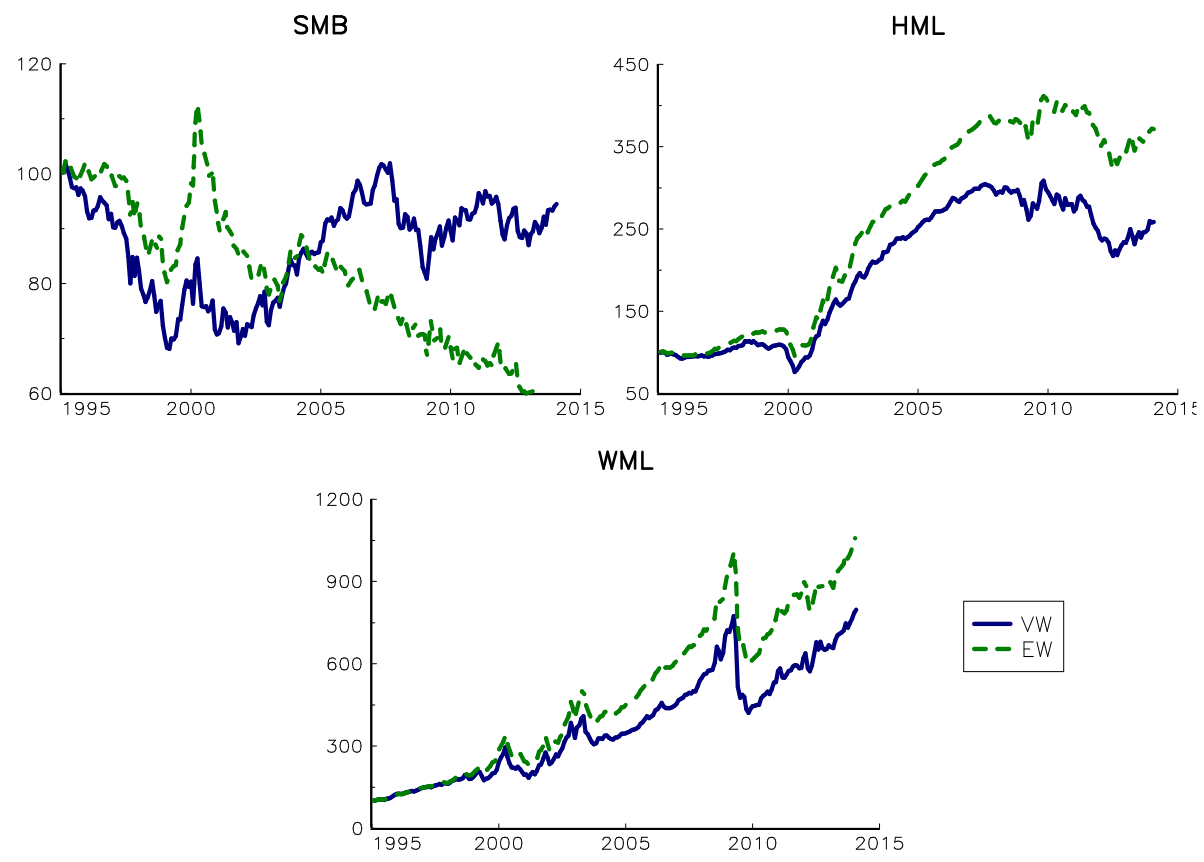
Figure 55: Comparison of VW and EW risk factors (Japan, 1995 - 2013)
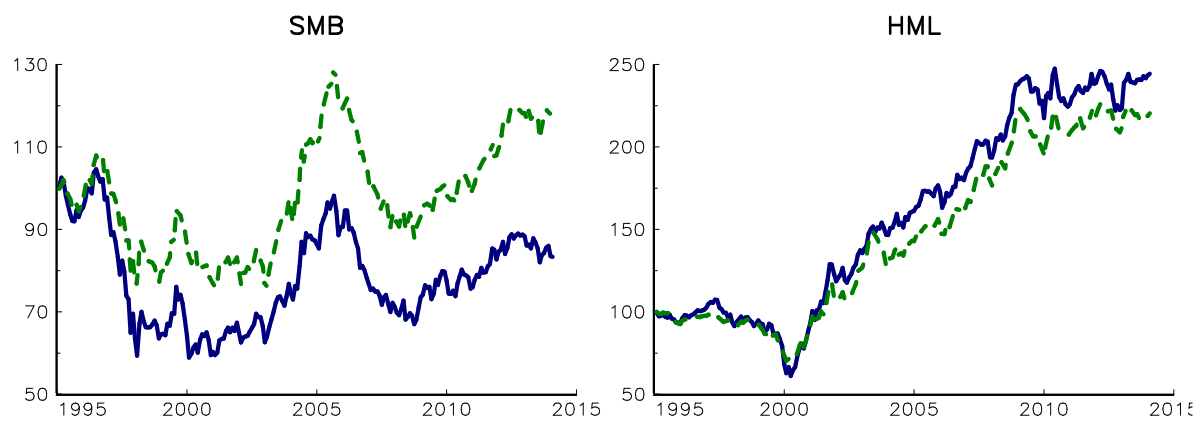

WML

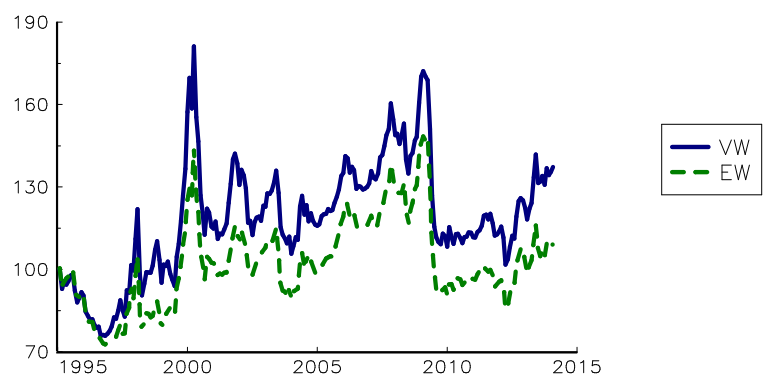

Figure 56: Comparison of VW and EW risk factors (North America, 1995 - 2013)
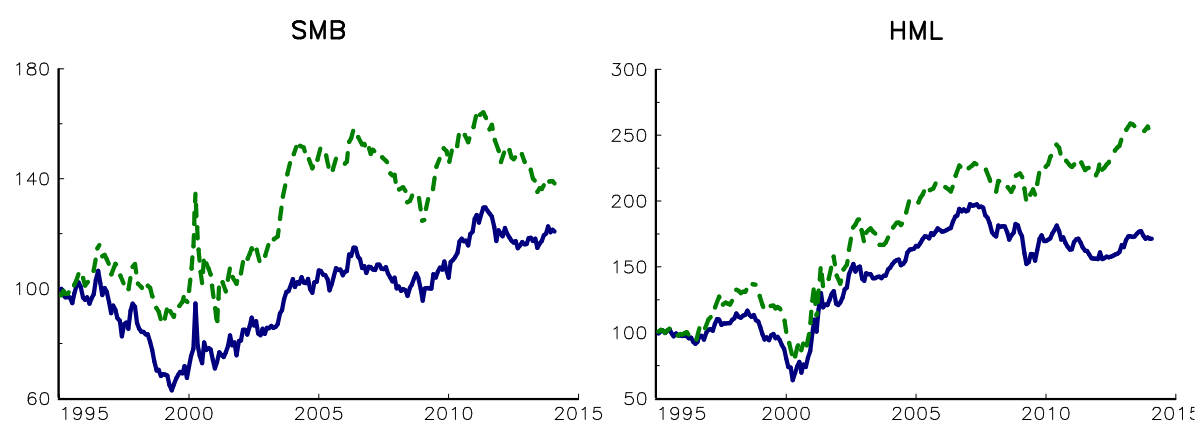

WML

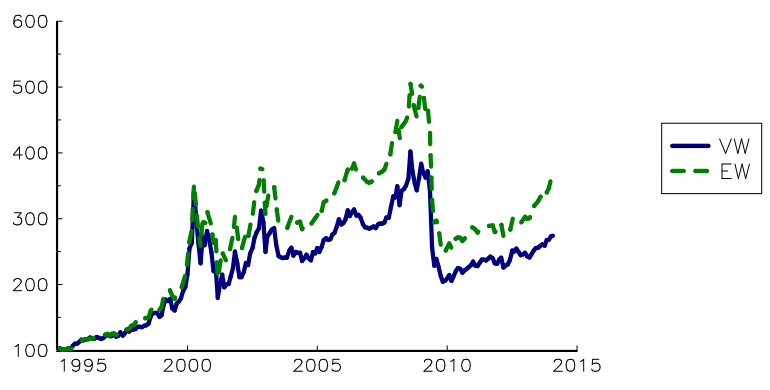

